\title{
Targeted treatment of cancer using the angiogenesis inhibitor anginex
}

Citation for published version (APA):

Brandwijk, R. J. M. G. E. (2007). Targeted treatment of cancer using the angiogenesis inhibitor anginex. [Doctoral Thesis, Maastricht University]. Universiteit Maastricht. https://doi.org/10.26481/dis.20070920rb

Document status and date:

Published: 01/01/2007

DOI:

10.26481/dis.20070920rb

Document Version:

Publisher's PDF, also known as Version of record

\section{Please check the document version of this publication:}

- A submitted manuscript is the version of the article upon submission and before peer-review. There can be important differences between the submitted version and the official published version of record.

People interested in the research are advised to contact the author for the final version of the publication, or visit the DOI to the publisher's website.

- The final author version and the galley proof are versions of the publication after peer review.

- The final published version features the final layout of the paper including the volume, issue and page numbers.

Link to publication

\footnotetext{
General rights rights.

- You may freely distribute the URL identifying the publication in the public portal. please follow below link for the End User Agreement:

www.umlib.nl/taverne-license

Take down policy

If you believe that this document breaches copyright please contact us at:

repository@maastrichtuniversity.nl

providing details and we will investigate your claim.
}

Copyright and moral rights for the publications made accessible in the public portal are retained by the authors and/or other copyright owners and it is a condition of accessing publications that users recognise and abide by the legal requirements associated with these

- Users may download and print one copy of any publication from the public portal for the purpose of private study or research.

- You may not further distribute the material or use it for any profit-making activity or commercial gain

If the publication is distributed under the terms of Article $25 \mathrm{fa}$ of the Dutch Copyright Act, indicated by the "Taverne" license above, 
Targeted treatment of cancer using the angiogenesis inhibitor anginex 
(C) Ricardo J.M.G.E. Brandwijk, Maastricht 2007 ISBN: 978-90-6464-154-1

Printed by grafisch bedrijf Ponsen en Looijen B.V., Wageningen

Cover design: Sabine Veenvliet - Brandwijk 


\section{Targeted treatment of cancer using the angiogenesis inhibitor anginex}

\section{Proefschrift}

Ter verkrijging van de graad van doctor aan de Universiteit Maastricht, op gezag van de Rector Magnificus, Prof. Mr. G.P.M.F. Mols volgens het besluit van het College van Decanen, In het openbaar te verdedigen op donderdag 20 september 2007 om 16.00 uur

door

Ricardo J.M.G.E. Brandwijk

geboren op 25 oktober 1976 te Leuth 
Promotor:

Prof. dr. A.W. Griffioen

Co-promotor:

Dr. V.L.J.L. Thijssen

Beoordelingscommissie:

Prof. dr. B.G. Wouters (voorzitter)

Dr. R.G. Beets-Tan

Prof. dr. H.F.P. Hillen

Dr. L. Hofstra

Prof. dr. V.C. Tjan-Heijnen

This work was financially supported by the Technologiestichting STW 
For the ones I love

- Boo!

- Take it away!

- It was terrible!

- It was awful!

- It was bad.

- I didn't really like it.

- It could have been a lot better.

- Uh, there were parts of it that were very good though.

- Well it wasn't bad ...

- Well, it was pretty good.

- Ah, it was great!

- I loved it!

- Bravo!

- More!

(Derived from 'Waldorf \& Statler' - The Muppet Show) 



\section{Contents}

Chapter 1 General introduction on angiogenesis and targeting

Chapter 2 Angiogenesis gene expression profiling in xenograft models to study cellular interactions

Chapter 3 Cloning an artificial gene encoding angiostatic anginex:

Chapter 4 Anti-angiogenesis and anti-tumor activity of recombinant anginex

Chapter 5 Targeted gene-delivery strategies for angiostatic cancer treatment

Chapter 6 Anginex-Conjugated Liposomes for Targeting of Angiogenic Endothelial Cells

Chapter 7 Galectin-1 is essential in tumor angiogenesis and is a target for antiangiogenesis therapy

Chapter 8 Discussion

Summary

Samenvatting

Abbreviations

Epiloog 



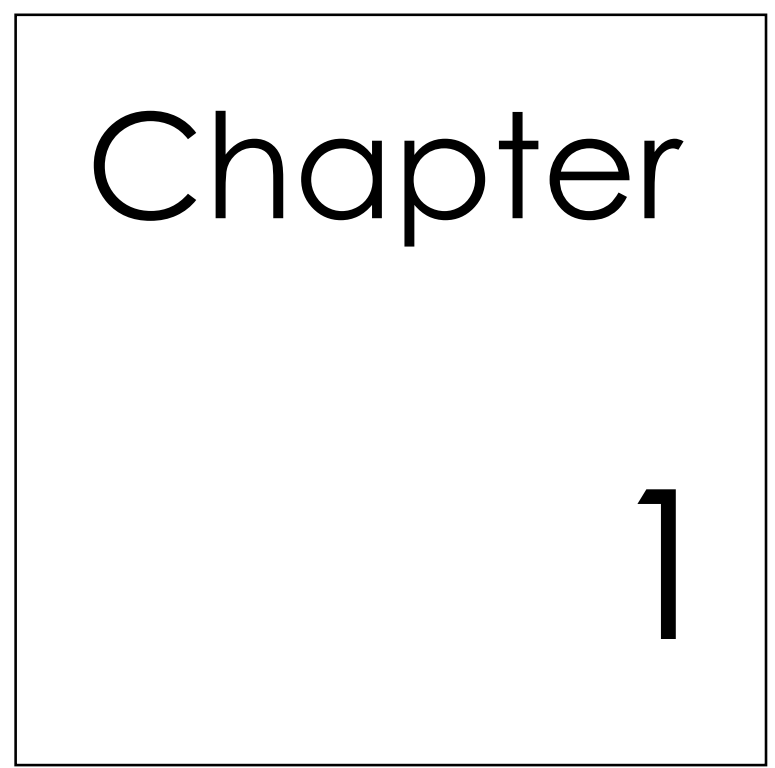

General introduction on angiogenesis and targeting 


\section{Introduction}

Cancer is one of the principal causes of death in developed countries. Over the last years, more than 100 cancer types have been identified ${ }^{1,}{ }^{2}$. Although they have comparable features, they should be considered as different diseases. The transformation of a normal cell into a cancer cell is a complicated multi-step process. Cancer cells have to modify their microenvironment, prevent apoptosis, enhance their replicative potential, and stimulate new blood vessel formation to be able to grow invasively and metastasize ${ }^{3}$. As a result of genetic and / or epigenetic modifications, genes encoding proteins that control cell division can be irreparably modified and the cell obtains usually a different and faster pattern of cell division. Thus, cancer is in general characterized by unlimited and uncontrolled cell division 2. To be able to continue this unlimited growth, new blood vessel formation is required. This process is often referred to as angiogenesis.

\section{Blood vessel formation}

To keep up with metabolic needs, growing tissues need new capillaries to provide nutrients and oxygen and to remove metabolic waste. Blood vessel development is involved in many processes, e.g. embryonic development and wound healing. The inner lining of blood vessels consists of a monolayer of endothelial cells (EC). Underneath this EC monolayer there are pericytes, smooth muscle cells and fibroblasts. The outer layer is formed by the extracellular matrix (ECM) ${ }^{4}$.

During embryonic development, blood vessels are initially formed via a process called vasculogenesis ${ }^{5,6}$. The endothelial cells for these new vessels develop out of endothelial precursor cells, so-called angioblasts. In adults, vasculogenesis can occur during tumor growth and revascularization after ischemia ${ }^{7}$. In this case, the EC derive from endothelial stem cells. However, new blood vessel formation in adults usually occurs via angiogenesis. Angiogenesis, the process of blood vessel formation out of pre-existing capillaries, is involved in physiological (wound healing, female reproductive cycle, embryonic development) and pathological (cancer, diabetic retinopathy, rheumatoid arthritis, cardiovascular disease) vascularization ${ }^{8}$. In general, pathological angiogenesis is characterized by irregular and chaotic vessel structures. In tumors, sprouting angiogenesis is the primary form of neovascularization ${ }^{9}$. Alternatively, existing vessels are divided by extension of the capillary walls into the lumen (intussusception or splitting angiogenesis) ${ }^{10}$ or via transendothelial cell bridges, which split into individual capillaries (bridging angiogenesis) ${ }^{11}$.

When sprouting angiogenesis (from now on referred to as angiogenesis) is initiated, the EC are activated by pro-angiogenic factors. As a result, vessels obtain an angiogenic phenotype and a cascade of processes is activated (Figure 1). In the 
first step, the existing vessels vasodilate and vascular permeability is increased. Subsequently, the ECM is locally degraded by matrix metalloproteinases (MMPs) produced mainly by activated EC and tumor cells ${ }^{12}$. By excreting stimulatory factors, tumors cells induce endothelial cell migration into the direction of the tumor. Next, EC start to proliferate and to form a tube-like structure. In the next step, when a new lumen is formed, perivascular cells are attracted to stabilize the new vessel. Finally, the ECM is fully recovered and a new mature vessel is formed 13,14

\section{Tumor Angiogenesis}

In 1971, Judah Folkman postulated the hypothesis that tumor growth is angiogenesis dependent ${ }^{15}$. Additionally, he proposed that anti-angiogenesis therapy could be an effective anti-tumor strategy. At that time these concepts were not accepted. Research on EC biology and the discovery of proteins that can stimulate or inhibit angiogenesis led to acceptance of the hypothesis in the 1980s. Nowadays, angiogenesis research is an established part of cancer research.

When cells transform into cancer cells, the resulting small tumors are not directly angiogenic. In fact, tumors are not dependent on angiogenesis when they are smaller than approximately $2-3 \mathrm{~mm}^{3}{ }^{16}$. Below that size they obtain nutrients and oxygen from the surrounding tissue by diffusion. When tumors grow beyond that size they have to induce angiogenesis by secretion of growth factors.

Besides primary tumor formation, the process of metastasis formation is angiogenesis dependent as well ${ }^{17}$. The probability of a tumor to form metastases increases when there is a higher vasculature density inside the tumor ${ }^{18}$. Within a vascularized tumor, cancer cells can enter newly formed vessels which often lack an intact endothelial wall. Furthermore, pro-angiogenesis factors produced by the tumor also induce the expression of pro-angiogenesis factors by EC (e.g. MMPs), which facilitates access to the circulation. Once the tumor cells are in the circulation, they home in general to the first microvascular bed downstream from the primary tumor. Although the majority of cells that escape from the primary tumor will not survive, those capable of invading into and out of the circulation can give rise to a metastatic tumor ${ }^{19,20}$. Once the metastatic tumor cell has invaded a target organ, angiogenesis is once more required for continued growth.

Besides angiogenesis, the tumor has some alternative ways to obtain sufficient blood supply ${ }^{21}$. Most well known are vasculogenic mimicry (VM) and vessel cooption. In VM, vessels are formed solely by tumor cells or by tumor cells and EC ${ }^{22}$. In vessel co-option, the tumor cells grow along existing vessels ${ }^{23}$. Presumably, both phenomena take place mainly in aggressive tumor types, when angiogenesis is not able to keep up with the speed of the tumor growth. Recently, it was 
suggested that these alternatives can be used by the tumor as an escape mechanism against angiostatic therapy ${ }^{24}$.

\section{Figure 1 - The process of sprouting angiogenesis inside tumors}

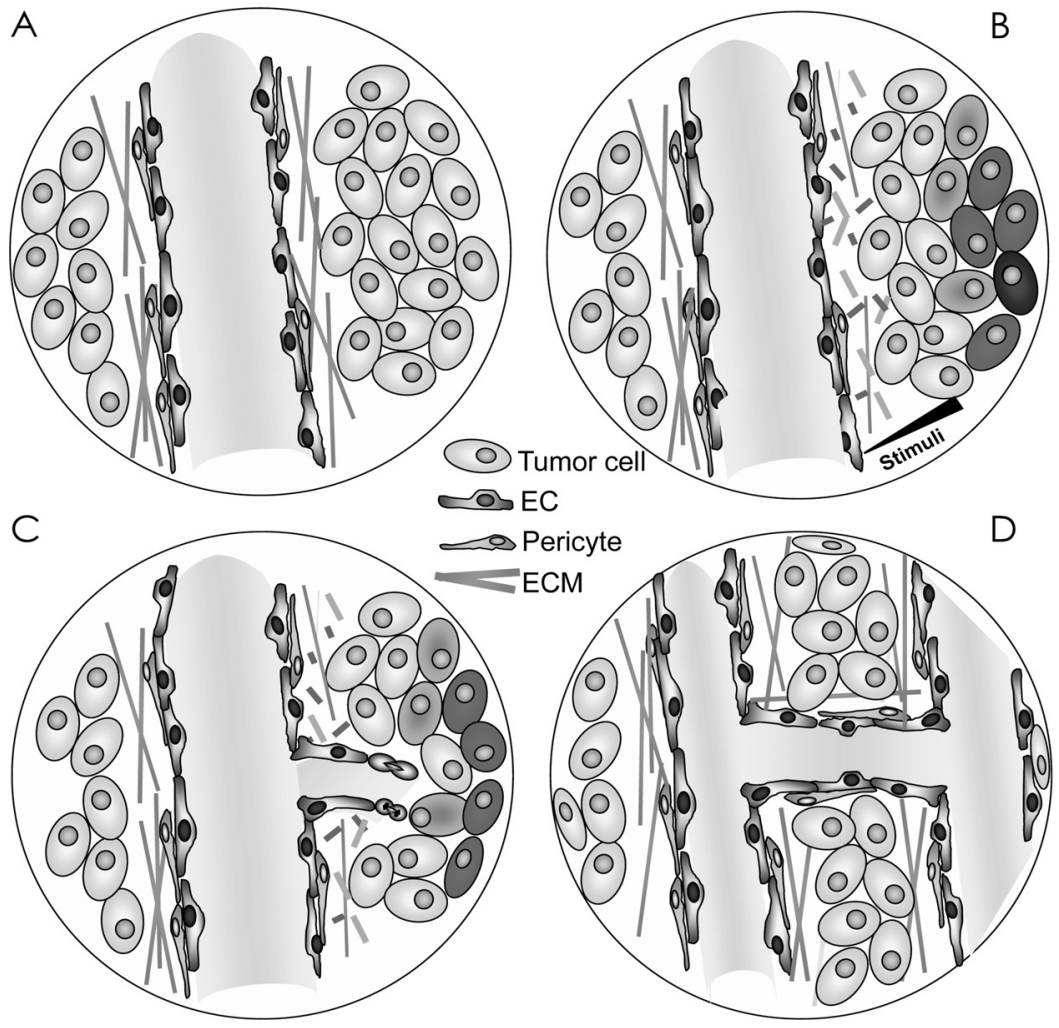

Figure 1 - The process of sprouting angiogenesis inside tumors

A) In the dormant tumor there is a balance between stimuli and inhibitors of angiogenesis, B) As a response to hypoxia, tumor cells start to produce angiogenic stimuli, as a result the angiogenic switch is induced and EC get activated and the ECM will be degraded, C) EC start to migrate and proliferate into the direction of the produced stimuli, D) A new vessel has been formed, the ECM is restored and the vessel is maturated.

\section{The angiogenic switch}

As described above, initial tumor growth can take place independent of angiogenesis. Tumors can stay dormant for months to years before they switch to 
an angiogenic phenotype ${ }^{25}$. In the dormant tumor there is a tight balance between angiogenesis stimulators and inhibitors. One of the major triggers of angiogenesis is hypoxia, which can be caused by increased local oxygen consumption or because of the irregular blood flow in the tumor vessels. The potent stimulating effect of hypoxia can be explained by up regulation of vascular endothelial growth factor (VEGF)-A, a strong stimulator of angiogenesis (see below) ${ }^{26}$. As a result, the balance is disturbed in favor of the pro-angiogenesis factors and tumors acquire an angiogenic phenotype. This process is generally referred to as the angiogenic switch 27,28

The stimuli that trigger the angiogenic switch can be derived from tumor cells or from cells which are recruited by the tumor (e.g. macrophages) ${ }^{29}$. In normal physiological angiogenesis, new vessels rapidly mature and become stabilized and quiescent again. This is in contrast to tumor vasculature which remains angiogenic leading to irregular and leaky vessels ${ }^{30}$. The types of triggers that induce angiogenesis are determined by the tumor microenvironment. Tumors can alter $\mathrm{pH}$, elicit paracrine and autocrine effects, and increase interstitial pressure ${ }^{31}$.

\section{Regulators of angiogenesis}

Over the last decades, many angiogenic and angiostatic molecules have been discovered and the list is still expanding. Angiogenic factors can be secreted by tumor cells, mobilized from ECM, or released from activated EC or inflammatory cells ${ }^{32}$. A better understanding of how these factors function will help elucidate the mechanism of angiogenesis thereby leading to new therapeutic opportunities. The most common protein families that have been associated with angiogenesis will be highlighted below.

\section{Promoters of angiogenesis}

Over the years, numerous inducers of angiogenesis have been identified. Basic fibroblast growth factor (bFGF or FGF2) was the first angiogenic protein isolated from a tumor and is one of the most important angiogenic proteins ${ }^{33}$. The main receptors are the fibroblast growth receptor family (FGFR1-4) and heparan-sulfate proteoglycans (HSPG). Basic FGF is stored in the ECM and during angiogenesis degradation of the ECM results in release of $b F G F$. The protein is a potent stimulator of DNA synthesis, cellular division, EC migration and proliferation, and in the formation of capillaries ${ }^{34,35}$. Furthermore, it also functions as a chemoattractant for EC and fibroblasts ${ }^{36-38}$. There are also studies indicating that bFGF induces neovascularisation by activation of the VEGF/VEGFR system ${ }^{39,40 .}$

One of the most potent angiogenic factor is vascular endothelial growth factor (VEGF). VEGF, also called VEGF-A, is a member of de platelet derived growth factor (PDGF) family. Other members of this family are placenta derived growth factor 
(PIGF), VEGF-B, VEGF-C, VEGF-D, and VEGF-E ${ }^{41}$. Several isoforms of VEGF exist of which $V E_{165}$, containing 165 amino acids, is the main form ${ }^{42}$. VEGF promotes migration, proliferation and tube formation by EC. Furthermore, it stimulates EC to express ECM degrading enzymes and acts as a chemoattractant to guide EC into the direction of tumor cells. The growth factor exerts its actions primarily via tyrosine kinase VEGF receptor 1 (VEGFR1 or Flt-1) and VEGF receptor 2 (VEGFR2 or Flk/KDR) ${ }^{43}$. VEGF-C and D bind to the third VEGF receptor (VEGFR3 or Flt-4) and are primarily involved in lymphangiogenesis ${ }^{44}$ (Figure 2). The EC response in angiogenesis is mainly mediated by VEGFR2. Having a higher affinity for VEGF compared to VEGFR2, VEGFR1 functions as a mechanism to control the availability of VEGF to VEGFR2 ${ }^{45}$. More recently it has been shown that VEGF also binds to neuropilins (NRP) which are originally described as receptors for semaphorins which mediate neuronal guidance ${ }^{46,47}$. Both NRP-1 and NRP2 can serve as receptors for

\section{Figure 2 - VEGF-receptors and ligands}
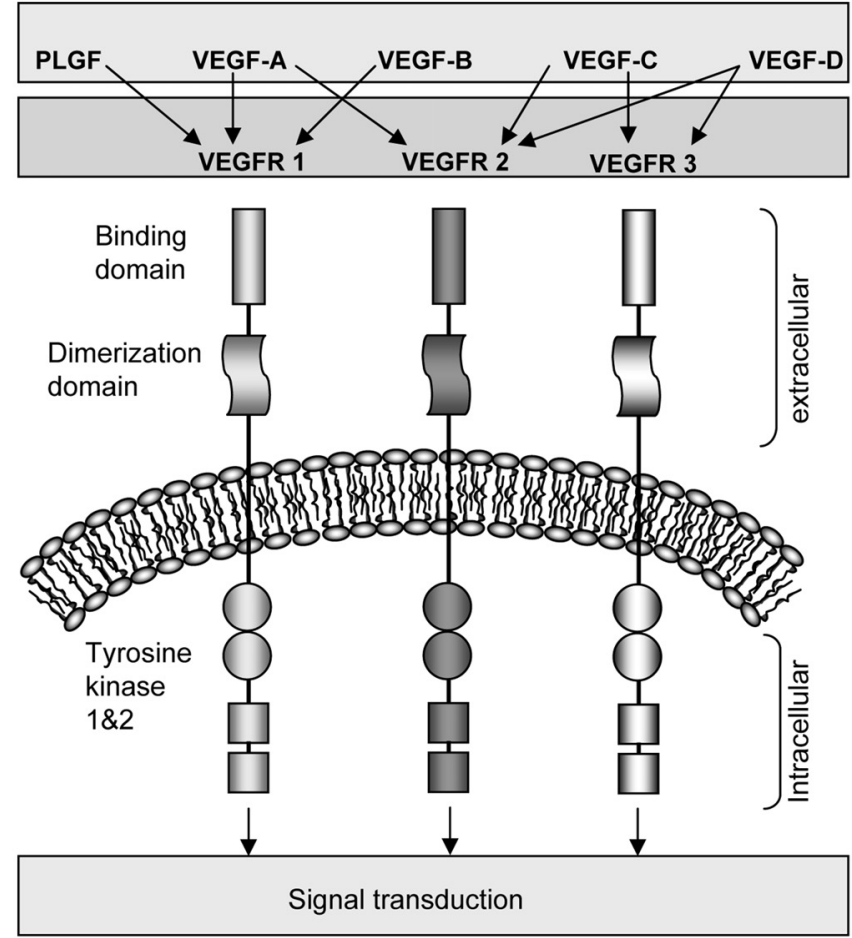

Figure 2 - VEGF-receptors and ligands 
PLGF and VEGF ${ }^{48}$. Neuropilin-1 enhances VEGF signaling via the VEGFR2 49,50 while NRP2 is thought to regulate VEGF function in angiogenesis and tumor lymph angiogenesis ${ }^{51,52}$.

Another important group is the angiopoietin (Ang) family. This family includes four ligands (Ang1-4) ${ }^{53}$ and two receptors (Tie 1 and 2). All angiopoietin bind to Tie2 ${ }^{54}$, while a clear role of Tie1 and its possible ligands has not been identified yet 55. Although Ang1 and Ang2 have the same receptor, they have an opposite function. Angiopoietin-1 induces autophosphorylation, while Ang2 blocks the induction of the receptor via Ang1 ${ }^{56}$. Ang-1 is a proangiogenesis factor that promotes EC migration, adhesion, survival, especially in the presence of VEGF. The function of Ang1 signaling is to induce EC to recruit pericytes and smooth muscle cells 57, 58. Angiopoietin-2 destabilizes the vasculature which leads to either the initiation of angiogenesis or the induction of EC apoptosis and vessel regression, depending on the presence or absence of VEGF ${ }^{59}$.

In the angiogenic process, the most important role of matrix metalloproteinases (MMPs) is the degradation of the ECM to facilitate migration of EC. This degradation results in the release of growth factors like VEGF, bFGF and TGF ${ }^{4}$. The activity of MMPs is mainly regulated by tissue inhibitors of metalloproteinases (TIMPs), alterations of gene expression and activation of latent zymogens ${ }^{60,61}$. In most human cancers, MMPs have a high expression levels and are correlated with metastatic potential and poor prognosis ${ }^{62}$.

Besides the ones mentioned above, there are several other important factors involved in angiogenesis, like interleukin-8, transforming growth factor- $\beta$ and tumor necrosis factor-a. Integrins also have an essential role. By expressing integrins, cells are able to anchor to the ECM. Integrins bind to ECM components through short peptide sequences (e.g. the arg-gly-asp (RGD) motif) ${ }^{63}$. Apart from MMP localization, integrins in tumors regulate proliferation, cellular motility and invasion, apoptosis, and angiogenesis ${ }^{64}$. Regarding the latter, it has been shown that integrin $\operatorname{av} \beta 3$ is almost absent on quiescent EC, whereas it is highly expressed on tumor EC ${ }^{65}$.

\section{Inhibitors of angiogenesis}

To counterbalance all stimulatory factors of angiogenesis, several endogenous antiangiogenesis factors exist. By virtue of a longer half-life than promoters of angiogenesis, these inhibitors are capable to interfere with initial tumor formation, to control tumor angiogenesis and to inhibit the outgrowth of metastasis. The trombospondin (TSP) glycoprotein family is one of the first endogenous angiogenesis inhibitors which were discovered ${ }^{66,67}$. For TSP1 and 2 it has been described that they have angiostatic properties 68, 69. In vitro, TSP1 inhibits adhesion, proliferation and migration, and induction of apoptosis in ECs and in vivo it prevents EC migration over a bFGF gradient and blocks neovascularization ${ }^{70,}{ }^{71}$. 
It has been suggested that the angiogenic switch during tumor formation is facilitated by loss of TSP1 expression ${ }^{72}$.

Fascinatingly, many endogenous angiogenesis inhibitors are cleavage products of larger proteins. For example, angiostatin turned out to be a cleavage product of the non-angiostatic protein plasminogen ${ }^{73}$, endostatin is the cleavage product of collagen XVIII ${ }^{74}$ and tumstatin originates after cleavage of the important ECM component collagen IV a3 chain. They all inhibit specifically EC, thereby eventually inducing apoptosis. Angiostatin and endostatin exert this effect via the extracellular signal-regulated kinase (ERK) pathway ${ }^{75,76}$ and tumstatin via the interaction with avß3 integrin ${ }^{77}$. Endostatin also appears to be suitable for gene therapy in various cancer types and species. In $80 \%$ of the studies an inhibitory effect was seen, even if not all tumor cells were transfected ${ }^{78,79}$.

Bactericidal / permeability-increasing protein (BPI) produced by neutrophils, was originally only known for its antibacterial effect ${ }^{80}$. The protein inhibits angiogenesis by inhibition of proliferation and sprouting of EC and induction of apoptosis in detached EC ${ }^{81}$. BPI is not the only anti-bactericidal protein with angiostatic capacities, e.g. PF-4 and TNP-470 also have these characteristics. Platelet factor-4 is a heparin binding chemokine capable of inhibiting EC migration and proliferation leading to inhibition of tumor growth ${ }^{82,83}$. By forming a complex with bFGF or VEGF, PF-4 prevents binding of both factors to the receptor and subsequent signaling ${ }^{84,85}$. Interferon-a is also a well known inhibitor which exerts its function predominantly via inhibition of bFGF expression ${ }^{86}$.

\section{Figure 3 - Overview of stimuli and inhibitors of angiogenesis as mentioned in the text}

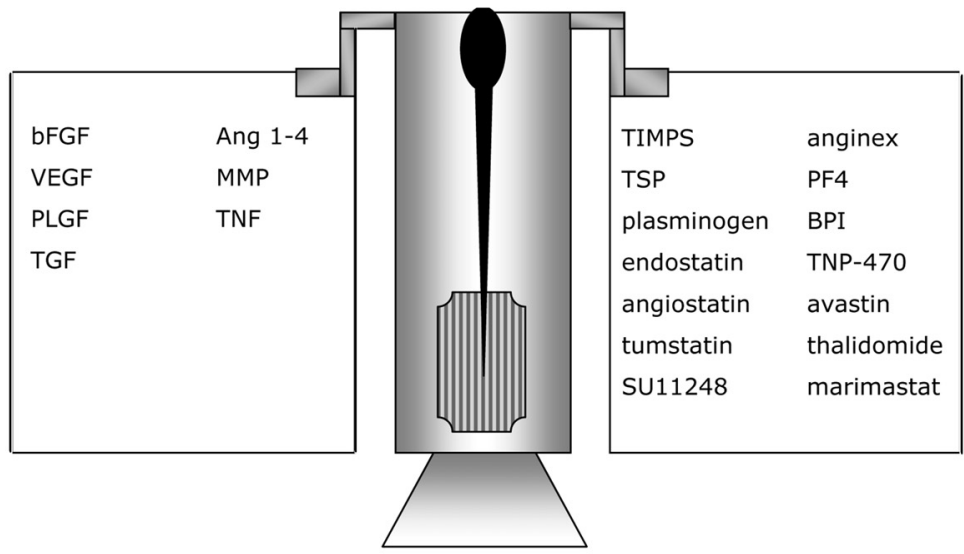

Figure 3 - Overview of stimuli and inhibitors of angiogenesis as mentioned in the text 


\section{Angiostatic therapy}

In general, conventional cancer treatment does not eliminate all tumor cells. This urged researchers to find new anti-cancer strategies. The fact that tumor growth and metastasis are dependent on angiogenesis, inspired many researchers to set up anti-angiogenesis therapy. Since EC have a pivotal role in angiogenesis, angiostatic therapy is usually directed against EC. The rationale for this is that by elimination of only a few EC, many tumor cells will already be affected. There are several benefits of angiostatic treatment. Endothelial cells are much easier accessible than tumor cells, because they form the inner lining of blood vessels and are therefore in direct contact with the blood circulation. Furthermore, the endothelium is less heterogeneous and genetically more stable compared to tumor cells. This makes endothelial mediated therapy less prone to induce drug resistance 74,87 , although in some cases resistance was reported ${ }^{88,89}$. It is also expected that angiostatic therapy has (almost) no effect on healthy tissues, since in adults angiogenesis is limited. An additional benefit might be that the therapy is applicable to tumors of different histology.

There are possible contra-indications for angiostatic therapy like wound healing, ischemia and hemorrhages. Although angiostatic therapy appears to be successful, it is believed that eventually it will not cure most cancer types. Instead, it will cause a stable chronic disease. From several studies, it has already become apparent that a combination of angiostatic therapy with e.g. chemotherapy would most likely be more effective $13,90,91$. The reason of the synergistic effect of combination of angiostatic agents and chemotherapy could be explained by the discovery that inhibitors seem to normalize tumor vessels before eliminating them. This would result in a decrease in the normally high interstitial pressure detected in solid tumors and in temporarily improved delivery of chemotherapy to tumor cells ${ }^{92}$.

Endogenous inhibitors which are involved in regulation of angiogenesis, as discussed above, can be used for therapy ${ }^{78}$. A potential benefit of endogenous inhibitors is that they are expected to be the safest and less toxic of all cancer therapies. Besides these endogenous inhibitors, many exogenous inhibitors have been developed. The naturally secreted antibiotic fumagillin, or its widespread used synthetic analogue TNP-470, inhibits EC proliferation and migration in vitro as well as tumor-induced angiogenesis in vivo ${ }^{93,94}$. Although its complete mechanism of action has not fully been elucidated, it is known to inhibit angiogenesis by binding to a MMP and suppression of cyclin A mRNA expression ${ }^{95,96}$.

Being the key mediator of the angiogenic process, VEGF and its receptors are interesting targets in the design of an angiostatic strategy. A well known anti-VEGF molecule is bevacizumab (Avastin). Avastin is a humanized monoclonal antibody developed from a murine antibody by recombinant DNA technology ${ }^{97}$. Avastin inhibits growth of a variety of cancer cell lines and is in the clinic successfully used 
for the treatment of especially colorectal cancer ${ }^{98,99}$. Contra-indications of the use of Avastin are physeal dysplasia and suppression of angiogenesis in the female reproductive tract 100,101 . Besides direct inhibition of VEGF, also its receptors can be affected. A successful tyrosine kinase inhibitor is SU11248, which binds selectively to VEGFR2 and prevents EC migration and tube formation in vitro and blood vesse formation in vivo ${ }^{102}$. Furthermore, a broad spectrum of inhibiters of the VEGFpathway is in development (e.g. ZD6474, CP-547, PTK787, soluble receptors and several recombinant antibodies).

As described previously, expression and activation of MMPs is one of the first steps in angiogenesis and a prerequisite for tumor metastasis. Therefore, the inhibition of these proteinases is thought to be a crucial step in cancer therapy. Marimastat is a soluble synthetic broad spectrum MMP-inhibitor (MMPI) capable of inhibiting MMP 1, 2,3,7 and $9{ }^{103}$. Although promising results in animal models, in clinical trials there are no differences in survival with or without marimastat. Unfortunately, this is the case with all available MMPIs (e.g. prinomastat, BAY129566) which were used in clinical phase III trials.

Nowadays, thalidomide is building a strong reputation in the battle against multiple myeloma ${ }^{104}$. Metabolites of thalidomide inhibit angiogenesis by inhibiting the expression of bFGF, VEGF and TNFa, down regulation of lymphocytes surface molecules and has a direct effect on myeloma cells themselves ${ }^{104-106}$.

Several conventional chemotherapeutics have been described to possess angiostatic properties as well. To act as an angiostatic agent these drugs have to be administrated for a sustained period at low dose (metronomic dosing), which is in contradiction with its use as a chemotherapeutic 90, 107. Examples of such agents are cyclophosphamide, paclitaxel, vinblastine and cisplatinum ${ }^{108,109}$.

\section{Anginex}

Anginex is a de novo designed 33-mer peptide (Figure 4) designed and developed in our laboratory in collaboration with the University of Minnesota. In order to design the angiostatic peptide, a comparison was made of the three-dimensional structures of several angiostatic proteins (e.g. endostatin, TNF, BPI). It was observed that many of these consist of primarily anti-parallel $\beta$-sheets and that this structure is of key importance for their angiogenic activities ${ }^{110}$. Based on basic folding principles and the amino acid sequence of PF4, BPI and IL-8, a library of water soluble $\beta$-sheet forming peptides was synthesized ${ }^{111}$. From this library, anginex was selected as a potent angiogenesis inhibitor based on its capacity to inhibit in vitro adhesion, migration and proliferation of activated EC and subsequent induction of apoptosis in these cells. To investigate the anti-tumor activity of anginex, it was tested in a syngeneic mouse tumor model (B16F10 melanoma in $\mathrm{C} 57 \mathrm{BL} / 6$ mice) as well in a human xenograft ovarian carcinoma model (MA148 in 
nude mice) ${ }^{112}$. In the aggressive B16F10 model, tumor growth was inhibited by approximately $63 \%$ and in the non-aggressive xenograft model by approximately $75 \%$. A significant reduction of microvessel density was observed in all anginex treated tumors. This indicates that the inhibitory effect is a result of angiogenesis inhibition. In vivo, anginex homes specifically to tumor vasculature as demonstrated with fluorescently labelled anginex ${ }^{112}$.

To elucidate the structure-activity relationship of anginex, an alanine scan and a library of short 12 amino acids overlapping peptides were synthesized and tested for angiostatic capacity. Based on these results it turned out that only the first six to seven (respectively $\mathrm{N}$-terminal and $\mathrm{C}$-terminal) amino acids flanking the first beta-turn were necessary for activity. Additionally, it was demonstrated that the bioactive conformation of anginex is an anti-parallel $\beta$-sheet ${ }^{113}$. With this knowledge mimetics with angiostatic properties were developed based on the organic molecules dibenzofuran and calix[4]arene ${ }^{114,115}$.

\section{Figure 4 - The amino acid sequence of anginex}

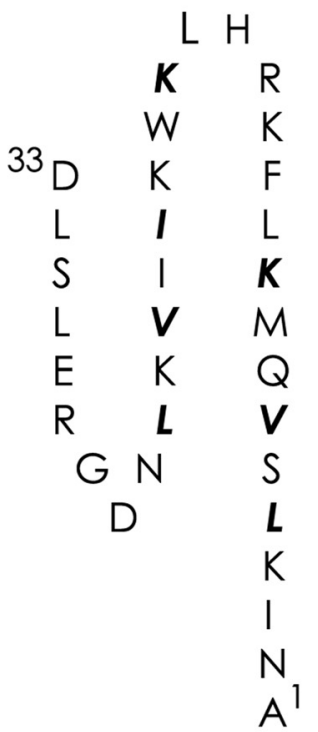

Figure 4 - The amino acid sequence of anginex

The 33-mer synthetic peptide Anginex has a three-stranded anti-parallel $\beta$-sheet structure. The key essential amino-acids for activity are highlighted in Bold Italic.

To date, the mechanism of action of anginex is not fully understood. It was reported that fibronectin is needed for anginex to exert its angiostatic function as 
demonstrated in fibronectin deficient mice. It was suggested that anginex forms a complex with fibronectin. Via the RGD motif in fibronectin this complex bind to a5 $\beta 1$ and av $\beta 3$ integrins, which are overexpressed in angiogenesis activated vessels. This would allow transport of anginex to the angiogenically active vessels ${ }^{116}$.

\section{Targeting of angiogenesis}

The goal of targeted therapy is to increase the specificity and efficiency of the applied treatment, thereby improving therapeutic outcome and reducing undesirable side effects. Targeting of tumor angiogenesis can be used to inhibit tumor vessel formation, to destruct tumor vessels but also for imaging of the tumor vasculature. Targeting strategies require understanding of the molecular mechanisms underlying the cause of the disease and identification of the differences between normal and diseased cells. The target cells should preferably express a molecule that is not present on healthy tissue. Furthermore, these molecules should be able to interact with a specific ligand or cell type and should ideally not be subjected to variations or mutations within a single patient or between different patients ${ }^{117}$.

Unfortunately, tumor cells continuously acquire new genetic alterations during tumor progression. As a consequence, the tissue becomes less differentiated and more heterogeneous which interferes with the identification of targeting molecules that are present on all tumor cells. Besides the intratumoral heterogeneity there is also a huge intertumoral heterogeneity which makes the development of tumortype independent therapy virtually impossible. Furthermore, the genetic instability of tumor cells can easily lead to resistance to treatment. Thus, effective targeted cancer therapy relies on a cell population that can be easily targeted, that is less genetically instable, and that is essential for tumor growth. The angiogenically active EC that are essential for tumor angiogenesis appear to fulfill all these requirements. However, because angiogenesis is not restricted to pathological conditions, markers have to be identified that are specific for tumor angiogenesis. The existence of these markers can be predicted because EC inside tumors are active while EC in normal vessels are quiescent. This resulted in several attempts to identify molecules specifically expressed in tumor EC as described in the next sections. The endothelium adapts its cellular characteristics to its environment ${ }^{118}$ therefore EC heterogeneity is mainly determined by its microenvironment. This can also be the reason that not all tumor types respond in the same way to angiostatic therapy. To date, targeted EC therapy is limited since only a few suitable markers are identified. 


\section{Markers for targeted angiostatic therapy}

Endothelial cells from normal vessels present a different phenotype than EC involved in tumor angiogenesis. These differences can be exploited for targeted therapy. Tumor EC express higher levels of specific molecules like E-selectin, endoglin and VEGF-receptors. However, many of these surface markers are not exclusively expresses by tumor EC, but shared in their expression by e.g. macrophages, dendritic cells, and lymphocytes ${ }^{119}$. Furthermore, they also express increased levels of enzymes such as heparinases, and express integrins which differ from the integrins on resting EC ${ }^{120}$. Although the EC is the most logical cell to find angiogenesis markers, they can also be found on supporting mural cells and the ECM, like e.g. NG2 proteoglycan and the EDB domain of fibronectin, respectively 121,122

As mentioned above, since angiogenesis is not restricted to pathological conditions and to the EC, careful evaluation of identified markers is needed in order to prevent undesirable side effects to physiological (angiogenic) processes, which eventually was one of the main principles of targeted therapy. The differences between tumor and normal vasculature inspired many researchers to start a search for markers which eventually can be used for targeting purposes. Most attempts were focused on the study of in vitro EC cultures. The EC were cultured under conditions which were thought to mimic the natural situation ${ }^{123}$.Several methods have been used to identify target molecules. In all these methods a comparison is made between the transcriptome of a diseased and healthy population of cells ${ }^{124}$. Although proteomics can also be used to identify population specific proteins, most studies examining differences at the transcriptional level ${ }^{125}$ and therefore a range of molecular techniques have been used. Especially the use of microarrays and identification of the human-genome has boosted gene expression profiling analysis. Several markers have been identified using a technique called serial analysis of gene expression (SAGE) ${ }^{126}$. This led to the identification of tumor endothelial markers (TEMs). From the identified markers, they selected the ones which were expressed on the cell surface (TEM 1/endosialin, TEM5, TEM7/PLXDC1, TEM8/anthrax toxin receptor), since they are the most interesting ones from a clinical point of view. TEM1,5 and 8 showed a strong and almost specific expression on tumor endothelium ${ }^{127}$. However, later studies determined TEM1 to be expresses by fibroblasts and a subset of pericytes associated with the tumor vessels and not by tumor endothelium ${ }^{128}$. This demonstrates that one has to be very cautious when selecting a marker. The identification of TEM8 as the anthrax toxin receptor and the successful targeting of this receptor in preclinical tumor models make this molecule a particularly attractive candidate for future vascular targeting studies ${ }^{127}$. In another study suppression subtractive hybridization ( $\mathrm{SSH}$ ) was used, which is like SAGE a method which is independent from previously cloned genes and existing 
sequence information. In this study, the tumor expression profile was not only corrected for the expression in resting endothelium but also for expression of EC in physiological angiogenesis ${ }^{129}$. The value of this approach was demonstrated by blocking vimentin, which is one of the identified targets, using an antibody. When applied in a mouse tumor model significant inhibition of tumor growth and reduced microvessel density was observed. An alternative strategy is to find first EC specific genes and subsequently to obtain its expression profile. Subsequently, using bioinformatics and data available in public databases new markers can be identified. This way roundabout-4 (ROBO4) and endothelial-specific protein disulphide isomerase (EndoPDI) were found. ROBO4 is an endothelial specific gene encoding a protein with homology to the axon guidance protein roundabout1 (ROBO1). Expression of magic roundabout in vitro was detected only in EC and was greater in cells exposed to hypoxia. Magic roundabout expression in the adult was restricted exclusively to sites of active angiogenesis, especially tumor vessels. Besides their role in axon guidance, the ROBO receptors and their Slit ligands appear to be involved in guidance of vascular EC ${ }^{130}$. EndoPDI is induced by hypoxia and seldom expressed in normal tissue. EndoPDI has a protective effect only in endothelial cells exposed to hypoxia. The loss of EndoPDI expression under hypoxia caused a significant decrease in the secretion of adrenomedullin, endothelin-1, and CD105; molecules that protect endothelial cells from hypoxia-initiated apoptosis ${ }^{131}$. Several other potential tumor vascular markers have been identified. Delta-like 4 (DII4), a membrane-bound ligand for Notch1 and Notch4, is selectively expressed in the developing endothelium and in some tumor endothelium, and it is induced by vascular endothelial growth factor (VEGF)-A and hypoxia. Notch and its ligands play critical roles in cell fate determination ${ }^{132}$. Tumor EC also expresses their own subset of integrins which distinguish them from normal resting EC. Integrins have an important role in cell proliferation and invasion. One of the most well-known integrin is av $\beta 3$, which is known to be overexpressed on tumor EC and has a key role in EC survival during angiogenesis. Antibodies against av $\beta 3$, like Vitaxin, have been shown to have angiostatic activities. Synthetic peptides of the integrin binding sequence RGD (Arg-Gly-Asp) are one of the most frequently used targeting ligands for angiostatic therapy. Endomucin is a transmembrane protein predominantly expressed on vascular EC and high endothelial venules. Its expression seems to correlate with EC proliferation which is increased upon stimulation with bFGF and TNFa ${ }^{133}$. Aminopeptidase- $N$ is also a potential marker expressed by EC and has been associated with cell migration and tumor invasion. Antibodies as well as enzymatic inhibitors of this protease were able to inhibit angiogenesis ${ }^{134}$. The extra-domain B (EDB) variant is an alternative splice variant of fibronectin and is almost absent in healthy adults. However, it is abundantly expressed in tumors. Conjugates of the synthetic anti-EDB antibody L19 efficiently localizes to the tumor vasculature and was able to inhibit tumor growth ${ }^{135}$. The cell surface proteoglycan 
NG2 is a marker of angiogenic pericytes. The protein is a membrane-spanning cellsurface molecule that is expressed in the neovasculature of tumors, regenerating tissues and in fetal vessels. An antibody against the protein was able to reduce angiogenesis, suggesting that the proteoglycan can be an effective target for antiangiogenic therapy.

Molecules interacting with the identified markers could e.g. be natural existing ligands or antibodies, or specifically designed ligands. When choosing a marker the availability should be taken into account. From a clinical point of view, targets accessible via the blood circulation are preferred. Surface or secreted proteins are most easily accessible, especially when large molecules like antibodies are used as therapeutic agent. When a suitable marker has been identified, the use of it should be validated using e.g. blocking agents, antibodies, knock down or knock out systems ${ }^{129,136 .}$

\section{Therapeutic targeting of angiogenesis}

Targeting for therapeutic purposes can be used to deliver therapeutic agents. Ligands, like antibody (fragments), peptides and aptamers, able to recognize specific markers can be conjugated directly to a drug or radioisotope and indirectly by conjugation to e.g. drug loaded lipidic vesicles or specific expression of the ligand on therapeutic cells after transfection. Targeting is also the preferred method to specifically deliver gene constructs via viral and lipidic vehicles. By using these vehicles it is possible to influence (specific) intracellular processes and to express therapeutic molecules. Targeting strategies can, in general, be divided into two ways: transductional and transcriptional targeting. In transductional targeting, the natural interaction of the delivery vehicle is modified so that gene or drug is only delivered to the cells of interest. This requires detailed knowledge of tissue-specific receptors and vehicle biology. In transcriptional targeting, tissue specific expression is achieved by placing the transgene under control of cell specific promoters/enhancers. The latter approach is hampered by the fact that only a limited number of specific promoters with acceptable activity have been identified so far.

The first evidence of therapeutic targeting was obtained by Burrows et al. By transfecting tumor cells with a cytokine gene, they were able to express MHC-II on tumor endothelium. Subsequently, they used an antibody against the MHC-II which was coupled to the immunotoxin ricin. When these conjugated antibodies were injected in tumor bearing mice, complete thrombosis of the tumor vasculature and tumor regression was obtained ${ }^{137}$. Nowadays, antibodies or antibody fragments are popular devices for targeting purposes since they can be raised against virtually any antigen. The most well known antibody for angiostatic therapy is obviously Avastin. Although, its use is not really targeting according to the definition as 
stated above. These days, there are not many real targeting studies since the availability of suitable targets is limited.

\section{Molecular imaging of angiogenesis}

The response of a tumor to conventional chemotherapy and radiotherapy is in general determined by measurement of tumor shrinkage. However, angiogenesis inhibitors are expected to be cytostatic instead of cytotoxic. Therefore, the imaging methods that have been used to diagnose and monitor tumors, which are based on tumor size and morphology, measure not the right parameter to determine the response to angiostatic therapy. For that reason, new imaging methodologies and effective biomarkers are needed to establish effective drug dosage and to monitor clinical response. Microvessel density is a prognostic indicator of angiostatic therapy for many cancers. However, imaging of angiogenic vasculature might be a better alternative than measuring microvessel density for assessing the response to angiogenesis inhibitors because it is noninvasive and can be used to assess much larger volumes than biopsy samples ${ }^{138}$.

Techniques used to image angiogenic vasculature include magnetic resonance imaging (MRI), x-ray computed tomography (CT), positron emission tomography $(P E T)$, single-photon emission tomography (SPECT), and ultrasound ${ }^{139}$. MRI is currently the most developed technique for the evaluation of antiangiogenic and antivascular compounds in early clinical trials ${ }^{140}$. The methodology can for instance be used to identify tumor load and to determine the minimum effective dose. MRI is a practical modality for assessing vascular changes over time because it is already widely used clinically to assess tumor growth ${ }^{139}$. MRI offers two main advantages over methods that use radio-labeled agents: higher special resolution and the ability to obtain anatomic, physiologic, and metabolic information in a single imaging session ${ }^{140}$.

To follow cellular and molecular processes, e.g. after treatment of tumors with angiogenesis inhibitors, molecular imaging methods have to be developed. Molecular imaging, or also called imaging of genetic expression, can be defined as the in vivo characterization and measurement of biological processes at the cellular level through the use of imaging devices ${ }^{141}$. Measuring and quantifying such processes would enable clinicians to stage the disease, to follow the progression of the disease, and to determine the effect of treatment. Unfortunately, using currently available imaging techniques, the angiogenic tumor microvessels cannot be depicted directly because of their microscopic size ${ }^{142}$. To be able to image the processes in these vessels contrast enhancers are needed. However, without the use of ligand mediated contrast agents the signal is diffused. Molecular imaging contrast agents must accumulate at specific biomarker sites in order to be detectable, i.e. specific targeting of contrast agents. Molecular imaging relies on the 
ability to target genes and proteins that are linked directly or indirectly to human disease. Imaging of proteins or protein function is more feasible, given the much larger number of such targets per cell compared with the number of DNA or mRNA targets per cell ${ }^{140}$. The most important characteristics of contrast agents are binding with high affinity to the marker of interest, prolonged half-life, high contrast-to-noise enhancement, low toxicity, and complete clearing of the agents 143. Contrast agents can be targeted to cellular markers by antibodies, peptides, polysaccharides, aptamers, and drug acting as ligands. Imaging of expression can also be used to predict the tumor response to available therapies. Potential biologic markers for imaging angiogenesis are of course the same as mentioned for therapeutic targeting of angiogenesis in preceding sections. In addition, markers which are preferentially expressed on activated tumor EC might be useful for imaging purposes whereas they can not be used for therapeutic targeting due to possible side effects. Furthermore, the expression levels of some markers can be used for tumor staging since the expression level is dependent on the stage of the disease.

Imaging can also be used to monitor other processes related to angiogenesis. For example, apoptosis is accelerated in the process of angiogenesis and can be non-invasively be monitored by detection of the activity of caspases ${ }^{144}$. Another approach to image apoptosis is to use annexin $\mathrm{V}$ as targeting ligand. Annexin binds to phosphatidylserine which is exposed by apoptotic cells ${ }^{145}$. Hypoxia in tumors is the result of limitation in diffusion in metabolics. MRI can detect tumor hypoxia via spectrometry, BOLD imaging or specific contrast agents ${ }^{142,146}$.

Molecular imaging agents can also be utilized for targeted drug delivery to provide a novel site-specific vehicle for the therapeutic application. In turn, they may be confirmed and quantified by noninvasive medical imaging techniques. For example, technetium labeled endostatin has been used to mark tumors in preclinical models ${ }^{147}$. Tumors could be clearly visualized and in vitro cell viability assays indicated no marked difference between uptake of conjugated endostatin and normal endostatin.

\section{Aim and outline of this thesis}

The rationale behind anti-angiogenesis cancer therapy is simple: by preventing the formation of new tumor vessels and by destroying existing tumor vasculature, tumors are not able to grow and existing tumor cells dye by lack of nutrients and oxygen. Effective angiostatic therapy requires compounds that specifically target and/or kill tumor EC. In our laboratory we developed anginex, a small synthetic peptide, which is a potent angiogenesis inhibitor in vitro as well as in vivo. We hypothesized that an artificial anginex gene encoding recombinant protein could be used as a molecular tool for receptor identification, angiostatic gene therapy and 
targeting. To that end, the aims of this thesis were to validate the therapeutic use of the artificial anginex gene and recombinant protein and to explore the application of anginex as a tumor vasculature targeting agent.

When a new anti-angiogenesis strategy or compound has been developed, it is important, in order to prevent undesirable side-effects, to evaluate not only the effect on their direct known parameters but also the influence on the microenvironment. Therefore, we developed a method, based on quantitative real time PCR, to rapidly compare the effects of different angiogenesis related molecules on endothelial cells in vitro and in vivo (Chapter 2). These days, the quest for new (angiostatic) cancer therapies has become more complicated and an increasing degree of these strategies rely on molecular biology. To be able to set up molecular based methods using anginex, first a gene encoding anginex had to be developed. To validate the use of the designed anginex gene and recombinant protein, the recombinant protein was produced in yeast. The activity of recombinant anginex was tested in several angiogenesis models, both in vitro and in vivo (Chapter 3 ). Finally, the use of recombinant anginex in angiostatic cancer therapy was confirmed in mouse tumor models. To provide a rationale for the use of the anginex gene for gene therapy purposes, we made a stable transfectant of a tumor cell line. By inoculating the transfected cell line into mice the therapeutic applicability of the gene was validated (Chapter 4). In Chapter 5 we review targeted gene delivery strategies for angiostatic cancer treatment. An extensive overview has been made of which targeting approaches exist for viral and non-viral gene delivery vehicles for angiostatic cancer therapy. The principle of vascular targeting was first confirmed with the well known av $\beta 3$-specific cyclic RGD peptide which was conjugated to paramagnetic quantum dots (Chapter 6). Next, we tested anginex as targeting moiety of liposomal therapeutic vehicles. Therefore, synthetic anginex was conjugated to fluorescently labeled paramagnetic liposomes. Furthermore, we investigated the effectivity of anginex to target MR imaging contrast agents to activated EC. Obtained results were compared with liposomes conjugated with cyclic RGD-peptides (Chapter 7). Finally, the anginex gene was used in a receptor finding study to get more insight in the mechanism of action of anginex and to enable the design of better targeting agents (Chapter 8). In chapter 9, the content of this thesis is discussed and in chapter 10 the main findings are summarized. 


\section{References}

1. Parkin, D.M., Bray, F., Ferlay, J., and Pisani, P. (2005) Global cancer statistics, 2002. CA Cancer J Clin 55, 74-108

2. Tannock, I., and Hill, R. (2005) The basic science of oncology. Mcgraw-Hill

3. Hanahan, D., and Weinberg, R.A. (2000) The hallmarks of cancer. Cell 100, 57-70

4. Kalluri, R. (2003) Basement membranes: structure, assembly and role in tumour angiogenesis. Nat Rev Cancer 3, 422-433

5. Patan, S. (2004) Vasculogenesis and angiogenesis. Cancer Treat Res 117, 3-32

6. Tang, D.G., and Conti, C.J. (2004) Endothelial cell development, vasculogenesis, angiogenesis, and tumor neovascularization: an update. Semin Thromb Hemost 30, 109-117

7. Lyden, D., Hattori, K., Dias, S., Costa, C., Blaikie, P., Butros, L., Chadburn, A., Heissig, B., Marks, W., Witte, L., Wu, Y., Hicklin, D., Zhu, Z., Hackett, N.R., Crystal, R.G., Moore, M.A., Hajjar, K.A., Manova, K., Benezra, R., and Rafii, S. (2001) Impaired recruitment of bone-marrow-derived endothelial and hematopoietic precursor cells blocks tumor angiogenesis and growth. Nat Med 7, 1194-1201

8. Carmeliet, P. (2003) Angiogenesis in health and disease. Nat Med 9, 653-660

9. Burri, P.H., Hlushchuk, R., and Djonov, V. (2004) Intussusceptive angiogenesis: its emergence, its characteristics, and its significance. Dev Dyn 231, 474-488

10. Burri, P.H., and Djonov, V. (2002) Intussusceptive angiogenesis--the alternative to capillary sprouting. Mol Aspects Med 23, S1-27

11. Carmeliet, P. (2000) Mechanisms of angiogenesis and arteriogenesis. Nat Med 6, 389-395

12. Griffioen, A.W., and Molema, G. (2000) Angiogenesis: potentials for pharmacologic intervention in the treatment of cancer, cardiovascular diseases, and chronic inflammation. Pharmacol Rev 52, 237-268

13. Bergers, G., and Hanahan, D. (2002) Combining antiangiogenic agents with metronomic chemotherapy enhances efficacy against latestage pancreatic islet carcinomas in mice. Cold Spring Harb Symp Quant Biol 67, 293-300

14. Risau, W. (1997) Mechanisms of angiogenesis. Nature 386, 671-674

15. Folkman, J. (1971) Tumor angiogenesis: therapeutic implications. N Engl J Med 285, 11821186

16. Folkman, J. (2002) Looking for a good endothelial address. Cancer Cell 1, 113-115

17. Folkman, J. (1995) Angiogenesis in cancer, vascular, rheumatoid and other disease. Nat Med $1,27-31$

18. MacDonald, I.C., Groom, A.C., and Chambers, A.F. (2002) Cancer spread and micrometastasis development: quantitative approaches for in vivo models. Bioessays 24, 885-893

19. Nicolson, G.L. (1988) Organ specificity of tumor metastasis: role of preferential adhesion, invasion and growth of malignant cells at specific secondary sites. Cancer Metastasis Rev 7, 143-188

20. Zetter, B.R. (1998) Angiogenesis and tumor metastasis. Annu Rev Med 49, 407-424

21. Ribatti, D., Vacca, A., and Dammacco, F. (2003) New non-angiogenesis dependent pathways for tumour growth. Eur J Cancer 39, 1835-1841

22. Folberg, R., Hendrix, M.J., and Maniotis, A.J. (2000) Vasculogenic mimicry and tumor angiogenesis. Am J Pathol 156, 361-381

23. de Waal, R.M., and Leenders, W.P. (2005) Sprouting angiogenesis versus co-option in tumor angiogenesis. Exs, 65-76

24. Rubenstein, J.L., Kim, J., Ozawa, T., Zhang, M., Westphal, M., Deen, D.F., and Shuman, M.A. (2000) Anti-VEGF antibody treatment of glioblastoma prolongs survival but results in increased vascular cooption. Neoplasia 2, 306-314

25. Holmgren, L., O'Reilly, M.S., and Folkman, J. (1995) Dormancy of micrometastases: balanced proliferation and apoptosis in the presence of angiogenesis suppression. Nat Med 1, 149-153

26. Shweiki, D., Itin, A., Soffer, D., and Keshet, E. (1992) Vascular endothelial growth factor induced by hypoxia may mediate hypoxia-initiated angiogenesis. Nature 359, 843-845

27. Bergers, G., and Benjamin, L.E. (2003) Tumorigenesis and the angiogenic switch. Nat Rev Cancer 3, 401-410

28. Hanahan, D., and Folkman, J. (1996) Patterns and emerging mechanisms of the angiogenic switch during tumorigenesis. Cell 86, 353-364

29. Folkman, J. (1992) The role of angiogenesis in tumor growth. Semin Cancer Biol 3, 65-71

30. Carmeliet, P., and Jain, R.K. (2000) Angiogenesis in cancer and other diseases. Nature 407, 249-257

31. Giordano, F.J., and Johnson, R.S. (2001) Angiogenesis: the role of the microenvironment in flipping the switch. Curr Opin Genet Dev 11, 35-40

32. Ribatti, D., Vacca, A., and Presta, M. (2000) The discovery of angiogenic factors: a historical review. Gen Pharmacol 35, 227-231

33. Shing, Y., Folkman, J., Sullivan, R., Butterfield, C., Murray, J., and Klagsbrun, M. (1984) Heparin affinity: purification of a tumor-derived capillary endothelial cell growth factor. Science 223, 12961299

34. Burgess, W.H., and Maciag, T. (1989) The heparin-binding (fibroblast) growth factor family of proteins. Annu Rev Biochem 58, 575-606

35. Folkman, J., and Klagsbrun, M. (1987) Angiogenic factors. Science 235, 442-447

36. Mignatti, P., and Rifkin, D.B. (2000) Nonenzymatic interactions between proteinases and the cell 
surface: novel roles in normal and malignant cell physiology. Adv Cancer Res 78, 103-157

37. Senior, R.M., Huang, S.S., Griffin, G.L., and Huang, J.S. (1986) Brain-derived growth factor is a chemoattractant for fibroblasts and astroglial cells. Biochem Biophys Res Commun 141, 67-72

38. Terranova, V.P., DiFlorio, R., Lyall, R.M., Hic, S., Friesel, R., and Maciag, T. (1985) Human endothelial cells are chemotactic to endothelial cell growth factor and heparin. J Cell Biol 101, 23302334

39. Seghezzi, G., Patel, S., Ren, C.J., Gualandris, A., Pintucci, G., Robbins, E.S., Shapiro, R.L., Galloway, A.C., Rifkin, D.B., and Mignatti, P. (1998) Fibroblast growth factor-2 (FGF-2) induces vascular endothelial growth factor (VEGF) expression in the endothelial cells of forming capillaries: an autocrine mechanism contributing to angiogenesis. J Cell Biol 141, 1659-1673

40. Gabler, C., Plath-Gabler, A., Killian, G.J., Berisha, B., and Schams, D. (2004) Expression pattern of fibroblast growth factor (FGF) and vascular endothelial growth factor (VEGF) system members in bovine corpus luteum endothelial cells during treatment with FGF-2, VEGF or oestradiol. Reprod Domest Anim 39, 321-327

41. Byrne, A.M., Bouchier-Hayes, D.J., and Harmey, J.H. (2005) Angiogenic and cell survival functions of vascular endothelial growth factor (VEGF). $J$ Cell Mol Med 9, 777-794

42. Ferrara, N., Gerber, H.P., and LeCouter, J. (2003) The biology of VEGF and its receptors. Nat Med 9, 669-676

43. Thomas, K.A. (1996) Vascular endothelial growth factor, a potent and selective angiogenic agent. $J$ Biol Chem 271, 603-606

44. Ferrara, N. (2004) Vascular endothelial growth factor as a target for anticancer therapy. Oncologist 9 Suppl 1, 2-10

45. Waltenberger, J., Claesson-Welsh, L., Siegbahn, A., Shibuya, M., and Heldin, C.H. (1994) Different signal transduction properties of KDR and Flt1, two receptors for vascular endothelial growth factor. $J$ Biol Chem 269, 26988-26995

46. He, Z., and Tessier-Lavigne, M. (1997) Neuropilin is a receptor for the axonal chemorepellent Semaphorin III. Cell 90, 739-751

47. Kolodkin, A.L., Levengood, D.V., Rowe, E.G., Tai, Y.T., Giger, R.J., and Ginty, D.D. (1997) Neuropilin is a semaphorin III receptor. Cell 90, 753-762

48. Soker, S., Takashima, S., Miao, H.Q., Neufeld, G., and Klagsbrun, M. (1998) Neuropilin-1 is expressed by endothelial and tumor cells as an isoform-specific receptor for vascular endothelial growth factor. Cell 92, 735-745

49. Rossignol, M., Gagnon, M.L., and Klagsbrun, M. (2000) Genomic organization of human neuropilin1 and neuropilin-2 genes: identification and distribution of splice variants and soluble isoforms. Genomics 70, 211-222

50. Yamada, Y., Takakura, N., Yasue, H., Ogawa, H., Fujisawa, H., and Suda, T. (2001) Exogenous clustered neuropilin 1 enhances vasculogenesis and angiogenesis. Blood 97, 1671-1678

51. Shen, J., Samul, R., Zimmer, J., Liu, H., Liang, X., Hackett, S., and Campochiaro, P.A. (2004) Deficiency of neuropilin 2 suppresses VEGFinduced retinal neovascularization. Mol Med 10, 12-18

52. Yuan, L., Moyon, D., Pardanaud, L., Breant, C., Karkkainen, M.J., Alitalo, K., and Eichmann, A. (2002) Abnormal lymphatic vessel development in neuropilin 2 mutant mice. Development 129, 47974806

53. Jones, N., Iljin, K., Dumont, D.J., and Alitalo, K. (2001) Tie receptors: new modulators of angiogenic and lymphangiogenic responses. Nat Rev Mol Cell Biol 2, 257-267

54. Jones, P.F. (2003) Not just angiogenesis--wider roles for the angiopoietins. J Pathol 201, 515-527

55. Saharinen, P., Kerkela, K., Ekman, N., Marron, M., Brindle, N., Lee, G.M., Augustin, H., Koh, G.Y., and Alitalo, K. (2005) Multiple angiopoietin recombinant proteins activate the Tie1 receptor tyrosine kinase and promote its interaction with Tie2. J Cell Biol 169, 239-243

56. Davis, S., Aldrich, T.H., Jones, P.F., Acheson, A., Compton, D.L., Jain, V., Ryan, T.E., Bruno, J., Radziejewski, C., Maisonpierre, P.C., and Yancopoulos, G.D. (1996) Isolation of angiopoietin-1, a ligand for the TIE2 receptor, by secretion-trap expression cloning. Cell 87, 11611169

57. Fong, T.A., Shawver, L.K., Sun, L., Tang, C., App H., Powell, T.J., Kim, Y.H., Schreck, R., Wang, X., Risau, W., Ullrich, A., Hirth, K.P., and McMahon, G. (1999) SU5416 is a potent and selective inhibitor of the vascular endothelial growth factor receptor (Flk-1/KDR) that inhibits tyrosine kinase catalysis, tumor vascularization, and growth of multiple tumor types. Cancer Res 59, 99-106

58. Shalaby, F., Rossant, J., Yamaguchi, T.P., Gertsenstein, M., Wu, X.F., Breitman, M.L., and Schuh, A.C. (1995) Failure of blood-island formation and vasculogenesis in Flk-1-deficient mice. Nature 376, 62-66

59. Yu, Q. (2005) The dynamic roles of angiopoietins in tumor angiogenesis. Future Oncol 1, 475-484

60. Brew, K., Dinakarpandian, D., and Nagase, H. (2000) Tissue inhibitors of metalloproteinases: evolution, structure and function. Biochim Biophys Acta 1477, 267-283

61. John, A., and Tuszynski, G. (2001) The role of matrix metalloproteinases in tumor angiogenesis and tumor metastasis. Pathol Oncol Res 7, 14-23

62. Vihinen, P., and Kahari, V.M. (2002) Matrix metalloproteinases in cancer: prognostic markers and therapeutic targets. Int J Cancer 99, 157-166

63. Ruoslahti, E., and Pierschbacher, M.D. (1986) ArgGly-Asp: a versatile cell recognition signal. Cell 44, 517-518

64. Varner, J.A., and Cheresh, D.A. (1996) Integrins and cancer. Curr Opin Cell Biol 8, 724-730 
65. Brooks, P.C., Clark, R.A., and Cheresh, D.A. (1994) Requirement of vascular integrin alpha $v$ beta 3 for angiogenesis. Science 264, 569-571

66. Taraboletti, G., Belotti, D., Borsotti, P., Vergani, V., Rusnati, M., Presta, M., and Giavazzi, R. (1997) The 140-kilodalton antiangiogenic fragment of thrombospondin-1 binds to basic fibroblast growth factor. Cell Growth Differ 8, 471-479

67. Taraboletti, G., Roberts, D., Liotta, L.A., and Giavazzi, R. (1990) Platelet thrombospondin modulates endothelial cell adhesion, motility, and growth: a potential angiogenesis regulatory factor. J Cell Biol 111, 765-772

68. Corless, C.L., Mendoza, A., Collins, T., and Lawler, J. (1992) Colocalization of thrombospondin and syndecan during murine development. Dev Dyn 193, 346-358

69. Kyriakides, T.R., Zhu, Y.H., Yang, Z., and Bornstein, P. (1998) The distribution of the matricellular protein thrombospondin 2 in tissues of embryonic and adult mice. $J$ Histochem Cytochem 46, 1007-1015

70. Good, D.J., Polverini, P.J., Rastinejad, F., Le Beau, M.M., Lemons, R.S., Frazier, W.A., and Bouck, N.P. (1990) A tumor suppressor-dependent inhibitor of angiogenesis is immunologically and functionally indistinguishable from a fragment of thrombospondin. Proc Natl Acad Sci U S A 87, 6624-6628

71. Tolsma, S.S., Volpert, O.V., Good, D.J., Frazier, W.A., Polverini, P.J., and Bouck, N. (1993) Peptides derived from two separate domains of the matrix protein thrombospondin-1 have antiangiogenic activity. J Cell Biol 122, 497-511

72. Laderoute, K.R., Alarcon, R.M., Brody, M.D., Calaoagan, J.M., Chen, E.Y., Knapp, A.M., Yun, Z., Denko, N.C., and Giaccia, A.J. (2000) Opposing effects of hypoxia on expression of the angiogenic inhibitor thrombospondin 1 and the angiogenic inducer vascular endothelial growth factor. Clin Cancer Res 6, 2941-2950

73. O'Reilly, M.S., Holmgren, L., Shing, Y., Chen, C., Rosenthal, R.A., Moses, M., Lane, W.S., Cao, Y., Sage, E.H., and Folkman, J. (1994) Angiostatin: a novel angiogenesis inhibitor that mediates the suppression of metastases by a Lewis lung carcinoma. Cell 79, 315-328

74. O'Reilly, M.S., Boehm, T., Shing, Y., Fukai, N., Vasios, G., Lane, W.S., Flynn, E., Birkhead, J.R., Olsen, B.R., and Folkman, J. (1997) Endostatin: an endogenous inhibitor of angiogenesis and tumor growth. Cell 88, 277-285

75. Redlitz, A., Daum, G., and Sage, E.H. (1999) Angiostatin diminishes activation of the mitogenactivated protein kinases ERK-1 and ERK-2 in human dermal microvascular endothelial cells. $J$ Vasc Res 36, 28-34

76. Kim, Y.M., Hwang, S., Kim, Y.M., Pyun, B.J., Kim, T.Y., Lee, S.T., Gho, Y.S., and Kwon, Y.G. (2002) Endostatin blocks vascular endothelial growth factor-mediated signaling via direct interaction with KDR/FIk-1. J Biol Chem 277, 27872-27879
77. Maeshima, Y., Sudhakar, A., Lively, J.C., Ueki, K., Kharbanda, S., Kahn, C.R., Sonenberg, N., Hynes, R.O., and Kalluri, R. (2002) Tumstatin, an endothelial cell-specific inhibitor of protein synthesis. Science 295, 140-143

78. Folkman, J. (2006) Antiangiogenesis in cancer therapy--endostatin and its mechanisms of action. Exp Cell Res 312, 594-607

79. Indraccolo, S. (2004) Undermining tumor angiogenesis by gene therapy: an emerging field. Curr Gene Ther 4, 297-308

80. Marra, M.N., Wilde, C.G., Collins, M.S., Snable, J.L., Thornton, M.B., and Scott, R.W. (1992) The role of bactericidal/permeability-increasing protein as a natural inhibitor of bacterial endotoxin. $J$ Immunol 148, 532-537

81. van der Schaft, D.W., Toebes, E.A., Haseman, J.R., Mayo, K.H., and Griffioen, A.W. (2000) Bactericidal/permeability-increasing protein (BPI) inhibits angiogenesis via induction of apoptosis in vascular endothelial cells. Blood 96, 176-181

82. Maione, T.E., Gray, G.S., Petro, J., Hunt, A.J., Donner, A.L., Bauer, S.I., Carson, H.F., and Sharpe, R.J. (1990) Inhibition of angiogenesis by recombinant human platelet factor-4 and related peptides. Science 247, 77-79

83. Sharpe, R.J., Byers, H.R., Scott, C.F., Bauer, S.I., and Maione, T.E. (1990) Growth inhibition of murine melanoma and human colon carcinoma by recombinant human platelet factor 4 . J Natl Cancer Inst 82, 848-853

84. Jouan, V., Canron, X., Alemany, M., Caen, J.P. Quentin, G., Plouet, J., and Bikfalvi, A. (1999) Inhibition of in vitro angiogenesis by platelet factor4-derived peptides and mechanism of action. Blood 94, 984-993

85. Perollet, C., Han, Z.C., Savona, C., Caen, J.P., and Bikfalvi, A. (1998) Platelet factor 4 modulates fibroblast growth factor 2 (FGF-2) activity and inhibits FGF-2 dimerization. Blood 91, 3289-3299

86. Singh, R.K., Gutman, M., Bucana, C.D., Sanchez, R., Llansa, N., and Fidler, I.J. (1995) Interferons alpha and beta down-regulate the expression of basic fibroblast growth factor in human carcinomas. Proc Natl Acad Sci U S A 92, 45624566

87. Cao, Y. (1999) Therapeutic potentials of angiostatin in the treatment of cancer. Haematologica 84, 643-650

88. Carmeliet, P. (2005) Angiogenesis in life, disease and medicine. Nature 438, 932-936

89. Miller, K.D., Sweeney, C.J., and Sledge, G.W., Jr. (2005) Can tumor angiogenesis be inhibited without resistance? Exs, 95-112

90. Browder, T., Butterfield, C.E., Kraling, B.M., Shi, B., Marshall, B., O'Reilly, M.S., and Folkman, J. (2000) Antiangiogenic scheduling of chemotherapy improves efficacy against experimental drugresistant cancer. Cancer Res 60, 1878-1886

91. Klement, G., Baruchel, S., Rak, J., Man, S., Clark, K., Hicklin, D.J., Bohlen, P., and Kerbel, R.S (2000) Continuous low-dose therapy with 
vinblastine and VEGF receptor-2 antibody induces sustained tumor regression without overt toxicity. $J$ Clin Invest 105, R15-24

92. Jain, R.K. (2005) Normalization of tumor vasculature: an emerging concept in antiangiogenic therapy. Science $307,58-62$

93. Figg, W.D., Pluda, J.M., Lush, R.M., Saville, M.W., Wyvill, K., Reed, E., and Yarchoan, R. (1997) The pharmacokinetics of TNP-470, a new angiogenesis inhibitor. Pharmacotherapy 17, 91-97

94. Ingber, D., Fujita, T., Kishimoto, S., Sudo, K. Kanamaru, T., Brem, H., and Folkman, J. (1990) Synthetic analogues of fumagillin that inhibit angiogenesis and suppress tumour growth. Nature $348,555-557$

95. Abe, J., Zhou, W., Takuwa, N., Taguchi, J., Kurokawa, K., Kumada, M., and Takuwa, Y. (1994) A fumagillin derivative angiogenesis inhibitor, AGM-1470, inhibits activation of cyclin-dependent kinases and phosphorylation of retinoblastoma gene product but not protein tyrosyl phosphorylation or protooncogene expression in vascular endothelial cells. Cancer Res 54, 34073412

96. Sin, N., Meng, L., Wang, M.Q., Wen, J.J., Bornmann, W.G., and Crews, C.M. (1997) The anti-angiogenic agent fumagillin covalently binds and inhibits the methionine aminopeptidase, MetAP-2. Proc Natl Acad Sci U S A 94, 6099-6103

97. Presta, L.G., Chen, H., O'Connor, S.J., Chisholm, V., Meng, Y.G., Krummen, L., Winkler, M., and Ferrara, N. (1997) Humanization of an antivascular endothelial growth factor monoclonal antibody for the therapy of solid tumors and other disorders. Cancer Res 57, 4593-4599

98. Ferrara, N., Hillan, K.J., and Novotny, W. (2005) Bevacizumab (Avastin), a humanized anti-VEGF monoclonal antibody for cancer therapy. Biochem Biophys Res Commun 333, 328-335

99. Goldberg, R.M., Hurwitz, H.I., and Fuchs, C.S. (2005) Angiogenesis inhibition in the treatment of colorectal cancer Part 3 of a 3-part series: targeting VEGF--current and future research directions. Clin Adv Hematol Oncol 3, 1-10; quiz 11

100. Gerber, H.P., Vu, T.H., Ryan, A.M., Kowalski, J. Werb, Z., and Ferrara, N. (1999) VEGF couples hypertrophic cartilage remodeling, ossification and angiogenesis during endochondral bone formation. Nat Med 5, 623-628

101. Ryan, A.M. (1999) Commentary: role of the pathologist in the identification and characterization of therapeutic molecules. Toxicol Pathol 27, 474-476

102. Osusky, K.L., Hallahan, D.E., Fu, A., Ye, F., Shyr, Y., and Geng, L. (2004) The receptor tyrosine kinase inhibitor SU11248 impedes endothelial cell migration, tubule formation, and blood vessel formation in vivo, but has little effect on existing tumor vessels. Angiogenesis 7, 225-233

103. Wojtowicz-Praga, S.M., Dickson, R.B., and Hawkins, M.J. (1997) Matrix metalloproteinase inhibitors. Invest New Drugs 15, 61-75
104. Richardson, P., Hideshima, T., and Anderson, K. (2002) Thalidomide: emerging role in cancer medicine. Annu Rev Med 53, 629-657

105. D'Amato, R.J., Loughnan, M.S., Flynn, E., and Folkman, J. (1994) Thalidomide is an inhibitor of angiogenesis. Proc Natl Acad Sci U S A 91, 40824085

106. Kumar, S., Witzig, T.E., and Rajkumar, S.V. (2002) Thalidomide as an anti-cancer agent. $J$ Cell Mol Med 6, 160-174

107. Miller, K.D. (2004) Recent translational research: antiangiogenic therapy for breast cancer - where do we stand? Breast Cancer Res 6, 128-132

108. Klement, G., Huang, P., Mayer, B., Green, S.K., Man, S., Bohlen, P., Hicklin, D., and Kerbel, R.S. (2002) Differences in therapeutic indexes of combination metronomic chemotherapy and an anti-VEGFR-2 antibody in multidrug-resistant human breast cancer xenografts. Clin Cancer Res 8, 221-232

109. Man, S., Bocci, G., Francia, G., Green, S.K., Jothy, S., Hanahan, D., Bohlen, P., Hicklin, D.J., Bergers, G., and Kerbel, R.S. (2002) Antitumor effects in mice of low-dose (metronomic) cyclophosphamide administered continuously through the drinking water. Cancer Res 62, 27312735

110. Dings, R.P., Nesmelova, I., Griffioen, A.W., and Mayo, K.H. (2003) Discovery and development of anti-angiogenic peptides: A structural link. Angiogenesis 6, 83-91

111. Griffioen, A.W., van der Schaft, D.W., BarendszJanson, A.F., Cox, A., Struijker Boudier, H.A., Hillen, H.F., and Mayo, K.H. (2001) Anginex, a designed peptide that inhibits angiogenesis. Biochem J 354, 233-242

112. van der Schaft, D.W., Dings, R.P., de Lussanet, Q.G., van Eijk, L.I., Nap, A.W., Beets-Tan, R.G., Bouma-Ter Steege, J.C., Wagstaff, J., Mayo, K.H., and Griffioen, A.W. (2002) The designer anti-angiogenic peptide anginex targets tumor endothelial cells and inhibits tumor growth in animal models. Faseb J 16, 1991-1993

113. Dings, R.P., Arroyo, M.M., Lockwood, N.A., van Eijk, L.I., Haseman, J.R., Griffioen, A.W., and Mayo, K.H. (2003) Beta-sheet is the bioactive conformation of the anti-angiogenic anginex peptide. Biochem J 373, 281-288

114. Dings, R.P., Chen, X., Hellebrekers, D.M., van Eijk, L.I., Zhang, Y., Hoye, T.R., Griffioen, A.W., and Mayo, K.H. (2006) Design of nonpeptidic topomimetics of antiangiogenic proteins with antitumor activities. J Natl Cancer Inst 98, 932936

115. Mayo, K.H., Dings, R.P., Flader, C., Nesmelova, I., Hargittai, B., van der Schaft, D.W., van Eijk, L.I., Walek, D., Haseman, J., Hoye, T.R., and Griffioen, A.W. (2003) Design of a partial peptide mimetic of anginex with antiangiogenic and anticancer activity. J Biol Chem 278, 4574645752 
116. Akerman, M.E., Pilch, J., Peters, D., and Ruoslahti, E. (2005) Angiostatic peptides use plasma fibronectin to home to angiogenic vasculature. Proc Natl Acad Sci U S A 102, 20402045

117. Abou-Jawde, R., Choueiri, T., Alemany, C., and Mekhail, T. (2003) An overview of targeted treatments in cancer. Clin Ther 25, 2121-2137

118. McCarthy, S.A., Kuzu, I., Gatter, K.C., and Bicknell, R. (1991) Heterogeneity of the endothelial cell and its role in organ preference of tumour metastasis. Trends Pharmacol Sci 12, 462-467

119. Sedlacek, H.H. (2001) Pharmacological aspects of targeting cancer gene therapy to endothelial cells. Crit Rev Oncol Hematol 37, 169-215

120. Dutour, A., and Rigaud, M. (2005) Tumor endothelial cells are targets for selective therapies: in vitro and in vivo models to evaluate antiangiogenic strategies. Anticancer Res 25, 3799-3807

121. Nilsson, F., Kosmehl, H., Zardi, L., and Neri, D. (2001) Targeted delivery of tissue factor to the ED-B domain of fibronectin, a marker of angiogenesis, mediates the infarction of solid tumors in mice. Cancer Res 61, 711-716

122. Ozerdem, U., Grako, K.A., Dahlin-Huppe, K., Monosov, E., and Stallcup, W.B. (2001) NG2 proteoglycan is expressed exclusively by mural cells during vascular morphogenesis. Dev Dyn 222, 218-227

123. Neri, D., and Bicknell, R. (2005) Tumour vascular targeting. Nat Rev Cancer 5, 436-446

124. van Beijnum, J.R., Eijgelaar, W.J., and Griffioen, A.W. (2006) Towards high-throughput functional target discovery in angiogenesis research. Trends Mol Med 12, 44-52

125. Oh, P., Li, Y., Yu, J., Durr, E., Krasinska, K.M., Carver, L.A., Testa, J.E., and Schnitzer, J.E. (2004) Subtractive proteomic mapping of the endothelial surface in lung and solid tumours for tissue-specific therapy. Nature 429, 629-635

126. St Croix, B., Rago, C., Velculescu, V., Traverso, G., Romans, K.E., Montgomery, E., Lal, A., Riggins, G.J., Lengauer, C., Vogelstein, B., and Kinzler, K.W. (2000) Genes expressed in human tumor endothelium. Science 289, 1197-1202

127. Nanda, A., and St Croix, B. (2004) Tumor endothelial markers: new targets for cancer therapy. Curr Opin Oncol 16, 44-49

128. MacFadyen, J.R., Haworth, O., Roberston, D., Hardie, D., Webster, M.T., Morris, H.R., Panico, M., Sutton-Smith, M., Dell, A., van der Geer, P., Wienke, D., Buckley, C.D., and Isacke, C.M. (2005) Endosialin (TEM1, CD248) is a marker of stromal fibroblasts and is not selectively expressed on tumour endothelium. FEBS Lett 579, 2569-2575

129. van Beijnum, J.R., Dings, R.P., van der Linden, E., Zwaans, B.M., Ramaekers, F.C., Mayo, K.H., and Griffioen, A.W. (2006) Gene expression of tumor angiogenesis dissected: specific targeting of colon cancer angiogenic vasculature. Blood 108, 2339-2348

130. Huminiecki, L., Gorn, M., Suchting, S., Poulsom, R., and Bicknell, R. (2002) Magic roundabout is a new member of the roundabout receptor family that is endothelial specific and expressed at sites of active angiogenesis. Genomics 79, 547-552

131. Sullivan, D.C., Huminiecki, L., Moore, J.W., Boyle, J.J., Poulsom, R., Creamer, D., Barker, J., and Bicknell, R. (2003) EndoPDI, a novel proteindisulfide isomerase-like protein that is preferentially expressed in endothelial cells acts as a stress survival factor. J Biol Chem 278, 47079-47088

132. Williams, C.K., Li, J.L., Murga, M., Harris, A.L., and Tosato, G. (2006) Up-regulation of the Notch ligand Delta-like 4 inhibits VEGF-induced endothelial cell function. Blood 107, 931-939

133. Liu, C., Shao, Z.M., Zhang, L., Beatty, P., Sartippour, M., Lane, T., Livingston, E., and Nguyen, M. (2001) Human endomucin is an endothelial marker. Biochem Biophys Res Commun 288, 129-136

134. Pasqualini, R., Koivunen, E., Kain, R., Lahdenranta, J., Sakamoto, M., Stryhn, A., Ashmun, R.A., Shapiro, L.H., Arap, W., and Ruoslahti, E. (2000) Aminopeptidase N is a receptor for tumor-homing peptides and a target for inhibiting angiogenesis. Cancer Res 60, 722727

135. Santimaria, M., Moscatelli, G., Viale, G.L., Giovannoni, L., Neri, G., Viti, F., Leprini, A., Borsi, L., Castellani, P., Zardi, L., Neri, D., and Riva, P. (2003) Immunoscintigraphic detection of the ED-B domain of fibronectin, a marker of angiogenesis, in patients with cancer. Clin Cancer Res 9, 571579

136. Thijssen, V.L., Postel, R., Brandwijk, R.J., Dings, R.P., Nesmelova, I., Satijn, S., Verhofstad, N., Nakabeppu, Y., Baum, L.G., Bakkers, J., Mayo, K.H., Poirier, F., and Griffioen, A.W. (2006) Galectin-1 is essential in tumor angiogenesis and is a target for antiangiogenesis therapy. Proc Nat Acad Sci U S A 103, 15975-15980

137. Burrows, F.J., and Thorpe, P.E. (1993) Eradication of large solid tumors in mice with an immunotoxin directed against tumor vasculature. Proc Natl Acad Sci U S A 90, 8996-9000

138. Miles, K.A. (1999) Tumour angiogenesis and its relation to contrast enhancement on computed tomography: a review. Eur J Radiol 30, 198-205

139. Miller, J.C., Pien, H.H., Sahani, D., Sorensen, A.G., and Thrall, J.H. (2005) Imaging angiogenesis: applications and potential for drug development. J Natl Cancer Inst 97, 172-187

140. Atri, M. (2006) New technologies and directed agents for applications of cancer imaging. J Clin Oncol 24, 3299-3308

141. Mulder, W.J., Strijkers, G.J., van Tilborg, G.A., Griffioen, A.W., and Nicolay, K. (2006) Lipidbased nanoparticles for contrast-enhanced MRI and molecular imaging. NMR Biomed 19, 142-164 
142. Daldrup-Link, H.E., Simon, G.H., and Brasch, R.C. (2006) Imaging of tumor angiogenesis: current approaches and future prospects. Curr Pharm Des 12, 2661-2672

143. Lanza, G.M., and Wickline, S.A. (2003) Targeted ultrasonic contrast agents for molecular imaging and therapy. Curr Probl Cardiol 28, 625-653

144. Mizukami, S., Kikuchi, K., Higuchi, T., Urano, Y., Mashima, T., Tsuruo, T., and Nagano, T. (1999) Imaging of caspase-3 activation in HeLa cells stimulated with etoposide using a novel fluorescent probe. FEBS Lett 453, 356-360

145. van Tilborg, G.A., Mulder, W.J., Deckers, N., Storm, G., Reutelingsperger, C.P., Strijkers, G.J., and Nicolay, K. (2006) Annexin A5-functionalized bimodal lipid-based contrast agents for the detection of apoptosis. Bioconjug Chem 17, 741749

146. Taylor, N.J., Baddeley, H., Goodchild, K.A., Powell, M.E., Thoumine, M., Culver, L.A., Stirling, J.J., Saunders, M.I., Hoskin, P.J., Phillips, H., Padhani, A.R., and Griffiths, J.R. (2001) BOLD MRI of human tumor oxygenation during carbogen breathing. J Magn Reson Imaging 14, 156-163

147. Yang, D.J., Kim, K.D., Schechter, N.R., Yu, D.F., Wu, P., Azhdarinia, A., Roach, J.S., Kalimi, S.K., Ozaki, K., Fogler, W.E., Bryant, J.L., Herbst, R., Abbruzzes, J., Kim, E.E., and Podoloff, D.A. (2002) Assessment of antiangiogenic effect using 99mTc-EC-endostatin. Cancer Biother Radiopharm 17, 233-245 


\section{Chapter}

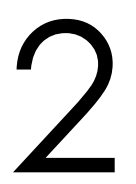

Angiogenesis gene expression profiling in xenograft models to study cellular interactions

Victor L.J.L. Thijssen, Ricardo J.M.G.E. Brandwijk, Ruud P.M. Dings, Arjan W. Griffioen

Experimental Cell Research 2004; 299(2):286-293 


\section{Abstract}

The present study describes a method to simultaneously obtain the angiogenic expression profile in tumor cells and vascular cells of a single tumor. Human and mouse specific primers were used for quantitative realtime RT-PCR to determine the expression of vascular endothelial growth factors A, B, C, and D, vascular endothelial growth factor receptors 1, 2, and 3 , neuropilin 1 , and 2, angiopoietin 1,2,3/4, tyrosine kinase receptors 1 and 2, basic fibroblast growth factor in xenograft tumors obtained by injection of human ovarian carcinoma cells in nude mice. In addition, the effect of treatment with anginex and taxol on the expression profile was analyzed. Most factors were expressed higher in vascular cells as compared to tumor cells. In response to treatment, tumor cells significantly upregulated bFGF expression and downregulated VEGF receptor expression. This was accompanied by downregulation of VEGF-B and $-D$ and upregulation of angiopoietin- 3 as well as the angiopoietin receptors in the non-tumor cells. In conclusion, real-time qRT-PCR combined with xenograft tumor models presents a sensitive method to monitor angiogenesis and to analyse interactions between tumor cells and nontumor cells in vivo. The approach can be applied to different research fields in which xenograft models are used. 


\section{Introduction}

Angiogenesis is essential for tumor growth ${ }^{1}$ and it is generally accepted that tumor angiogenesis is the result of an unbalanced expression of stimulating and inhibiting factors ${ }^{2}$. The general concept that tackling unfavourable angiogenesis could provide novel therapeutic strategies has made angiogenesis an attractive field of research ${ }^{3}$. Up to now, the research on angiogenic gene expression has often been focussed on specific angiogenic factors, thus ignoring the overall angiogenic balance. Furthermore, most in vitro studies address the expression in either the tumor cells or the endothelial cells. Reports on the effect of in vivo interactions between tumor cells and tumor vasculature on gene expression are scarce ${ }^{4,5}$.

Recently, two studies were published in which real-time quantitative RT-PCR (qRT-PCR) was used as a sensitive and efficient method to monitor the expression of a large panel of factors involved in tumor angiogenesis ${ }^{6,7}$.

Here we describe a qRT-PCR approach that enables an extensive survey of signalling between the tumor cells and the vascular cells in vivo. Mice were inoculated with human tumor cells to generate human/mouse xenograft tumors. A novel primer design approach was used to analyze the expression level of 16 angiogenesis related genes in the tumor cells and tumor vasculature by real-time qRT-PCR. In addition, the response of both tumor and vasculature compartments to different treatment strategies was determined.

\section{Materials and methods}

\section{Cell cultures}

Human ovarian carcinoma cell line MA148 and mouse melanoma cell line B16F10 were cultured in RPMI-1640 (Invitrogen), supplemented with $10 \%$ FCS (BioWhittaker), $50 \mathrm{ng} / \mathrm{ml}$ streptomycin, and $50 \mathrm{U} / \mathrm{ml}$ penicillin. All cultures were incubated at $37^{\circ} \mathrm{C}$ and $5 \% \mathrm{CO}_{2}$.

\section{Tumor models}

The ovarian carcinoma xenograft model ${ }^{8}$ and the mouse melanoma model were used as described previously ${ }^{9}$. Anti-tumor treatment was applied to the xenograft model and consisted of either anti-angiogenesis therapy (anginex) or chemotherapy (paclitaxel) which was started two weeks after injection of the tumor cells. Anginex $(6.0 \mathrm{mg} / \mathrm{kg} /$ day; $n=7)$ dissolved in saline or just saline $(n=7)$, was administered continuously $(0.25 \mu \mathrm{l} / \mathrm{hr})$ using a single osmotic minipump (Alzet) which was implanted in the left flank. Paclitaxel $(6.0 \mathrm{mg} / \mathrm{kg} /$ week; $\mathrm{n}=7)$ dissolved in $100 \mu \mathrm{l}$ saline was administered by I.P. injection. Mouse weight and tumor growth was measured throughout the experiment. Tumor volume was calculated as width ${ }^{2} x$ length $\times 0.52$. After 20 days of treatment the mice were sacrificed and the tumors 
were rapidly frozen in liquid nitrogen. All experiments were approved by the local ethical review committee.

\section{Immunohistochemistry}

Tumor tissue was embedded in tissue freezing medium (Miles Inc.) and shock frozen in liquid nitrogen. Ten $\mu \mathrm{m}$ thick sections were brought to room temperature, air dried overnight, and fixed in acetone for 10 minutes. Next, the slides were air dried and washed three times for 5 minutes in phosphate-buffered saline (PBS). Samples were blocked with PBS containing $0.1 \%$ bovine serum albumin and $3 \%$ human serum albumin and subsequently incubated with phycoerytrin (PE)conjugated monoclonal antibody to CD-31 (PECAM-1) in a 1:50 dilution (Pharmigen) to stain for microvessel density. Finally, the slides were washed with PBS and immediately imaged using an Olympus BX-60 fluorescence microscope at 200X magnification. Digital images were stored and processed using Adobe Photoshop (Adobe Inc.). Quantification of microvessel density was determined in 3 mice of each group in random areas of at least 2 sections as described elsewhere. ${ }^{10}$

\section{RNA isolation and CDNA synthesis}

Total RNA was isolated from cultured cells or from tumor tissue using the RNeasy RNA isolation kit (Qiagen) according to the supplier's protocol. Possible genomic DNA contaminations were removed by on column DNAse treatment with the RNasefree DNAse set (Qiagen). The purity and integrity of the RNA was checked by gel electrophoresis according to standard procedures. One $\mu \mathrm{g}$ total RNA reverse transcribed with $200 \mathrm{U}$ of M-MLV reverse transcriptase (Promega) according standard procedures. Following inactivation of the reverse transcriptase activity cDNA was stored at $-20^{\circ} \mathrm{C}$.

\section{Primer design}

Primers were targeted against beta-actin (B-Actin), cyclophilinA, vascular endothelial growth factors $A, B, C$, and D (VEGF-A, -B, -C, -D), vascular endothelial growth factor receptors 1,2 , and 3 (VEGF-R1, -R2, -R3), neuropilin 1, and 2 (NRP$1,-2$ ), angiopoietin 1, 2, (mouse) 3, and (human) 4 (ANG-1, -2, -3, -4), tyrosine kinase receptors 1 and 2 (TIE-1, -2 ), basic fibroblast growth factor (bFGF), and placental growth factor (PIGF). The primers were specific for either human or mouse sequences and selected based on the following requirements: i) high percentage of mismatch in $3^{\prime}$ region with at least 1 nucleotide (nt) mismatch at the $3^{\prime}$ end, ii) primer melting temperature of $\sim 60^{\circ} \mathrm{C}$, iii) GC-content of $\sim 55 \%$, iv) preferably no $\mathrm{G}$ at $5^{\prime}$ end, $\mathrm{v}$ ) avoid runs of more than 3 identical nucleotides, vi) amplicon length of $\sim 100$ nucleotides, and vii) high overall homology between the human and mouse amplicon. Specificity and cross-reactivity was checked with the Basic Local Alignment Search Tool (BLAST; http://www.ncbi.nlm.nih.gov/BLAST) 
and the Multiple Sequence Alignment Program (ClustalW; http://www.ch.embnet.org/software/ClustalW.html). The specific melting point of the amplicons was analyzed using the ABI PRISM 7700 Dissociation curve software (Applied Biosystems). All primers were synthesized by Sigma-Genosys.

Table 1 - Selected markers and species specific primers for xenograft expression profiling

\begin{tabular}{|c|c|c|c|c|}
\hline & Target & $\begin{array}{l}\text { Accession } \\
\text { number }\end{array}$ & $\begin{array}{c}\text { Reverse primer } \\
\mathbf{5}^{\prime}-\mathbf{3}^{\prime}\end{array}$ & $\begin{array}{l}\text { Forward primer } \\
\qquad 5^{\prime}-\mathbf{3}^{\prime}\end{array}$ \\
\hline $\mathrm{h}$ & cyclophilin & NM_003376 & CTAGGCATGGGAGGGAACA & CTCGAATAAGTITGACTTGTGTTT \\
\hline $\mathrm{m}$ & cyclophilin & NM_009505 & AGCTAGACTTGAAGGGGAATG & АTTTCTITTGACTTGCGGGC \\
\hline $\mathrm{h}$ & $\beta$-actin & NM_003377 & GGAGGAGCTGGAAGCAGCC & GCTGTGCTACGTCGCCCTG \\
\hline $\mathrm{m}$ & $\beta$-actin & NM_011697 & GGAGGAAGAGGATGCGGCA & GAAGCTGTGCTATGTTGCTCTA \\
\hline $\mathrm{h}$ & VEGF-A & NM_005429 & CCAGGCCCTCGTCATTG & AAGGAGGAGGGCAGAATCAT \\
\hline $\mathrm{m}$ & VEGF-A & NM_009506 & CTCCAGGGCTTCATCGTTA & CAGAAGGAGAGCAGAAGTCC \\
\hline $\mathrm{h}$ & VEGF-B & NM_004469 & TGCCCATGAGCTCCACAG & CCCAGCCTGATGCCCCTG \\
\hline $\mathrm{m}$ & VEGF-B & NM_010216 & TGCCCATGAGTTCCATGC & CCCAGTITGATGGCCCCA \\
\hline $\mathrm{h}$ & VEGF-C & NM_002019 & TTTAACAAGCATTTCTGTGGAC & AACAAACTCTTCCCCAGCCA \\
\hline $\mathrm{m}$ & VEGF-C & NM_010228 & TITAAGGAAGCACTTCTGTGTGT & GTAAAAACAAACTTTTCCСТАATTC \\
\hline $\mathrm{h}$ & VEGF-D & NM_002253 & GGGTGCTGGATTAGATCTTTG & GCAGGAGGAAAATCCACTTG \\
\hline $\mathrm{m}$ & VEGF-D & NM_010612 & GGTGCTGAATGAGATCTCCC & GCAAGACGAGACTCCACTGC \\
\hline $\mathrm{h}$ & VEGF-R1 & NM_002020 & CTCCTTGTAGAAACCGTCAG & CCAGCAGCGAAAGCTTTGCG \\
\hline $\mathrm{m}$ & VEGF-R1 & NM_008029 & GCTGCTTGGAGATCTCACTG & TCAGCAGCTCAAGTGTCACC \\
\hline $\mathrm{h}$ & VEGF-R2 & NM_003873 & CCCAGATGCCGTGCATGAG & ATGACATTITGATCATGGAGC \\
\hline $\mathrm{m}$ & VEGF-R2 & NM_008737 & TTCCAGATGCTGGGCAAGTC & ATGACATCTTGATTGTGGCAT \\
\hline $\mathrm{h}$ & VEGF-R3 & NM_003872 & CAGGCTTGGCGGGCTGTCC & TGCAAAGAGGAAGAGGAGGTCT \\
\hline $\mathrm{m}$ & VEGF-R3 & XM_129720 & TGCATGCTGGGTGGACTATCA & GCAGGAGGAGGAAGAGGAGC \\
\hline $\mathrm{h}$ & NRP-1 & NM_001146 & GTCATCACATTCATCCACCAA & CCCGAGAGAGCCACTCATG \\
\hline $\mathrm{m}$ & NRP-1 & NM_009640 & CGTCACACTCATGCACTGG & CCCTGAGAGAGCCACACACA \\
\hline $\mathrm{h}$ & NRP-2 & NM_001147 & CCGGTCGTITGGGCTGGA & CAATTGCAACTTCGATTTCCTC \\
\hline $\mathrm{m}$ & NRP-2 & NM_007426 & TGTTCTGTCATTGGGGTTAGC & AACTGCAACTITGATTTTCCG \\
\hline $\mathrm{h}$ & ANG-1 & NM_015985 & CAAAGATTGACAAGGTTGTG & AGCTACCACCAACAACAGTG \\
\hline $\mathrm{m}$ & ANG-1 & NM_009641 & GCAAAGGCTGATAAGGTTATGA & AGCTACCAACAACAACAGCA \\
\hline $\mathrm{h}$ & ANG-2 & NM_005424 & TTCTTCTTTAGCAACAGTGGG & TGCCACGGTGAATAATTCAG \\
\hline $\mathrm{m}$ & ANG-2 & NM_011587 & TTCTTCTTTACGGATAGCAAC & AGCCACGGTCAACAACTCGC \\
\hline $\mathrm{h}$ & ANG-4 ${ }^{A}$ & NM_000459 & GCTTCGCCTTCTTGCTGA & AACAGCGCGCTCGAGAAG \\
\hline $\mathrm{m}$ & ANG- $3^{A}$ & NM_013690 & GCAGTTGTTCCCTCTTCTCTT & AACAGGGCCCTGGAGACC \\
\hline $\mathrm{h}$ & TIE1 & NM_002006 & CACAATGGTCGACCAGTCC & CCCCGCTGGTCTCGTTCTC \\
\hline
\end{tabular}


Table 1 continued

\begin{tabular}{|c|c|c|c|c|}
\hline & Target & $\begin{array}{l}\text { Accession } \\
\text { number }\end{array}$ & $\begin{array}{c}\text { Reverse primer } \\
5^{\prime}-3^{\prime}\end{array}$ & $\begin{array}{l}\text { Forward primer } \\
\qquad 5^{\prime}-3^{\prime}\end{array}$ \\
\hline $\mathrm{m}$ & TIE1 & NM_008006 & AATGGCAGACCAGGCAATC & CCCCACTGGTCTCCTTTAG \\
\hline $\mathrm{h}$ & TIE2 & NM_002632 & GTTGACTCTAGCTCGGACCAC & TTGAAGTGGAGAGAAGGTCTG \\
\hline $\mathrm{m}$ & TIE2 & NM_008827 & GTTGACTCTAGCTCGGACTGT & GAAGTCGAGAGGCGATCCC \\
\hline $\mathrm{h}$ & bFGF & NM_021130 & CACATTTAGAAGCCAGTAATCT & CCCGACGGCCGAGTTGAC \\
\hline $\mathrm{m}$ & bFGF & NM_008907 & ACTTAGAAGCCAGCAGCCG & CCCGACGGCCGCGTGGAT \\
\hline $\mathrm{h}$ & PLGF & NM_001101 & GGGAACAGCATCGCCGCA & TGCAGCTCCTAAAGATCCGT \\
\hline $\mathrm{m}$ & PLGF & NM_007393 & CTCTTCCCCTTGGTTTTCCT & ATGCAGATCTTGAAGATTCCC \\
\hline
\end{tabular}

Table 1 - Selected markers and species specific primers for xenograft expression profiling Primer sequences are shown as large caps $\left(5^{\prime} \rightarrow 3^{\prime}\right) ; \mathrm{h}=$ human; $m=$ mouse. ${ }^{A}$ ANG-3 and ANG-4 represent interspecies orthologues.

Quantitative real-time RT-PCR qRT-PCR was performed on an ABI PRISM 7700 Sequence Detection System apparatus (Applied Biosystems) using the SYBR Green PCR master mix (Applied Biosystems). The PCR reaction was performed in a $25 \mu \mathrm{L}$ volume containing $40 \mathrm{ng}$ CDNA, 1x SYBR Green PCR master mix, and $800 \mathrm{nM}$ of the forward and the reverse primer. The PCR profile was as follows, 10 minutes at $95^{\circ} \mathrm{C}$, followed by 50 cycles of 15 seconds at $95^{\circ} \mathrm{C}$ and 1 minute at $60^{\circ} \mathrm{C}$. Absolute mRNA copy numbers were calculated from standard curves which were obtained by dilution of precisely quantified template DNA. The expression of each target gene was normalized to the expression of the control genes (beta-actin and cyclophilinA).

\section{Statistical analysis}

Tumor volumes and qRT-PCR data are given as mean values \pm SEM. The WilcoxonMann-Whitney rank sum test was used to analyze the differences between the different treatment groups and to analyze the diference between tumor cells and tumor vasculature of the control group. Vessel parameters are given as mean values \pm SEM and analyzed using the Student's $t$-test. All values are two-sided and P-values $<0.05$ were considered statistically significant. Statistical computations were performed in SPSS 10.0.5.

\section{Results}

In this study we present a novel primer design approach to obtain real-time qRTPCR primers that are able to distinguish between human and mouse homologues while PCR kinetics are maintained. A set of genes was selected that comprised of known regulators of angiogenesis (Table 1 ). The coding regions of the mouse and 
human homologous mRNA were aligned and regions of low homology were identified in which the primer sequences were selected (Figure 1A). To ensure primer specificity, the $3^{\prime}$ end of each primer was placed in a human/mouse mismatch region (Figure $1 \mathrm{~B}$ ). Primer specificity was confirmed using the BLAST module (NCBI) and by a false template PCR in which both the combination of human breast tumor cDNA with mouse primers and mouse melanoma cDNA with human primers failed to produce detectable amounts of nonspecific amplicons (Figure 2A). Each primer set was also tested for PCR efficiency. Of each gene, a human and a mouse cDNA fragment encompassing the real-time primers was cloned, which were used to generate dilution series with exactly quantified concentrations (Figure 2B). All primer sets showed a linear amplification rate down to 1 femtogram of template DNA with the expected slope of -3.3 (Figure 2C).

\section{Figure 1- VEGFR-1 primer design}

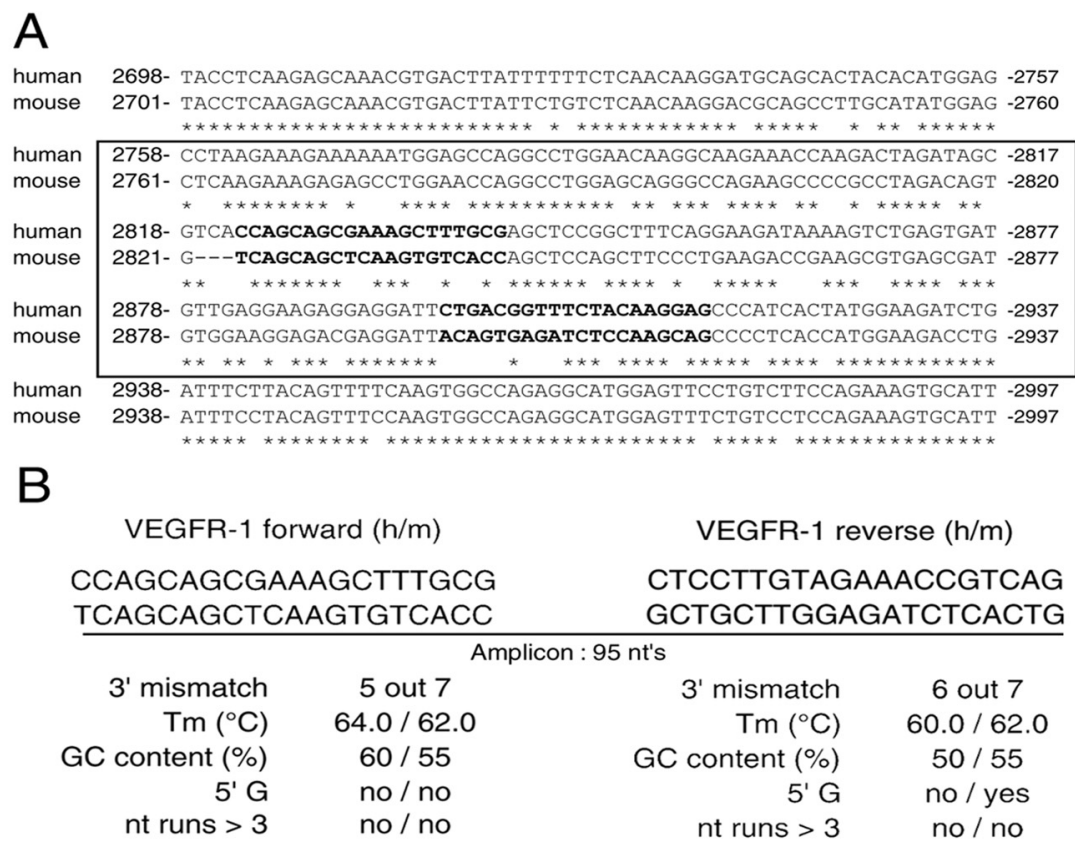

Figure 1 - VEGFR-1 primer design

A) Detail of alignment between human and mouse VEGFR-1 CDNA (overall homology: $83 \%$ ). The box indicates a region of relatively low homology (71\%). Selected primers are shown in bold. B) Characteristics of the selected forward and reverse primers with respect to the primer requirements. 
As proof of principle, the primers were used to analyze the gene expression in a xenograft tumor model. Nude mice (host) were injected with $10^{6}$ human MA148 ovarian carcinoma cells (donor) and 5 weeks after injection, tumor volumes were approximately $500 \mathrm{~mm}^{3}$. All 'donor' tumors had recruited a 'host' vasculature and the expression profile of the tumor compartment and the stromal/vascular compartment was determined by real-time qRT-PCR (Figure 3A). The expression of each gene was normalized to cyclophilinA which displayed a perfect correlation with another commonly used housekeeping gene, B-actin (correlation coefficient: 0.968, $\mathrm{p}<0.0001$ ). Clear angiogenic profiles were obtained, showing that bFGF and PIGF were expressed by the tumor cells as well as by the non-tumor cells. The bFGF mRNA copynumber was almost 300 fold higher in the vasculature as compared to the tumor (Figure 3B). VEGF-A and VEGF-B were also expressed at high levels by both compartments whereas the expression of VEGF-D was relatively high in the non-tumor cells. VEGF-C expression was virtually absent in both compartments. Similar to VEGF-D, VEGF-R1 and VEGF-R2 expression was low in tumor cells and high in non-tumor cells, whereas VEGF-R3 expression was relatively high in both compartments. Of all the VEGF-binding receptors, the expression of NRP-1 and NRP-2 were the highest. In fact, NRP-2 appeared to be the main receptor in tumor cells while NRP-1 was the predominant receptor in the non-tumor compartment. Angiopoietin signalling was also confined to the non-tumor compartment, with ANG2 as most abundantly expressed factor. Except for ANG-1, the expression of ANG-2, ANG-4, TIE-1, and TIE-2 was virtually absent in tumor cells.

Because the previous results indicated that the approach allowed expression profiling of a mixed human/mouse mRNA population, the method was used to investigate the in vivo effects of different anti-cancer treatments. To that end, tumor bearing mice were treated for 20 days with either paclitaxel (Taxol), anginex 9 , or saline (control). Tumor growth was significantly inhibited by both paclitaxel and anginex (by $25 \%$ and $56 \%$ respectively) as compared to saline treated control mice (Figure 4A). Histological analysis revealed a significant reduction in microvessel density after treatment with anginex $(-47 \% \pm 10 \%, P<0.01)$. A similar trend, though not significant, was observed with paclitaxel (Figure 4B). Similar results were observed at the level of vessel architecture (Figure 4C).

With respect to the expression levels, both paclitaxel and anginex treatment resulted in a significantly increased bFGF expression in tumor cells while the expression VEGF-R3 and NRP-2 was significantly reduced (Figure 5A). There was also a trend towards increased PIGF expression but this was only significant in case of anginex treatment. VEGF-D expression was signifcantly upregulated after treatment with paclitaxel. The response of non-tumor cells to paclitaxel and anginex treatment is shown in Figure 5B. In contrast to tumor cells, the vascular expression of neither bFGF nor PIGF was significantly affected by either treatment. However, both treatments resulted in a significantly decreased expression of VEGF- 


\section{Figure 2 - Analysis of primer specificity and sensitivity}

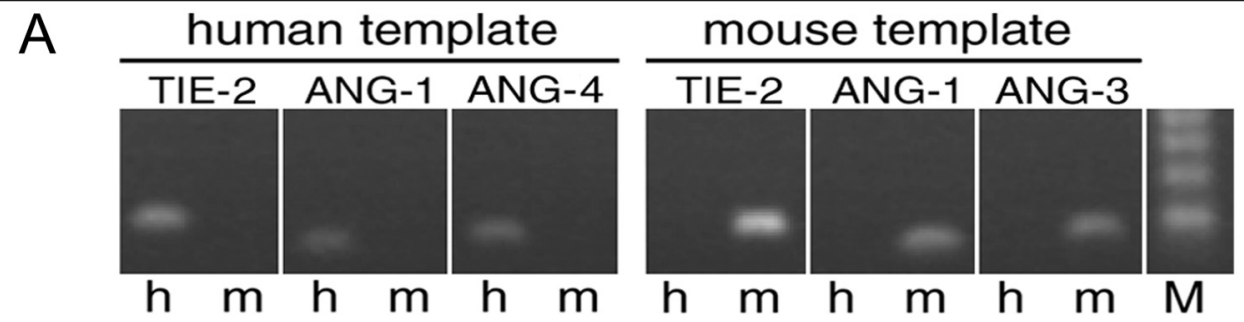

B
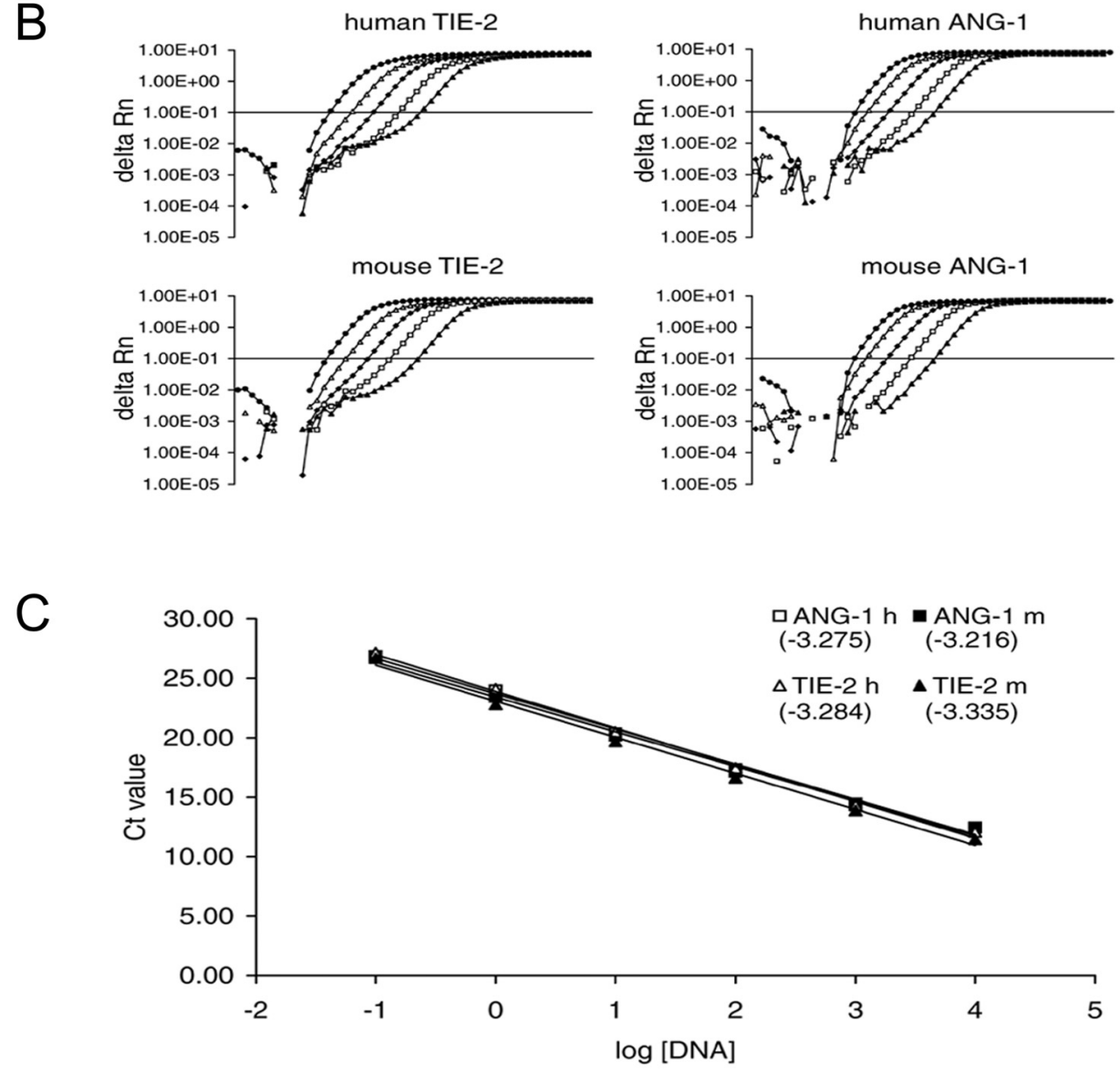
Figure 2 - Analysis of primer specificity and sensitivity

A) Agarose gel electrophoresis of amplicons generated during PCR with primers specific for human (h) or mouse $(\mathrm{m})$ isoforms on cloned CDNA fragments of mouse and human receptor TIE-2 and the ligands ANG-1, ANG-3, or ANG-4. CDNA fragments were cloned from either mouse B16F10 tumor tissue or human breast tumor tissue. $M=100$ bp marker. B) Amplification plots generated during quantitative real-time PCR on dilutions series of human and mouse isoforms of TIE-2 and ANG-1. Cloned fragments were diluted in 10-fold steps down to 1 femtogram. C) Standard curves for human and mouse isoforms of TIE-2 and ANG-1. The slope is indicated in brackets. All primers displayed a linear detection range down to 1 femtogram with an expected slope of approximately -3.3 .

$B$ and VEGF-D while the expression of ANG-3, TIE-1, and TIE-2 were significantly upregulated. In addition, paclitaxel treatment significantly decreased the expression of VEGF-A while the expression of VEGF-R2 was increased. Finally, the expression of NRP-1 was significantly decreased only by anginex treatment.

\section{Figure 3 - Molecular profiling in xenograft fumors}

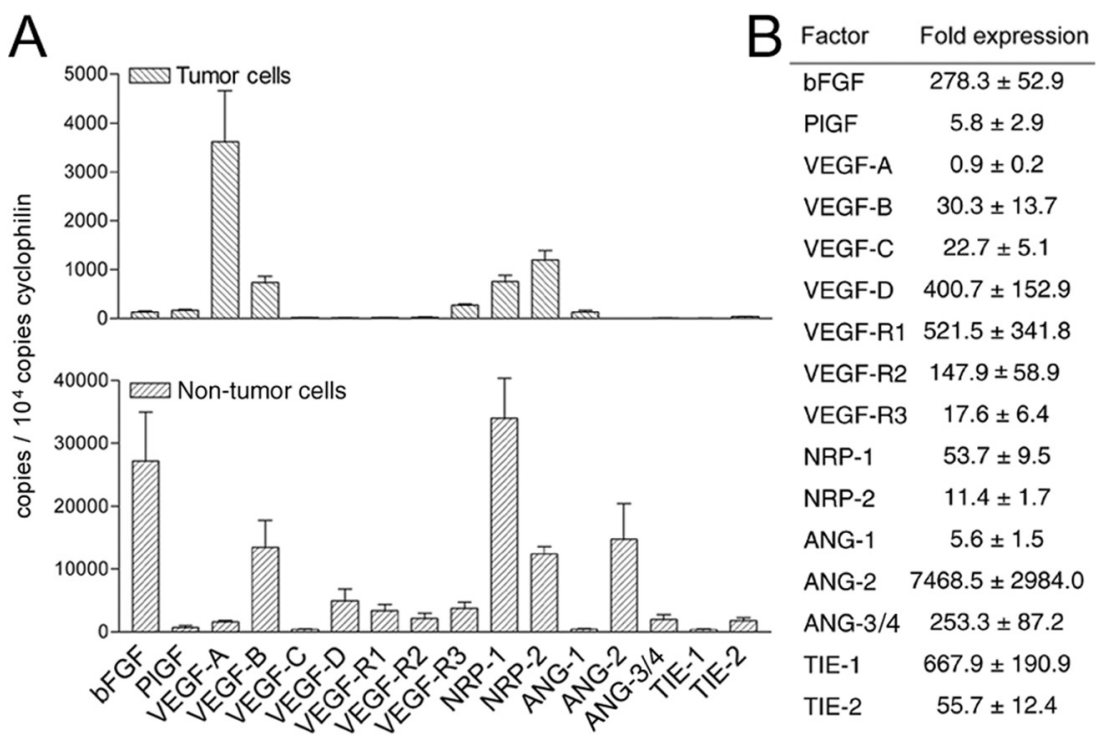

Figure 3 - Molecular profiling in xenograft tumors

A) Quantification of mRNA copy number in tumor cells (upper panel) or in non-tumor cells (lower panel) of mice injected subcutaneously with human ovarian carcinoma cells. Copy numbers were calculated from standard curves and normalized to ten thousand copies of cyclophilin. B) Fold expression in non-tumor cells as compared to tumor cells. 


\section{Discussion}

Xenograft tumor models are common tools in cancer and angiogenesis research ${ }^{11}$ 12. We recently established the anti-tumor activity of the angiogenesis inhibitor anginex in a xenograft model of nude mice injected with human ovarian carcinoma cells. It was shown that anginex, which is a designed beta-sheet forming peptide potently inhibited tumor growth, and synergistically improved the therapeutic effects of carboplatin and angiostatin ${ }^{8}, 9$. Because our main interest is the functional mechanism of angiogenesis inhibition, we set out to develop a method that allowed us to distinguish between the effects of treatment on tumor cells and tumor vasculature. Several groups had already shown that qRT-PCR could be used to analyze the expression of a large panel of genes with high sensitivity and specificity ${ }^{6}, 7,13$. In a recent study, Czechowski and co-workers developed a qRTPCR-based method to quantify the expression of over 1400 Arabidopsis transcription factors (TFs). Their approached proved more sensitive and accurate as compared to micro-array chip analsysis ${ }^{14}$. We used the high specificity of qRT-PCR to discriminate between human and mouse mRNA within the same xenograft tissue. Species specific primer sets were designed to amplify the exact same region in human and mouse mRNA in order to guarantee comparable PCR kinetics for the homologues amplicons. Between the species specific primers, at least 3 out of 6 nucleotides displayed a $3^{\prime}$ end mismatch (Figure 1B) whereas already a single $3^{\prime}$ nucleotide mismatch can be used to distinguish between two different targets ${ }^{15}$. These additional requirements garanteed comparable but species specific PCR kinetics. This was confirmed by determination of the PCR efficiency. Plotting the $\mathrm{Ct}$ value against the logarithm of input DNA should theoretically result in a linear curve with a slope of -3.3. We tested all primer sets for PCR efficiency and designed alternative primers in case they fell $5 \%$ outside the efficiency range ( $3.14 \leq$ slope $\leq 3.47$ ). We also observed that the standard curves of homologues amplicons were virtually identical, confirming identical PCR kinetics. This implies that the primers designed by this method are suitable for quantification by means of the comparative Ct method in stead of using the standard curve method for absolute quantification, even when different species are compared.

Expression profiling on xenograft tumors revealed differences in the expression patterns of tumor cells and non-tumor cells which would not have been detected if tissue from a syngeneic tumor had been used. It was found that most of the selected genes were expressed at higher levels in the non-tumor compartment of the tissue. It is realized that the non-tumor compartment consists of mouse derived vasculature, and various cell types such as endothelial cells pericytes, fibroblasts, and leukocytes. An appropriate selection of cell type specific candidate genes could be used to determine variations in any given host derived cell type within the 
vascular compartment, e.g. alpha smooth muscle cell actin to detect smooth muscle cells or CD31 to detect the endothelial cells.

\section{Figure 4 - The effect of anti-tumor treatment}
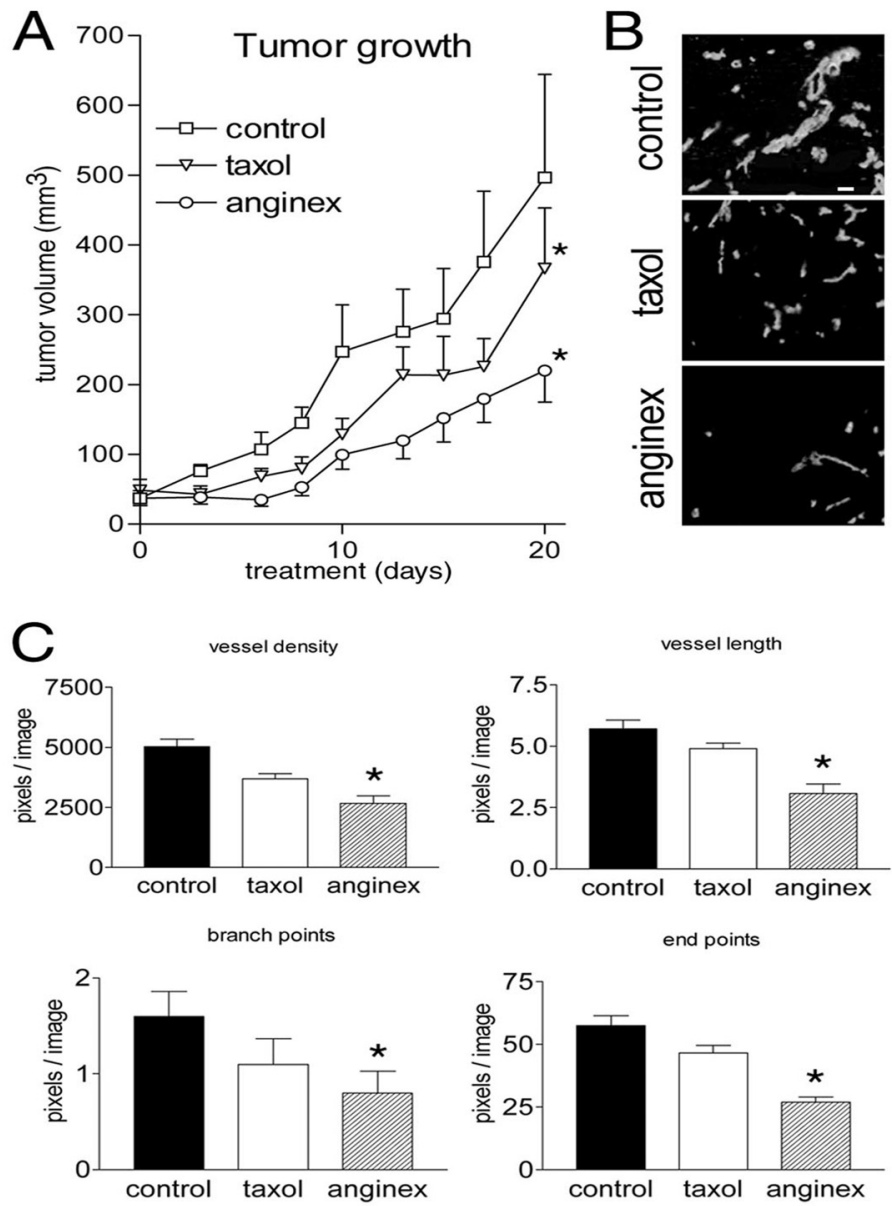

Figure 4 - The effect of anti-tumor treatment

A) The effect of 20 days of anti-tumor treatment on tumor volume. Mice were injected subcutaneously with human ovarian carcinoma cells and after two weeks treatment with saline, paclitaxel, or anginex was started. * P<0.05 treatment vs. control. B) Immunohistochemical staining on $10 \mu \mathrm{m}$ thick cryosections of treated and untreated tumors with PE-conjugated rat anti-mouse CD31 antibody. Original magnification is 200x. Scale bar $=50 \mathrm{~m}$. C) The microvessel density and vessel characteristics of the different treatment groups. ${ }^{*} \mathrm{P}<0.05$ treatment vs. control. 
We also detected expression of VEGF receptors and ANG receptors in tumor cells. Most of these receptors are usually associated with endothelial cells. However, studies on localization of expression use techniques like immunohistochemistry or in situ hybridization which are not as sensitive as qRT-PCR. Since the expression levels of most of the receptors was low in tumor cells as compared to the nontumor cells it is likely that less sensitive approaches did not detect it. In addition, there are a few reports on expression of these factor in tumor cells. For example, it has been shown that high VEGF-R3 expression in carcinoma cells correlates with poor survival ${ }^{16}$. Upregulation of VEGF-R2 expression in breast carcinoma cells correlates with tumor cell proliferation ${ }^{17}$ and overexpression of TIE-1 has also been reported to occur in breast cancer cells ${ }^{18}$. It is most likely that the expression of these factor in tumor cells is involved in tumor cell growth regulation ${ }^{16}$.

The full power of the xenograft approach was revealed when we analyzed the effect of treatment on gene expression. Both tumor compartments responded differently to the same treatment and some changes were indicative of cross-talk between the tumor cells and tumor vasculature. For example, previous studies in ovarian carcinomas have shown that bFGF is expressed in both tumor cells and vascular cells ${ }^{19,20}$. It has been suggested that stimulation of endothelial migration by endogenous bFGF expression requires exogenous bFGF ${ }^{21}$. Here, bFGF expression was found to be approximately 300-fold higher in tumor vasculature as compared to tumor cells. However, the tumor cells rather than the vascular cells responded to anti-cancer treatment by significantly upregulating their bFGF expression, possibly to stimulate endothelial migration.

Also within the VEGF family cross-talk was observed. Recently, VEGF-D and its receptor (VEGF-R3) have been shown to be prognostic factors for ovarian carcinoma and endometrial carcinoma in patients ${ }^{16,22}$. Here, VEGF-D and VEGF-R3 were expressed in both tumor and vascular cells. Treatment with paclitaxel or anginex induced downregulation of VEGF-D expression in the vasculature accompanied by downregulation of VEGF-R3 expression in tumor cells which indicates cross-talk between both compartments. In summary, in this study we describe a method that allows a rapid and sensitive analysis of gene expression by means of real-time qRT-PCR in xenograft tumors. The relevance of the method is the fact that it allows a simultaneous analysis of host cell expression and donor cell expression with comparable PCR kinetics within a single tissue. In addition, the method can be used to determine signalling between different cellular compartments, e.g. by using specific overexpressing or knock-out hosts or donors. Although this study was focussed on angiogenesis, appropriate candidate gene selection will allow researchers to adapt the method to their field of interest which will result in a better understanding of intercellular signalling in vivo. 


\section{Figure 5 - The effect of anti-tumor treatment on gene expression}

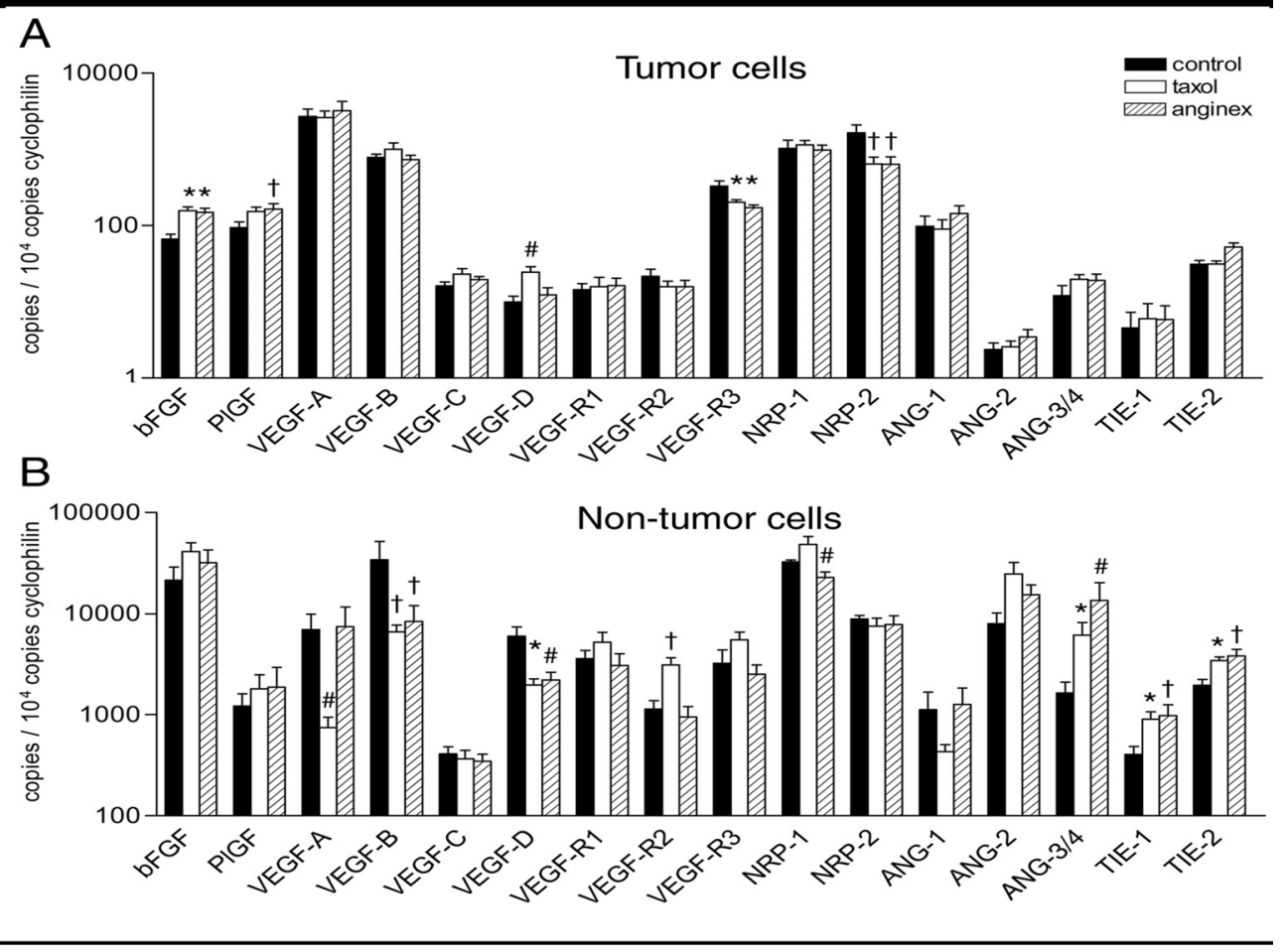

Figure 5 - The effect of anti-tumor treatment on gene expression

Effect of anti-tumor treatment on the expression of angiogenesis factors in tumor cells (A) and non tumor cells (B). QRT-PCR with human specific primers was performed on xenograft tumors after 20 days of treatment with saline, paclitaxel, or anginex. ${ }^{*} P<0.01$ vs. control, \# $P<0.02$ vs. control, $\dagger$ $\mathrm{P}<0.05$ vs. control. 


\section{References}

1. Folkman, J. (1995) Angiogenesis in cancer, vascular, rheumatoid and other disease. Nat Med 1, 27-31

2. Folkman, J. (2002) Role of angiogenesis in tumor growth and metastasis. Semin Oncol 29, 15-18

3. Griffioen, A.W., and Molema, G. (2000) Angiogenesis: potentials for pharmacologic intervention in the treatment of cancer, cardiovascular diseases, and chronic inflammation. Pharmacol Rev 52, 237-268

4. Huang, S.M., Li, J., and Harari, P.M. (2002) Molecular inhibition of angiogenesis and metastatic potential in human squamous cell carcinomas after epidermal growth factor receptor blockade. Mol Cancer Ther 1, 507-514

5. Shim, W.S., Teh, M., Bapna, A., Kim, I., Koh, G.Y., Mack, P.O., and Ge, R. (2002) Angiopoietin 1 promotes tumor angiogenesis and tumor vessel plasticity of human cervical cancer in mice. Exp Cell Res 279, 299-309

6. Shih, S.C., Robinson, G.S., Perruzzi, C.A., Calvo, A., Desai, K., Green, J.E., Ali, I.U., Smith, L.E., and Senger, D.R. (2002) Molecular profiling of angiogenesis markers. Am J Pathol 161, 35-41

7. Paradis, V., Bieche, I., Dargere, D., Laurendeau, I., Nectoux, J., Degott, C., Belghiti, J., Vidaud, M., and Bedossa, P. (2003) A quantitative gene expression study suggests a role for angiopoietins in focal nodular hyperplasia. Gastroenterology 124 , 651-659

8. Dings, R.P., Yokoyama, Y., Ramakrishnan, S., Griffioen, A.W., and Mayo, K.H. (2003) The designed angiostatic peptide anginex synergistically improves chemotherapy and antiangiogenesis therapy with angiostatin. Cancer Res 63, 382-385

9. van der Schaft, D.W., Dings, R.P., de Lussanet, Q.G., van Eijk, L.I., Nap, A.W., Beets-Tan, R.G., Bouma-Ter Steege, J.C., Wagstaff, J., Mayo, K.H., and Griffioen, A.W. (2002) The designer antiangiogenic peptide anginex targets tumor endothelial cells and inhibits tumor growth in animal models. Faseb J 16, 1991-1993

10. Wild, R., Ramakrishnan, S., Sedgewick, J., and Griffioen, A.W. (2000) Quantitative assessment of angiogenesis and tumor vessel architecture by computer-assisted digital image analysis: effects of VEGF-toxin conjugate on tumor microvessel density. Microvasc Res 59, 368-376

11. de Pinieux, G., Legrier, M.E., Poirson-Bichat, F., Courty, Y., Bras-Goncalves, R., Dutrillaux, A.M., Nemati, F., Oudard, S., Lidereau, R., Broqua, P., Junien, J.L., Dutrillaux, B., and Poupon, M.F. (2001) Clinical and experimental progression of a new model of human prostate cancer and therapeutic approach. Am J Pathol 159, 753-764

12. DeFeo-Jones, D., Garsky, V.M., Wong, B.K., Feng, D.M., Bolyar, T., Haskell, K., Kiefer, D.M., Leander, K., McAvoy, E., Lumma, P., Wai, J., Senderak, E.T., Motzel, S.L., Keenan, K., Van Zwieten, M., Lin, J.H., Freidinger, R., Huff, J., Oliff, A., and
Jones, R.E. (2000) A peptide-doxorubicin 'prodrug' activated by prostate-specific antigen selectively kills prostate tumor cells positive for prostatespecific antigen in vivo. Nat Med 6, 1248-1252

13. Van Trappen, P.O., Ryan, A., Carroll, M., Lecoeur, C., Goff, L., Gyselman, V.G., Young, B.D., Lowe, D.G., Pepper, M.S., Shepherd, J.H., and Jacobs, I.J. (2002) A model for co-expression pattern analysis of genes implicated in angiogenesis and tumour cell invasion in cervical cancer. $\mathrm{Br} \mathrm{J}$ Cancer 87, 537-544

14. Czechowski, T., Bari, R.P., Stitt, M., Scheible, W.R., and Udvardi, M.K. (2004) Real-time RT-PCR profiling of over 1400 Arabidopsis transcription factors: unprecedented sensitivity reveals novel root- and shoot-specific genes. Plant J 38, 366-379

15. Hiratsuka, M., Agatsuma, Y., and Mizugaki, M. (1999) Rapid detection of CYP2C9*3 alleles by real-time fluorescence PCR based on SYBR Green. Mol Genet Metab 68, 357-362

16. Yokoyama, Y., Charnock-Jones, D.S., Licence, D., Yanaihara, A., Hastings, J.M., Holland, C.M., Emoto, M., Sakamoto, A., Sakamoto, T., Maruyama, H., Sato, S., Mizunuma, H., and Smith, S.K. (2003) Expression of vascular endothelial growth factor (VEGF)-D and its receptor, VEGF receptor 3, as a prognostic factor in endometrial carcinoma. Clin Cancer Res 9, 1361-1369

17. Nakopoulou, L., Stefanaki, K., Panayotopoulou, E., Giannopoulou, I., Athanassiadou, P., GakiopoulouGivalou, H., and Louvrou, A. (2002) Expression of the vascular endothelial growth factor receptor2/Flk-1 in breast carcinomas: correlation with proliferation. Hum Pathol 33, 863-870

18. Yang, X.H., Hand, R.A., Livasy, C.A., Cance, W.G., and Craven, R.J. (2003) Overexpression of the receptor tyrosine kinase Tie-1 intracellular domain in breast cancer. Tumour Biol 24, 61-69

19. Davidson, B., Goldberg, I., Kopolovic, J., Gotlieb, W.H., Givant-Horwitz, V., Nesland, J.M., Berner, A., Ben-Baruch, G., Bryne, M., and Reich, R. (2000) Expression of angiogenesis-related genes in ovarian carcinoma--a clinicopathologic study. Clin Exp Metastasis 18, 501-507

20. Puri, R., Tousson, A., Chen, L., and Kakar, S.S. (2001) Molecular cloning of pituitary tumor transforming gene 1 from ovarian tumors and its expression in tumors. Cancer Lett 163, 131-139

21. Biro, S., Yu, Z.X., Fu, Y.M., Smale, G., Sasse, J., Sanchez, J., Ferrans, V.J., and Casscells, W. (1994) Expression and subcellular distribution of basic fibroblast growth factor are regulated during migration of endothelial cells. Circ Res 74, 485-494

22. Yokoyama, Y., Charnock-Jones, D.S., Licence, D., Yanaihara, A., Hastings, J.M., Holland, C.M., Emoto, M., Umemoto, M., Sakamoto, T., Sato, S., Mizunuma, H., and Smith, S.K. (2003) Vascular endothelial growth factor- $D$ is an independent prognostic factor in epithelial ovarian carcinoma. Br J Cancer 88, 237-244 


\section{Chapter}

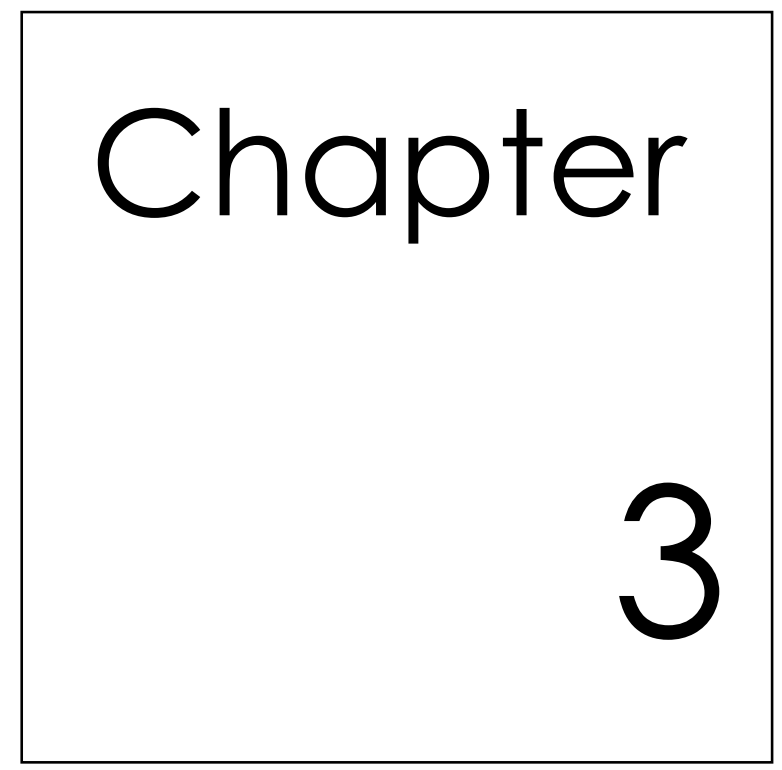

\section{Cloning an artificial gene encoding angiostatic anginex: from designed peptide to functional recombinant protein}

Ricardo J.M.G.E. Brandwijk, Irina Nesmelova, Ruud P.M. Dings, Kevin H. Mayo, Victor L.J.L. Thijssen, Arjan W. Griffioen 


\section{Abstract}

Anginex, a designed peptide 33-mer, is a potent angiogenesis inhibitor and anti-tumor agent in vivo. Anginex functions by inhibiting endothelial cell (EC) proliferation and migration leading to detachment of activated EC and their subsequent apoptosis. To better understand tumor endothelium targeting properties of anginex and enable its use in gene therapy, we constructed an artificial gene encoding the biologically exogenous peptide and produced the protein recombinantly in Pichia pastoris. Mass spectrometry shows recombinant anginex to be a dimer and circular dichroism shows the recombinant protein folds with $\beta$-strand structure like the synthetic peptide. Moreover, like parent anginex, the recombinant protein is active at inhibiting EC growth and migration, as well as inhibiting angiogenesis in vivo in the chorioallantoic membrane (CAM) of the chick embryo. This study demonstrated that it is possible to produce a functionally active protein version of a rationally designed peptide, using an artificial gene and the recombinant protein approach. 


\section{Introduction}

Angiogenesis is crucial to a variety of pathological processes, such as tumor growth and metastasis, rheumatoid arthritis, and various inflammatory disorders ${ }^{1}$. In the oncology field, both outgrowth of primary tumors and tumor metastasis are angiogenesis dependent ${ }^{2-5}$. Therefore, the abrogation of angiogenesis makes for an effective anticancer strategy. Recently, we described the design of the angiostatic agent anginex, an antiparallel $\beta$-sheet forming peptide 33mer of which the structure is based on the 3-dimensional folding of the a-chemokines platelet factor 4 (PF4) and interleukin- $8{ }^{6}$. Anginex has been shown to prevent adhesion and migration of activated endothelial cells (EC), leading to apoptosis induction in these cells. It has also been demonstrated that these effects lead to a significant tumor growth reduction in various mouse models ${ }^{7-9}$.

Although a synthetic approach for future clinical applications with anginex has some advantages, large-scale production may be more economical through a recombinant approach. We therefore have constructed an artificial gene of anginex, and cloned it for production of recombinant protein in the Pichia pastoris yeast expression system. This eukaryotic system has proven to be suitable for low-cost production of high levels of functionally active recombinant protein of known angiogenesis inhibitors, such as angiostatin ${ }^{10}$, endostatin ${ }^{11}$ and tumstatin ${ }^{12}$. Aside from facilitating large-scale production of the peptide, the anginex gene will be important for use as a molecular biological tool, for example to identify the anginex receptor using yeast-2-hybrid methodology.

Cloning of the anginex gene and isolation from the culture medium yielded recombinant anginex, which has comparable properties as its synthetic form. This was demonstrated both structurally as measured by circular dichroism (CD), and functionally as measured in vitro by inhibition of EC proliferation and migration, and in vivo by inhibition of angiogenesis in the chorioallantoic membrane (CAM)-assay. These results validate the use of the anginex gene in further developing anginex as a useful clinical agent and understanding its mechanism of action. The approach presented here will assist in designing other peptides and their corresponding genes that encode for specific receptor antagonists and the use of these genes in genetherapy.

\section{Materials and methods}

\section{Materials}

Restriction enzymes and T4 DNA ligase were obtained from New England Biolabs (Leusden, the Netherlands). Oligonucleotide primers were synthesized by Eurogentec (Liege, Belgium). Nucleotide sequencing was carried out on an Applied 
Biosystems DNA sequencer, utilizing the ABI prism Big dye terminator reaction mix (Nieuwerkerk aan den IJssel, the Netherlands). All tissue culture reagents, the TAcloning kit and the Pichia pastoris expression system were purchased from Invitrogen (Breda,The Netherlands). BIAcore equipment and reagent kits and chips were obtained from BIAcore life sciences (Breda, the Netherlands).

\section{Design and cloning of the anginex gene}

The gene encoding anginex was made using 4 primers in a PCR reaction. The DNA codons used to code for the amino acids were chosen in such a way that the primers did not form stable secondary structures in the PCR reactions. Formation of the artificial 99 bp gene of anginex was a two-step process. Two partial overlapping oligonucleotides were designed to form the gene of anginex: (A) $5^{\prime}$ GCAAACATAAAACTAAGCGTACAAATGAAACTATTCAAAAGACACCTAAAATGGAAAATA-

3'; (B) 5' -GTCTAGGCTTAGTTCTCTTCCGTCGTTTAGTTTIACTATTATTTTCCATTTTAG GTGTCT- 3'. In a secondary PCR, primers (1) 5' -TATGAATTCATGGCAAA CATAAAACTAAGCGTAC-3' and (2) 5'-TTATTCTAGACGGTCTAGGCTTAGTTCTCTTCC were used to introduce restriction sites for ECoRI and XbaI (shown in bold). The coding sequence for endostatin was obtained using PCR on CDNA of a human colon tumor. The following primers were used: 5'-TATGAATTCATGCACAGCCACCG-3' and 5'-TATTCTAGATACTTGGAGGCAGTCATG-3'. Both amplicons were cloned into the pCR2.1 TOPO-TA cloning kit and the sequence was verified by sequencing. Using the flanking restriction enzymes ECORI and $X b a I$, the anginex and endostatin coding sequence were cloned into the yeast expression vector pPICZ $\alpha-A$. The new expression constructs were sequence verified with primer 5'AOX: 5'GACTGGTTCCAATTGACAAGC-3', confirming an in-frame fusion with the Pichia pastoris $\alpha$-factor secretion signal sequence at the $\mathrm{N}$-terminal side of and the c-myc $\& 6 x$ His-tag sequence at the C-terminal side of both genes.

Transformation of Pichia pastoris, determination of the mut phenotype and expression of recombinant anginex

Both expression vectors were linearized using the restriction enzyme SacI in order to facilitate integration at the $A O X 1$ locus of the yeast genome. The linearized vector was transformed into the Pichia pastoris strains GS115 and X33 by using the Pichia Easycomp kit (Invitrogen) according to the manufacturers instructions. For each construct, several zeocine-resistant clones were selected and tested for a Mut ${ }^{+}$ phenotype by patching the colonies, respectively, on $\mathrm{MMH}$ (minimal methanol with histidine) and $\mathrm{MDH}$ (minimal dextrose with histidine) plates. From the clones that had a Mut+ phenotype, ten colonies were selected for a small-scale expression test in order to select the best expressing strain. Using these clones, $25 \mathrm{ml}$ BMGY (1\% yeast extract, $2 \%$ peptone, $100 \mathrm{mM}$ potassium phosphate, $\mathrm{pH} 6.0,1.34 \% \mathrm{YNB}$, 


\section{Figure 1 - Folded structure of anginex, amino acid sequence, genetic translation and vector construction}

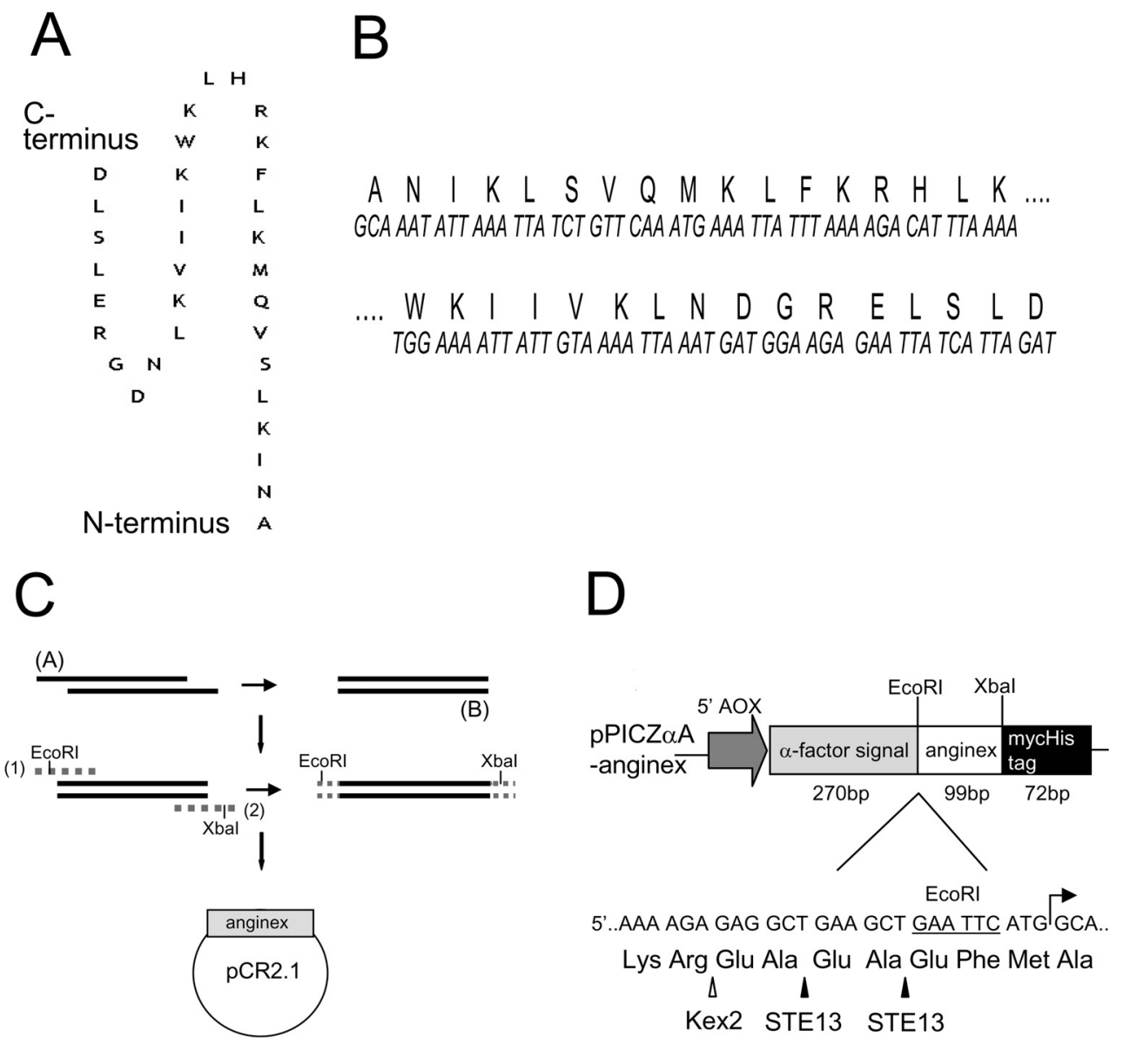

Figure 1 - Folded structure of anginex, amino acid sequence, genetic translation and vector construction

A) Amino acid sequence and secondary structure of anginex. B) Codons used for construction of the artificial gene coding for anginex. C) Construction of the anginex gene by recursive PCR. Restriction sites EcoRl and Xbal were added to the gene by incorporation of the sites in primer 1 and 2. The gene is cloned in PCR2.1 to facilitate easy gene reproduction. D) Map of the pPICZaAanginex cloning site. The start site of the amino acid sequence of anginex is indicated with an arrow. The open arrowhead shows the Kex2 protease cleavage site. The solid arrowheads show the STE13 signal protease cleavage site. 
$4 * 10^{-5} \%$ biotin, $1 \%$ glycerol) was inoculated. The culture was grown with shaking (300rpm) at $30^{\circ} \mathrm{C}$ until the culture reaches an OD600 nm of 2.0 . Cells were harvested and resuspended in 50ml BMMY (1\% yeast extract, $2 \%$ peptone, $100 \mathrm{mM}$ potassium phosphate, $\mathrm{pH} 6.0,1.34 \% \mathrm{YNB}, 4 * 10^{-5} \%$ biotin, $0.5 \%$ methanol). For continuous expression, methanol was added every 24 hours to a final concentration of $0.05 \%$. After 3 days, the cells were harvested, and the supernatant was tested for recombinant protein using standard $15 \%$ SDS-PAGE.

\section{Large scale expression and His-tag affinity isolation of recombinant anginex}

Clones that secreted the highest amount of recombinant protein were selected and used to inoculate $50 \mathrm{ml} \mathrm{BMGY}$ at $30^{\circ} \mathrm{C}$ and shaking (300 rpm) for 24 hours to create biomass. This culture was added to $1 \mathrm{~L}$ BMGY and cultured for another 24 hours. Cells were harvested and resuspended in 2 L BMMY in order to induce expression. After 24 hours, the supernatant was collected and concentrated using Centricon-plus 80 biomax 5 concentrators (Millipore Amsterdam, the Netherlands) to approximately $50 \mathrm{ml}$. Recombinant anginex/his-tag-related fusion proteins were isolated using $1 \mathrm{ml}$ His-select beads (Sigma; Zwijndrecht, the Netherlands) according to the native batch purification method described by the manufacturer. Eluted recombinant proteins were dialysed three times against $5 \mathrm{~L}$ water for at least 3 hours at $4^{\circ} \mathrm{C}$. The dialysates were concentrated using a centricon YM-3 (Millipore) ultrafiltration device. Concentration of recombinant proteins was measured using the micro BCA protein assay reagent kit (Pierce; Etten-Leur, the Netherlands) according to the instruction manual.

\section{Mass spectrometry and amino acid analysis of recombinant anginex}

A MALDI-TOF Voyager DE-PRO mass spectrometer (Applied Biosystems) was used to analyze the mass of recombinant anginex. In this MALDI technique, recombinant anginex was mixed with a matrix (alpha cyano-4-hydroxycinnamic acid). The crystallized sample was irradiated by a laser beam for desorption and ionization of the peptide. Automated $\mathrm{N}$-terminal Edman degradation consisted of repetitive cycles of Edman chemistry, followed by PTH analysis on a HPLC column according to standard procedures. The first $11 \mathrm{~N}$-terminal amino acids were determined.

\section{Biacore analysis}

Real time monitoring of protein interactions was performed at $25^{\circ} \mathrm{C}$ using the BIAcore 1000 biosensor according to the manufacturers instructions. Synthetic anginex was mobilized on a CM5 sensor chip using the Amine Coupling Kit with a target resonance level of $4000 \mathrm{RU}$. For interaction analysis, proteins diluted in HBSEP (0.01M HEPES pH7.4, 0.15M NaCl, 3mM EDTA, 0.005\% surfactant p20) were injected at a flow rate of $10 \mu \mathrm{l} /$ minute after which the flow cells were regenerated 
by injection of regeneration buffer $(10 \mathrm{mM}$ glycine- $\mathrm{HCl} \mathrm{pH} 2.0)$ at a flow of $10 \mu \mathrm{l} / \mathrm{minute}$. Data were analysed using the BIAevaluation software (version 3.0).

\section{Circular dichroism}

For CD measurements, freeze-dried synthetic or recombinant anginex was

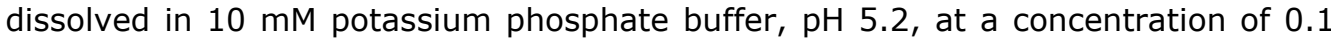
mM. CD spectra were recorded on a Jasco J-710 spectropolarimeter (Jasko, Easton MD) from 190 to $250 \mathrm{~nm}$ using a $0.1 \mathrm{~mm}$ path-length thermally jacketed quartz cuvette maintained at room temperature. Acquisition was performed using a 0.1 $\mathrm{nm}$ step resolution, $100 \mathrm{~nm} / \mathrm{min}$ scan speed, and a $1.0 \mathrm{~nm}$ bandwidth. The response time was $2 \mathrm{~s}$, and the sensitivity was 100 mdeg. Reported spectra are averages of six scans.

\section{Cell proliferation}

Human umbilical vein ECs (HUVECs) were harvested from normal human umbilical cords and cultured in fibronectin-coated flasks in HUVEC culture medium (RPMI1640 with 20\% (v/v) human serum, 2mM glutamine, $100 \mathrm{U} / \mathrm{ml}$ penicillin and $0.1 \mathrm{mg} / \mathrm{ml}$ streptomycin. Cells were cultured at $37^{\circ} \mathrm{C}$ and $5 \% \mathrm{CO}_{2}$. For the proliferation assay, HUVECs were seeded at 5000 cells/well in fibronectin-coated flat-bottomed 96-well tissue culture plates and grown for 3 days in culture medium supplemented with $1 \mathrm{ng} / \mathrm{ml}$ bFGF, with or without inhibitors. On the third day, 0.3 $\mu \mathrm{Ci} /$ well ${ }^{3} \mathrm{H}$-thymidine was added and incorporation was allowed to occur for 6 hours. After harvesting the cells, thymidine incorporation was quantified by liquid scintillation counting.

\section{Migration assay}

HUVEC cultures were grown to confluency in gelatine-coated 24-well tissue culture plates. A cross-shape wound was made by scratching the monolayer with a plastic tip. Wounded monolayers were washed with PBS and incubated with fresh culture medium supplemented with $10-\mathrm{ng} / \mathrm{ml}$ bFGF, with or without inhibitors. The wound width was measured microscopically at 4 different places at 0, 2, 4, 6 and 8 hours after wounding the culture.

\section{Chorioallantoic membrane (CAM) assay}

Fertilized Lohman-selected white leghorn eggs were incubated for three days at $37^{\circ} \mathrm{C}$ and $55 \%$ relative humidity and rotated once every hour. On day 3 , a rectangular window $(1 \times 2 \mathrm{~cm})$ was made in the egg-shell, and covered with tape to prevent dehydration. The window allowed undisturbed observation of the developing vasculature of the CAM. On day 7, a silicon ring (10 mm diameter) was placed on the CAM to allow local drug administration within the ring. Compounds were dissolved in sterile saline $(0.9 \% \mathrm{NaCl})$, and applied daily in aliquots of $65 \mu \mathrm{l}$ 
from day 10 to day 13 . On day 14 , CAMs were photographed. Photographs were scanned, and stereological principles were applied as follows. Five concentric rings were projected on the image, and the number of intersections of rings and blood vessels was determined and used as a measure of vessel density.

\section{Statistical analysis}

Proliferation and migration data are given as mean values \pm SEM. The MannWhitney $U$ test was used to analyse differences between treatment and control groups. For the analysis of vessel density obtained by CAM-assay, the MannWhitney $U$ test was used to determine the statistical significance of observed differences. All values are two-sided, and $P$ values $<0.05$ were considered statistically significant. Statistical computations were performed in SPSS 10.0.5.

\section{Results \& Discussion}

Design and cloning of the artificial gene for anginex

Anginex, a peptide 33-mer having an anti-parallel $\beta$-sheet structure (Figure 1A), was selected from a small library of designed $\beta$-sheet forming peptides 13,14 because of its strong anti-angiogenic activity ${ }^{6}$. To produce recombinant anginex, an artificial gene first had to be designed. The 33 amino acid sequence was translated into a 99 bp genetic code, excluding the possibility of strong secondary structure formation of transcribed mRNA (Figure 1B), which was checked using the RNA mFOLD server ( $\mathrm{dG}=-3.5 \mathrm{kcal} / \mathrm{mole}){ }^{15}$. Using recursive $P C R$, the gene was formed out of four oligonucleotides. In the first reaction, a double stranded DNAfragment encoding the 33 amino acid residues of anginex was formed using two partially overlapping $60 \mathrm{bp}$ oligonucleotides. In a second PCR, the restriction sites EcoRI and $X b a I$ were introduced at the $5^{\prime}$ and $3^{\prime}$ end, respectively. Due to the profound bactericidal activity from anginex ${ }^{6}, 13,16,17$, initial cloning steps were performed in a non-expressing bacterial system. The product of the secondary PCR was then cloned into the bacterial TA-cloning vector PCR2.1 to facilitate gene production (Figure 1C). As a reference and control, the DNA fragment coding for the well-known angiogenesis inhibitor endostatin, which was also obtained by PCR, was simultaneously cloned into the pCR2.1 vector. For recombinant protein production, both genes were digested and cloned into the Pichia pastoris expression vector pPICZ $\alpha$ A. This vector introduces a secretion signal peptide and a His-tag on to the anginex and endostatin genes (Figure 1D). Nucleotide sequencing confirmed the in-frame fusion construct of both genes, with the $\mathrm{N}$-terminally-linked $\alpha$-factor secretion signal and the C-terminally linked 6xHis-tag. 


\section{Figure 2 - Characterization of recombinant anginex}

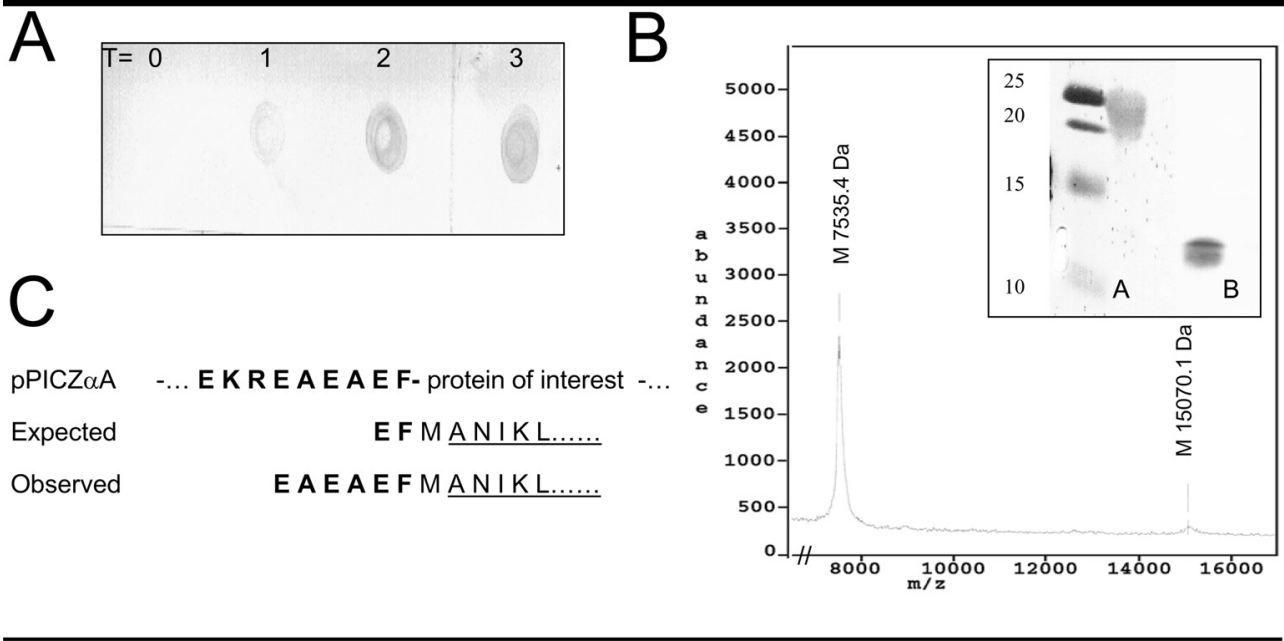

Figure 2 - Characterization of recombinant anginex

A) Determination of the optimal time post-methanol induction. During 5 days, cultur supernatant was collected and 12,5 $\mu$ was spotted on nitrocellulose. Anginex was probed with an anti-pentaHis-tag antibody and bound antibody was detected using HRP-conjugated secondary antibody. B) Mass-spectrometry analysis of recombinant anginex revealed two fragments of 7,5 and $15 \mathrm{kDa}$. Inset: Western blot analysis of recombinant anginex (lane B) and endostatin (lane A). Anginex was probed with an anti-penta-His-tag antibody and endostatin with an anti-endostatin antibody. Bound antibody was detected using HRP-conjugated secondary antibody. Bands were visualized using DAP. C) N-terminal sequencing of recombinant anginex (vector-related sequence shown in bold; anginex sequence is underlined).

\section{Expression, purification and characterisation of recombinant anginex}

After confirming that the constructs were correct, the DNA was linearized and transformed into competent yeast cells. Aside from being easy to manipulate, the Pichia pastoris expression system has other advantages, such as proper eukaryotic protein processing, protein folding and posttranslational modification. In addition, this expression system is faster and less expensive to use than other eukaryotic expression systems and generally expresses at higher levels ${ }^{18,19}$. From the initial colonies, clones most responsive to methanol-induction (Mut+ phenotype), were selected. Small-scale expression experiments showed a maximum level of expression of recombinant anginex already 48 hours after induction (Figure 2A).The clone with the highest expression level was then selected for large-scale expression in a $5 \mathrm{~L}$ culture. The secreted recombinant protein was isolated from the concentrated supernatant using nickel-chelated beads that bind His-tagged proteins. The yield was relatively low, ranging from $0.4 \mathrm{mg} / \mathrm{L}$ to $0.8 \mathrm{mg} / \mathrm{L}$ of yeast culture. Currently, optimized fermentor technology is being used to increase 
efficiency with respect to generating biomass, expression levels ${ }^{20}$ and isolation of His-tagged proteins.

Since endostatin has been produced already by others using the same expression system ${ }^{21}$, cloning and expression of endostatin was performed as an overall control for production procedures and some functional assays. The protein was secreted into the culture media and isolated using $\mathrm{Ni}$-chelated beads in the same way as was done for recombinant anginex. The expected molecular weight of endostatin (23.6kd) was verified using Western blotting, which was immunostained with an anti-endostatin antibody (Figure 2B).

\section{Figure 3 - Structural analysis of recombinant anginex}

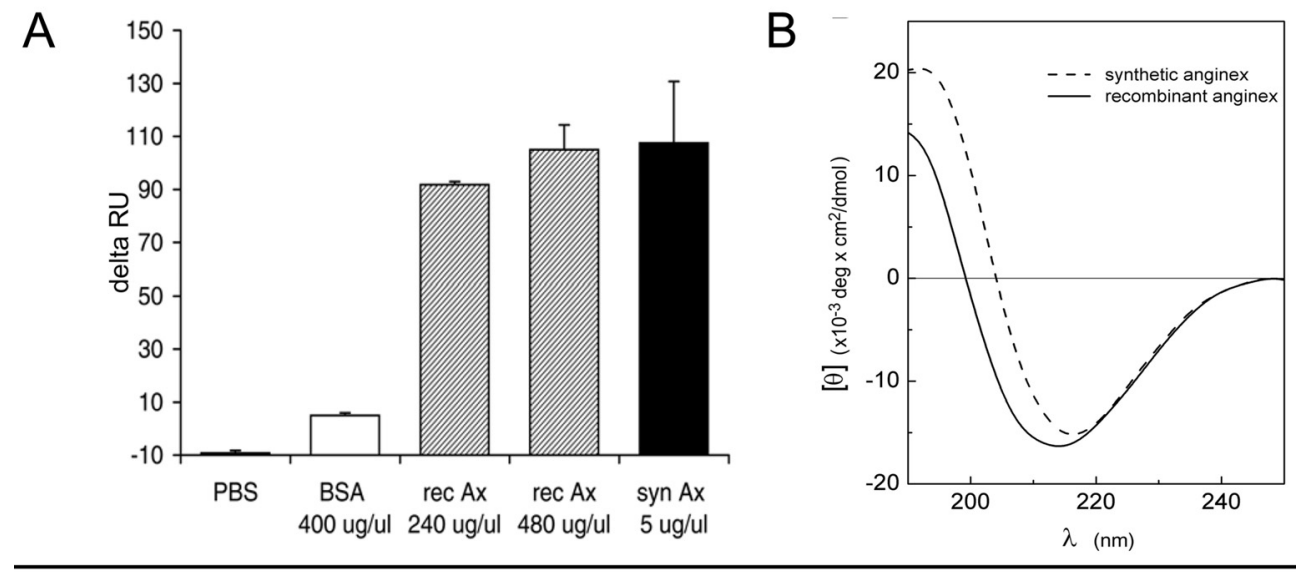

Figure 3 - Structural analysis of recombinant anginex

A) Interaction between recombinant and synthetic anginex as determined with BIAcore technology. Synthetic anginex was used as reference and BSA as an irrelevant control. B) CD spectra of synthetic (dashed line) and recombinant (solid line) anginex. Peptides were dissolved at a concentration of $0.1 \mathrm{mM}$ in $10 \mathrm{mM}$ potassium phosphate buffer, pH5.2. The fitting of linear combinations of secondary structure basis spectra to experimental curves yielded $86 \% \beta$-sheet and $14 \%$ random coil in synthetic anginex, and $72 \%$ and $28 \%$ random coil in recombinant peptide.

Detection of recombinant anginex was also carried out by Western blotting and was immunostained using a mouse anti-penta-His antibody (Figure 2B). Recombinant anginex appeared on the Western blot as a broad band of 12-14 kD. This was essentially double the size of the predicted size of $7.2 \mathrm{kD}$. To see if there were functional epitopes available, a Western blot was stained with a specific antianginex antibody. The antibody did not stain any bands on the gel. This could be explained by the addition of $\mathrm{N}$-terminal amino acids in recombinant anginex, which are likely to block the epitope of the antibody (unpublished data). 
To determine the purity of the isolated protein and to help explain the increased molecular weight of recombinant anginex, mass spectrometry (MS) was used. MS analysis revealed the presence of two main peaks, the first representing a $7.5 \mathrm{kD}$ species ( $86 \%$ of total protein) and the second a $15.0 \mathrm{kD}$ species (Figure $2 \mathrm{~A}$ ). Nterminal protein sequencing demonstrated that the $7.5 \mathrm{kD}$ fragment was indeed anginex flanked by the signal sequence as expected (Figure $2 \mathrm{C}$ ). In this regard, the $15 \mathrm{kD}$ MS peak probably represents dimerized anginex, a feature that has been previously reported to occur with synthetic anginex ${ }^{22}$. N-terminal amino acid sequencing also revealed that the processing of the $\alpha$-factor signalling sequence was incomplete (Figure 2C). Instead of three, there were seven extra amino acids at the $\mathrm{N}$-terminus of anginex. The first four amino acids originated from the STE13 signal cleavage site. The processing of the $\alpha$-signal sequence involves two steps ${ }^{23}$. The first step of signal cleavage occurs at the Arg-Glu site belonging to $\alpha$-factor Cterminus by Kex2 endopeptidase. This is followed by cleavage of two Glu-Ala repeats by the STE13 protein. The efficiency and completeness of this process can be affected by the surrounding amino acid sequence ${ }^{24}$. This is not an uncommon observation, since similar observations have been reported for other proteins as well 25,26 . The incomplete cleavage of the STE13 protease suggests that the 3dimensional structure of anginex influences the cleavage efficiency of the STE13 protease or that the amount of protein produced exceeds the catalytic power of the protease for effective cleavage of the fusion protein. Given the low yield of recombinant anginex in the Pichia pastoris expression system, the latter is not likely.

Subsequent BIAcore analysis confirmed that recombinant anginex does associate with synthetic anginex (Figure $3 \mathrm{~A}$ ). This suggests that the $\beta$-sheet folding of recombinant anginex is preserved. This is supported by structural analysis using $C D$, which demonstrates the presence of a prominent band at $217 \mathrm{~nm}$, characteristic of $\beta$-sheet structure ${ }^{13,14}$. Figure 3B compares CD traces for synthetic and recombinant anginex. Both spectral traces indicate the predominance of $\beta$ sheet conformation in these peptides. Linear combinations of secondary structure basis spectra ( $\alpha$-helix, $\beta$-sheet and random coil) fitted to the CD spectra showed the $\beta$-sheet content of $86 \%$ and $72 \%$ in the synthetic and recombinant peptide, respectively. The remaining portion of the $C D$ curve arises from unstructured regions in the peptides. Larger content of random coil in recombinant anginex is expected due to amino acid extensions at both peptide termini, primarily to the six histidine residues at the C-terminus. Note, that because small peptides are relatively flexible, the secondary structure contributions are used here merely to confirm that recombinant anginex adopts $\beta$-sheet conformation. 
Recombinant anginex inhibits endothelial cell proliferation and migration in vitro To demonstrate that recombinant anginex is biologically active, the endothelial cell (EC) proliferation assay using ${ }^{3} \mathrm{H}$-thymidine incorporation was performed and compared to the anti-proliferative activity from synthetic anginex. We found that recombinant anginex inhibited EC proliferation, albeit to a lesser degree than from positive controls synthetic anginex and PF4. Although the actual activity of recombinant anginex was lower $\left(E_{50}\right.$ 8-10 $\left.\mu \mathrm{M}\right)$ than that from synthetic anginex $\left(E_{50} 1-3 \mu \mathrm{M}\right)$ (Figure $4 \mathrm{~A}$ ), recombinant anginex still demonstrated significant activity at a concentration of $2.5 \mu \mathrm{M}(\mathrm{p}<0.037)$. Moreover, recombinant anginex also markedly inhibited the migration of $\mathrm{EC}$ in the in vitro wound-healing assay (Figure 4B). As a control, we used synthetic anginex and recombinant endostatin, known inhibitors of EC migration (Figure 4B). Recombinant endostatin functions very well at early time points. Interestingly, in contrast to the inhibition of proliferation, recombinant anginex was essentially as effective as synthetic anginex after 2 hours $(p<0.006$ versus $p<0.013)$. After 24 hours, however, the wound was still clearly visible in the cell layer treated with recombinant anginex, whereas the culture treated with synthetic anginex was almost completely grown to confluency.

Differences in activities between synthetic and recombinant anginex may be explained by the recombinant peptide having an additional seven amino acids at the $\mathrm{N}$-terminus and the tags at its $\mathrm{C}$-terminus. From previous studies 22,27 , it is known that the amino acids important for the activity of anginex are situated at the $\mathrm{N}$-terminal and second $\beta$-strands. Therefore, we expect that the tags at the $\mathrm{C}$ terminus would have less of an influence than the additional residues at the $\mathrm{N}$ terminus. Moreover, we also know that addition of a single methionine to the $\mathrm{N}$ terminus of anginex can affect its function by inhibiting EC proliferation without leading to apoptosis (unpublished data). Observed functional differences can also be explained by differential glycosylation. Although for the synthetic anginex, glycosylation is absent, it is possible that expression in the eukaryotic system has introduced some glycosylation, thereby modifying function ${ }^{28}$. However, based on the amino acid sequence, glycosylation is not expected. In addition, MS analysis did not indicate the presence of sugar groups. Therefore, either the amino acid sequence difference, or some small change in the folded structure of the protein may be responsible for the slight loss of activity as compared to synthetic anginex. Nevertheless, differences in recombinant anginex have led to a somewhat greater effect on the signalling pathways affecting migration, as compared to pathways involved in EC proliferation.

\section{Recombinant anginex inhibits angiogenesis in vivo}

To study inhibition of angiogenesis in vivo, the chick embryo chorioallantoic membrane (CAM)-assay was used. This assay, which measures developmental angiogenesis, is routinely used as the first step in in vivo testing of angiostatic 


\section{Figure 4 - In vitro functional analysis of recombinant anginex}
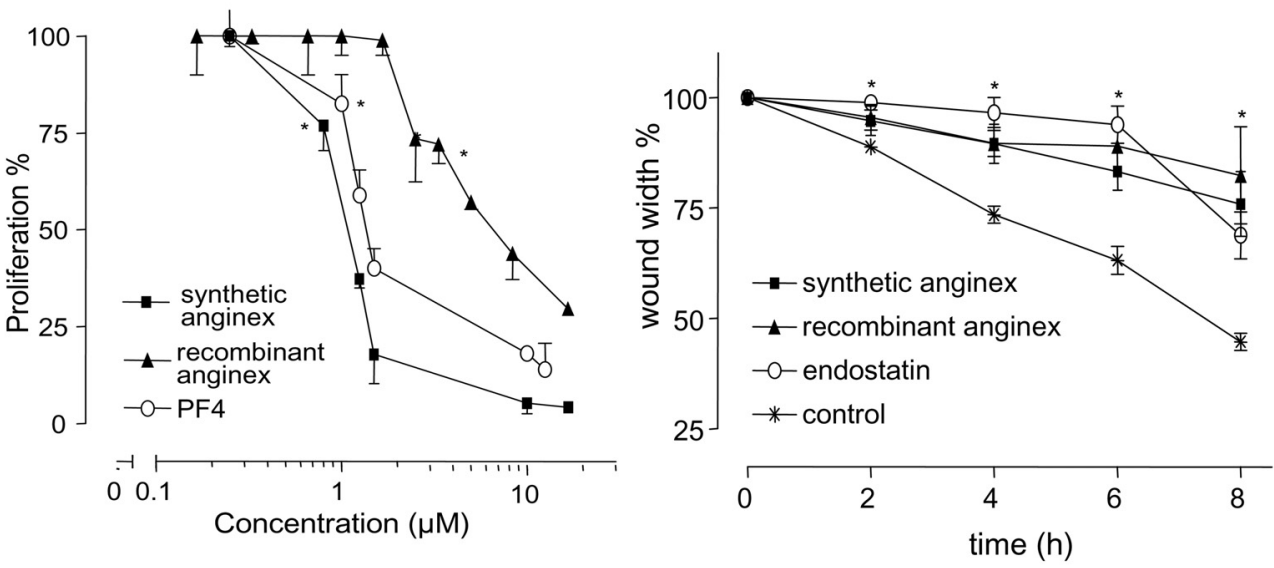

Figure 4 - In vitro functional analysis of recombinant anginex

(A) Proliferation of bFGF-stimulated HUVEC cultures was measured using a [3H]-thymidine incorporation assay. Dose-response curve of recombinant anginex relative to synthetic anginex. The well-known angiogenesis inhibitor platelet factor-4 (PF4) is used as a positive control. Results are expressed as mean counts per minute ( \pm SD) of three independent experiments from triplicate cultures. $P<0.037$ recombinant $(2.5 \mu \mathrm{M})$ vs. control, $p<0.037$ synthetic $(0.8 \mu \mathrm{M})$ vs. control, $p<0.037$ PF4 (1 $\mu \mathrm{M})$ vs. control. (B) The inhibitory effect on migration was determined using the wound healing assay. A confluent layer of HUVECs was wounded and subsequently cultured with or without (recombinant) peptides $(100 \mu \mathrm{g} / \mathrm{ml})$. Results are expressed as mean wound widths of duplicate cultures from two independent experiments. Recombinant endostatin $(100 \mu \mathrm{g} / \mathrm{ml})$ was used as a positive control. $P<0.006$ recombinant vs. control ( $t=2), p<0.013$ synthetic vs. Control $(t=2), p<0.004$ endostatin vs. control $(t=2), p<0.010$ recombinant vs. synthetic $(t=6)$.

compounds. In CAMs treated with recombinant anginex between day 10 and 13 of development (65 $\mathrm{\mu l}$ of $25 \mu \mathrm{M}$, daily), a profound inhibition of micro-vessel formation was observed, whereas larger pre-existing vessels were apparently unaffected. Figure 5 shows the development of CAM vasculature at day 14 postfertilization and following treatment with recombinant anginex, synthetic anginex or vehicle alone. Post-treatment vessel counts with recombinant anginex were $88 \pm$ 15 vs. $150 \pm 12$ for treatment with vehicle alone $(41 \%$ inhibition, $p<0.014)$. The angiostatic effect using recombinant anginex was essentially the same as that from synthetic anginex (36\% inhibition, $\mathrm{p}<0.060)$ (Figure 5 ). 


\section{Figure 5 - In vivo angiogenesis inhibition from recombinant anginex}
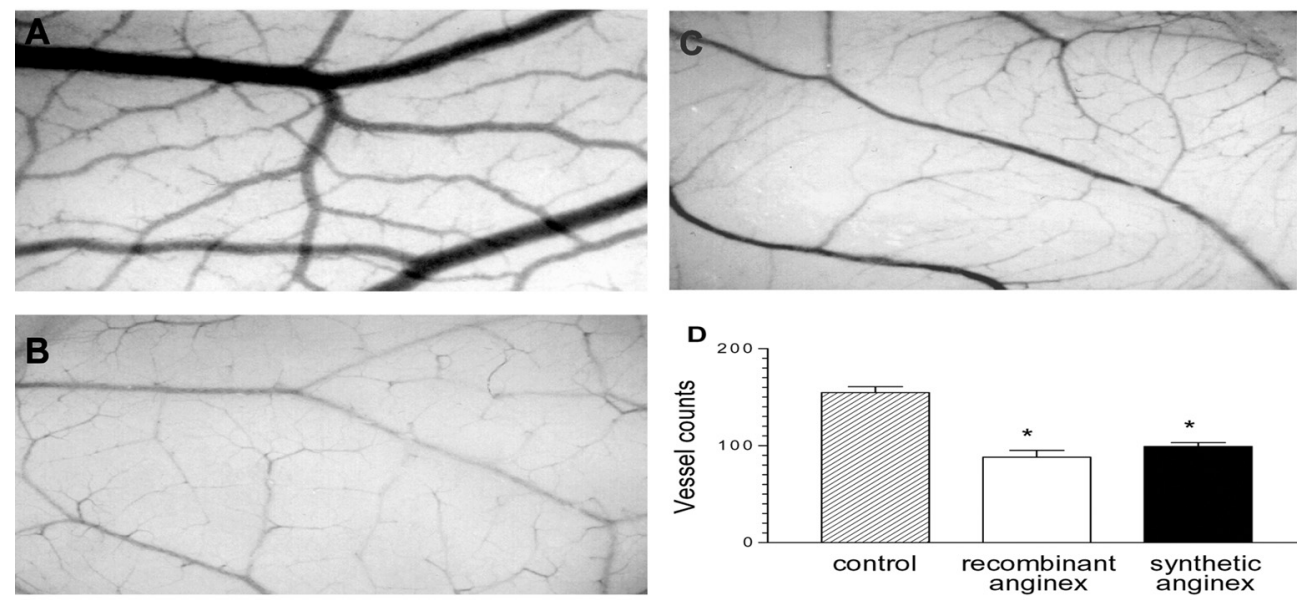

Figure 5 - In vivo angiogenesis inhibition from recombinant anginex

Chorioallantoic membrane assay (CAM) of recombinant and synthetic anginex. On day 10 , peptides $(25 \mu \mathrm{M})$ were added daily, and on day 14 , photographs were taken from the CAM. $P<0.014$ recombinant vs. control, $p<0.060$ synthetic vs. control.

\section{Conclusion}

We have designed a completely artificial gene coding for the non-naturallyoccurring peptide anginex. Using this gene construct, we were able to produce a recombinant protein that maintained $\beta$-sheet conformation, as well as the antiangiogenic capacity of the synthetic peptide, both in vitro and in vivo. The reported strategy here allows for the design of specific antagonist and corresponding genes that can have multiple applications, not only in large-scale production, but also in molecular biological technologies, unravelling mechanisms of action or create opportunities for (gene) therapy. 


\section{References}

1. Griffioen, A.W., and Molema, G. (2000) Angiogenesis: potentials for pharmacologic intervention in the treatment of cancer, cardiovascular diseases, and chronic inflammation. Pharmacol Rev 52, 237-268

2. Folkman, J., Watson, K., Ingber, D., and Hanahan, D. (1989) Induction of angiogenesis during the transition from hyperplasia to neoplasia. Nature 339, 58-61

3. Hori, A., Sasada, R., Matsutani, E., Naito, K., Sakura, Y., Fujita, T., and Kozai, Y. (1991) Suppression of solid tumor growth by immunoneutralizing monoclonal antibody against human basic fibroblast growth factor. Cancer Res 51, 6180-6184

4. Kim, K.J., Li, B., Winer, J., Armanini, M., Gillett, N., Phillips, H.S., and Ferrara, N. (1993) Inhibition of vascular endothelial growth factor-induced angiogenesis suppresses tumour growth in vivo. Nature 362, 841-844

5. Millauer, B., Shawver, L.K., Plate, K.H., Risau, W., and Ullrich, A. (1994) Glioblastoma growth inhibited in vivo by a dominant-negative Flk-1 mutant. Nature 367, 576-579

6. Griffioen, A.W., van der Schaft, D.W., BarendszJanson, A.F., Cox, A., Struijker Boudier, H.A., Hillen, H.F., and Mayo, K.H. (2001) Anginex, a designed peptide that inhibits angiogenesis. Biochem J 354, 233-242

7. van der Schaft, D.W., Dings, R.P., de Lussanet, Q.G., van Eijk, L.I., Nap, A.W., Beets-Tan, R.G., Bouma-Ter Steege, J.C., Wagstaff, J., Mayo, K.H., and Griffioen, A.W. (2002) The designer antiangiogenic peptide anginex targets tumor endothelial cells and inhibits tumor growth in animal models. Faseb J 16, 1991-1993

8. Dings, R.P., van der Schaft, D.W., Hargittai, B., Haseman, J., Griffioen, A.W., and Mayo, K.H. (2003) Anti-tumor activity of the novel angiogenesis inhibitor anginex. Cancer Lett 194, 55-66

9. Thijssen, V.L., Brandwijk, R.J., Dings, R.P., and Griffioen, A.W. (2004) Angiogenesis gene expression profiling in xenograft models to study cellular interactions. Exp Cell Res 299, 286-293

10. Sim, B.K., O'Reilly, M.S., Liang, H., Fortier, A.H., He, W., Madsen, J.W., Lapcevich, R., and Nacy, C.A. (1997) A recombinant human angiostatin protein inhibits experimental primary and metastatic cancer. Cancer Res 57, 1329-1334

11. Dhanabal, M., Volk, R., Ramchandran, R., Simons, M., and Sukhatme, V.P. (1999) Cloning, expression, and in vitro activity of human endostatin. Biochem Biophys Res Commun 258, 345-352

12. Maeshima, Y., Manfredi, M., Reimer, C., Holthaus, K.A., Hopfer, H., Chandamuri, B.R., Kharbanda, S., and Kalluri, R. (2001) Identification of the antiangiogenic site within vascular basement membrane-derived tumstatin. J Biol Chem 276 15240-15248

13. Mayo, K.H., Haseman, J., Ilyina, E., and Gray, B. (1998) Designed beta-sheet-forming peptide 33mers with potent human bactericidal/permeability increasing protein-like bactericidal and endotoxin neutralizing activities. Biochim Biophys Acta 1425, 81-92

14. Mayo, K.H., Ilyina, E., and Park, H. (1996) A recipe for designing water-soluble, beta-sheet-forming peptides. Protein Sci 5, 1301-1315

15. Zuker, M. (2003) Mfold web server for nucleic acid folding and hybridization prediction. Nucleic Acids Res 31, 3406-3415

16. Gray, B.H., Haseman, J.R., and Mayo, K.H. (1995) $\mathrm{B} / \mathrm{PI}$-derived synthetic peptides: synergistic effects in tethered bactericidal and endotoxin neutralizing peptides. Biochim Biophys Acta 1244, 185-190

17. van der Schaft, D.W., Wagstaff, J., Mayo, K.H., and Griffioen, A.W. (2002) The antiangiogenic properties of bactericidal/permeability-increasing protein (BPI). Ann Med 34, 19-27

18. Romanos, M.A., Scorer, C.A., and Clare, J.J. (1992) Foreign gene expression in yeast: a review. Yeast 8, 423-488

19. Faber, K.N., Harder, W., Ab, G., and Veenhuis, M. (1995) Review: methylotrophic yeasts as factories for the production of foreign proteins. Yeast 11, 1331-1344

20. Zhang, J., Reddy, J., Buckland, B., and Greasham, R. (2003) Toward consistent and productive complex media for industrial fermentations: studies on yeast extract for a recombinant yeast fermentation process. Biotechnol Bioeng 82, 640652

21. Dhanabal, M., Ramchandran, R., Volk, R., Stillman, I.E., Lombardo, M., Iruela-Arispe, M.L., Simons, M., and Sukhatme, V.P. (1999) Endostatin: yeast production, mutants, and antitumor effect in renal cell carcinoma. Cancer Res 59, 189-197

22. Dings, R.P., Arroyo, M.M., Lockwood, N.A., van Eijk, L.I., Haseman, J.R., Griffioen, A.W., and Mayo, K.H. (2003) Beta-sheet is the bioactive conformation of the anti-angiogenic anginex peptide. Biochem J 373, 281-288

23. Zhu, A., Monahan, C., Wang, Z.K., and Goldstein, J. (1996) Expression, purification, and characterization of recombinant alpha-Nacetylgalactosaminidase produced in the yeast Pichia pastoris. Protein Expr Purif 8, 456-462

24. Cereghino, J.L., and Cregg, J.M. (2000) Heterologous protein expression in the methylotrophic yeast Pichia pastoris. FEMS Microbiol Rev 24, 45-66

25. Brake, A.J., Merryweather, J.P., Coit, D.G., Heberlein, U.A., Masiarz, F.R., Mullenbach, G.T., Urdea, M.S., Valenzuela, P., and Barr, P.J. (1984) Alpha-factor-directed synthesis and secretion of 
mature foreign proteins in Saccharomyces cerevisiae. Proc Natl Acad Sci U S A 81, 46424646

26. Almeida, M.S., Cabral, K.S., de Medeiros, L.N., Valente, A.P., Almeida, F.C., and Kurtenbach, E. (2001) cDNA cloning and heterologous expression of functional cysteine-rich antifungal protein Psd1 in the yeast Pichia pastoris. Arch Biochem Biophys 395, 199-207

27. Mayo, K.H., Dings, R.P., Flader, C., Nesmelova, I., Hargittai, B., van der Schaft, D.W., van Eijk, L.I.,
Walek, D., Haseman, J., Hoye, T.R., and Griffioen, A.W. (2003) Design of a partial peptide mimetic of anginex with antiangiogenic and anticancer activity. J Biol Chem 278, 45746-45752

28. Bobbink, I.W., de Boer, H.C., Tekelenburg, W.L., Banga, J.D., and de Groot, P.G. (1997) Effect of extracellular matrix glycation on endothelial cell adhesion and spreading: involvement of vitronectin. Diabetes 46, 87-93 
Cloning an artificial gene encoding angiostatic anginex: from designed peptide to functional recombinant protein 
Chapter 3 


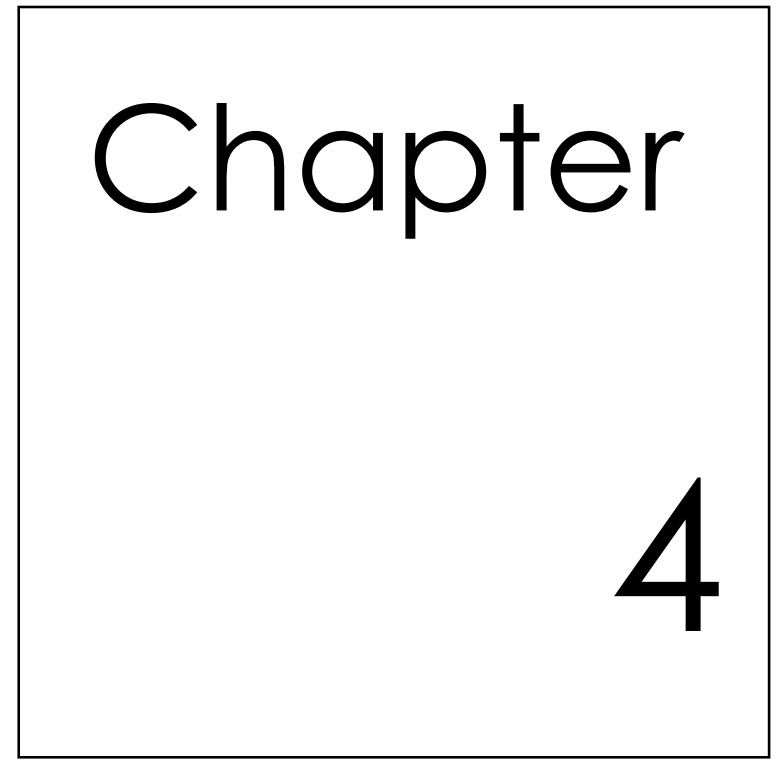

\section{Anti-angiogenesis and anti-tumor activity of recombinant anginex}

Ricardo J.M.G.E. Brandwijk, Ruud P.M. Dings, Edith van der Linden, Kevin H. Mayo, Victor L.J.L. Thijssen, Arjan W. Griffioen 


\begin{abstract}
Anginex, a synthetic 33-mer angiostatic peptide, specifically inhibits vascular endothelial cell proliferation and migration along with induction of apoptosis in endothelial cells. Here we report on the in vivo characterization of recombinant anginex and use of the artificial anginex gene for gene therapy approaches. Tumor growth of human MA148 ovarian carcinoma in athymic mice was inhibited by $80 \%$ when treated with recombinant anginex. Histological analysis of the tumors showed an appoximate 2.5 -fold reduction of microvessel density, suggesting that angiogenesis inhibition is the cause of the anti-tumor effect. Furthermore, there was a significant correlation between the gene expression patterns of 16 angiogenesis related factors after treatment with both recombinant and synthetic anginex. To validate the applicability of the anginex gene for gene therapy, stable transfectants of murine B16F10 melanoma cells expressing recombinant anginex were made. Supernatants of these cells inhibited endothelial cell proliferation in vitro. Furthermore, after subcutaneous injection of these cells in C57BL/6 mice, an extensive delay in tumor growth was observed.These data show that the artificial anginex gene can be used to produce a recombinant protein with similar activity as its synthetic counterpart and that the gene can be applied in gene therapy approaches for cancer treatment.
\end{abstract}




\section{Introduction}

The development of several angiogenesis inhibitors has been hindered by difficulties in their production and pharmacokinetics ${ }^{1}$. Some of these limitations might be solved using a gene therapy approach whereby the angiostatic proteins are expressed in vivo. The major advantage of this approach is that the therapeutic agent is produced locally in a high concentration and for a sustained period, thereby avoiding the problems encountered with administration of recombinant proteins, antibodies, or drugs ${ }^{2}$.

We have previously described the designed angiostatic peptide anginex ${ }^{3}$. The structure of this synthetic peptide is based on the 3-dimensional beta-sheet structures of the alpha-chemokines platelet factor 4 (PF4) and interleukin-8 (IL-8). Anginex inhibits angiogenesis through preventing proliferation and migration of activated endothelial cells and by inducing apoptosis in these cells ${ }^{4,5}$. Recently, we designed an artificial gene encoding anginex and validated the production and isolation of the recombinant protein from $P$. pastoris culture supernatant. The recombinant protein was shown to have comparable angiostatic properties as the synthetic peptide. ${ }^{6}$.

In the current study we set out to determine the therapeutic effect of recombinant anginex in an in vivo tumor model, and to analyze the potential of the anginex gene for gene therapy applications. Treatment of an ovarian carcinoma model in mice with recombinant anginex resulted in a strong inhibition of tumor growth and a similar angiostatic activity compared to synthetic anginex. Introduction of the anginex gene in mouse melanoma cells induced an extensive delay in tumor growth following injection into mice.

Taken together, our data show that the artificial anginex gene can be used to produce a recombinant protein with similar activity as its synthetic counterpart and that the gene can be applied in gene therapy approaches for cancer treatment.

\section{Materials and methods}

\section{Expression and isolation of recombinant anginex}

Expression and isolation of recombinant anginex was performed as described previously ${ }^{6}$. In short, $1 \mathrm{~L} \mathrm{BMGY}$ was inoculated with a $50 \mathrm{ml}$ overnight culture of $P$. pastoris strain GS115 (Invitrogen) transformed with pPICZ $\alpha$-A-anginex and cultured for 24 hours at $30^{\circ} \mathrm{C}$ with shaking. These cells were harvested and resuspended in 2 L BMMY in order to induce expression. After 72 hours, supernatant was collected and concentrated using centricon-plus 80 biomax5 concentrators (Millipore). His-tagged recombinant anginex was isolated from the concentrated supernatant with His-select beads (Sigma). After dialysis against 
water and concentrating the recombinant anginex, protein concentration was measured using the micro BCA protein assay reagent kit (Pierce).

\section{MA148 ovarian carcinoma xenograft mouse model}

The ovarian carcinoma xenograft model was used as described previously ${ }^{7}$. Antiangiogenesis therapy using either synthetic anginex or recombinant anginex was started 25 days after subcutaneous injection of $2 \times 10^{6}$ MA148 cells in the flank of 21 athymic (nu/nu) mice. Mice were randomly divided into three groups. Synthetic anginex $(10 \mathrm{mg} / \mathrm{kg}$ ), recombinant anginex (equimolar to synthetic anginex) and PBS (control) were IP injected every 3 days. Tumor growth was measured throughout the experiment and tumor volumes were calculated as width ${ }^{2} \mathrm{x}$ length $\mathrm{x}$ 0.52. Mice were sacrificed 15 days after start of treatment. Tumors were quickly dissected and snap-frozen in liquid nitrogen. Animal experiments were approved by the local ethical committee.

\section{B16F10 melanoma mouse model}

The B16F10 melanoma mouse model was used as described previously ${ }^{5}$. Five C57BL/6 mice were subcutaneously injected on the right flank with 100000 stably transfected B16F10 melanoma cells (see below). Tumor growth was measured throughout the experiment and tumor volume was calculated as width ${ }^{2} \mathrm{x}$ length $\mathrm{x}$ 0.52. The experiment was stopped at day 25 when only two mice had palpable tumor. Tumors were dissected and quickly snap-frozen in liquid nitrogen. Tumor growth was compared to historical growth curves of B16F10 and B16F10 treated with synthetic anginex, since these tumors and their response to treatment with synthetic anginex is very comparable between different experiments.

\section{Immunohistochemistry}

Approximately $50 \%$ of each tumor was fixed in paraformaldehyde and subsequently paraffin embedded. Deparaffinized tissue sections were immunostained with monoclonal antibodies from the 9F1 rat monoclonal cell-line (Generous gift from A.Duijvestijn) specific for mouse $\mathrm{EC}^{8}$. Before application of the primary antibody, sections were blocked for endogenous peroxidase activity by $0.3 \%$ hydrogen peroxide in methanol for 20 minutes. For antigen retrieval, sections were microwaved with $10 \mathrm{mM}$ TRIS/1 mM EDTA buffer $\mathrm{pH}$ 8.0. Primary antibody was incubated for one hour and secondary (donkey anti rat-Ig-biotin; Dako) and tertiary antibody (Streptavidin ABC complex HRP; Dako) were incubated for 30 minutes. Antibody localization was visualized by incubation with diaminobenzidine. Sections were counterstained with hematoxylin. Quantification of microvessel density (MVD) was determined in the complete section, corrected for the size of the section. 
RNA isolation and CDNA synthesis

Total RNA was isolated from homogenized tumor samples using the RNeasy RNA isolation kit (Qiagen) according to the manufacturers manual. To prevent contamination with genomic DNA, the on-column DNase treatment as suggested by the supplier was applied. RNA concentration and purity was determined using a Nanodrop spectrophotometer. cDNA synthesis was performed using $1 \mu \mathrm{g}$ total RNA and the iScript cDNA synthesis kit (Bio-Rad) as described in the suppliers manual.

\section{Real-time quantitative $P C R$}

For real-time quantitative PCR, the I-cycler IQ system (Bio-Rad) was employed using Sybr Green chemistry. All tumors were analyzed for 16 angiogenesis factors (bFGF, PLGF, VEGF-A/B/C/D, VEGFR1/2/3, Tie1/2, Nrp1/2, Ang1/2/3) with primers (Eurogentec) specific for human as well as mouse transcripts as described previously ${ }^{9}$. Cyclophilin A was used as reference gene. Conditions for PCR were 10 minutes $95^{\circ} \mathrm{C}$, followed by 50 cycles at $95^{\circ} \mathrm{C}$ for 15 seconds and $60^{\circ} \mathrm{C}$ for 1 minute. The PCR reaction was performed in a $25 \mu$ l reaction volume containing $1 x$ IQ Sybr green supermix (Bio-Rad), 25 ng cDNA and $800 \mathrm{nM}$ forward and reverse primer. To compare the different relative expression levels between treatments, the 'deltadelta Ct method' was applied. All experiments were performed in triplo.

Cloning of pcDNA3.1-anginex

Anginex was PCR amplified from the previously described anginex gene ${ }^{6}$ using the following primers: Forward TAGGTACCACCATGGCAAACATAAAACTAAGCGTAC, Reverse TATCTAGACTAGTCTAGGCTTAGTTCTCTTCC. The amplified anginex fragment was digested with $K p n I$ and $X b a I$ (NEB), purified and cloned into the expression vector pcDNA3.1+-hygro (Invitrogen). The obtained pcDNA3.1-angx vector was sequence verified using a T7 promoter universal primer.

Generation of a stable anginex expressing B16F10 melanoma cell line B16F10 melanoma cells were cultured as described previously ${ }^{5}$. Empty vector was used as control. Before transfection, vectors were linearized using restriction enzyme Fsp I (NEB). Cells were transfected in a 24 well format with a DNA:lipid ratio of 2:3 using Fugene (Roche) according the manufacturer instructions. The next day, selective pressure was applied using $150 \mu \mathrm{g} / \mathrm{ml}$ hygromycin B (Roche). After confirmation of the identity of the cell line, using RT-PCR with primers specific for the vector (Forward TAGAAGGCACAGTCGAGG, Reverse TAATACGACTCACTAT AGGG), a clonal cell line was made by limited dilution. 


\section{Cell proliferation}

Human umbilical vein EC (HUVEC) were harvested from normal human umbilical cords and cultured in fibronectin-coated flasks in HUVEC culture medium (RPMI1640 with 20\% (v/v) human serum, $2 \mathrm{mM}$ glutamine, $100 \mathrm{U} / \mathrm{ml}$ penicillin and $0.1 \mathrm{mg} / \mathrm{ml}$ streptomycin. Cells were cultured at $37^{\circ} \mathrm{C}$ and $5 \% \mathrm{CO}_{2}$. For the proliferation assay, HUVEC were seeded at 5000 cells/well in fibronectin-coated flat-bottomed 96-well tissue culture plates and grown for 3 days in supernatant of the cell lines supplemented with $1 \mathrm{ng} / \mathrm{ml}$ bFGF. On the third day, $0.3 \mu \mathrm{Ci} / \mathrm{well}^{3} \mathrm{H}$ thymidine was added and incorporation was allowed to occur for 6 hours. After harvesting the cells, thymidine incorporation was quantified by liquid scintillation counting.

\section{Statistical analysis}

Tumor volumes are given as mean values \pm SD. The effect of treatment in the mouse tumor model was analyzed by 2-way ANOVA. Microvessel density and proliferation data were analyzed using the Student's t-test. Correlations were determined using Spearman's rho. P-values $<0.05$ were considered significant and all statistical calculations were performed using Prism 3.0 software.

\section{Results and discussion}

Tumor growth is strongly dependent on the formation of new blood vessels, i.e. angiogenesis ${ }^{10}$. The discovery of angiogenesis inhibitors has confirmed the feasibility of angiogenesis inhibition for cancer treatment as postulated by Dr. Folkman in the early seventies ${ }^{11}$. Unfortunately, the development of several promising angiogenesis inhibitors has been hampered by difficulties in production and activity [1]. Some of these limitations might be solved using a gene therapy approach whereby the angiostatic proteins are expressed in vivo. The feasibility of the recombinant approach was applied to several angiogenesis inhibitors, e.g. endostatin, angiostatin, thrombospondin-1 and angiogenin ${ }^{12-15}$. Also for PF4, which is one of the molecules anginex is based on, active recombinant protein was obtained using recombinant DNA technology ${ }^{12}$. In the present report we set out to determine the anti-tumor activity of the recently described recombinant anginex ${ }^{6}$. In addition, we analyzed the potential of the artificial anginex gene for gene therapy applications.

The activity of recombinant anginex was studied in a xenograft mouse model of human ovarian carcinoma. Athymic mice were subcutaneously injected with human MA148 cells. This model has been extensively used to study the anti-tumor effect of synthetic anginex as well as other angiostatic compounds 4,16 . Treatment was initiated when tumors became visible and was continued for 2 weeks. At the end of 


\section{Figure 1 - Anti-fumor activity of recombinant anginex}
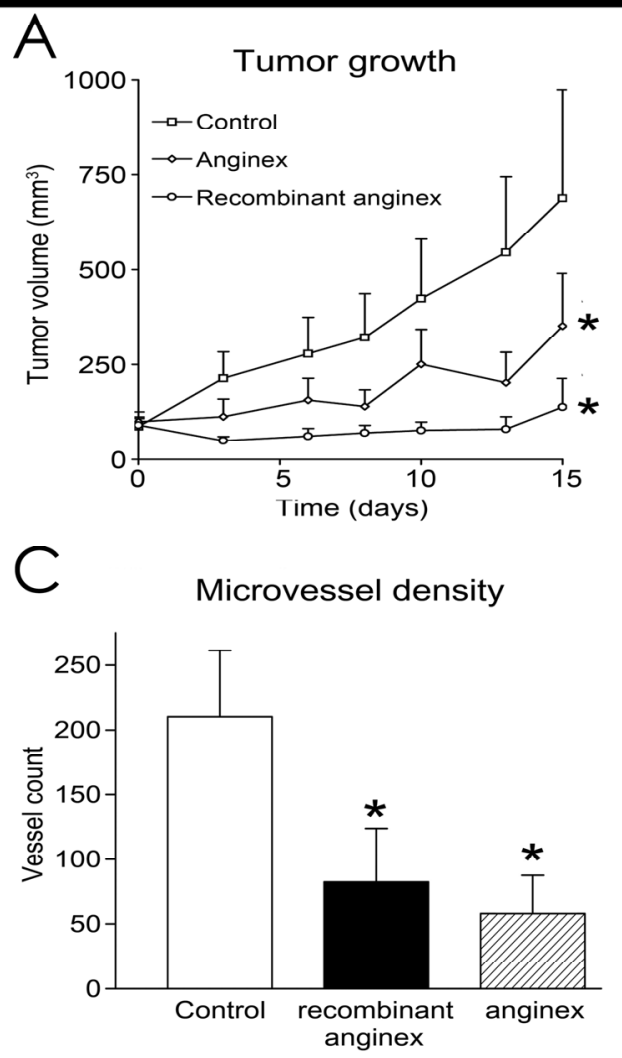

B
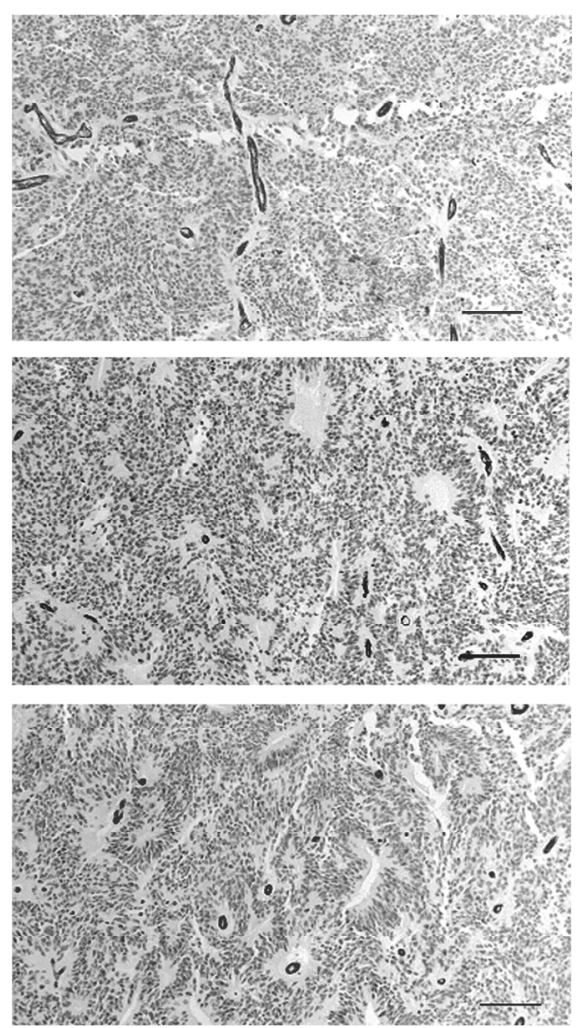

Figure 1 - Anti-tumor activity of recombinant anginex

(A) Tumor growth curves of the xenograft MA 148 ovarian carcinoma mouse model. Treatment was started in palpable tumors by IP injection every 3 days $(10 \mathrm{mg}$ anginex $/ \mathrm{kg}$ and equivalent dose for recombinant anginex). ${ }^{*} p<0,01$ treatment vs. control. (B) Immunohistochemical stainings of endothelial cells in the different tumors. (C) Quantification of microvessel density in the different treatment groups. * $p<0,03$ treatment vs. control.

the treatment period, tumor growth was significantly inhibited by approximately $80 \%(p<0.0001)$ and $55 \%(p<0.001)$ by recombinant and synthetic anginex, respectively (Figure $1 \mathrm{~A}$ ). This inhibition was not the result of toxicity as indicated by similar weight-gain curves in the control as well as in the treated animals (data not shown). These observations are in perfect agreement with previous findings with synthetic anginex in the same model as well as in other tumor models in mice ${ }^{4,5}$. 
It has been shown that the anti-tumor effect of synthetic anginex is caused by inhibition of angiogenesis. Therefore we also determined microvessel density in the tumors treated with recombinant anginex. To that end, immunohistochemical staining was performed on paraffin embedded tumor tissue sections with the endothelial cell specific antibody $9 \mathrm{~F} 1^{8}$ (Figure 1B). Quantification of the number of vessels revealed a significant inhibition of MVD after both treatments. The mean MVD in the control group was $210 \pm 47$ microvessels $/ 10 \mathrm{~mm}^{2}$, while treatment with recombinant anginex and synthetic anginex significantly reduced this number to $94 \pm 39 / 10 \mathrm{~mm}^{2}(p<0.028)$ and $76 \pm 29 / 10 \mathrm{~mm}^{2}(p<0.014)$, respectively (Figure $\left.1 \mathrm{C}\right)$. These data strongly suggest that the observed anti-tumor effect is caused by inhibition of angiogenesis. Furthermore they confirm the previously observed comparable angiostatic activity of synthetic and recombinant anginex in vitro ${ }^{6}$.

\section{Figure 2 - Effect of treatment on angiogenesis expression profile}
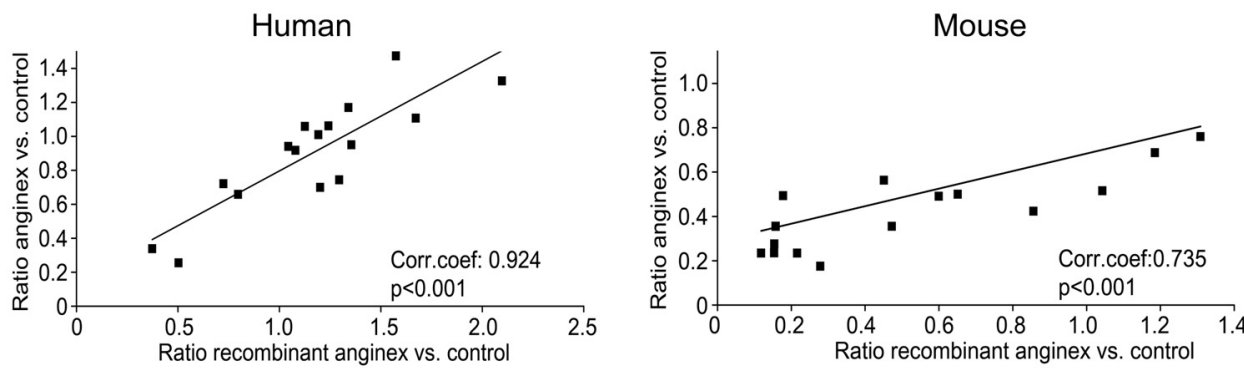

Figure 2 - Effect of treatment on angiogenesis expression profile

Scatter plots of response in gene expression after treatment with recombinant or synthetic anginex. A total of 16 angiogenesis factors was included in the analysis. By using species specific primers a distinction could be made between the response in the tumor compartment (Panel A, human) and the response in the vascular compartment (Panel B, mouse) of the xenograft tumor tissues.

To get more insight in the angiostatic activity of recombinant anginex, we determined the mRNA expression levels of 16 well-known angiogenesis factors by a method described by us previously. This method utilizes specifically designed primers for real-time RT-PCR that allows simultaneous analysis of gene expression levels in different compartments of a single xenograft tumor tissue ${ }^{9}$. First, total RNA was isolated from cryosections of treated and untreated tumors. Subsequently, real-time RT-PCR was performed with mouse and human specific primers to 
determine gene expression levels in respectively the vascular and non-vascular compartment of the tumor tissue. Expression levels were normalized to cyclophilin A of which has been shown that it is a suitable reference gene for this particular model ${ }^{9}$. We observed a significant correlation in expression and regulation of expression between treatment with recombinant versus synthetic anginex in both tumor compartments (tumor cells: corr.coef. 0.924, $p<0.001$, vascular cells: corr.coef. $0.735, \mathrm{p}<0.001$ ) (Figure 2). This further proves comparable activity of the two sources of anginex.

To verify the hypothesis that the artificial anginex gene is suitable for gene therapy approaches, a stable transfected B16F10 melanoma cell line capable of producing anginex was created. Therefore, the anginex gene was PCR amplified from the yeast expression vector and cloned into the eukaryotic expression vector pcDNA3.1. This clone was stably transfected into B16F10 mouse melanoma cells, which was confirmed by PCR. In the mock transfectant a 170 bp fragment was amplified while in the recombinant anginex transfectant an expected 204 bp fragment was observed (Figure $3 \mathrm{~A}$ ). The stable transfection of recombinant anginex had no apparent effect on B16F10 cell morphology or growth rate in vitro. This was expected given the observation that anginex has an exclusive effect on activated endothelial cells ${ }^{3,5}$. In addition, using the same expression vector and transfection procedure, Tao et. al. also achieved significant inhibition of tumor growth of stable transfected hepatocellular carcinoma cells expressing angiostatin after injection into nude mice, without effect on growth speed and morphology of the cells in vitro ${ }^{17}$. Recently, similar results were observed in other studies when tumor cell lines were stable transfected with e.g. endostatin and angiostatin ${ }^{18,19}$. Since no tag was added to recombinant anginex, which would allow Western blot analysis, the bioactivity of recombinant anginex was tested in EC proliferation experiments using tritium thymidine incorporation assays. As expected, culture supernatants of recombinant anginex transfected B16F10 cells, inhibited the proliferation of cultured HUVEC (Figure 3B).

To determine whether the introduction of the anginex gene affected B16F10 tumor growth in vivo, C57BL/6 mice were subcutaneously injected in the flank with anginex transfected cells. Compared to wild-type B16F10 cells, an extensive tumor growth delay was observed. Even when compared to tumors treated systemically with synthetic anginex there was a considerable delay in tumor growth. At day 16, when the mice had to be sacrificed due to the large tumor size in the control group, only 2 out of 5 mice injected with transfected tumor cells displayed a small tumor. It took over 20 days for the first tumors to become detectable in the remaining 3 mice and tumor growth was extremely slow up to day 40, when these mice were sacrificed (Figure 3C). Real-time RT-PCR analysis on the tumors demonstrated extensive expression of recombinant anginex mRNA by the transfected tumor cells and not by the control cells ( figure 3D ). Furthermore, all tumors of anginex 


\section{Figure 3 - Anti-tumor activity of the artificial recombinant anginex gene}
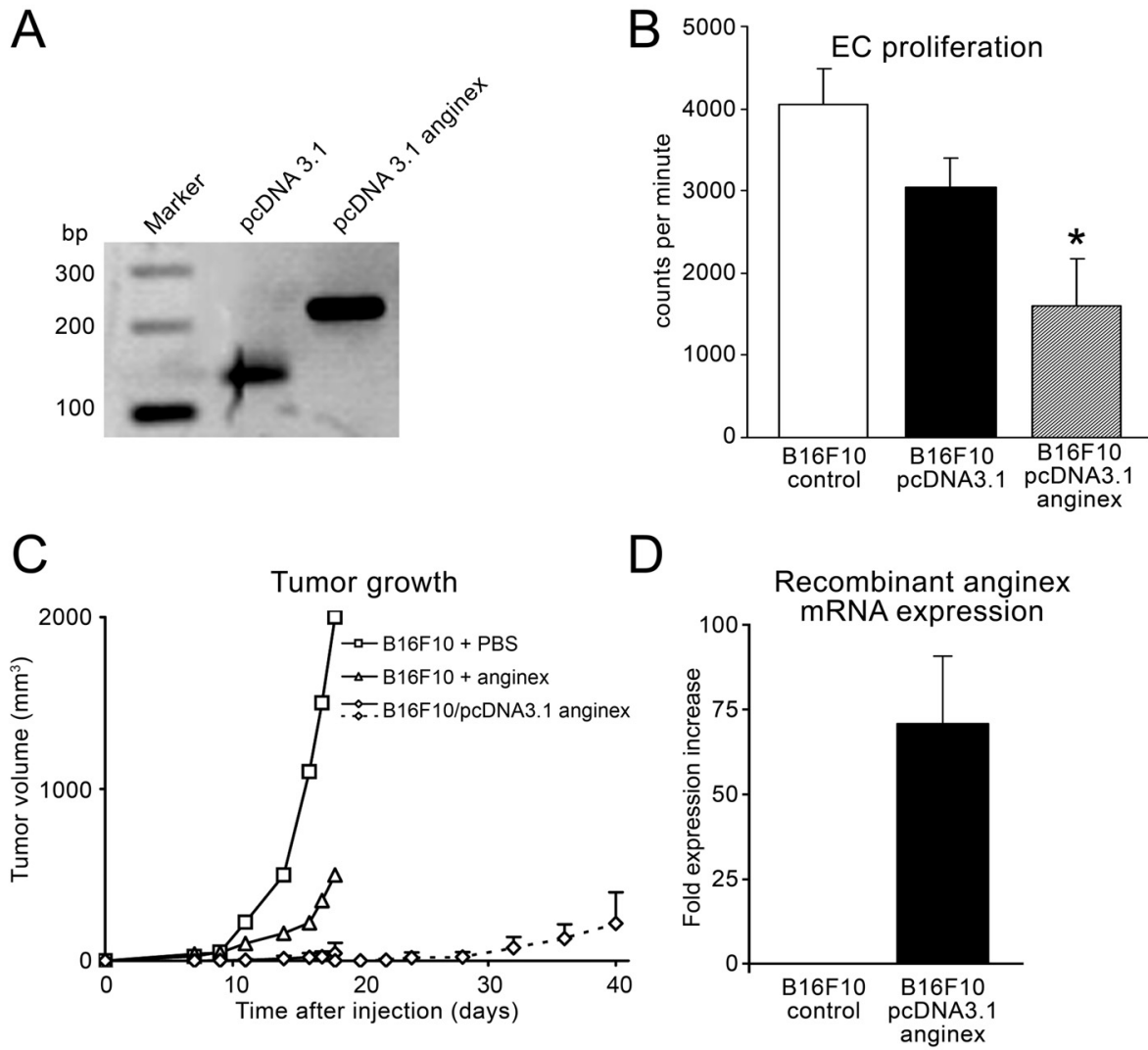

Figure 3 - Anti-tumor activity of the artificial recombinant anginex gene

(A) Agarose gel electrophoresis showing PCR genotyping of B16F10 cells stably transfected with pcDNA3.1 and pcDNA3.1-anginex. bp = basepairs (B) Proliferation assay on HUVEC with culture supernatants of transfected cell lines. Proliferation was determined using the tritium thymidine incorporation assay. ${ }^{*} p<0,01$ treatment vs. control. (C) Tumor growth curves of B16F10 melanoma cells stable transfected with the anginex gene and B16F10 treated with synthetic anginex or saline. Dotted line represents mice that had no visible tumor at day 16 and therefore were not sacrificed until day 40. (D) Expression level of recombinant anginex in excised tumors as determined by realtime RT-PCR with anginex specific primers.

B16F10 cells displayed extensive areas of necrosis, which unfortunately prevented proper determination of microvessel density. Apparently, the local production of anginex from the immediate onset of tumor growth effectively inhibits angiogenesis 
and tumor growth. Whether a similar effect can be reached in already established tumors remains to be determined, e.g. after gene delivery using viral vectors.

In summary, our current data in an in vivo tumor model together with previous findings in vitro show that recombinant anginex has strong angiostatic activity, similar as its synthetic counterpart. Furthermore, initial evidence suggests that the artificial gene, which has been designed to encode recombinant anginex, might be used for gene therapy based angiostatic cancer therapy. These findings will contribute to further developments in the field of non-endogenous angiogenesis inhibitors like anginex and might lead to novel therapeutic strategies. 


\section{References}

1. Regulier, E., Paul, S., Marigliano, M., Kintz, J., Poitevin, Y., Ledoux, C., Roecklin, D., Cauet, G., Calenda, V., and Homann, H.E. (2001) Adenovirus-mediated delivery of antiangiogenic genes as an antitumor approach. Cancer Gene Ther 8, 45-54

2. Dell'Eva, R., Pfeffer, U., Indraccolo, S., Albini, A., and Noonan, D. (2002) Inhibition of tumor angiogenesis by angiostatin: from recombinant protein to gene therapy. Endothelium 9, 3-10

3. Griffioen, A.W., van der Schaft, D.W., Barendsz-Janson, A.F., Cox, A., Struijker Boudier, H.A., Hillen, H.F., and Mayo, K.H. (2001) Anginex, a designed peptide that inhibits angiogenesis. Biochem J 354, 233242

4. Dings, R.P., van der Schaft, D.W., Hargittai, B., Haseman, J., Griffioen, A.W., and Mayo, K.H. (2003) Anti-tumor activity of the novel angiogenesis inhibitor anginex. Cancer Lett $194,55-66$

5. van der Schaft, D.W., Dings, R.P., de Lussanet, Q.G., van Eijk, L.I., Nap, A.W., Beets-Tan, R.G., Bouma-Ter Steege, J.C., Wagstaff, J., Mayo, K.H., and Griffioen, A.W. (2002) The designer anti-angiogenic peptide anginex targets tumor endothelial cells and inhibits tumor growth in animal models. Faseb J 16, 1991-1993

6. Brandwijk, R.J., Nesmelova, I., Dings, R.P., Mayo, K.H., Thijssen, V.L., and Griffioen, A.W. (2005) Cloning an artificial gene encoding angiostatic anginex: From designed peptide to functional recombinant protein. Biochem Biophys Res Commun 333, 1261-1268

7. Dings, R.P., Yokoyama, Y., Ramakrishnan, S., Griffioen, A.W., and Mayo, K.H. (2003) The designed angiostatic peptide anginex synergistically improves chemotherapy and antiangiogenesis therapy with angiostatin. Cancer Res 63, 382-385

8. Harder, R., Uhlig, H., Kashan, A., Schutt, B., Duijvestijn, A., Butcher, E.C., Thiele, H.G., and Hamann, A. (1991) Dissection of murine lymphocyte-endothelial cell interaction mechanisms by SV-40-transformed mouse endothelial cell lines: novel mechanisms mediating basal binding, and alpha 4integrin-dependent cytokine-induced adhesion. Exp Cell Res 197, 259-267

9. Thijssen, V.L., Brandwijk, R.J., Dings, R.P., and Griffioen, A.W. (2004) Angiogenesis gene expression profiling in xenograft models to study cellular interactions. Exp Cell Res 299, 286-293

10. Griffioen, A.W., and Molema, G. (2000) Angiogenesis: potentials for pharmacologic intervention in the treatment of cancer, cardiovascular diseases, and chronic inflammation. Pharmacol Rev 52, 237-268

11. Folkman, J. (1971) Tumor angiogenesis: therapeutic implications. N Engl J Med 285, 1182-1186

12. Myers, J.A., Gray, G.S., Peters, D.J., Grimaila, R.J., Hunt, A.J., Maione, T.E., and Mueller, W.T. (1991) Expression and purification of active recombinant platelet factor 4 from a cleavable fusion protein. Protein Expr Purif 2, 136-143

13. O'Reilly, M.S., Boehm, T., Shing, Y., Fukai, N., Vasios, G., Lane, W.S., Flynn, E., Birkhead, J.R., Olsen, B.R., and Folkman, J. (1997) Endostatin: an endogenous inhibitor of angiogenesis and tumor growth. Cell 88, 277-285

14. O'Reilly, M.S., Holmgren, L., Shing, Y., Chen, C., Rosenthal, R.A., Cao, Y., Moses, M., Lane, W.S., Sage, E.H., and Folkman, J. (1994) Angiostatin: a circulating endothelial cell inhibitor that suppresses angiogenesis and tumor growth. Cold Spring Harb Symp Quant Biol 59, 471-482

15. Shapiro, R., Harper, J.W., Fox, E.A., Jansen, H.W., Hein, F., and Uhlmann, E. (1988) Expression of Met-(-1) angiogenin in Escherichia coli: conversion to the authentic less than Glu-1 protein. Anal Biochem 175, 450-461

16. Dings, R.P., Chen, X., Hellebrekers, D.M. van Eijk, L.I., Zhang, Y., Hoye, T.R., Griffioen, A.W., and Mayo, K.H. (2006) Design of nonpeptidic topomimetics of antiangiogenic proteins with antitumor activities. J Natl Cancer Inst 98, 932-936

17. Tao, K.S., Dou, K.F., and Wu, X.A. (2004) Expression of angiostatin CDNA in human hepatocellular carcinoma cell line SMMC7721 and its effect on implanted carcinoma in nude mice. World J Gastroenterol 10, 1421-1424

18. Cui, R., Takahashi, K., Takahashi, F., Tanabe, K.K., and Fukuchi, Y. (2006) Endostatin gene transfer in murine lung carcinoma cells induces vascular endothelial growth factor secretion resulting in upregulation of in vivo tumorigenecity. Cancer Lett 232, 262-271 
19. Yang, D.Z., He, J., Zhang, J.C., and Wang, Z.R. (2006) Expression of angiostatin CDNA in human gallbladder carcinoma cell line GBC-SD and its effect on endothelial proliferation and growth. World J Gastroenterol 12, 2762-2766 


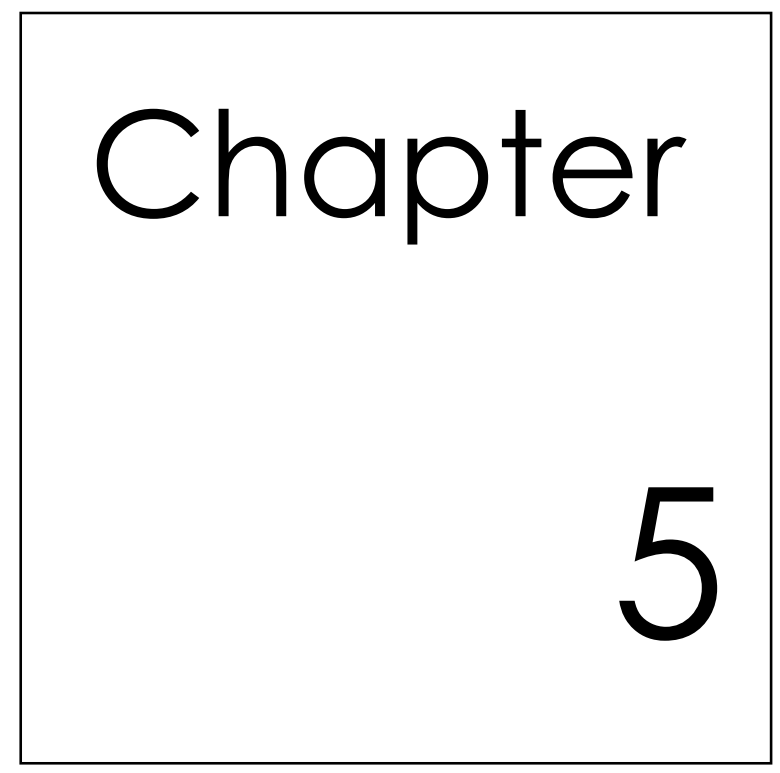

\section{Targeted gene delivery strategies for angiostatic cancer treatment}

Ricardo J.M.G.E. Brandwijk, Arjan W. Griffioen, Victor L.J.L. Thijssen 


\section{Abstract}

Gene therapy is one of the promising strategies in cancer treatment. Recent studies identified molecular targets on angiogenically activated endothelial cells that can be used to specifically deliver gene transfer vehicles to the tumor site. Furthermore, non-viral vehicles are emerging as an alternative for traditional viral gene therapy approaches. These developments justify a review on the available methods for targeting gene therapy vehicles to the tumor endothelium. Here we describe how viral and non-viral gene transfer vehicles have been and can be modified in order to target tumor endothelial cells for anti-angiogenesis gene therapy. Improving the specificity and safety of existing gene therapy vehicles will make angiogenesis targeted cancer gene therapy a valuable tool in the clinic. 


\section{Targeting angiogenesis for cancer gene therapy}

Gene therapy aims to cure a disease by providing specific cells of a patient with novel genetic information. In general, it consists of introducing new genes in cells in order to replace a missing or defective gene or to express a therapeutic protein. Since cancer is in most cases a genetic disease, caused by genetic aberrations and subsequent gene defects, cancer gene therapy has been a promise for years. Strategies for cancer gene therapy include introduction or (re)activation of tumor suppressor genes, inactivation of oncogenes, and introduction of genes leading to expression of enzymes, toxic proteins or activate the immune system ${ }^{1}$. To avoid transduction of all kinds of cells throughout the body, such gene therapy should be targeted to the cells of interest ${ }^{2}$, i.e. targeted gene therapy (Box 1 and Figure 1).

Targeted cancer gene therapy relies on a cell population that can be easily targeted and that is important in tumor growth. Tumor angiogenesis (Box 2 and Figure 2), and more specifically, the angiogenically active endothelial cells (EC) that are essential for tumor angiogenesis fulfill these requirements. Endothelial cells are easily accessible, less prone to mutations, and disturbing the vasculature by killing

\section{Box 1 - Targeted gene therapy}

The goal of targeted gene therapy is to increase the specificity and efficiency of gene transfer, thereby improving therapeutic outcome and reducing undesirable side effects. Understanding the molecular mechanisms underlying the disease and identifying the differences between normal and diseased cells is at the core of targeted gene therapy. For example, to target tumor tissues, the cancer cells must preferably express a molecule that should not be present on healthy tissue ${ }^{70}$. Ideally, such a molecule, also called target molecule, should be able to interact with a specific antibody or ligand and it should not be subjected to variations or mutations within a single patient or between different patients ${ }^{71}$.

Once a suitable target molecule has been identified, a gene delivery vehicle has to be developed that only induces gene expression in the cells of interest. This can be achieved by either transductional or transcriptional targeting (Figure 1). In transductional targeting, the natural interaction of the delivery vehicle is modified so that gene is only delivered to the cells of interest. This requires detailed knowledge of tissue-specific receptors and vehicle biology. In transcriptional targeting, tissue specific expression is achieved by placing the gene under control of cell specific promoters/enhancers. The latter approach is hampered by the fact that only a limited number of specific promoters with acceptable activity have been identified so far. 


\section{Figure 1 - Targeting strategies to achieve EC-specific transcription}

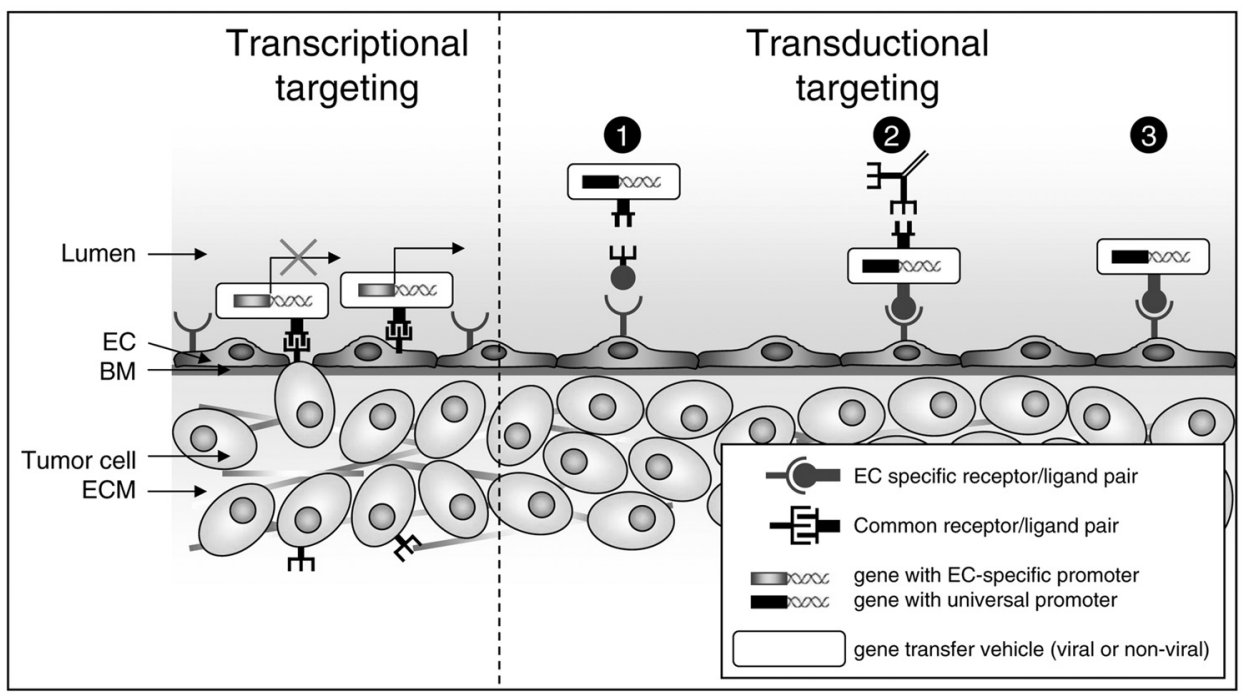

Figure 1 - Targeting strategies to achieve EC-specific transcription In transcriptional targeting, tissue specific expression is achieved by placing the gene under control of cell specific promoters/enhancers. In transductional targeting, the natural interaction of the delivery vehicle is modified so that the gene is only delivered to the cells of interest. This can be achieved by using adaptor molecules which are able to block the natural interaction ligand of the vehicle and to interact specifically with a receptor of the target cell (1), by blocking the natural interaction ligand of the vehicle with e.g. an antibody (2), or by expressing/conjugating a new ligand specific for the target cell (2 \& 3).

a few EC will result in massive tumor cell death ${ }^{3}$. Furthermore, a continuously increasing number of molecules are identified that distinguish the tumor endothelial cells from normal endothelium 4,5 . This makes tumor angiogenesis an excellent target for targeted gene therapy.

Over the years, several diverse tools have been developed to transport a therapeutic gene to the site of interest. These so-called gene transfer vehicles can be divided into two subgroups: viral and non-viral vehicles (Figure 3 and Table 1). Recent developments in the targeting of these gene transfer vehicles, together with the recognition of tumor angiogenesis as an excellent target for gene therapy justifies the current review. In this review, we give an extensive overview of the different methods that can be and have been used to target gene transfer vehicles to the tumor vasculature. Firstly, the targeting of viral gene transfer vehicles will be 
described, focusing on the most common and successful approaches. Secondly, recent developments in the field of non-viral targeting of the tumor endothelium will be described. Finally, we will discuss the future directions of this promising field and recapitulate the hurdles that have to be taken before angiogenesis targeted gene therapy can fulfill its promise in the clinical setting.

\section{Box 2 - Tumor angiogenesis}

Like all living cells, cancer cells need oxygen and nutrients for growth ${ }^{70}$. To fulfill these metabolic requirements, the expanding tumor tissue continuously induces the growth of new vessels from the existing vascular bed, a process referred to as angiogenesis. Both outgrowth of primary tumors and formation of metastasis are angiogenesis dependent ${ }^{3}$. To induce vessel growth the tumors acquire an angiogenic phenotype, characterized by an increased release of pro-angiogenesis factors like vascular endothelial growth factor (VEGF) and basic fibroblast growth factor (bFGF) ${ }^{72}$. These factors induce a cascade of events leading to the growth of new vessels (Figure 2 ).

The dependence of tumor growth on the development of new blood vessels makes angiogenesis an attractive target for therapy ${ }^{73}$. Damaging a single vessel can potentially result in the death of thousands of tumor cells ${ }^{74}$. The endothelial cells (EC), which are the key players in the angiogenesis cascade, are especially suitable for targeting because they line the interior of blood vessels. Therefore, they are the first cells that vehicles encounter after systemic delivery. Endothelial cells are genetically more stable and more homogeneous as compared to tumor cells ${ }^{1}$. Furthermore, it is generally thought that angiogenesis follows similar steps regardless of the type of tumor, allowing tumor-independent treatment strategies. Most importantly, the protein expression in the activated EC of the morphological abnormal tumor vasculature is different compared to expression in quiescent EC or in physiological activated $E C^{5,75}$. These differences can be used to guide the gene transfer vehicles specifically to the vessels of the tumor. By targeting EC it is possible to apply angiostatic therapy, i.e. expression of angiogenesis related molecules which have an influence on the angiogenic switch, or cytostatic therapy by expressing molecules which affect tumor growth or vascular development in an angiogenesis independent way. One of the first studies showing the feasibility of vascular targeting was published by Burrows. In this study the expression of MHC class II was stimulated on EC. Using an anti-Class II-deglycosylated Ricin A-chain immunotoxin they were able to induce death of IFN-activated EC in culture. When injected into nude mice they showed complete thrombosis of the tumor vasculature, infarction, and dramatic regressions of large solid tumors ${ }^{76}$. 


\section{Figure 2 - Tumor angiogenesis}

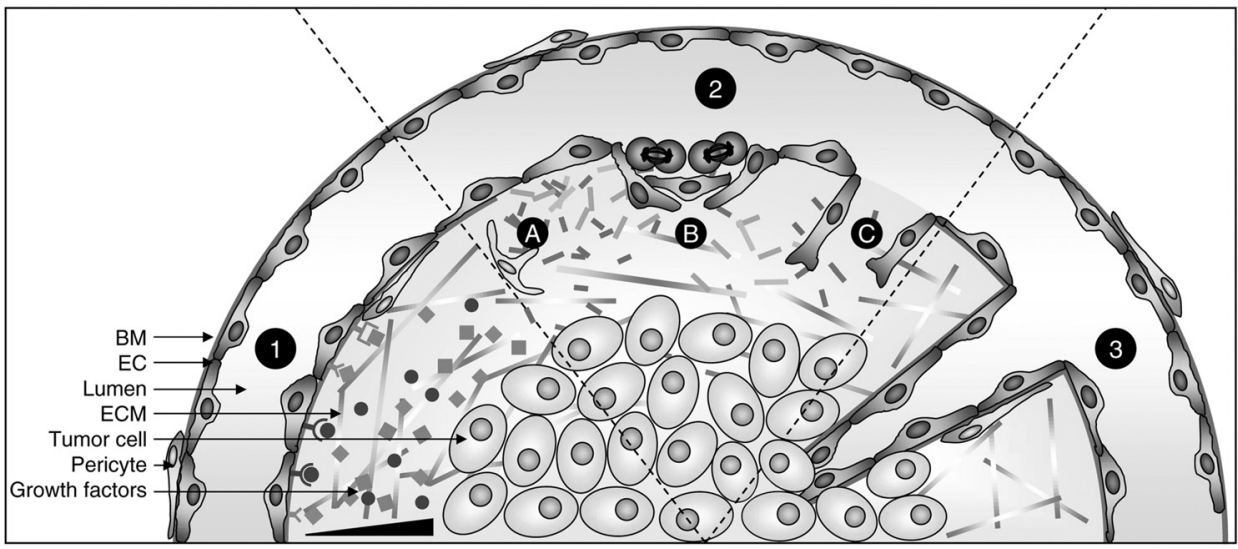

Figure 2 - Tumor angiogenesis

(1) Tumor angiogenesis is initiated by an angiogenic switch of the tumor cells. The tumor cells start to release angiogenesis stimulating growth factors into the surrounding tissue. When these signal are picked up by endothelial cells in nearby vessels, the cells are activated and start the angiogenesis cascade. (2) First, the activated EC increase the production of proteases to degrade the basement membrane (BM) and the extracellular matrix (ECM) (a). Next, the EC start to proliferate (b) and migrate (c) towards the tumor cells thereby forming new vascular structures. (3) Finally, a new basement membrane is produced and vessel stabilizing cells like pericytes are attracted to form a functional and mature blood vessel.

\section{Viral gene delivery}

Viruses for gene therapy can be classified in two major groups based on their ability to integrate genetic material into the genome of the host. Integrating viruses (e.g. retrovirus and lentivirus) have the advantage that they induce stable expression of the transgene and that the transgene is transmitted to all the progeny of transduced cells. Non-integrating viruses (e.g. adenovirus and herpesvirus) only induce transient expression. In the latter case, it can be necessary to repeat viral administration which increases the risk of eliciting an immuneresponse against the virus. In anti-angiogenesis cancer therapy, three types of viruses are most commonly used, i.e. adenoviruses, retroviruses, and herpes simplex viruses (Box 3 ). The next paragraphs will describe the most recent developments in targeting these viruses specifically to tumor vasculature. 


\section{Adenoviruses}

Adenoviruses are probably the most efficient viral vectors to achieve transgene expression. Based on their cell surface antigens, adenoviruses are divided in many different serotypes which have different natural tropism. Although serotypes 4 and 11 have been shown to be more effective for gene transfer into $\mathrm{EC}^{6}$, serotype 5 has been used in most gene therapy studies because it demonstrates a high efficacy of gene transfer in vivo and its biology is well known. Without any specific targeting, adenovirally transduced cells can be used as production facility of antiangiogenesis compounds, which has been done successfully for e.g. murine endostatin ${ }^{7}$.

Transductional targeting (Box 1 and Figure 1) of adenoviruses can be accomplished by blocking or changing the natural tropism of the virus. Complete blocking of the high affinity interaction between the fiberknob and the CAR-receptor can be achieved by adaptor molecules like neutralizing antibodies ${ }^{8}$. However, antibodies or scFv's are unable to block both the fiberknob and the penton baseintegrin interaction and they can dissociate in the serum after in vivo administration making the blocking of tropism less attractive for therapy. Changing the natural tropism of the virus can be accomplished by modifying the adenovirus genome in such a way that the fiber no longer to binds the CAR-receptor but only with a receptor of choice. Since proper incorporation into the adenovirus capsid requires fiber trimerization, modifications are only allowed as long as the trimer formation is not disturbed. This limits the possibilities to modify the fiber and in most cases the modified vector is not truly retargeted and still able to bind the CAR receptor though to a lesser extend. Recently, Shinozaki et al. achieved infection of mainly EC by replacing the complete Ad5 fiber with the fiber of serotype $35^{9}$. As a result, these particles interact with CD46 instead of the CAR receptor on the cell surface. The expression of CD46 seems to relate with tumor progression and is suitable for EC targeting 10,11 Schagen et al. circumvented the difficult modification of the knob by fusing the virion-anchoring domain of the fiber to the oligomerization domain of reovirus attachment protein $\sigma 1^{12}$. These new fibers can much more easily be modified to interact with targets specifically expressed on activated endothelium ${ }^{13}$. Besides the CAR-receptor interaction, also the RGD motif in the penton base can be abolished ${ }^{14}$. However, in case of targeting tumor vasculature this is not necessary because the main receptor for RGD, i.e. integrin $\alpha v \beta 3$, is upregulated in activated endothelium which automatically provides a better infection of EC.

As described in Box 1, transcriptional targeting relies on the identification of celltype specific promoters. To evaluate EC specific promoters in adenoviruses for vascular gene therapy, Nicklin et al. compared the promoters of FLT-1, intercellular adhesion molecule-2 (ICAM-2), and von Willebrand factor for EC restricted expression. After in vitro transduction, $\beta$-galactosidase expression was analyzed in human umbilical vein EC, human saphenous vein EC and three non-EC lines. The 
von Willebrand and FLT-1 promoter evoked both an EC specific expression level, whereas ICAM-2 was also extremely active in non-EC. When the viruses were applied in an ex vivo human model and systemically to mice, the FLT-1 promoter demonstrated extremely low levels of gene expression in non-EC, thereby identifying FLT-1 as the most selective promoter ${ }^{15}$. Other endothelial specific promoters used for adenoviral targeting include the preproendothelin-1 (PPE) promoter, and VEGF-receptor 2 (FLK) promoter ${ }^{16,17}$.Using these promoters almost exclusive EC specificity was achieved and, when applied into suitable vectors, tumor reduction could be accomplished in vivo. An advantage of transcriptional targeting is the possibility to clone more than one gene under control of the specific promoter or to use multiple adenoviruses in one therapy. For example, Raikwar et al. developed two adenovirus vectors, one that expressed a fusion protein of the angiogenesis inhibitor endostatin and angiostatin, while the second expressed a soluble form of the EC specific Tie-2 receptor. Both vectors inhibited tumor growth, but the best results were obtained when a combination therapy was applied, leading to $80 \%$ tumor free survival in a PC-3 prostate xenograft tumor model in mice ${ }^{18}$. Thorne et al. used a combination of an anti-angiogenesis and an oncolytic adenovirus. The angiostatic virus expressed a soluble VEGF receptor while the replication of the oncolytic virus was restricted to cancer cells with a loss in the G1$S$ cell cycle checkpoint. Co-infection of tumor cell lines with both viruses allowed replication and repackaging of the replication deficient angiostatic virus. Coadministration of both viruses in vivo in colon HCT116 and prostate PC-3 tumor xenografts models in mice significantly enhanced anti-tumor effects in comparison to the monotherapies ${ }^{19}$.

A limitation of most available adenoviral vectors is their sub-optimal transduction efficiency in vivo. To circumvent this problem replicative vectors can be used. Ideally, these vectors are designed in such way that virus replication is restricted to the target cells. Savontaus et al. made conditionally replicating adenoviruses which were targeted to dividing EC. The E1A\&B genes, which are required for replication, were placed under control of the regulatory elements of FLK-1 and endoglin genes. The vectors preferably infected EC and inhibited approximately $85 \%$ of capillary network formation in in vitro angiogenesis assays with HUVECs ${ }^{17}$.

Another limitation of adenoviruses is their ability to evoke an inflammatory reaction and an immuneresponse after in vivo administration ${ }^{20}$. To overcome this problem adeno-associated viruses (AAV) have been developed ${ }^{21}$. AVV vectors are non-envelope single stranded DNA parvoviruses that depend on a helper virus, in most cases adenoviruses, to replicate. They are also able to infect both quiescent and dividing cells. More importantly, they can integrate specifically or randomly into the host genome, preferentially in chromosome 19, resulting in prolonged transgene expression. Using serotype 1 and 5 , Chen et al. showed efficient 
transduction of vascular EC ${ }^{22}$, while serotype 7 and 8 are less efficient ${ }^{23}$. Work et al. employed in vivo phage display to identify vascular specific peptides which were indeed able to make AAV more specific for the vasculature ${ }^{24}$.

\section{Box 3 Viral vectors for anti-angiogenesis gene transfer}

The viral vectors that are most commonly used as gene transfer vehicles for antiangiogenesis gene therapy include adenoviruses, retroviruses, and herpes simplex viruses. Adenoviruses are non-envelope linear double stranded DNA viruses that do not have to go through a RNA intermediate for replication. They can transduce both dividing and quiescent cells ${ }^{77}$. The virion consists of an icosahedral capsid with on every corner a pentonbase bearing a fiber protein. Virus uptake involves binding of the fiber proteins with the Coxsacky adenovirus receptor, interaction of the penton base with cellular integrins, and binding with heparan sulphate glycosaminoglycans. Following receptor mediated endocytosis and acidification induced degradation of the endosome, the virions enter the cytosol ${ }^{78}$.

Retroviruses are single stranded RNA viruses that can integrate into the genome of cells which results in stable replication and transmitted to all the progeny of these cells. Retroviruses can only transduce dividing cells which makes them suitable for targeting EC in the tumor vasculature. Viral infection is initiated by an interaction between the viral envelope surface protein and specific receptor molecule(s) on the target cell. Different types of retroviruses recognize different receptors and not all cell types of a given species are transfected equally with retroviruses. Other molecules, like intracellular adhesion/communication molecules or extracellular matrix proteins like heparan sulphate proteoglycans, also play a role in the initial steps of infection ${ }^{79}$. Following attachment, the virus is taken up by endocytosis. In the cell, a double stranded DNA intermediate is formed which enters the nucleus and randomly integrates into the host genome ${ }^{80}$.

Herpes Simplex viruses are enveloped double stranded DNA viruses that are highly infectious and can infect a broad range of both dividing and non-dividing cell types $^{81}$. They do not integrate into the host genome and induce only transient expression in the infected cell population. The virion consists of a lipid envelope, which is responsible for several functions including receptor-mediated cellular entry 82. The first event of the attachment occurs through binding to GAG moieties on cell surface proteoglycans ${ }^{83}$. Consequently, viral glycoproteins bind to the cellular receptor and the viral envelope fuses with the cell membrane, allowing release of the virion content into the cell. Infections with HSV can be lytical or establish a latent infection for years which both can be exploited in therapeutic strategies ${ }^{84}$. 


\section{Retroviruses}

Retroviruses are one of the earliest recombinant vectors that were used for cancer gene therapy. There are three ways to change the tropism of retroviruses to achieve transductional retargeting. First, pseudotyping, which involves the exchange of the envelope glycoprotein for the glycoprotein of another retrovirus. It can be used for difficult to transduce cell types, although pseudotyped viruses not always reproduce the specific tropism of the parental virus ${ }^{25}$. Second, genetic modification can be used to change the envelope glycoprotein or to express other molecules. For example, Hall et al. made a fusion protein of von Willebrand factor clotting factor domain and the envelope glycoprotein to target the endothelium. After in vivo systemic administration, transduced cells were detected in liver metastasis ${ }^{26}$. The third method is the use of so-called adaptor molecules that modify the specificity of the infection. These molecules recognize both the envelope glycoprotein and the target cell, e.g. a ligand-conjugated antibody ${ }^{27}$. In general, the retargeted viruses have improved infection capacities to the target cell but at the same time they are sub-optimal in their entry efficiency in comparison to the natural infection capacity.

In case of angiostatic cancer gene therapy with retroviruses, transcriptional targeting has been mainly used. Retroviral expression is usually regulated by just a single promoter in the $5^{\prime}$ long terminal repeat (LTR). For transcriptional targeting to EC, several promoters have been tested including Tie1, Tie2, FLK-1, VE-cadherin, ICAM2, E-selectin, and KDR 28, 29. De Palma and coworkers found that lentiviral vectors, which are a subclass of retroviruses, containing the Tie2 promoter achieved remarkable specificity of expression in EC in vitro and in vivo ${ }^{28}$. Modlich et al. reach higher expression levels using hypoxia inducible enhancers for the weak EC specific KDR and E-selectin promoter ${ }^{29}$. By placing herpes simplex virusthymidine kinase (HSV-TK) under control of elements of the EC specific preproendothelin-1 promoter, Mavria et al. showed that efficacious EC specific therapeutic gene expression can be achieved in vivo. Additionally, they showed that in combination with the chemotherapeuticum ganciglovir a significant effect on the regrowth rate of relapsed tumors as well as the survival time could be achieved in a SW620 colon tumor xenograft model. Thus, by targeting and destroying the vasculature, they sensitized the tumor for treatment with chemotherapy ${ }^{30}$.

\section{Herpes simplex viruses}

Herpes simplex viruses (HSV) are flexible and effective vehicles for introducing and expressing foreign genes in mammalian cells both in vivo and in vitro. For antiangiogenesis therapy, the oncolytic properties of HSV are often used ${ }^{31}$. However, infections of tumors by oncolytic HSV results in tumor reduction but not tumor regression. 
Like retroviruses, HSV can be retargeted by pseudotyping, genetic modification and transcriptional targeting ${ }^{32}$. Reinblatt et al. and Pin et al. used HSV to express soluble VEGF receptors under control of a multimerized hypoxia response element. When PC1 xenograft tumors were treated under hypoxia there was a much higher expression level of soluble VEGF receptor than under normoxic conditions. Besides smaller tumor volumes there was a higher capillary reduction under hypoxic conditions ${ }^{33,}{ }^{34}$. In a study of Mullen et al. the murine endostatin gene was incorporated into the HSV genome. The produced endostatin was capable of inhibition of angiogenesis in a human $\mathrm{HT} 29$ colon carcinoma model ${ }^{35}$.

\section{Figure 3 - Schematic drawing of the most common gene transfer vehicles and their size compared to a capillary blood vessel}

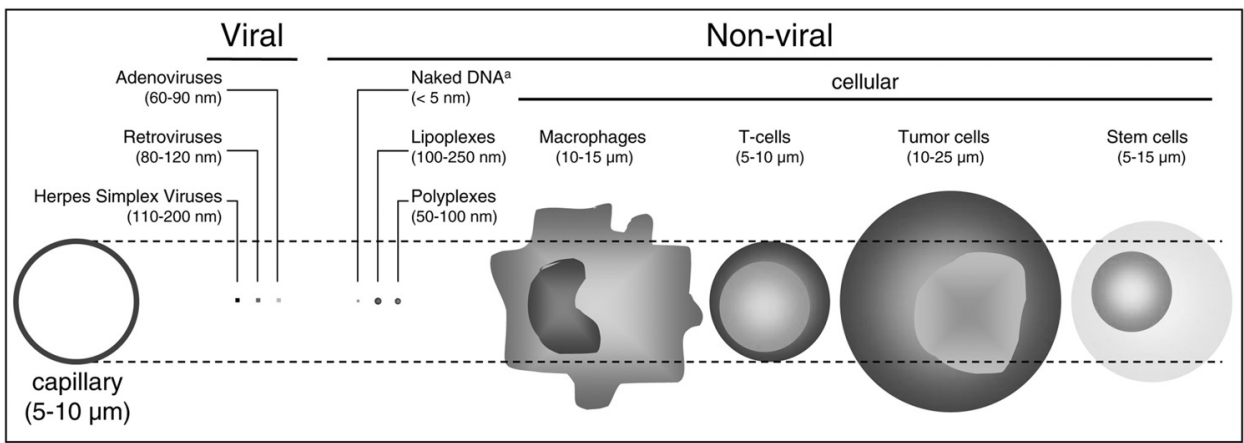

${ }^{a}$ Naked DNA is less suitable for targeting and is not discussed in this review

Figure 3 - Schematic drawing of the most common gene transfer vehicles and their size compared to a capillary blood vessel

\section{Non-viral gene delivery}

Non-viral vehicles are particularly suitable with respect to their lack of inducing a specific immune response, simplicity, packaging capacity, and potential for large scale production. The simplest form of non-viral gene therapy is direct injection of naked DNA at the site of interest. However, since this approach does not allow active retargeting it will not be discussed here. Besides injection of naked DNA, non-viral gene delivery can be achieved by employing lipoplex formulations or even whole cells. 


\section{Lipoplex vehicles}

The majority of non-viral DNA delivery systems are lipid based vehicles (also called lipoplexes) such as liposomes and micelles (Box 4). The function of the lipidic component is to protect the DNA from degradation, to stabilize the particles for endocytosis, and to promote endosomal release by membrane fusion. For in vivo application, lipoplexes should 1 ) be able to entrap a high concentration of DNA, 2) be small, 3) have a long half-life, 4) be stable in serum, 5) be non-immunogenic and 6 ) be able to deliver its DNA content specifically in the target cell.

We and others have already successfully used the RGD-peptide for targeting liposomal formulations to angiogenic endothelium 36, 37. RGD-peptides bind to integrin alphaVbeta3 which is overexpressed on actively proliferating endothelium 38. Schiffelers et al. used a cyclic RGD-peptide to target lipoplexes loaded with doxorubicin to murine c26 colon carcinoma, which is insensitive for doxorubicin. They proved that tumor growth inhibition was a result of anti-angiogenesis ${ }^{39}$.

\section{i. Cationic liposomes}

Cationic liposomes are in most cases the method of choice for in vitro transfections. Due to their positive charge, they bind easily to the negatively charged DNA forming a dense complex. When the formulation of the lipids is chosen so that the cationic liposome/DNA complex has a net positive charge, easy cell binding can also be achieved through electrostatic interactions with anionic sulphated proteoglycans associated with the cell membrane ${ }^{40}$. The in vivo gene transfer of cationic liposomes is in general low and depends on the way of administration. Cationic liposomes can be administrated via the respiratory system, via intratumoral injection, or via intravenous injections. Using the first two methods, there is predominantly transgene expression in the first organ/tissue the liposomes encounter, e.g. the pulmonary system or the peritoneum. With intravenous injection it is difficult to reach expression levels of therapeutic magnitude ${ }^{41}$.

To target tumors with cationic liposomes, different kind of ligands have been used like the folate receptor, antibodies and scFv's ${ }^{42-44}$. In case of anti-angiogenic therapy, most studies rely on the passive targeting capacity of the vehicles together with the expression of angiostatic proteins like endostatin ${ }^{45}$. Cationic liposomes target angiogenic EC of solid tumors primarily because of size, and secondly, because of a charge-related mechanism. Eichhorn et al. exploited this system by first charging the EC by injection of the polycation protamine which increased the selectivity of cationic liposomes in targeting angiogenic microvessels 46. The group of Imamura used cationic liposomes conjugated with inactivated hemagglutinating virus of Japan (HVJ) to target the tumor vessels in models of human gastric cancer (MKN45 and HT1080S). By expressing soluble FLT-1, the MVD decreased which resulted in a significantly longer survival period of treated 
mice than the control mice ${ }^{47}$. Gorrin-Rivas used the same HVJ cationic liposomes to induce angiostatin production by expression of macrophage metalloelastase in a mouse model of CT-26 colon cancer. Tumor growth was predominantly inhibited by decreased MVD ${ }^{48}$. We have used cationic liposomes to image the angiogenic blood vessels in tumors. By coupling RGD-peptides to MRI-detectable liposomes, specific binding to activated tumor endothelium in vivo could be achieved ${ }^{36}$.

\section{Box 4 - Lipoplex mediated gene delivery}

To release its DNA content into the target cells, lipoplexes have to be taken up by the cell via receptor mediated internalization or via endocytosis. Degradation of the endosome and the lipoplex together with its genetic content, as a result of the progressive acidification, can be avoided by designing the lipoplex in a way that facilitates the release of the DNA into the cytoplasm. Optimizing this release is one of the main bottlenecks regarding transfection efficiency. To release its DNA, the lipids from the lipoplex and the endosome have to merge. This can be achieved by including lipids into the liposomal formulation that destabilize the endosomal membrane. The choice of helper lipids, like DOPE or cholesterol, can significantly improve the transfection efficiency and stabilize the complex in serum.

Once in the cytoplasm still a few hurdles have to be taken. Firstly, the DNA can be degraded in the cytoplasm by cytosolic Ca2+-sensitive nucleases ${ }^{85}$. Secondly, the DNA has to pass the nuclear membrane. In general, only $0.1 \%$ of naked DNA or $1 \%$ of polyplex associated DNA will reach the nucleus from the cytoplasm ${ }^{86}$.

The major drawback of classical lipoplexes was their fast clearance from the blood circulation. This is the result of adsorption of proteins, called opsonins, by the lipoplexes from the serum. These opsonins trigger the recognition and uptake by the mononuclear phagocytic system (MPS). To escape MPS recognition, surface modified (stealth) liposomes were developed. The inclusion of e.g. derivates of polyethyleneglycol (PEG) increases the half-life from a few minutes to a few hours 87. Apart from rapid clearance, the low transfection efficiency of lipoplexes in comparison to viral systems is also partly due to the distribution of lipoplexes in vivo ${ }^{88}$. Following systemic administration they tend to aggregate and deposit in the first vascular beds they encounter, resulting in a relative high expression level at these places, usually the lungs and the liver ${ }^{89}$.

The ability of the target cell to internalize ligand targeted lipoplexes is also an important selection criterion in choosing a targeting ligand because this will lead to a higher concentration into the cytoplasm. Targeting of lipoplexes to angiogenic endothelial cells by conjugation of e.g. peptides is an attractive approach, since targeted lipoplexes reach the tumors the same way as non-targeted lipoplexes, i.e. by extravasating through gaps in tumor capillary endothelium. As a result, the 
number of targeted lipoplexes that reach the tumor's interstitial space is no higher than the number of non-targeted lipoplexes.

\section{ii. Coated cationic liposomes}

The disadvantage of most lipoplex gene delivery systems is the poor expression level after in vivo systemic delivery. Coated cationic liposomes (CCL) fulfil many of the above described requirements for an ideal systemic in vivo gene delivery vehicle. They are small, non-immunogenic, have a high DNA entrapment efficiency (>90\%) and are very stable in the circulation (half-life of several hours) ${ }^{49}$. When CCLs are prepared, the negative charge of the DNA is neutralized with cations. These complexes are subsequently 'coated' with neutral lipids. The formulation of the coating can be optimized for the specific application.

Without targeting there is a very low interaction with cells. By coupling ligands, they can be made specific for several cell types ${ }^{50}$. In a study of Bartsch et al., untargeted CCLs were compared to CCLs targeted with poly anion aconitylated human serum albumin (Aco-HAS). Although the PEG-stabilized untargeted particles showed long circulating properties with a half-life of $>10$ hours, untargeted CCLs bound hardly to liver EC while targeted CCLs massively and specifically interacted with these cells. With the targeted CCLs down-regulation of ICAM was achieved by delivering antisense ODNs ${ }^{51}$.

\section{Polymer-based vehicles}

The biggest benefit of polymer-based gene delivery systems is their solubility and stability in serum, making them very suitable vehicles for in vivo systemic administration. In most studies cationic polymers are used and complexes of these polymers with DNA are also called polyplexes. Like lipoplex formulations, the difficulty for polyplexes is to escape from the endosomes after cellular uptake. Therefore, cell transfection requires the co-delivery of an endosome-lytic agent like inactivated adenovirus ${ }^{52}$. As an alternative, polymers like polyethylenimine (PEI) can be used. PEI itself induces an endosome disruption mechanism by buffering the contents of the endosomes ${ }^{53}$, causing an influx of chloride protons ${ }^{54}$. This process, called proton motive force, results in a net increase in ion concentration which causes expansion of the PEI and subsequent swelling and disruption of the endosome.

Transfection efficiency of polyplexes depends on the length of the polymer. A long polymer is also beneficial for condensing and protection of DNA. In a study of Gautam et al., a significant reduction of B16F10 lung tumor growth was achieved after aerosol delivery of PEI-p53 expressing DNA in mainly the epithelial cells lining the airways. The mean length of survival of the mice increased by about $50 \%$. The p53 transfection induced an up-regulation of the anti-angiogenesis factor trombospondin-1, a down regulation of VEGF, and a decrease in the angiogenic 
phenotype of the tumors ${ }^{55}$. To achieve targeted uptake of siRNA against VEGFreceptor 2 in tumor neovasculature, Schiffeler et al. made complexes with PEI that was PEGylated with an RGD peptide ligand. Cell delivery and activity was found to be siRNA sequence specific and depended on the presence of peptide ligand. Intravenous administration into tumor-bearing mice gave selective tumor uptake, siRNA sequence-specific inhibition of protein expression within the tumor, and inhibition of both tumor angiogenesis and growth rate ${ }^{56}$.

\section{Cellular vehicles}

In cell based therapy, a cell carries the DNA vector to the site of interest. Nowadays, the ex vivo loading of cell is adequate while tumor specific homing capacities and in vivo gene transfer efficiency still need improvement. Obviously, choosing the appropriate cell vehicle is a critical factor for successful gene delivery 57. When autologous cells are used, the immune response can be avoided or diminished. Also, the toxic effects of high doses of viral vehicles can be circumvented. Furthermore, in vitro transfection methods can be applied to the carrier cell which ensures high transfection efficiency. Finally, by transferring DNA constructs, the homing characteristics of a given cell type can be modified, e.g. by expressing specific receptors or ligands.

Human umbilical vein EC preferentially accumulate to the tumor vasculature ${ }^{58}$. Ojeifo et al. infected HUVECs with a retroviral vehicle containing the LacZ gene. Beta-galactosidase expressing cells were i.v. injected in mice bearing a NIH 3T3 murine fibroblast tumor that secreted fibroblast growth factor-1 (FGF-1). The transduced HUVECs accumulated at sites of FGF-1, induced angiogenesis and persisted for at least four weeks ${ }^{59}$.

Apart from HUVEC, other cell types like immune cells, stem cells and even tumor cells have been used. Kershaw et al. used lymphocytes were genetically modified with a gene construct encoding single-chain antibody fragment against VEGF receptor-2 (KDR) via retroviruses. The lymphocytes were assessed for their ability to secrete cytokines in response to KDR binding. They demonstrated that incubation of these lymphocytes with HUVECs results in both target cell lysis and secretion of cytokines and chemokines ${ }^{60}$. Niederman et al. followed a similar approach and loaded CD8 lymphocytes with a chimeric receptor consisting of VEGF-coding sequences. The transduced cells possessed an efficient killing specificity for cells expressing the VEGF receptor (flk-1). The modified T-cells showed a strong inhibition of tumor growth in three in vivo cancer models in mice. Tumor growth was even more inhibited when treatment was combined with the angiogenesis inhibitor TNP-470 ${ }^{61}$.

In a study of Davidoff et al., murine bone marrow cells were transduced with a retroviral vector to deliver a gene encoding for a soluble truncated form of VEGF receptor-2. In transplanted mice, the EC in the tumor were partly derived from the 
bone marrow precursors and tumor growth was significantly inhibited ${ }^{62}$. De Palma et al. demonstrated that bone marrow progenitor cells, loaded with a suicide gene under control of transcription regulatory elements of Tie2/TEK gene, marked a hematopoietic population that homed to the tumor ${ }^{63}$.

The observation that cells of a given histological cell type bind preferentially to cells of the same histological type, made autologous tumor cells a candidate as cell carrier ${ }^{64}$. Even tumor cells of unrelated origin associate with, and adhere to other primary tumor cells ${ }^{65}$. Obviously, the disadvantage of tumor cells as carrier is the risk of introducing a new source of neoplasm into the body and the fact that they can only adhere at places where the tumor is in direct contact with the blood. For clinical use, it would be desirable to have a supplemental mechanism by which the adoptive transferred cells could be killed after fulfilling their functions.

\begin{tabular}{|c|c|c|c|c|c|c|}
\hline Vehicle & $\begin{array}{c}\text { Packaging } \\
\text { capacity }\end{array}$ & $\begin{array}{c}\text { Ease of } \\
\text { production }\end{array}$ & $\begin{array}{c}\text { Transfection } \\
\text { efficiency }\end{array}$ & $\begin{array}{c}\text { Genomic } \\
\text { integration }\end{array}$ & $\begin{array}{l}\text { Transgene } \\
\text { expression }\end{array}$ & $\begin{array}{c}\text { Immuno- } \\
\text { genic }\end{array}$ \\
\hline $\begin{array}{l}\text { Adeno- } \\
\text { virus }{ }^{1,} 77, \\
78\end{array}$ & $\sim 30 \mathrm{~kb}$ & $+/-$ & ++ & No & Transient & Yes \\
\hline $\begin{array}{l}\text { Retrovirus } \\
80,90\end{array}$ & $\sim 8 \mathrm{~kb}$ & $+/-$ & + & Yes & Stable & No \\
\hline $\begin{array}{l}\text { Herpes } \\
\text { simplex } \\
\text { virus } 81, \\
82,91\end{array}$ & $30-50 \mathrm{~kb}$ & $+/-$ & + & No & Transient & Yes \\
\hline $\begin{array}{l}\text { Lipoplex } \\
88,92\end{array}$ & Unlimited & +++ & $+/-$ & Infrequently & $\begin{array}{l}\text { Usually } \\
\text { transient }\end{array}$ & No \\
\hline $\begin{array}{l}\text { Polyplex } \\
92\end{array}$ & Unlimited & +++ & $+/-$ & Infrequently & $\begin{array}{c}\text { Usually } \\
\text { transient }\end{array}$ & No \\
\hline $\begin{array}{l}\text { Cellular } \\
\text { vehicle }\end{array}$ & Unlimited $\left.^{*}\right)$ & + & - & Yes/no*) & $\begin{array}{l}\text { Usually } \\
\text { transient }\end{array}$ & $\begin{array}{l}\text { Only after } \\
\text { heterolo- } \\
\text { gous } \\
\text { trans- } \\
\text { plantation }\end{array}$ \\
\hline
\end{tabular}

\section{Future directions}

Gene therapy is a promising approach for cancer treatment. Continuing research has lead to much progress regarding the development of novel strategies and transfer vehicles. Nevertheless, there is still a lack of gene transfer vehicles that are safe, non-immunogenic, efficacious as well as tumor selective, and several 
questions have to be addressed before angiogenesis targeted cancer gene therapy will become a valuable tool in the clinic.

Viral vehicles are still a topic of new studies. Although much improvement has been made regarding their gene transfer mechanisms, further development relies on a more detailed understanding of the biology underlying virus-host interactions. In addition, the in vivo transduction efficiency of viral vehicles has to be improved. A major step forward will include methods to prevent uptake of the vehicles by MPS in the circulation. Progressions will also arise from the use of replication competent viruses and the development of non-viral vehicles which represent a simple, cheap, and safe alternative to viral vectors. However, barriers such as low transfection efficiency and insufficient distribution to target cells in vivo remain substantial. Two of the most important needs for effective use of lipoplexes are an improved control over DNA release after internalization and an enhanced regulation of gene expression. Additional success will rely on the formulation of customized lipids for specific cell types and applications.

Another important challenge will be the use of cellular vehicles for gene transfer. Several recent reports have described the homing of bone marrow derived endothelial precursor cells (EPC) to tumor sites where they contribute to angiogenesis 66, 67. Such cells would provide an excellent opportunity for angiogenesis targeted gene therapy. However, the frequency of incorporation of EPCs in the tumor vasculature appears to be rather low. Although radiation therapy can increase this percentage ${ }^{68}$, it remains to be studied whether the numbers of stem cells would be sufficient to yield a therapeutic effect.

Besides the development of adequate transfer vehicles and regulation of adequate and therapeutic expression levels of the transgene, the main future challenge will be the implementation of specific targeting ligands in the gene transfer vehicles. Over the last decade, we and others have identified such targets which allow the design of both viral and non-viral vehicles that specifically home to the angiogenic vasculature 4, 5, 13. Using these molecules in the different gene transfer vehicles will improve the targeting specificity and reduce the toxicity. It is this step that will facilitate the translation of angiogenesis targeted cancer gene therapy to the clinical setting.

\section{Concluding remarks}

Targeted gene delivery, has emerged as a promising approach to enhance the efficacy of tumor-selective gene delivery. Because the endothelial cells in the tumor vasculature express specific molecules, they can be used for selective targeting of gene transfer vehicles, i.e. viral or non-viral vectors. The targeting of such vectors can be achieved via specific ligands, receptors, (part of) antibodies, peptides, or transcriptional control elements. Additional benefits of targeting the tumor 
vasculature instead of the tumor cells are accessibility, genetic stability, and the possibility to be effective against more than one cancer type. Furthermore, antiangiogenesis gene therapy does not exclude other cancer therapies like chemotherapy or radiation therapy. Combination therapy might even work better 69

Despite promising results using different gene transfer vehicles there are still limitations that have to be solved before angiogenesis targeted cancer gene therapy can be routinely used in the clinic. Nevertheless, it can be expected that future research will bring successful angiostatic specific gene delivery strategies for the treatment of cancer.

\section{Box 5 Outstanding questions}

- Will future improvements make gene transfer vehicles safe for long time administration?

- Can viral vehicles truly be retargeted without loosing transduction efficiency?

- Is it possible to reach therapeutic levels of the transgene in vivo?

- Are there markers on tumor EC which are available in most tumor types and stages of development?

- What is the required expression level needed for successful gene therapy?

- To what extend is the tortuous vasculature inside tumors an obstruction for efficient delivery of gene transfer vehicles?

- Will the tumor homing capacity of ex vivo loaded endothelial precursor cells be sufficient? 


\section{References}

1. Hughes, R.M. (2004) Strategies for cancer gene therapy. J Surg Oncol 85, 28-35

2. Nathwani, A.C., Benjamin, R., Nienhuis, A.W., and Davidoff, A.M. (2004) Current status and prospects for gene therapy. Vox Sang 87, 73-81

3. Griffioen, A.W., and Molema, G. (2000) Angiogenesis: potentials for pharmacologic intervention in the treatment of cancer, cardiovascular diseases, and chronic inflammation. Pharmacol Rev 52, 237-268

4. Thijssen, V.L., Postel, R., Brandwijk, R. J., Dings, R. P., Nesmelova, I., Satijn, S. A., Verhofstad, N., Nakabeppu, Y., Baum, L. G., Bakkers, J., Mayo, K. H., Poirier, F., and Griffioen, A. W. (2006) Galectin-1 is essential in angiogenesis and is a target for anti-angiogenesis therapy.

Proc.Natl.Acad.Sci.USA, In press., 2006

5. van Beijnum, J.R., Eijgelaar, W.J., and Griffioen, A.W. (2006) Towards highthroughput functional target discovery in angiogenesis research. Trends $\mathrm{Mol}$ Med 12, 44-52

6. Zhang, L.Q., Mei, Y.F., and Wadell, G. (2003) Human adenovirus serotypes 4 and 11 show higher binding affinity and infectivity for endothelial and carcinoma cell lines than serotype 5. J Gen Virol 84, 687695

7. Sauter, B.V., Martinet, O., Zhang, W.J., Mandeli, J., and Woo, S.L. (2000) Adenovirus-mediated gene transfer of endostatin in vivo results in high level of transgene expression and inhibition of tumor growth and metastases. Proc Natl Acad Sci U S A 97, 4802-4807

8. Haisma, H.J., Grill, J., Curiel, D.T., Hoogeland, S., van Beusechem, V.W., Pinedo, H.M., and Gerritsen, W.R. (2000) Targeting of adenoviral vectors through a bispecific single-chain antibody. Cancer Gene Ther 7, 901-904

9. Shinozaki, K., Suominen, E., Carrick, F., Sauter, B., Kahari, V.M., Lieber, A., Woo, S.L., and Savontaus, M. (2006) Efficient infection of tumor endothelial cells by a capsid-modified adenovirus. Gene Ther 13, 52-59

10. Havenga, M.J., Lemckert, A.A., Grimbergen, J.M., Vogels, R., Huisman, L.G., Valerio, D., Bout, A., and Quax, P.H. (2001) Improved adenovirus vectors for infection of cardiovascular tissues. J Virol 75, 33353342
11. Ni, S., Gaggar, A., Di Paolo, N., Li, Z.Y., Liu, Y., Strauss, R., Sova, P., Morihara, J., Feng, Q., Kiviat, N., Toure, P., Sow, P.S., and Lieber, A. (2006) Evaluation of adenovirus vectors containing serotype 35 fibers for tumor targeting. Cancer Gene Ther 13, 1072-1081

12. Schagen, F.H., Wensveen, F.M., Carette, J.E., Dermody, T.S., Gerritsen, W.R., and van Beusechem, V.W. (2006) Genetic targeting of adenovirus vectors using a reovirus sigma1-based attachment protein. Mol Ther 13, 997-1005

13. Neri, D., and Bicknell, R. (2005) Tumour vascular targeting. Nat Rev Cancer 5, 436446

14. Wickham, T.J., Carrion, M.E., and Kovesdi, I. (1995) Targeting of adenovirus penton base to new receptors through replacement of its RGD motif with other receptor-specific peptide motifs. Gene Ther 2, 750-756

15. Nicklin, S.A., Reynolds, P.N., Brosnan, M.J., White, S.J., Curiel, D.T., Dominiczak, A.F., and Baker, A.H. (2001) Analysis of cellspecific promoters for viral gene therapy targeted at the vascular endothelium. Hypertension 38, 65-70

16. Greenberger, S., Shaish, A., Varda-Bloom, N., Levanon, K., Breitbart, E., Goldberg, I., Barshack, I., Hodish, I., Yaacov, N., Bangio, L., Goncharov, T., Wallach, D., and Harats, D. (2004) Transcription-controlled gene therapy against tumor angiogenesis. J Clin Invest 113, 1017-1024

17. Savontaus, M.J., Sauter, B.V., Huang, T.G., and Woo, S.L. (2002) Transcriptional targeting of conditionally replicating adenovirus to dividing endothelial cells. Gene Ther 9, 972-979

18. Raikwar, S.P., Temm, C.J., Raikwar, N.S. Kao, C., Molitoris, B.A., and Gardner, T.A. (2005) Adenoviral vectors expressing human endostatin-angiostatin and soluble Tie2: enhanced suppression of tumor growth and antiangiogenic effects in a prostate tumor model. Mol Ther 12, 1091-1100

19. Thorne, S.H., Tam, B.Y., Kirn, D.H., Contag, C.H., and Kuo, C.J. (2006) Selective Intratumoral Amplification of an Antiangiogenic Vector by an Oncolytic Virus Produces Enhanced Antivascular and Antitumor Efficacy. Mol Ther

20. Muruve, D.A. (2004) The innate immune response to adenovirus vectors. Hum Gene Ther 15, 1157-1166 
21. Li, C., Bowles, D.E., van Dyke, T., and Samulski, R.J. (2005) Adeno-associated virus vectors: potential applications for cancer gene therapy. Cancer Gene Ther 12, 913-925

22. Chen, S., Kapturczak, M., Loiler, S.A., Zolotukhin, S., Glushakova, O.Y., Madsen, K.M., Samulski, R.J., Hauswirth, W.W., Campbell-Thompson, M., Berns, K.I., Flotte, T.R., Atkinson, M.A., Tisher, C.C., and Agarwal, A. (2005) Efficient transduction of vascular endothelial cells with recombinant adeno-associated virus serotype 1 and 5 vectors. Hum Gene Ther 16, 235-247

23. Denby, L., Nicklin, S.A., and Baker, A.H. (2005) Adeno-associated virus (AAV)-7 and -8 poorly transduce vascular endothelial cells and are sensitive to proteasomal degradation. Gene Ther 12, 1534-1538

24. Work, L.M., Buning, H., Hunt, E., Nicklin, S.A., Denby, L., Britton, N., Leike, K., Odenthal, M., Drebber, U., Hallek, M., and Baker, A.H. (2006) Vascular bed-targeted in vivo gene delivery using tropism-modified adeno-associated viruses. Mol Ther 13, 683693

25. Desmaris, N., Bosch, A., Salaun, C., Petit, C., Prevost, M.C., Tordo, N., Perrin, P., Schwartz, O., de Rocquigny, H., and Heard, J.M. (2001) Production and neurotropism of lentivirus vectors pseudotyped with lyssavirus envelope glycoproteins. Mol Ther 4, 149-156

26. Liu, L., Anderson, W.F., Beart, R.W., Gordon, E.M., and Hall, F.L. (2000) Incorporation of tumor vasculature targeting motifs into moloney murine leukemia virus env escort proteins enhances retrovirus binding and transduction of human endothelial cells. J Virol 74, 5320-5328

27. Etienne-Julan, M., Roux, P., Bourquard, P., Carillo, S., Jeanteur, P., and Piechaczyk, M. (1992) Cell targeting by murine recombinant retroviruses. Bone Marrow Transplant 9 Suppl 1, 139-142

28. De Palma, M., Venneri, M.A., and Naldini, L. (2003) In vivo targeting of tumor endothelial cells by systemic delivery of lentiviral vectors. Hum Gene Ther 14, 11931206

29. Modlich, U., Pugh, C.W., and Bicknell, R. (2000) Increasing endothelial cell specific expression by the use of heterologous hypoxic and cytokine-inducible enhancers. Gene Ther 7, 896-902

30. Mavria, G., Harrington, K.J., Marshall, C.J., and Porter, C.D. (2005) In vivo efficacy of HSV-TK transcriptionally targeted to the tumour vasculature is augmented by combination with cytotoxic chemotherapy. J Gene Med 7, 263-275

31. Yang, C.T., Lin, Y.C., Lin, C.L., Lu, J., Bu, X., Tsai, Y.H., and Jia, W.W. (2005) Oncolytic herpesvirus with secretable angiostatic proteins in the treatment of human lung cancer cells. Anticancer Res 25, 2049-2054

32. Laquerre, S., Anderson, D.B., Stolz, D.B., and Glorioso, J.C. (1998) Recombinant herpes simplex virus type 1 engineered for targeted binding to erythropoietin receptorbearing cells. J Virol 72, 9683-9697

33. Reinblatt, M., Pin, R.H., Bowers, W.J., Federoff, H.J., and Fong, Y. (2005) Herpes simplex virus amplicon delivery of a hypoxia-inducible soluble vascular endothelial growth factor receptor (sFlk-1) inhibits angiogenesis and tumor growth in pancreatic adenocarcinoma. Ann Surg Oncol $12,1025-1036$

34. Pin, R.H., Reinblatt, M., Bowers, W.J., Federoff, H.J., and Fong, Y. (2004) Herpes simplex virus amplicon delivery of a hypoxia-inducible angiogenic inhibitor blocks capillary formation in hepatocellular carcinoma. J Gastrointest Surg 8, 812-822; discussion 822-813

35. Mullen, J.T., Donahue, J.M., Chandrasekhar, S., Yoon, S.S., Liu, W., Ellis, L.M., Nakamura, H., Kasuya, H., Pawlik, T.M., and Tanabe, K.K. (2004) Oncolysis by viral replication and inhibition of angiogenesis by a replication-conditional herpes simplex virus that expresses mouse endostatin. Cancer 101, 869-877

36. Mulder, W.J., Strijkers, G.J., Habets, J.W., Bleeker, E.J., van der Schaft, D.W., Storm, G., Koning, G.A., Griffioen, A.W., and Nicolay, K. (2005) MR molecular imaging and fluorescence microscopy for identification of activated tumor endothelium using a bimodal lipidic nanoparticle. Faseb J 19, 2008-2010

37. Pattillo, C.B., Sari-Sarraf, F., Nallamothu, R., Moore, B.M., Wood, G.C., and Kiani, M.F. (2005) Targeting of the antivascular drug combretastatin to irradiated tumors results in tumor growth delay. Pharm Res 22, 11171120

38. Hynes, R. (2002) A reevaluation of integrins as regulators of angiogenesis. nature medicine 8, 918-921

39. Schiffelers, R.M., Koning, G.A., ten Hagen, T.L., Fens, M.H., Schraa, A.J., Janssen, A.P., Kok, R.J., Molema, G., and Storm, G. (2003) Anti-tumor efficacy of tumor vasculaturetargeted liposomal doxorubicin. J Control Release 91, 115-122 
40. Wiethoff, C.M., Smith, J.G., Koe, G.S., and Middaugh, C.R. (2001) The potential role of proteoglycans in cationic lipid-mediated gene delivery. Studies of the interaction of cationic lipid-DNA complexes with model glycosaminoglycans. J Biol Chem 276, 32806-32813

41. Liu, Y., Mounkes, L.C., Liggitt, H.D., Brown, C.S., Solodin, I., Heath, T.D., and Debs, R.J. (1997) Factors influencing the efficiency of cationic liposome-mediated intravenous gene delivery. Nat Biotechnol 15, 167-173

42. Hattori, Y., and Maitani, Y. (2005) Folatelinked nanoparticle-mediated suicide gene therapy in human prostate cancer and nasopharyngeal cancer with herpes simplex virus thymidine kinase. Cancer Gene Ther $12,796-809$

43. van Zanten, J., Doornbos-Van der Meer, B., Audouy, S., Kok, R.J., and de Leij, L. (2004) A nonviral carrier for targeted gene delivery to tumor cells. Cancer Gene Ther 11, 156164

44. Xu, L., Huang, C.C., Huang, W., Tang, W.H., Rait, A., Yin, Y.Z., Cruz, I., Xiang, L.M., Pirollo, K.F., and Chang, E.H. (2002) Systemic tumor-targeted gene delivery by anti-transferrin receptor scFvimmunoliposomes. Mol Cancer Ther 1, 337346

45. Dutour, A., Monteil, J., Paraf, F., Charissoux, J.L., Kaletta, C., Sauer, B., Naujoks, K., and Rigaud, M. (2005) Endostatin cDNA/cationic liposome complexes as a promising therapy to prevent lung metastases in osteosarcoma: study in a human-like rat orthotopic tumor. Mol Ther 11, 311-319

46. Eichhorn, M.E., Strieth, S., Krasnici, S., Sauer, B., Teifel, M., Michaelis, U., Naujoks, K., and Dellian, M. (2004) Protamine enhances uptake of cationic liposomes in angiogenic microvessels. Angiogenesis 7, 133-141

47. Mori, A., Arii, S., Furutani, M., Mizumoto, M., Uchida, S., Furuyama, H., Kondo, Y., Gorrin-Rivas, M.J., Furumoto, K., Kaneda, Y., and Imamura, M. (2000) Soluble Flt-1 gene therapy for peritoneal metastases using HVJ-cationic liposomes. Gene Ther 7, 1027-1033

48. Gorrin-Rivas, M.J., Arii, S., Mori, A., Kaneda, Y., and Imamura, M. (2001) Mouse macrophage metalloelastase gene delivery by HVJ-cationic liposomes in experimental antiangiogenic gene therapy for murine CT26 colon cancer. Int J Cancer 93, 731-735

49. Stuart, D.D., and Allen, T.M. (2000) A new liposomal formulation for antisense oligodeoxynucleotides with small size, high incorporation efficiency and good stability. Biochim Biophys Acta 1463, 219-229

50. Pastorino, F., Brignole, C., Marimpietri, D. Di Paolo, D., Zancolli, M., Pagnan, G., and Ponzoni, M. (2004) Targeted delivery of oncogene-selective antisense oligonucleotides in neuroectodermal tumors: therapeutic implications. Ann NY Acad Sci 1028, 90-103

51. Bartsch, M., Weeke-Klimp, A.H., Hoenselaar, E.P., Stuart, M.C., Meijer, D.K., Scherphof, G.L., and Kamps, J.A. (2004) Stabilized lipid coated lipoplexes for the delivery of antisense oligonucleotides to liver endothelial cells in vitro and in vivo. $J$ Drug Target 12, 613-621

52. Wagner, E., Zatloukal, K., Cotten, M., Kirlappos, H., Mechtler, K., Curiel, D.T., and Birnstiel, M.L. (1992) Coupling of adenovirus to transferrin-polylysine/DNA complexes greatly enhances receptor-mediated gene delivery and expression of transfected genes. Proc Natl Acad Sci U S A 89, 60996103

53. Boussif, O., Lezoualc'h, F., Zanta, M.A., Mergny, M.D., Scherman, D., Demeneix, B., and Behr, J.P. (1995) A versatile vector for gene and oligonucleotide transfer into cells in culture and in vivo: polyethylenimine. Proc Natl Acad Sci U S A 92, 7297-7301

54. Kichler, R.B., J; Erbacher,p (1999) Polyethyleniminies: a family of potent polymers for nucleic delivery. In Nonviral vectors for gene therapy (Huang, I.H., M; Wagner, E, ed), 191-206, Academic Press

55. Gautam, A., Densmore, C.L., Melton, S., Golunski, E., and Waldrep, J.C. (2002) Aerosol delivery of PEI-p53 complexes inhibits B16-F10 lung metastases through regulation of angiogenesis. Cancer Gene Ther 9, 28-36

56. Schiffelers, R.M., Ansari, A., Xu, J., Zhou, Q., Tang, Q., Storm, G., Molema, G., Lu, P.Y., Scaria, P.V., and Woodle, M.C. (2004) Cancer siRNA therapy by tumor selective delivery with ligand-targeted sterically stabilized nanoparticle. Nucleic Acids Res 32 e149

57. Pfeifer, A., and Verma, I.M. (2001) Gene therapy: promises and problems. Annu Rev Genomics Hum Genet 2, 177-211

58. Roni, V., Habeler, W., Parenti, A., Indraccolo, S., Gola, E., Tosello, V., Cortivo, R., Abatangelo, G., Chieco-Bianchi, L., and Amadori, A. (2003) Recruitment of human umbilical vein endothelial cells and human primary fibroblasts into experimental tumors growing in SCID mice. Exp Cell Res 287, 2838 
59. Ojeifo, J.O., Forough, R., Paik, S., Maciag, T., and Zwiebel, J.A. (1995) Angiogenesisdirected implantation of genetically modified endothelial cells in mice. Cancer Res 55, 2240-2244

60. Kershaw, M.H., Westwood, J.A., Zhu, Z., Witte, L., Libutti, S.K., and Hwu, P. (2000) Generation of gene-modified $T$ cells reactive against the angiogenic kinase insert domaincontaining receptor (KDR) found on tumor vasculature. Hum Gene Ther 11, 2445-2452

61. Niederman, T.M., Ghogawala, Z., Carter, B.S., Tompkins, H.S., Russell, M.M., and Mulligan, R.C. (2002) Antitumor activity of cytotoxic $\mathrm{T}$ lymphocytes engineered to target vascular endothelial growth factor receptors. Proc Natl Acad Sci U S A 99, 7009-7014

62. Davidoff, A.M., Ng, C.Y., Brown, P., Leary, M.A., Spurbeck, W.W., Zhou, J., Horwitz, E., Vanin, E.F., and Nienhuis, A.W. (2001) Bone marrow-derived cells contribute to tumor neovasculature and, when modified to express an angiogenesis inhibitor, can restrict tumor growth in mice. Clin Cancer Res 7, 2870-2879

63. De Palma, M., Venneri, M.A., Roca, C., and Naldini, L. (2003) Targeting exogenous genes to tumor angiogenesis by transplantation of genetically modified hematopoietic stem cells. Nat Med 9, 789795

64. Namba, H., Tagawa, M., Iwadate, Y., Kimura, M., Sueyoshi, K., and Sakiyama, S. (1998) Bystander effect-mediated therapy of experimental brain tumor by genetically engineered tumor cells. Hum Gene Ther 9, 5-11

65. Pereboeva, L., and Curiel, D.T. (2004) Cellular vehicles for cancer gene therapy: current status and future potential. BioDrugs $18,361-385$

66. Tepper, O.M., Sealove, B.A., Murayama, T., and Asahara, T. (2003) Newly emerging concepts in blood vessel growth: recent discovery of endothelial progenitor cells and their function in tissue regeneration. J Investig Med 51, 353-359

67. Rafii, S., and Lyden, D. (2003) Therapeutic stem and progenitor cell transplantation for organ vascularization and regeneration. Nat Med 9, 702-712

68. Ferrari, N., Glod, J., Lee, J., Kobiler, D., and Fine, H.A. (2003) Bone marrow-derived, endothelial progenitor-like cells as angiogenesis-selective gene-targeting vectors. Gene Ther 10, 647-656
69. Marshall, J. (2005) The role of bevacizumab as first-line therapy for colon cancer. Semin Oncol 32, S43-47

70. Brannon-Peppas, L., and Blanchette, J.O. (2004) Nanoparticle and targeted systems for cancer therapy. Adv Drug Deliv Rev 56, 1649-1659

71. Abou-Jawde, R., Choueiri, T., Alemany, C., and Mekhail, T. (2003) An overview of targeted treatments in cancer. Clin Ther 25, 2121-2137

72. Folkman, J. (2002) Role of angiogenesis in tumor growth and metastasis. Semin Oncol 29, 15-18

73. Cherrington, J.M., Strawn, L.M., and Shawver, L.K. (2000) New paradigms for the treatment of cancer: the role of antiangiogenesis agents. Adv Cancer Res 79, 138

74. Brock, C.S., and Lee, S.M. (2002) Antiangiogenic strategies and vascular targeting in the treatment of lung cancer. Eur Respir $]$ $19,557-570$

75. St Croix, B., Rago, C., Velculescu, V., Traverso, G., Romans, K.E., Montgomery, E., Lal, A., Riggins, G.J., Lengauer, C., Vogelstein, B., and Kinzler, K.W. (2000) Genes expressed in human tumor endothelium. Science 289, 1197-1202

76. Burrows, F.J., and Thorpe, P.E. (1993) Eradication of large solid tumors in mice with an immunotoxin directed against tumor vasculature. Proc Natl Acad Sci U S A 90, 8996-9000

77. Smith, A.E. (1995) Viral vectors in gene therapy. Annu Rev Microbiol 49, 807-838

78. Harris, J.D., and Lemoine, N.R. (1996) Strategies for targeted gene therapy. Trends Genet 12, 400-405

79. Mondor, I., Ugolini, S., and Sattentau, Q.J. (1998) Human immunodeficiency virus type 1 attachment to HeLa CD4 cells is CD4 independent and gp120 dependent and requires cell surface heparans. J Virol 72, 3623-3634

80. Lin, X. (1998) Construction of new retroviral producer cells from adenoviral and retroviral vectors. Gene Ther 5, 1251-1258

81. Krisky, D.M., Wolfe, D., Goins, W.F., Marconi, P.C., Ramakrishnan, R., Mata, M., Rouse, R.J., Fink, D.J., and Glorioso, J.C. (1998) Deletion of multiple immediate-early genes from herpes simplex virus reduces cytotoxicity and permits long-term gene expression in neurons. Gene Ther 5, 15931603

82. Spear, S. (1997) Structural biology of viruses. In Structural Biology of Viruses 
(Wah Chiu, R.M.B., Robert Garcea, ed), 312-351, Oxford University Press, USA

83. Williams, R.K., and Straus, S.E. (1997) Specificity and affinity of binding of herpes simplex virus type 2 glycoprotein $B$ to glycosaminoglycans. J Virol 71, 1375-1380

84. Boviatsis, E.J., Scharf, J.M., Chase, M., Harrington, K., Kowall, N.W., Breakefield, X.O., and Chiocca, E.A. (1994) Antitumor activity and reporter gene transfer into rat brain neoplasms inoculated with herpes simplex virus vectors defective in thymidine kinase or ribonucleotide reductase. Gene Ther 1, 323-331

85. Pollard, H., Toumaniantz, G., Amos, J.L., Avet-Loiseau, H., Guihard, G., Behr, J.P., and Escande, D. (2001) Ca2+-sensitive cytosolic nucleases prevent efficient delivery to the nucleus of injected plasmids. J Gene Med 3, 153-164

86. Pollard, H., Remy, J.S., Loussouarn, G., Demolombe, S., Behr, J.P., and Escande, D. (1998) Polyethylenimine but not cationic lipids promotes transgene delivery to the nucleus in mammalian cells. $\mathrm{J}$ Biol Chem 273, 7507-7511

87. Allen, T.M., and Hansen, C. (1991) Pharmacokinetics of stealth versus conventional liposomes: effect of dose. Biochim Biophys Acta 1068, 133-141

88. Ziady, A.G., Davis, P.B., and Konstan, M.W. (2003) Non-viral gene transfer therapy for cystic fibrosis. Expert Opin Biol Ther 3, 449458

89. Mahato, R.I., Kawabata, K., Takakura, Y., and Hashida, M. (1995) In vivo disposition characteristics of plasmid DNA complexed with cationic liposomes. J Drug Target 3, 149-157

90. Vile, R.G., Tuszynski, A., and Castleden, S. (1996) Retroviral vectors. From laboratory tools to molecular medicine. Mol Biotechnol 5, 139-158

91. Burton, E.A., Fink, D.J., and Glorioso, J.C. (2002) Gene delivery using herpes simplex virus vectors. DNA Cell Biol 21, 915-936

92. Dass, C.R. (2004) Lipoplex-mediated delivery of nucleic acids: factors affecting in vivo transfection. J Mol Med 82, 579-591 


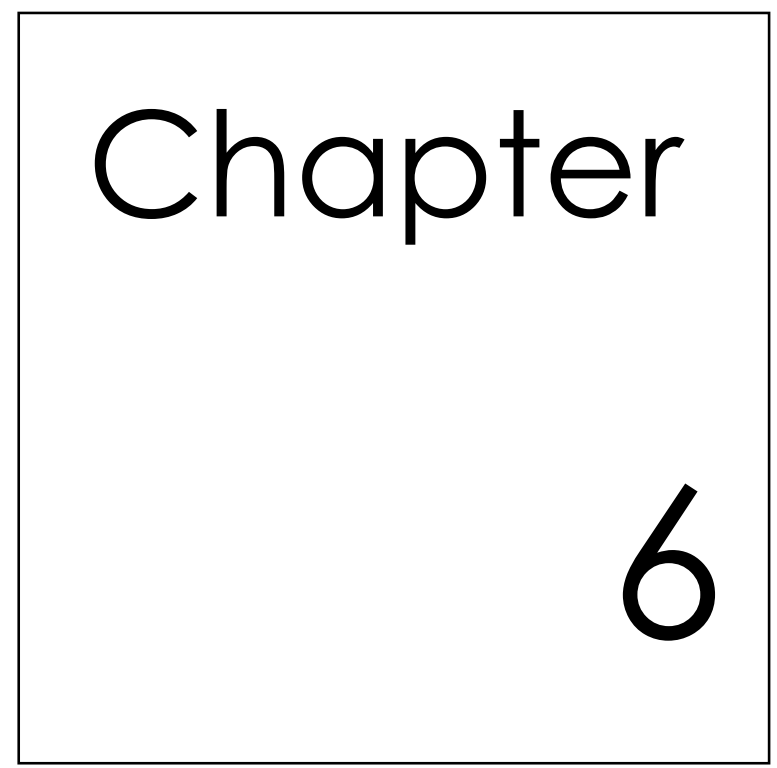

\section{Anginex conjugated liposomes for targeting of angiogenic endothelial cells}

Ricardo J.M.G.E. Brandwijk, Willem J.M. Mulder, Klaas Nicolay, Kevin H. Mayo, Victor L.J.L. Thijssen, Arjan W. Griffioen 


\section{Abstract}

Identification of a tumor angiogenesis specific ligand would allow targeting of tumor vasculature. Lipidic vehicles can be used to deliver therapeutic agents for treatment of disease or contrast agents for molecular imaging. A targeting ligand would allow specific delivery of such formulations to angiogenic sites, thereby reducing side effects and gaining efficiency. Anginex, a synthetic 33-mer angiostatic peptide, has been described to home angiogenically activated endothelium, suggesting being an ideal candidate as targeting ligand. To investigate this application of anginex, fluorescently labeled paramagnetic liposomes were conjugated with anginex. Using phase contrast and fluorescence microscopy as well as magnetic resonance imaging (MRI), we demonstrate that anginex conjugated liposomes bind specifically to activated endothelial cells, suggesting application as angiogenesis targeting agent for molecular targeting and molecular imaging of angiogenesis dependent disease. 


\section{Introduction}

Lipid based vesicles, such as liposomes, can be used as therapeutic vehicle to transport e.g. drugs, DNA, proteins/peptides and antibodies ${ }^{1,2}$ or for diagnostic purposes like the delivery of MRI contrast agents ${ }^{3}$. However, liposomes have a relative short circulation time because they are taken up by the mononuclear phagocyte system (MPS) ${ }^{4-6}$. In order to increase their circulation time, hydrophilic carbohydrates or polymers (e.g. PEG) can be included in the lipidic formulation which prevents rapid clearance and uptake by MPS ${ }^{7}$. Moreover, the use of pegylated lipids with distal functional moieties like maleimide allows the conjugation of targeting ligands to the liposomes. Targeted liposomes enhance the specificity and efficiency of treatment which may result in a higher therapeutic success rate and in reduction of undesirable side effects ${ }^{8}$. An important requirement for successful targeted delivery is the specificity of the ligand/receptor pair for the site of interest. For example, we have previously demonstrated that a RGD-peptide functions as a targeting ligand for integrin av $\beta 3$ which can be used to target liposomes specifically to angiogenically activated endothelial cells ${ }^{9}$.

Angiogenesis, i.e. the outgrowth of new vessels from pre-existing vasculature, is a prerequisite for tumor growth and metastasis ${ }^{10,11}$. The tumors' dependence on this process, together with the observation that the endothelial cells that mediate the vessel growth, change the expression of specific cell surface related molecules 12, makes tumor angiogenesis receptive for targeted treatment strategies. We have previously described the (33-mer) synthetic angiostatic peptide anginex that inhibits migration and proliferation of activated EC in vitro ${ }^{13,14}$ and exerts a strong anti-tumor response in vivo without affecting physiological angiogenesis ${ }^{15}$. It has been demonstrated that fluorescently labeled anginex specifically homes to tumor vasculature ${ }^{15,16}$. Recently, we identified galectin- 1 as the main receptor of anginex on activated endothelial cells ${ }^{17}$.

In the clinical oncology field there is a need for targeting ligands that allow more specific therapy and can be used for non-invasive imaging techniques ${ }^{18}$. Using tumor angiogenesis markers for targeting, non-invasive imaging would allow more accurate diagnosis, monitoring of angiogenic development and the effect of angiostatic treatment ${ }^{19,20}$. Based on our observations we hypothesized that anginex is an excellent ligand for targeting of therapeutic or diagnostic liposomes to activated endothelial cells in the tumor vasculature. To test this hypothesis, we conjugated anginex to fluorescently labeled and paramagnetic liposomes. The endothelial cell specificity of the anginex-liposomes was confirmed on human umbilical vein endothelial cells (HUVEC) and an immortalized endothelial cell line (EVL-C2). In addition, we were able to demonstrate by microscopic analysis and by MR imaging, that anginex conjugated liposomes specifically bind to and are taken 
up by activated endothelial cells, making them attractive vehicles for targeted delivery or diagnostic use in the treatment of disease.

\title{
Materials and methods
}

\begin{abstract}
Materials
1,2-Distearoyl-sn-glycero-3-phosphocholine (DSPC), cholesterol (Chol), 1,2distearoyl-snglycero-3-phosphoethanolamine-N-[methoxy(polyethylene glycol)2000] (PEG2000-DSPE), 1,2-distearoyl-sn-glycero-3-phosphoethanolamine-N[maleimide(polyethylene glycol)2000] (Mal-PEG2000-DSPE), and 1,2-dipalmitoylsn-glycero-3-phosphoethanolamine- $\mathrm{N}$-(lissamine rhodamine $\mathrm{B}$ sulfonyl) (rhodamine-PE) were obtained from Avanti Polar Lipids (Albaster, AL). Gd-DTPAbis(stearylamide) (Gd-DTPA-BSA) was purchased from Gateway Chemical Technology (St.Louis, MO). HEPES was obtained from Merck (Darmstadt, Germany). All other chemicals were of analytic grade or the best grade available. Polycarbonate filters for liposome extrusion were from Costar (Cambridge, MA).
\end{abstract}

\section{Peptide synthesis}

Anginex with an additional cysteine at the $\mathrm{N}$-terminal site was synthesized using a Milligen/Biosearch 9600 peptide solid-phase synthesizer using Fmoc chemistry. Lyophilized peptides were purified by preparative reversed-phase HPLC on a C18 column with an elution gradient of $0-60 \%(\mathrm{v} / \mathrm{v})$ acetonitrile with $0.1 \%(\mathrm{v} / \mathrm{v})$ trifluoroacetic acid in water. Purity and composition of the peptides were verified by HPLC (Beckman Model 6300) analysis of amino acid composition of hydrolysates prepared by treating the peptides under argon in $6 \mathrm{~N} \mathrm{HCl}$ for 24 hours at $110^{\circ} \mathrm{C}$. The amino acid sequences of peptides were confirmed by $\mathrm{N}$-terminal sequencing and mass spectometry. As described before, the cyclic 5-mer RGD peptide (c(RGDf(-Sacetylthioacetyl)K)) was synthesized at a purity of $95 \%$ by Ansynth Service BV ${ }^{9}$.

\section{Liposome preparation}

Liposomes were prepared by lipid film hydration. A mixture of the appropriate amounts of lipids (typically 100-200 $\mu \mathrm{mol}$ of total lipid) was dissolved in chloroform/methanol $1: 1(\mathrm{v} / \mathrm{v})$ and evaporated to dryness by rotary evaporation at $40^{\circ} \mathrm{C}$. For the paramagnetic PEG liposomes that were used to couple RGD or anginex peptides covalently to the distal end of the PEG chains, Gd-BSA, DSPC, cholesterol, PEG2000-DSPE, and Mal-PEG2000-DSPE were mixed at a molar ratio of $0.75 / 1.10 / 1 / 0.075 / 0.075$. For fluorescence microscopy, $0.1 \mathrm{~mol}$ percent of rhodamine-PE was added. The lipid film was subsequently hydrated in $3 \mathrm{ml}$ of HEPES-buffered saline (HBS), containing $20 \mathrm{mM}$ HEPES and $135 \mathrm{mM} \mathrm{NaCl}(\mathrm{pH} \mathrm{6.5)}$. The resulting lipid dispersion was extruded sequentially 6 times through 
polycarbonate membrane filters with a pore diameter of $400 \mathrm{~nm}$ and subsequently 10 times through filters with a pore diameter of $200 \mathrm{~nm}$ using a Lipofast Extruder (Avestin, Canada). The temperature during extrusion was $65^{\circ} \mathrm{C}$.

\section{Peptide coupling to liposomes}

The cyclic 5mer RGD (c(RGDf(-S-acetylthioacetyl)K)) and anginex were conjugated to the liposomes by sulfhydryl-maleimide couplingmaleimide-PEG-DSPE. Acetylprotected RGD-peptide was deacetylated in 0.05 M HEPES/0.05 M hydroxylamine$\mathrm{HCl} / 0.03 \mathrm{mM}$ ethylenediamine tetraacetic acid $(\mathrm{pH} 7.0)$ for 1 hour at room temperature ${ }^{21}$. The activated peptide was added to the Mal-PEG2000-DSPEcontaining liposomes in a $3 \mu \mathrm{g}$ peptide / $\mu \mathrm{mol}$ lipid ratio. Anginex, synthesized with a C-terminal cysteine, was dissolved in water and added to the liposomal solution (10 $\mathrm{\mu g}$ peptide $/ 1 \mu \mathrm{mol}$ lipid ). Coupling of both peptides was allowed overnight at $4^{\circ} \mathrm{C}$ and uncoupled peptide was separated from the liposomes by centrifugating at $200,000 \times g$ with a Beckman OptimaTM LE-80K ultracentrifuge and a Ti70 fixed angle rotor for 60 minutes. The liposomes were respectively conjugated with $\sim 700$ cyclic RGD moieties and $\sim 125$ anginex moieties per particle. The supernatant was removed and an appropriate amount of buffer, typically $1.5 \mathrm{ml}$, was added to the pellet to obtain a lipid suspension with a lipid concentration of $\sim 40 \mathrm{mM}(10 \mathrm{mM}$ gadolinium). The final liposomal suspension was stored at $4{ }^{\circ} \mathrm{C}$ under $\mathrm{N}_{2}$.

\section{Cell culture}

HUVECs were isolated as described before ${ }^{22}$. Isolated cells were cultured in gelatin coated culture flasks (Costar) with RPMI1640 (Gibco) supplemented with 20\% human serum, $2 \mathrm{mM}$ L-glutamine (Gibco) and $50 \mathrm{U} / \mathrm{ml}$ penicillin/streptomycin (Life sciences). Immortalized endothelial cell line EVL-C2 ${ }^{23}$ was cultured under the same culture conditions as HUVEC. Cultures were incubated at $37^{\circ} \mathrm{C}$ in the presence of $5 \% \mathrm{CO}_{2}$.

In vitro targeting of endothelial cells

For all tested applications the initial steps were similar. Endothelial cells were cultured in gelatin coated flasks to approximately $75 \%$ confluency (appoximately 1.5* $10^{6}$ cells) using standard culture conditions. Flasks were washed once with PBS before $4 \mathrm{ml}$ fresh culture medium was added. Anginex-conjugated, RGDconjugated and non-conjugated liposomes (150 $\mu$ liposomes; total amount anginex $60 \mu \mathrm{g}$ ) were added to the cells and incubated in the $\mathrm{CO}_{2}$ - incubator at $37^{\circ} \mathrm{C}$ for 3 hours. Subsequently, liposome containing medium was removed and the cells were washed with $14 \mathrm{ml}$ PBS and fresh medium was added. Final wash step was skipped for the control cells. Finally, the association of the targeted and non-targeted liposomes with endothelial cells was assessed under a phase contrast fluorescence microscoop (Leica), at 20 and 40 times magnification. Experiments were carried out 
in triplo. Competition experiments were performed with free anginex. To that end, anginex $(3 \mathrm{mg} / \mathrm{ml}$ in $\mathrm{MQ})$ was added to the medium to a final concentration of respectively 10 or $30 \mu \mathrm{g} / \mathrm{ml}$ (total anginex concentration respectively 60 and 180 $\mu \mathrm{g}$ ) immediately before addition of the liposome solution.

\section{Magnetic Resonance Imaging of cell pellets}

For MRI imaging, cells were harvested using trypsine digestion and centrifuged for 5 minutes at $400 \mathrm{~g}$. The obtained cell pellet was washed with approximately $5 \mathrm{ml}$ culture medium. After a second centrifugation step, the cell pellet was fixed with $1 \%$ paraformaldehyde and put in small $200 \mu \mathrm{l}$ tubes. MRI experiments were performed on fixed cell pellets using a 6.3 Tesla horizontal bore magnet (Oxford Instruments Superconductivity, Eynsham, Oxon, England) interfaced to a Varian (Varian, Palo Alto, CA) VXR-S MRI console. A $3 \mathrm{~cm}$ quadrature-driven birdcage coil was used. The cups containing cell pellets were placed in a custom-made sample holder, capable of carrying four Eppendorf cups. Quantification of $T 1$ was done with an inversion recovery spin-echo sequence with 13 different inversion times, ranging from $10 \mathrm{~ms}$ to $3100 \mathrm{~ms}$ in an exponential fashion. The MRI data analysis was performed using Mathematica 5.0 (Wolfram Research, Inc., Champaign, IL). T1 maps of HUVEC pellets were calculated in one slice through the pellet on a pixel-bypixel basis. The $T 1$ is reported as mean \pm SD of the pixels in a circular region of interest (ROI) defined by the contour of the pellet. Student's $t$ tests. $P<0.05$ was considered statistically significant.

\section{Results}

We set out to test the applicability of anginex as a ligand to target liposomes to activated endothelial cells. To that end, fluorescent paramagnetic liposomes were prepared to allow parallel detection of the liposomes with optical methods as well as with MR imaging. Targeting specificity was introduced by covalently linking anginex containing a free cysteine via the thiol group to the maleimide group of the lipid MAL-PEG-DSPE ${ }^{24}$. As control, cyclic RGD was coupled as described previously ${ }^{9}$. A schematic presentation of the ligand-conjugated liposomes is given in Figure 1.

To demonstrate specific binding to endothelial cells, cultured human umbilical vein endothelial cells (HUVEC) were incubated for 3 hours with either anginexconjugated liposomes or with bare liposomes. After liposome incubation and extensive washing, phase contrast microscopy revealed that only anginexconjugated liposomes efficiently bound to the cell surface (data not shown). RGD conjugated liposomes, used as a positive control, also bound the endothelial monolayer. Using fluorescence microscopy, the liposomes were visualized and were found to bind throughout the endothelial surface (Figure 2a, left and middle panel). Cells incubated with bare liposomes did marginally or not show fluorescence signal 


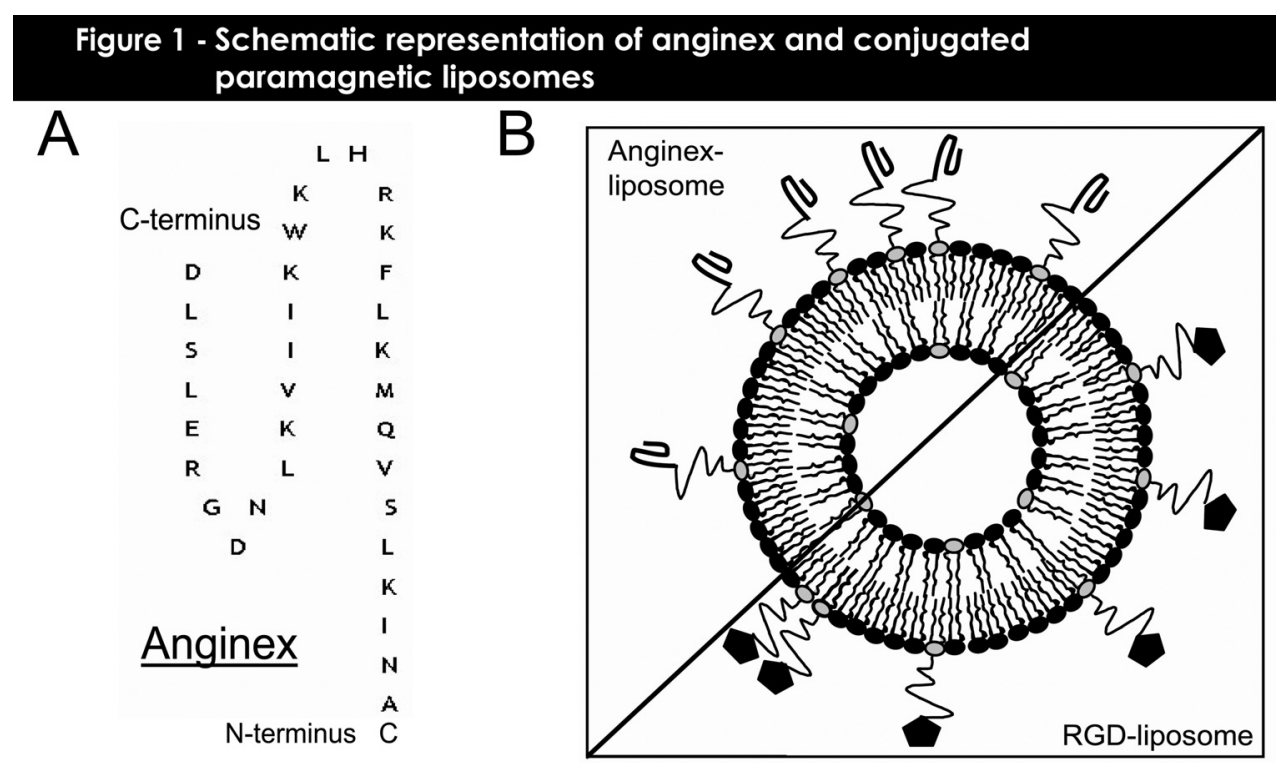

Figure 1 - Schematic representation of anginex and conjugated paramagnetic liposomes Schematic representation of (A) anginex and (B) paramagnetic liposomes conjugated to the peptides anginex and cyclic-RGD respectively. The black lipids represent Gd-DTPA-BSA and the grey lipids PEG-DSPE. Peptides are covalently conjugated to the maleimide group of MAL-PEGDSPE.

(Figure 2a, right panel). Although small differences in morphology were visible between the three independent experiments due to different passage numbers, the binding or presence of the liposomes did not induce obvious changes in EC morphology or signs of apoptosis. At higher magnification, internalization of part of the conjugated liposomes was visible in vesicles (Figure $2 \mathrm{~b}$, middle panel). Addition of the nuclear stain 4,6-diamidino-2-phenylindole (DAPI), demonstrated that the liposomes did not enter the nucleus. Similar results were obtained with the RGDliposomes (data not shown).

To demonstrate that the interaction of the anginex-liposomes with the HUVEC was mediated through anginex, a competition assay with free anginex was performed by adding anginex prior to incubation with the anginex-liposomes. There was a clear concentration dependent inhibition of anginex-liposome binding following addition of free anginex (Figure 2c). At a concentration of $10 \mu \mathrm{g} / \mathrm{ml}$ reduced fluorescence signal from the anginex-liposomes was observed as compared to the situation in which no free anginex was added to HUVEC (Figure 2c, middle panel). In case the cells were pre-incubated with $30 \mu \mathrm{g} / \mathrm{ml}$ anginex almost no association of anginex-liposomes with HUVEC was observed (Figure 2c, right 


\section{Figure 2 - Fluorescence microscopy of HUVEC incubated with fluorescently} labeled paramagnetic liposomes

A

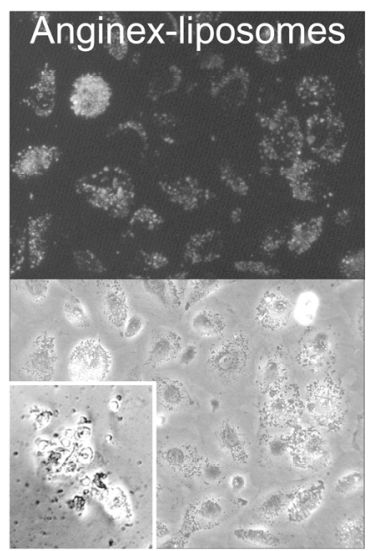

B

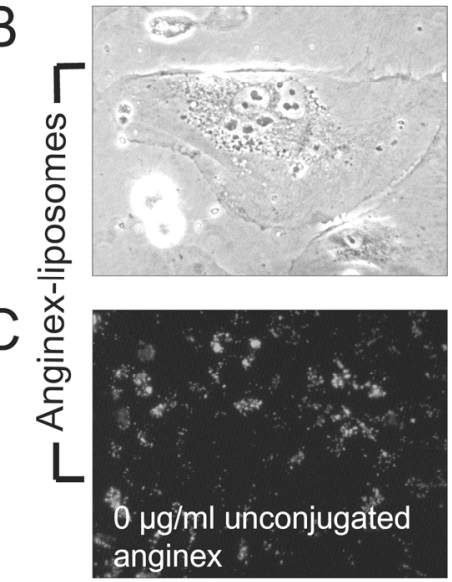

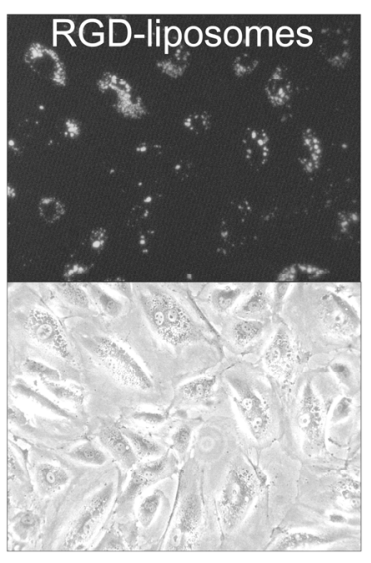
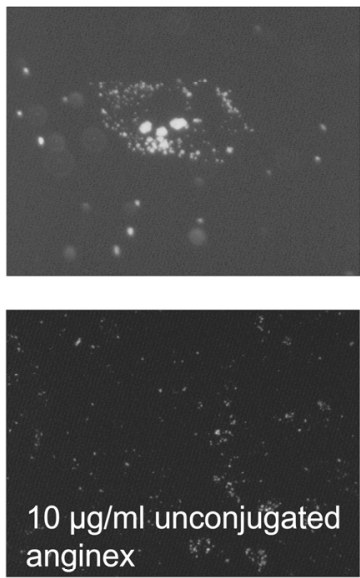
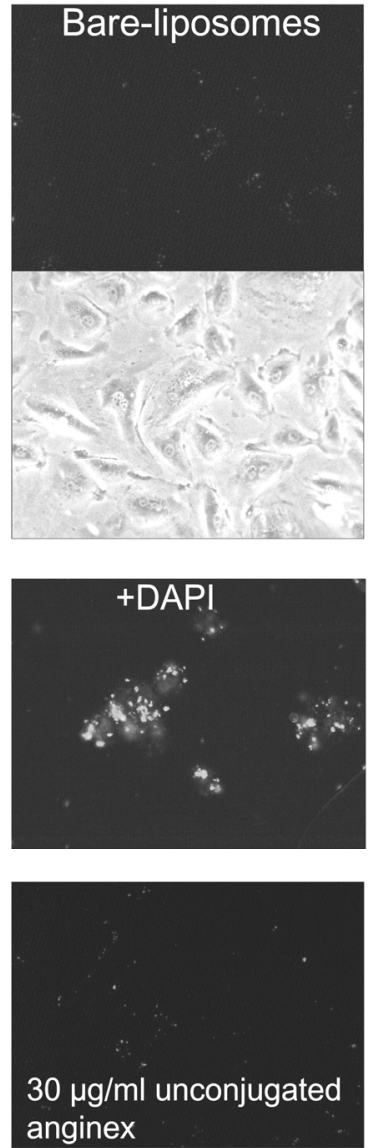

Figure 2 - Fluorescence microscopy of HUVEC incubated with fluorescently labeled paramagnetic liposomes

Pictures are representative for all experiments. (A) HUVEC were incubated for 3 hours with respectively anginex, RGD and non-targeted liposomes. Insert: HUVEC undergoing apoptosis as a result of anginex treatment (B) Perinuclear localization of anginex-liposomes in one HUVEC cell shown by phase contrast and fluorescence image. Anginex-liposomes do not enter the nucleus as shown by blue DAPI counter staining. (C) Competition of anginex-liposomes with respectively 0,10 , $30 \mu \mathrm{g} / \mathrm{ml}$ free anginex. 
panel). Comparable results were obtained with the endothelial cell line EVL-c2 (data not shown).

To test the applicability of anginex targeted contrast agents, magnetic resonance imaging was applied to HUVEC incubated with paramagnetic conjugated liposomes. After 3 hours of incubation with either anginex, RGD or bare liposomes, HUVEC were washed twice and pelleted in small cups. As control non-treated cells were used. Visible inspection of the pelleted cells revealed an intense pink color in only anginex- and RGD-liposome treated cells. Before imaging, all cells were fixed with $1 \%$ paraformaldehyde. MR imaging was performed on approximately $1.5 \times 10^{6}$ cells (Figure 3a). A quantitative T1-map, in which cells with a high concentration of contrast liposomes have a lower $T 1$ than cells with a low concentration of contrast liposomes, was made of the various cell pellets. The $T 1$-values of cell pellets that were incubated with anginex and RGD-liposomes had comparable values, which was significantly lower than the controls (Figure $3 \mathrm{~b}$ ). The $T 1$ of the anginex pellet was $862 \pm 41 \mathrm{~ms}$ and for RGD $1287 \pm 33 \mathrm{~ms}$, whereas control HUVEC and nonligand liposomes were respectively $2363 \pm 88 \mathrm{~ms}$ and $1766 \pm 30 \mathrm{~ms}$. These data show that the level of association of the anginex-liposomes, like the control RGDliposomes, is sufficient to be detected by MRI.

\section{Figure 3 - T1 weighed image of cells incubated with anginex, bare liposomes} or without liposomes

\begin{tabular}{|c|c|c|c|}
\hline Control & $2.5 \mathrm{~s}$ & $\begin{array}{l}\text { HUVEC } \\
\text { incubated with } \\
(\mathrm{n}=2)\end{array}$ & $T_{1}(\mathrm{~ms})$ \\
\hline Bare & & Control & $2363 \pm 88$ \\
\hline & & Bare liposomes & $1766 \pm 30$ \\
\hline & & RGD-liposomes & $1287 \pm 33$ \\
\hline & 0 & $\begin{array}{l}\text { Anginex- } \\
\text { liposomes }\end{array}$ & $862 \pm 41$ \\
\hline
\end{tabular}

Figure 3 - Tl weighed image of cells incubated with anginex, bare liposomes or without liposomes The $T 1$ relaxation times of the different cell pellets are presented on the right. 


\section{Discussion}

We hypothesized that anginex is an excellent ligand for targeted delivery of lipidic vehicles with therapeutic and/or contrast agents to activated endothelial cells in the tumor vasculature. In this study, we demonstrate that anginex can be conjugated to liposomes and these conjugated liposomes indeed target to activated endothelial cells. Furthermore, we show that anginex targeted paramagnetic liposomes can be used for MR imaging of activated endothelial cells in vitro.

To develop improved and new anti-tumor therapies, specific targets are needed to deliver drugs or contrast agents for imaging to the tumor without introducing of toxic side effects or background signals. Tumor angiogenesis is a very suitable process for targeting, because tumor growth and metastasis are dependent on angiogenesis. Furthermore, activated endothelial cell, which are the key players in this process, have a unique expression profile, are easy accessible and less prone to develop resistance against treatment. We previously described anginex, a de novo designed small 33 amino acid angiostatic peptide, which is capable of inhibition of angiogenic endothelial cell migration and proliferation subsequently leading to apoptosis. Additionally, anginex was shown to home specifically to tumor vasculature in a mouse model. To confirm the targeting qualities of anginex, we coupled the peptide covalently to maleimide moieties exposed at the distal end of PEG-chains of liposomes. The applicability of these contrast enhancing paramagnetic liposomes has already been demonstrated for the use of molecular MR imaging of endothelial cells in vitro using an E-selectin specific antibody and in vivo by using cyclic RGD-peptide as targeting unit ${ }^{9}{ }^{24}$. Similar as for RGD, we observed binding of anginex-liposomes to activated endothelial cells in vitro. Conjugated liposomes seemed to bind to all available endothelial cells, whereas using unconjugated liposomes hardly any binding was observed. This indicates a specific binding of the liposomes due to conjugation of the ligand, supporting the hypothesis of the applicability of anginex as a potent targeting ligand. Apparently, adding an additional cysteine to the $\mathrm{N}$-terminus of anginex and linking it to a lipidic vehicle does not affect the binding of anginex to its receptor. This was expected since recombinant anginex, which has an extra $\mathrm{N}$-terminal methionine is also fully active and retains the required $\beta$-sheet structure ${ }^{25}$. Furthermore, addition of human serum albumin has also no influence on the in vitro activity of anginex ${ }^{26}$. This is most likely due to the fact that the $\mathrm{N}$-terminus is flexible and that the $\mathrm{N}$ terminal amino acids are not required for the function of anginex ${ }^{14,27}$.

An important prerequisite for targeting is the presence of a site-specific interaction molecule for the targeting ligand. For the RGD-liposomes this is the av $\beta 3$-integrin receptor ${ }^{28}$. We recently identified galectin-1 as the main tumor endothelial cell specific receptor for anginex ${ }^{17}$. Galectin-1 expression is rapidly upregulated upon endothelial cell activation and expression levels have been shown 
to be increased in the vasculature of different human tumors $17,29,30$. This renders anginex/galectin-1 an excellent pair for targeting of liposomes to tumor vessels, which makes it an attractive target that can be used for diagnostic purposes in imaging.

Fluorescence microscopy revealed that a substantial part of the anginexconjugated liposomes is internalized into the cell in perinuclear vesicles. This is consistent with galectin-1 mediated uptake of free anginex ${ }^{17}$. This was confirmed in our competition experiment where increasing amounts of free anginex were able to inhibit binding and internalization of anginex-liposomes, indicating an anginex dependent binding of the anginex-liposomes to HUVEC. The concentrations of free anginex in the competition experiments were based on the concentration needed to reach maximum therapeutic effect $(40 \mu \mathrm{g} / \mathrm{ml})^{13}$. Considering that not all anginex molecules conjugated to the liposomes will be available for binding to the cell, we expected that the used concentrations would be sufficient to attain partial or complete blocking of anginex-liposome binding. Ultimate proof for receptormediated uptake of the anginex-liposomes would be obtained in galectin-1 knockout endothelial cells. Indeed, tumors in galectin-1 knockout mice no longer respond to anginex treatment, suggesting that the binding of the anginexliposomes to HUVEC is anginex and galectin-1 dependent.

To evaluate if anginex is also suitable as targeting ligand for MRI contrast agents, a quantitative T1-measurement was made of HUVEC pellets incubated with anginex conjugated paramagnetic liposomes. As a positive control RGD-liposomes were used ${ }^{9}$ and as negative control bare paramagnetic liposomes or no liposomes were applied. Both conjugated paramagnetic liposomes were shown to bind specifically to endothelial cells. Furthermore, a clear difference in contrast was seen between ligand conjugated liposomes and the controls leading to a significant difference in $T 1$ values. The fact that the conjugated liposomes were internalized might also be a benefit for imaging. By internalizing the contrast agent, the concentration per cell can be elevated revealing a brighter signal ${ }^{31}$.

Besides diagnostic applications, anginex targeted liposomes might be used as drug carrier. Therefore, water soluble drugs (e.g. doxorubicin) or even DNA constructs for gene therapy can be put inside the liposomal lumen 32,33 . Thus, anginex mediated targeting to tumor vasculature might be used to combine diagnosis and local therapy of cancer. However, for imaging, stabilization of liposomes is useful with drug delivery because the stability causes a slow release of the drugs. Another problem is the measurement of the amount of drugs released in the tissue. This can be solved by combining the drug and the contrast agent instead of loading drugs into liposomes with contrast enhancing components in their bilayer 34,35 . Nevertheless, preliminary data with contrast enhancing liposomes loaded with doxorubicin show promising results in vivo (Unpublished data). 
Anginex is a potent angiostatic agent and one of the main angiostatic characteristics of anginex is induction of apoptosis in activated EC. Although this might interfere with targeting, we have demonstrated that the induction of apoptosis by anginex occurs more than 48 hours after administration ${ }^{13}$. This is far beyond the time-frame of targeting, suggesting that the induction of apoptosis will not affect targeting. This is supported by the fact that other vascular targeting ligands, like RGD-peptides, also induce endothelial cell apoptosis 36-38 without affecting their applicability as a targeting ligand ${ }^{39,40}$.

Similar as for apoptosis, the time frame of the experiments in this study did not allow us to investigate the effects of conjugated anginex on migration and proliferation ${ }^{41}$. However, for imaging purposes, a possible effect will not influence the targeting ability and its function as a contrast agent.

In conclusion, we have demonstrated that the angiostatic peptide anginex is a potent ligand for the targeting of liposomes to activated endothelial cells. In addition, the in vitro results show a high specificity of the anginex conjugated paramagnetic liposomes for endothelial cells that was confirmed by MRI. Therefore, anginex might serve as a targeting ligand for drug and gene therapy applications and for imaging of tumor vasculature in order to diagnose, treat, and monitor cancer. 


\section{References}

1. Brandwijk, R.J.M.G.E., Grifiioen, A.W., Thijssen, V.L.J.L. Targeted gene delivery strategies for angiostatic cancer treatment. In preparation

2. Koning, G.A., Schiffelers, R.M., and Storm, G. (2002) Endothelial cells at inflammatory sites as target for therapeutic intervention. Endothelium 9, 161-171

3. Torchilin, V.P. (2005) Recent advances with liposomes as pharmaceutical carriers. Nat Rev Drug Discov 4, 145-160

4. Lasic, D. Liposomes: from physics to applications. Book

5. Papahadjopoulos, D., and Gabizon, A. (1990) Liposomes designed to avoid the reticuloendothelial system. Prog Clin Biol Res 343, 85-93

6. Allen, T.M. (1994) The use of glycolipids and hydrophilic polymers in avoiding rapid uptake of liposomes by the mononuclear phagocyte system

advanced drug delivery reviews 13, 285-309

7. Allen, T.M., and Hansen, C. (1991) Pharmacokinetics of stealth versus conventional liposomes: effect of dose. Biochim Biophys Acta 1068, 133-141

8. Backer, M.V., Aloise, R., Przekop, K., Stoletov, K., and Backer, J.M. (2002) Molecular vehicles for targeted drug delivery. Bioconjug Chem 13, 462-467

9. Mulder, W.J., Strijkers, G.J., Habets, J.W., Bleeker, E.J., van der Schaft, D.W., Storm, G., Koning, G.A., Griffioen, A.W., and Nicolay, K. (2005) MR molecular imaging and fluorescence microscopy for identification of activated tumor endothelium using a bimodal lipidic nanoparticle. Faseb J 19, 2008-2010

10. Folkman, J. (1995) Angiogenesis in cancer, vascular, rheumatoid and other disease. Nat Med 1, 27-31

11. Molema, G., and Griffioen, A.W. (1998) Rocking the foundations of solid tumor growth by attacking the tumor's blood supply. Immunol Today 19, 392-394

12. Bergers, G., and Benjamin, L.E. (2003) Tumorigenesis and the angiogenic switch. Nat Rev Cancer 3, 401-410

13. Griffioen, A.W., van der Schaft, D.W., Barendsz-Janson, A.F., Cox, A., Struijker Boudier, H.A., Hillen, H.F., and Mayo, K.H. (2001) Anginex, a designed peptide that inhibits angiogenesis. Biochem J 354, 233242

14. Dings, R.P., Arroyo, M.M., Lockwood, N.A., van Eijk, L.I., Haseman, J.R., Griffioen,
A.W., and Mayo, K.H. (2003) Beta-sheet is the bioactive conformation of the antiangiogenic anginex peptide. Biochem $\mathrm{J} 373$, 281-288

15. van der Schaft, D.W., Dings, R.P., de Lussanet, Q.G., van Eijk, L.I., Nap, A.W., Beets-Tan, R.G., Bouma-Ter Steege, J.C., Wagstaff, J., Mayo, K.H., and Griffioen, A.W. (2002) The designer anti-angiogenic peptide anginex targets tumor endothelial cells and inhibits tumor growth in animal models. Faseb J 16, 1991-1993

16. Akerman, M.E., Pilch, J., Peters, D., and Ruoslahti, E. (2005) Angiostatic peptides use plasma fibronectin to home to angiogenic vasculature. Proc Natl Acad Sci U $S$ A 102, 2040-2045

17. Thijssen, V.L., Postel, R., Brandwijk, R. J., Dings, R. P., Nesmelova, I., Satijn, S. A., Verhofstad, N., Nakabeppu, Y., Baum, L. G., Bakkers, J., Mayo, K. H., Poirier, F., and Griffioen, A. W. (2006) Galectin-1 is essential in angiogenesis and is a target for anti-angiogenesis therapy.

Proc.Natl.Acad.Sci.USA, In press., 2006

18. McDonald, D.M., and Choyke, P.L. (2003) Imaging of angiogenesis: from microscope to clinic. Nat Med 9, 713-725

19. moseley, M. (2004) Multimodality Imaging: Introduction. Stroke 35, 2632-2634

20. Doubrovin, M., Serganova, I., MayerKuckuk, P., Ponomarev, V., and Blasberg, R.G. (2004) Multimodality in vivo moleculargenetic imaging. Bioconjug Chem 15, 13761388

21. Kok, R.J., Schraa, A.J., and Bos, E.J. (2002) Preparation and functional evaluation of RGD-modified proteins as alpha(v)beta(3) integrin directed therapeutics. Bioconjugate Chemistry 13, 128-135

22. van der Schaft, D.W., Toebes, E.A., Haseman, J.R., Mayo, K.H., and Griffioen, A.W. (2000) Bactericidal/permeabilityincreasing protein (BPI) inhibits angiogenesis via induction of apoptosis in vascular endothelial cells. Blood 96, 176181

23. van Leeuwen, E.B., Veenstra, R., van Wijk, R., Molema, G., Hoekstra, A., Ruiters, M.H., and van der Meer, J. (2000) Characterization of immortalized human umbilical and iliac vein endothelial cell lines after transfection with SV40 large T-antigen. Blood Coagul Fibrinolysis 11, 15-25

24. Mulder, W.J., Strijkers, G.J., Griffioen, A.W., van Bloois, L., Molema, G., Storm, G., 
Koning, G.A., and Nicolay, K. (2004) A liposomal system for contrast-enhanced magnetic resonance imaging of molecular targets. Bioconjug Chem 15, 799-806

25. Brandwijk, R.J., Dings, R.P., van der Linden, E., Mayo, K.H., Thijssen, V.L., and Griffioen, A.W. (2006) Anti-angiogenesis and antitumor activity of recombinant anginex. Biochem Biophys Res Commun 349, 10731078

26. Dings, R.P., van der Schaft, D.W., Hargittai, B., Haseman, J., Griffioen, A.W., and Mayo, K.H. (2003) Anti-tumor activity of the novel angiogenesis inhibitor anginex. Cancer Lett 194, 55-66

27. Mayo, K.H., Dings, R.P., Flader, C., Nesmelova, I., Hargittai, B., van der Schaft, D.W., van Eijk, L.I., Walek, D., Haseman, J., Hoye, T.R., and Griffioen, A.W. (2003) Design of a partial peptide mimetic of anginex with antiangiogenic and anticancer activity. J Biol Chem 278, 45746-45752

28. Ruoslahti, E., and Pierschbacher, M.D. (1986) Arg-Gly-Asp: a versatile cell recognition signal. Cell 44, 517-518

29. Clausse, N., van den Brule, F., Waltregny, D., Garnier, F., and Castronovo, V. (1999) Galectin-1 expression in prostate tumorassociated capillary endothelial cells is increased by prostate carcinoma cells and modulates heterotypic cell-cell adhesion. Angiogenesis 3, 317-325

30. Lotan, R., Belloni, P.N., Tressler, R.J., Lotan, D., Xu, X.C., and Nicolson, G.L. (1994) Expression of galectins on microvessel endothelial cells and their involvement in tumour cell adhesion. Glycoconj J 11, 462468

31. van Tilborg, G.A., Mulder, W.J., Deckers, N., Storm, G., Reutelingsperger, C.P., Strijkers, G.J., and Nicolay, K. (2006) Annexin A5functionalized bimodal lipid-based contrast agents for the detection of apoptosis. Bioconjug Chem 17, 741-749

32. Allen, T.M. (1997) Liposomes. Opportunities in drug delivery. Drugs 54 Suppl 4, 8-14

33. Drummond, D.C., Meyer, O., Hong, K., Kirpotin, D.B., and Papahadjopoulos, D. (1999) Optimizing liposomes for delivery of chemotherapeutic agents to solid tumors. Pharmacol Rev 51, 691-743

34. Ponce, A.M., Viglianti, B.L., Yu, D., Yarmolenko, P.S., Michelich, C.R., Woo, J., Bally, M.B., and Dewhirst, M.W. (2007) Magnetic resonance imaging of temperature-sensitive liposome release: drug dose painting and antitumor effects. $J$ Natl Cancer Inst 99, 53-63

35. Viglianti, B.L., Ponce, A.M., Michelich, C.R., Yu, D., Abraham, S.A., Sanders, L., Yarmolenko, P.S., Schroeder, T., MacFall, J.R., Barboriak, D.P., Colvin, O.M., Bally, M.B., and Dewhirst, M.W. (2006) Chemodosimetry of in vivo tumor liposomal drug concentration using MRI. Magn Reson Med 56, 1011-1018

36. Meerovitch, K., Bergeron, F., Leblond, L., Grouix, B., Poirier, C., Bubenik, M., Chan, L., Gourdeau, H., Bowlin, T., and Attardo, G. (2003) A novel RGD antagonist that targets both alphavbeta3 and alpha5beta1 induces apoptosis of angiogenic endothelial cells on type I collagen. Vascul Pharmacol 40, 77-89

37. Modlich, U., Kaup, F.J., and Augustin, H.G. (1996) Cyclic angiogenesis and blood vessel regression in the ovary: blood vessel regression during luteolysis involves endothelial cell detachment and vessel occlusion. Lab Invest 74, 771-780

38. Westlin, W.F. (2001) Integrins as targets of angiogenesis inhibition. Cancer $\mathrm{J} 7$ Suppl 3, S139-143

39. Meyer, A., Auernheimer, J., Modlinger, A., and Kessler, H. (2006) Targeting RGD recognizing integrins: drug development, biomaterial research, tumor imaging and targeting. Curr Pharm Des 12, 2723-2747

40. Temming, K., Schiffelers, R.M., Molema, G., and Kok, R.J. (2005) RGD-based strategies for selective delivery of therapeutics and imaging agents to the tumour vasculature. Drug Resist Updat 8, 381-402

41. Brandwijk, R.J., Nesmelova, I., Dings, R.P., Mayo, K.H., Thijssen, V.L., and Griffioen, A.W. (2005) Cloning an artificial gene encoding angiostatic anginex: From designed peptide to functional recombinant protein. Biochem Biophys Res Commun 333, 1261-1268 


\section{Chapter}

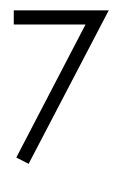

\section{Galectin-1 is essential in tumor angiogenesis and is a target for antiangiogenesis therapy}

Victor L.J.L. Thijssen, Ruben Postel, Ricardo J.M.G.E. Brandwijk, Ruud P.M. Dings, Irina Nesmelova, Sietske Satijn, Nicole Verhofstad, Yusaku Nakabeppu, Linda Baum, Jeroen Bakkers, Kevin H. Mayo, Françoise Poirier, Arjan W. Griffioen 


\section{Abstract}

We describe that galectin-1 is a receptor for the angiogenesis inhibitor anginex and that the protein is crucial for tumor angiogenesis. Galectin-1 is overexpressed in endothelial cells of different human tumors. Expression knockdown in cultured endothelial cells inhibits cell proliferation and migration. The importance of galectin-1 in angiogenesis is illustrated in the zebrafish model, where expression knockdown results in impaired vascular guidance and growth of dysfunctional vessels. The role of galectin-1 in tumor angiogenesis is demonstrated in galectin-1 null mice, in which tumor growth is markedly impaired due to insufficient tumor angiogenesis. Furthermore, tumor growth in galectin-1 null mice no longer responds to anti-angiogenesis treatment by anginex. Thus, galectin-1 regulates tumor angiogenesis and is a target for angiostatic cancer therapy. 


\section{Introduction}

An adequate vasculature is a prerequisite for tumors to grow, and the need for neovessel formation (or angiogenesis) provides a target for treatment of cancer ${ }^{1}$. Endothelial cells (EC) that line the tumor vasculature are particularly suitable target cells for therapeutic approaches since they are easily accessible to agents delivered via the blood ${ }^{2}$. However, to affect only tumor vasculature, specific targets on angiogenically active EC are essential. To date, only a few targets of tumor vasculature have been identified ${ }^{3}$.

We recently developed the specific angiostatic peptide anginex that inhibits tumor growth through specific inhibition of angiogenesis ${ }^{4-6}$. Although a broad profile of activities of anginex is known, such as prevention of EC adhesion and induction of apoptosis, the molecular target on tumor EC was never identified. In a receptor finding study using a yeast two-hybrid screening approach, we identified galectin-1 as a target protein of anginex.

Galectin-1 belongs to a family of carbohydrate binding proteins that share a conserved carbohydrate recognition domain (CRD) of approximately 130 amino acids ${ }^{7-9}$. Over a dozen mammalian galectins have been described ${ }^{10,11}$ and members of this family are expressed in a wide range of species, suggesting an important role for galectins in basic cellular mechanisms. Galectins can be secreted, and depending on the cell type or state of differentiation, they have been found in the nucleus, in the cytoplasm, or in the extracellular matrix. It has been proposed that galectin-1 mediates cell adhesion and migration ${ }^{12}$, and is involved in several processes including proliferation ${ }^{13}$, apoptosis ${ }^{14}$, and even mRNA splicing ${ }^{15}$. The role of galectin-1 in EC function or in vascular biology has not been extensively studied.

Here, we describe the function of galectin-1 in the angiogenesis. We provide direct functional evidence that galectin-1 is required for tumor angiogenesis and for outgrowth of tumors. Furthermore, we show that galectin-1 is the target for the potent angiogenesis inhibitor anginex, thus establishing galectin-1 as an important target for anti-cancer therapy.

\section{Materials and Methods}

\section{Cell cultures}

Human umbilical vein EC (HUVEC) and the human microvascular EC line HMEC were cultured as described elsewhere ${ }^{5}$. F9 teratocarcinoma cells (kind gift from Dr. H. Weich) were cultured in RPMI-1640 supplemented with $10 \%$ fetal bovine serum, $1 \%$ glutamin, $50 \mathrm{U} / \mathrm{ml}$ penicillin, and $50 \mathrm{ng} / \mathrm{ml}$ streptomycin. 


\section{Mouse tumor model}

A total of 14 adult $129 \mathrm{P} 3 / \mathrm{J} \mathrm{gal-1^{-/- }}$ mutant mice ${ }^{16}$ and 17 matched $129 \mathrm{P} 3 / \mathrm{J} \mathrm{gal-1^{+/+ }}$ (wild type) mice were used in this study. On day 1 , animals were injected s.c. with $3 \times 10^{6}$ syngeneic F9 teratocarcinoma cells. On day 7, anginex treatment (10 $\mathrm{mg} / \mathrm{kg} /$ day) was started in 7 wild type and 9 mutant mice by daily i.p. injections. Tumor volume and mouse weight were measured daily throughout the experiment. Animals were given water and standard chow ad libitum, and they were kept on a 12-hour light/dark cycle. All experiments were approved by the local ethical review committee.

Knockdown of galectin-1 expression in vitro

Knockdown of gal-1 expression in vitro was obtained using a gal-1 specific antisense oligodeoxynucleotide (hgal1 ODN: GTCACCGTCAGCTGCCATGT). As control, a random nonspecific antisense oligodeoxynucleotide (control ODN: TCCCTAGTGACTCTTCCC) was used. ODNs were renewed every other day.

\section{FACS analysis}

FACS analysis of gal-1 protein expression was performed on ethanol fixed HUVEC. Cells were washed in $0.1 \%$ BSA $/ 0.01 \%$ sodium azide/PBS, incubated on ice with polyclonal rabbit anti-galectin antibody ${ }^{17}$, and washed with PBS. Next, the cells were incubated with FITC-labeled polyclonal goat anti-rabbit Ig antibody (Dako) and washed with PBS. Five thousand events were acquired for each sample on a FACSCalibur flow cytometer (Beckton Dickinson). All experiments were performed in triplicate.

\section{Migration, proliferation, and CAM assay}

Migration, proliferation, and CAM assays were performed as described elsewhere ${ }^{18}$. Within each proliferation experiment, treatments were done in triplicate and all proliferation and migration experiments were performed at least three times. For the CAM, two independent experiments were performed (overall $n=13 /$ treatment group).

\section{Real-time PCR}

Total RNA isolation, subsequent CDNA synthesis, and real-time PCR were performed as described previously ${ }^{19}$ with primers targeted against human gal-1 (Forward: TGCAACAGCAAGGACGGC; Reverse: CACCTCTGCAACACTTCCA). Primers were purchased from Eurogentec and experiments were performed in triplicate.

\section{Immunohistochemistry}

Immunohistochemical staining of anginex uptake was performed on HUVEC cytospins. Cells were acetone fixed and air dried. Following incubation in $1 \%$ 
paraformaldehyde cells were incubated in fetal calf serum after which mouse 2D10 monoclonal anti-anginex antibody ${ }^{5}$ was applied in $0.05 \%$ Triton X100/PBS. Following incubation with Texas Red labeled goat-anti-mouse Ig antibody, the cells were washed with PBS and mounted in Immumount (Shandon Inc.) supplemented with $1 \mathrm{\mu g} / \mathrm{ml} \mathrm{4',6-diamidino-2-phenylindole} \mathrm{(DAPI;} \mathrm{Molecular} \mathrm{Probes).} \mathrm{In} \mathrm{the}$ negative control, incubation with the first antibody was omitted.

Doublestaining for Ki67 and CD31/34 on paraffin-embedded tissue sections was performed as previously described ${ }^{20}$. Tissues from normal colon, colon carcinoma, and Ewing sarcoma were obtained from the stocks of the Department of Pathology, University Hospital Maastricht. For gal-1 staining, paraffin-embedded tissue sections were dewaxed and endogenous peroxidase activity was blocked with $0.3 \%$ $\mathrm{H}_{2} \mathrm{O}_{2}$ in methanol. Next, the slides were microwave pretreated in citric acid. After blocking with $1 \%$ BSA/PBS primary antibody was applied in $0.5 \%$ BSA/PBS. Next, biotin-labeled secondary antibody was applied and staining was performed with the StreptABComplex/HRP kit (Dako) according the suppliers protocol. The tissue sections were counterstained with haematoxilin (Merck), dehydrated and mounted in Entellan (Merck). The same protocol was used for EC staining with the EC specific antibody $9 \mathrm{~F} 1{ }^{21}$. Staining for $\mathrm{CD} 45+$ and $\mathrm{CD} 8+$ cells was performed on frozen tissue sections which were fixed in acetone and air dried. Endogenous peroxidase activity was blocked with $0.3 \%$ hydrogen peroxidase/PBS and aspecific binding was blocked with 20\% FCS/0.1\% Tween20/PBS. Next, the primary antibody (MP33 rat antimouse CD45 or 53.6.27 rat anti-mouse CD8) was applied, followed by incubation with biotin labeled secondary antibody. Staining was visualized using the Vectastain $A B C$ kit (Vector Laboratories) and subsequently, sections were counterstained with haematoxylin, dehydrated, and mounted with Entellan. Within each section, the number of positive cells was scored at 4 different locations in a blinded fashion by two different observers. Fluorescent staining of $\mathrm{CD} 31$ in murine tumors and subsequent scoring of vessel characteristics was performed as described before ${ }^{6}$.

\section{Zebrafish experiments}

For in vivo experiments, the previously described $T g(f l i 1: e g f p)^{y 1}$ zebrafish was used 22. Knock-down of $L g a l s 1-L 2$ and $-L 3$ expression was achieved by injection of specific morpholino-modified antisense oligonucleotides (MOs; Genetools) into 1cell stage embryos ${ }^{23}$. The following MOs were used: Lgals1-L2 ATG-MO, 5'GTATAAGCACACCGGCCATTTTGAC-3'; Lgals1-L3 ATG-MO， 5'-AAGATCCCAGGCT AAGGACGTCATT-3'; Lgals1 L2 splice-MO， 5'-TTGTAATATACTCACGGCCATTTTG-3'; Lgals1 L3 splice-MO, 5'-ATGTCTGTACTCACGCATCACAGCC-3'. Before 24 hours postfertilization (hpf), 1-Phenyl-2-thiourea (PTU, 0.002\%) was added to prevent pigment development. For imaging, dechorionated embryos were anesthetized with $0.003 \%$ tricaine methanesulfonate and mounted in $2 \%$ low melting agarose. Confocal scanning microscopy was performed using a Leica TCS NT. 
For whole mount blood staining, dechorionated and PTU treated embryos were incubated in $40 \% \mathrm{EtOH}, 0.01 \mathrm{M} \mathrm{NaAc} \mathrm{pH} 5.2,2.0 \% \mathrm{H}_{2} \mathrm{O}_{2}$, in the presence of 0.8 $\mathrm{mg} / \mathrm{ml}$ o-dianisidine. Following rehydration in a graded series of EtOH/PBST the embryos were stored in $50 \%$ glycerol at $4^{\circ} \mathrm{C}$.

Whole mount in situ hybridization on zebrafish embryos was carried out as previously described ${ }^{24}$. For VE-cadherin riboprobe synthesis we used the previously published plasmid 25. For Lgals1-L2 antisense probe synthesis RZPD clone IMAGp998D0710947Q3 (in pSPORT1) was linearized with BamHI and transcribed with T7 RNA polymerase. Zebrafish Lgals1-L3 was cloned from RZPD clone IMAGp998J1712051Q3 into pBluescript KS giving rise to Igal1-L3/pBs. For Igal1-L3 antisense probe synthesis, plasmid $/ g a / 1-L 3 / p B s$ was linearized with Acc65I and transcribed with T7 RNA polymerase. For sectioning, the embryos were embedded in Technovit 8100 (Heraeus Kulzer, Wehrheim Germany). Seven $\mu M$ thick sections were cut and counterstained with neutral red dye.

\section{Statistics}

All data are shown as mean with standard error except where indicated otherwise. Data from in vitro proliferation, real-time PCR, CAM assay, FACS analysis, and CD45/CD8 scores were analyzed using the Mann-Whitney $U$ test. Tumor growth curves and migration assay data were analyzed using 2-way ANOVA. The Student's t-test was used to analyze the vascular parameters. All values are two-sided and Pvalues $<0.05$ were considered statistically significant. Two-way ANOVA was performed in Graphpad Prism 3.0 (Graphpad Software Inc.). All other statistical computations were performed in SPSS 10.0.5. (SPSS Inc.).

\section{Results}

Galectin-1 binds the angiostatic peptide anginex

The goal of the present study was to identify the receptor of anginex, an angiogenesis inhibitor which has previously been shown to specifically target tumor endothelial cells (EC) ${ }^{5}$. Immunohistochemistry revealed vesicular uptake of anginex by EC within 2 hours (Fig. 1A). Electron microscopy showed anginex located at the membrane of intracellular vesicles, suggesting receptor-mediated uptake (Fig. 1B). To identify this receptor, yeast two-hybrid $(\mathrm{Y} 2 \mathrm{H})$ analysis was performed. To that end, the recently described artificial anginex gene ${ }^{18}$ was cloned in frame with the GAL-4 DNA binding domain of the $\mathrm{Y} 2 \mathrm{H}$ bait vector pGBDT7, which was confirmed by Western blotting (not shown). Multiple screens against cDNA libraries of activated EC identified galectin-1 (gal-1) as the receptor for anginex (Suppl. Table 1/Suppl. Fig. 1) which was independently confirmed using three approaches. i) Double staining of anginex treated EC showed co-localization of anginex and gal-1. ii) Analysis of NMR spectra revealed chemical shift changes of 
certain resonances from gal-1 upon addition of anginex, indicative of a specific molecular interaction. iii) Plasmon resonance spectroscopy (BIAcore analysis) was used to further define the kinetics and stoichiometry of the interaction. Analysis of the binding kinetics revealed a 1:1 Langmuir association with a rate constant $\left(k_{a}\right)$ of $\sim 6.5 \times 10^{3} \mathrm{Ms}^{-1}$, while the dissociation kinetics followed a biphasic pattern with dissociation rate constants of $4.2 \times 10^{-2} \mathrm{~s}^{-1}$ and $5.9 \times 10^{-4} \mathrm{~s}^{-1}$, respectively. These data suggest that dimerized anginex binds to gal-1 and that subsequently the two anginex molecules dissociate as monomers with a $K_{\mathrm{d}}$ of $6.4 \mu \mathrm{M}$ for dissociation of first anginex molecule and a $K_{d}$ of $90 \mathrm{nM}$ for the second molecule. This result is supported by mass spectrometry which displayed a major peak with a mass of 22.8 kD (gal-1 monomer (14.7 kD) + anginex dimer ( 8 kD) (not shown). The data above show that gal-1 and anginex interact, suggestive of gal-1 serving as receptor for anginex.

Galectin-1 is overexpressed in tumor EC; a crucial role in EC proliferation and migration

To determine the role of gal-1 in tumor EC biology, we first analyzed gal-1 expression in human tumor blood vessels by immunohistochemistry. While gal- 1 is only weakly expressed in EC of normal tissue (colon is shown: Figure 1C, left panels), a strong expression was found in EC of human colon carcinoma (Figure 1C, middle panels) and breast carcinoma (not shown), especially in EC that stained positive for the proliferation marker Ki67. Similar results were observed for a sarcoma type of tumor (Ewing sarcoma) in which the gal-1 staining was almost exclusively observed in vessels (Figure $1 \mathrm{C}$, right panels). These data demonstrate that the amount of gal-1 protein is upregulated in angiogenically active EC. Indeed, growth factor activation of freshly isolated human umbilical vein EC resulted in a significant increase in gal-1 mRNA expression and a concomitant $>10$-fold induction of gal-1 protein expression (Figure 1D). Furthermore, treatment of activated EC with a gal-1 specific antisense oligodeoxynucleotide (ODN) resulted in inhibition of EC proliferation, while a random ODN had no effect (Figure 1E). Next to EC proliferation, EC migration was also inhibited by treatment with either the gal-1 specific ODN (Figure 1F) or the rabbit polyclonal anti-gal-1 antibody (Figure 1G). These data strongly suggest a role for gal-1 in EC biology.

\section{Galectin-1 is required for coordinated angiogenesis in vivo}

The role of gal-1 in angiogenesis in vivo was first studied in the chick chorioallantoic membrane (CAM). Treatment of the CAM with a rabbit polyclonal anti-gal-1 antibody induced a significant inhibition of microvessel density, similar as previously published for anginex ${ }^{4-6}$ albeit less pronounced. Interestingly, treatment caused tortuous and irregular growth of the vessels, suggesting a defect in vascular 


\section{Figure 1- Galectin-1 binds to anginex and galectin-1 expression is enhanced in activated EC and tumor EC; role in EC function}

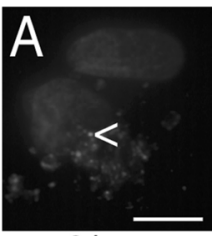

$2 \mathrm{hrs}$

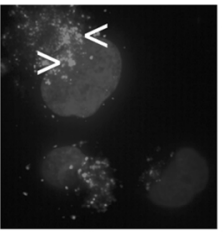

$8 \mathrm{hrs}$

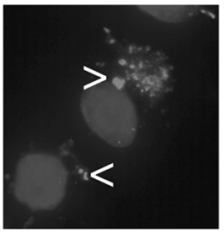

$24 \mathrm{hrs}$

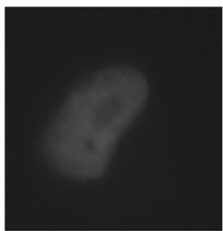

control
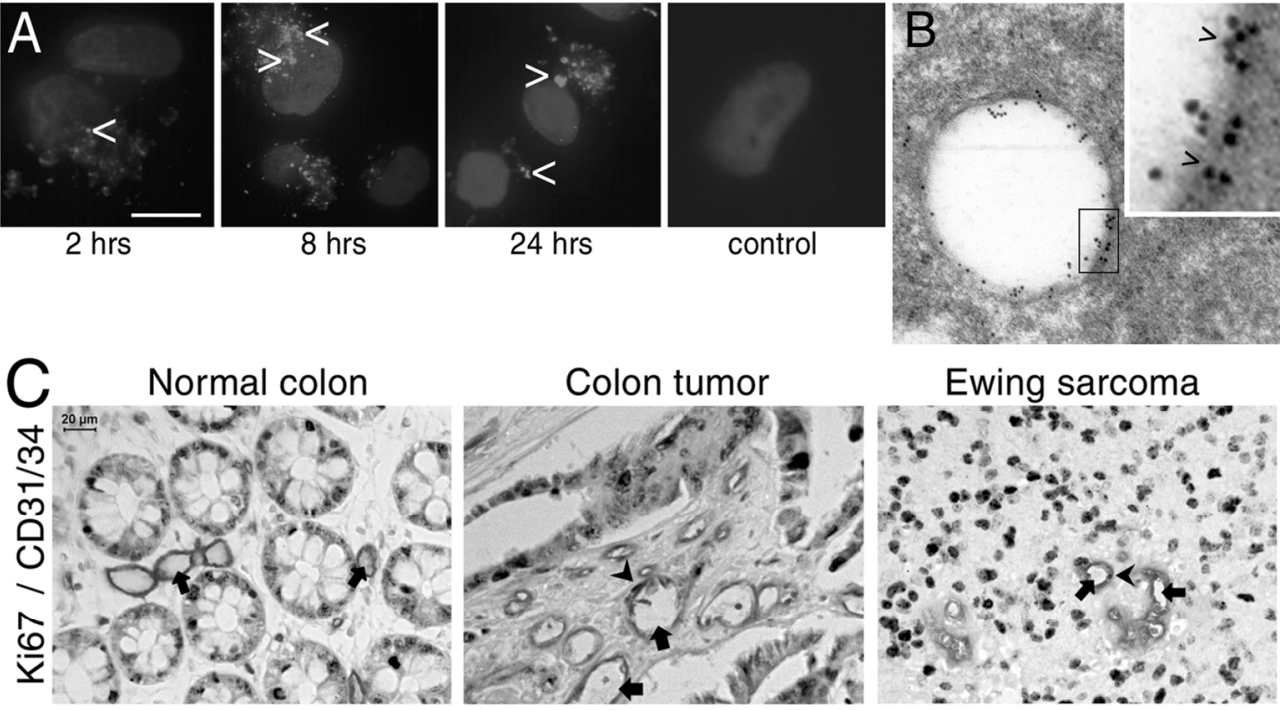

Ewing sarcoma
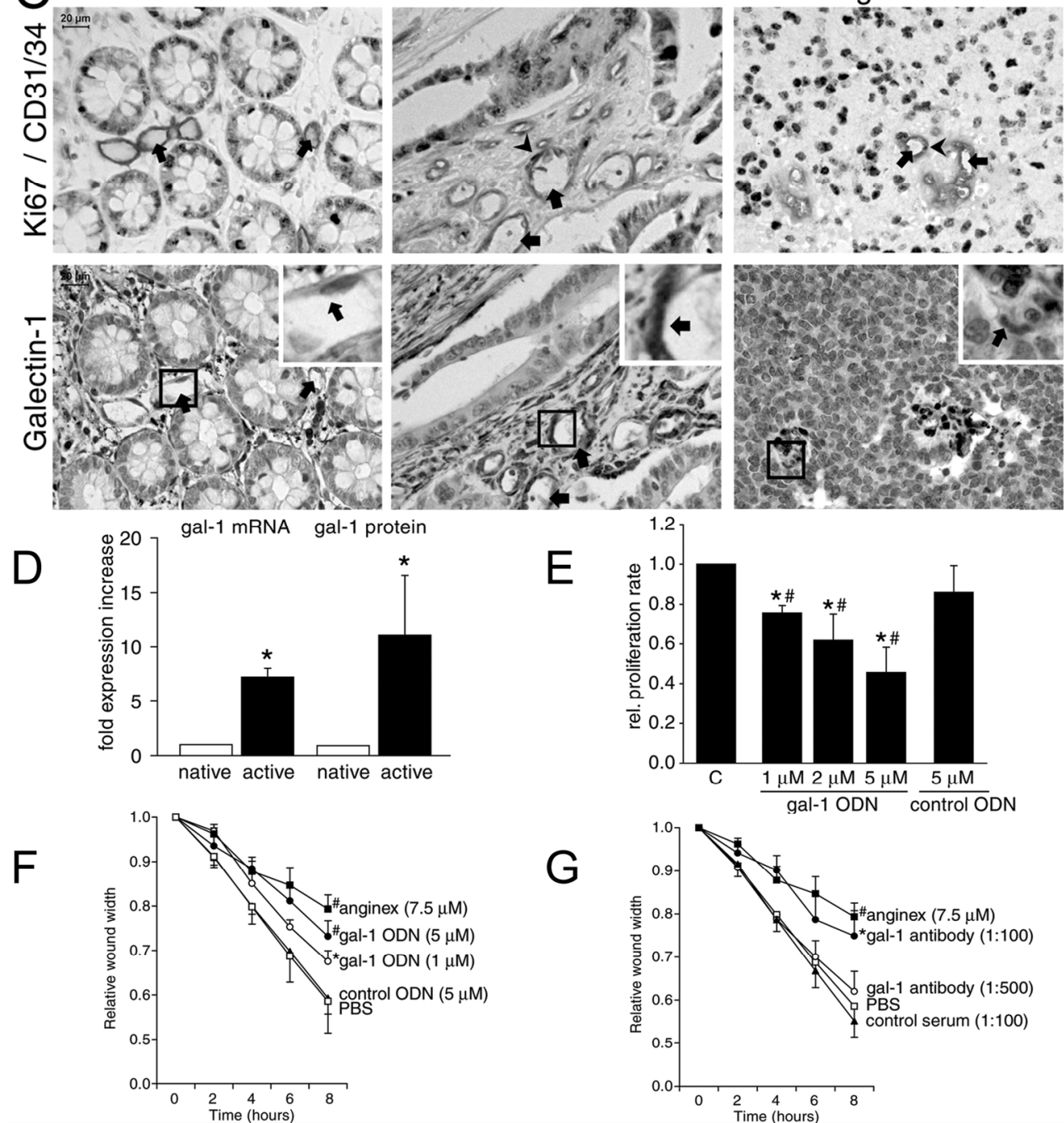

G

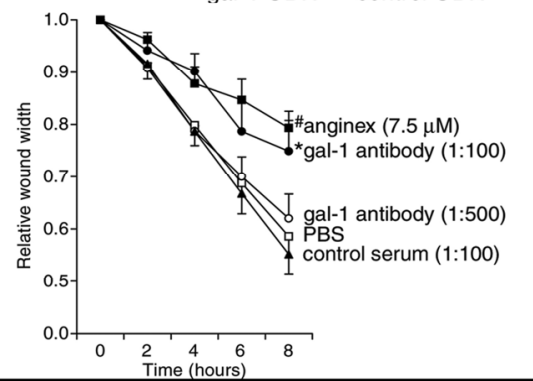


Figure 1 - Galectin-1 binds to anginex and galectin-1 expression is enhanced in activated EC and tumor EC; role in EC function

(A) Immunohistochemical detection of anginex treated HUVEC using mouse monoclonal 2D10 anti-anginex antibody (red staining) in a time-lapse experiment. Nuclei are counterstained with DAPI (blue staining). Anginex appears in vesicular structures (arrowheads). In the control, the primary antibody was omitted. Bar in the left panel represents $10 \mu \mathrm{m}$. (B) Electron microscopy of an immunogold labeling of anginex demonstrating the accumulation of anginex in HUVEC. Inset: Detail showing the membrane localization of anginex (arrowheads). Magnification: 80,500x. (C) Gal-1 is overexpressed in EC of human colon carcinoma and Ewing sarcoma as compared to normal human colon. The top panels show a double staining for the EC (CD31/34, blue) and the proliferation marker Ki67 (brown/black). The lower panels show staining of a consecutive section for gal-1 (brown) with hematoxylin as counterstain (blue). The arrows indicate blood vessels. Arrowheads point towards individual proliferating EC. The insets show a detail of gal-1 staining in EC (arrow). (D) Gal-1 mRNA ( $q P C R ; n=5$ ) and protein (FACS; n=4) expression are upregulated in activated HUVEC. Expression was determined in cells immediately following isolation from the umbilical vein (native) and after culturing the cells for three additional days in medium containing $20 \%$ human serum (active). ${ }^{*} p<0.05$. vs. native. (E) Knockdown of gal- 1 expression with ODN results in a concentration dependent inhibition of EC proliferation ( $n=4) ;{ }^{*} p<0.05$ vs. control; $\# p<0.05$ vs. control ODN. (F) Treatment with $1 \mu \mathrm{M}$ or $5 \mu \mathrm{M}$ gal-1 ODN results in a significant inhibition of EC migration ( $n=4$ ); $\# p<0.005$ vs. blank; ${ }^{p} p<0.05$ vs. blank. (G) Treatment with a gal-1 antibody results in a significant inhibition of EC migration ( $n=3) ; \# p<0.005$ vs. PBS; ${ }^{p}<0.01$ vs. PBS.

guidance (Suppl. Fig. 2). For further insight in the role of gal-1 during angiogenesis in vivo, we used the $T g(f l i 1: e g f p)^{y 1}$ zebrafish model. In this model, EC are marked by expression of green fluorescent protein (GFP) ${ }^{22}$. Recently, 3 prototype galectins were described in zebrafish (Lgals1-L1/L2/L3) of which Lgals1-L2 was found to preferentially bind $\mathrm{N}$-acetyllactosamine, similar to human gal-1 ${ }^{26}$. Since $L g a / s 1-L 1$ is not expressed during embryogenesis ${ }^{26}$ we only studied the role of the other two prototype galectins in vascular development. Whole mount RNA in situ hybridization at 48 hours post-fertilization revealed specific expression of $L g a l s 1-L 2$ in the eyes around the lens and in the ventricular zone in the head (Figure 2A). Lgals1-L3 expression was broader and largely overlapped with that of Lgals1-L2 (Figure 2B). Furthermore, cross sections at the level of the midbrain showed co-localization of both Lgals1-L2/-L3 and the EC specific marker VE-cadherin in the retinal vessels (Figures $2 \mathrm{C}-\mathrm{E}$ ) and in the blood vessels in the brain (not shown).

To determine the function of $L g a / s 1-L 2$ and $-L 3$ on vascular development, morpholino-modified antisense oligonucleotides (MOs) were designed to specifically target either the translation start site (ATG-MO) or the splice donor site (spliceMO). We verified that injection of each splice-MO successfully interfered with the splicing of the respective transcripts (not shown). Injection of either Lgals1-L2 or L3 ATG-MO induced hemorrhages in the head and in/behind the eyes of the 


\section{Figure 2 - Expression of zebrafish Lgals-1 L2 and Lgals-1 L3}

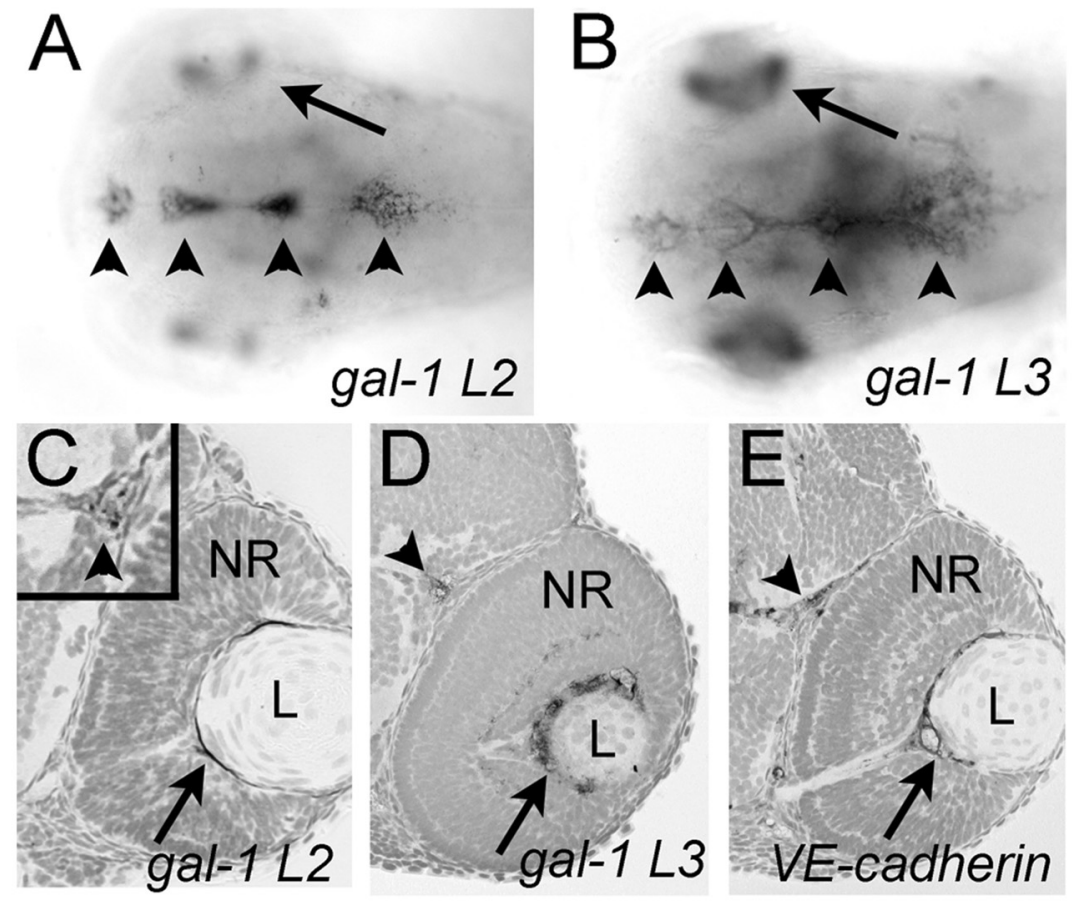

Figure 2 - Expression of zebrafish Lgals- 1 L2 and Lgals- 1 L3

Whole mount in situ hybridization on $48 \mathrm{~h}$ zebrafish embryos. (A) Lgals-1 L2 is strongly expressed in the eyes around the lens (arrow) and in the ventricular zone in the head (arrowheads). (B) Lgals- 1 L3 expression is less restricted but does overlap with L2 expression around the lens (arrow) and in the ventricular zone (arrow heads). (C-E) Cross sections at the level of the midbrain of whole mount in situ hybridizations of (C) Lgals- 1 L2 (inset is photographed from more anterior section), (D) Lgals-1 L3, and (E) VE-cadherin. Expression of both Lgals- 1 L2 and L3 is observed in blood vessels in the brain (arrowhead in $C$ and D) and in the retinal vessels (arrow in $C$ and $D$ ) and colocalizes with the expression of EC marker VE-cadherin.

embryos at 2.5 days post fertilization, as detected with a sensitive o-Dianisidine blood staining. Co-injection of both $L g a / s 1-L 2$ and $-L 3$ MOs resulted in even more severe hemorrhages (Figures 3A-D). Similar results were observed with the spliceMOs (not shown). Confocal scanning laser microscopy in the ventricular zone of $T g(f l i 1: e g f p)^{y 1}$ zebrafish revealed vascular defects, at the location of the hemorrhages, after co-injection of Lgals1-L2 and -L3 ATG MO. Compared to untreated zebrafish (Figure 3F), abnormal sprouting and misguidance of vessels 
clearly appeared in the mid-cerebral area of the $L g a l s 1-L 2$ and $-\angle 3$ ATG MO treated animals (Figures 3E-H). Vascular network formation of the middle cerebral-, dorsal longitudinal-, mesencephalic- and anterior cerebral veins was also distorted by both MOs, and most severely in the double knockdown (Figure 3G). The same defects were observed upon co-injection of both splice MOs, indicating specificity of the knockdown defects (Figure $3 \mathrm{H}$ ), while single injection of each splice $\mathrm{MO}$ revealed weaker defects (not shown). Similar to those in the ventricular zone, retinal vessels showed abnormal sprouting and growth in the regions where hemorrhages occurred (not shown). Together with observations from the CAM, results in zebrafish indicate that gal-1 is important in vivo for coordinated vessel outgrowth and vascular network formation.

\section{Galectin-1 facilitates tumor progression through angiogenesis}

The presented results urged us to study the role of gal-1 by analyzing tumor angiogenesis in the gal-1 null mice ${ }^{16}$. To compare tumor growth in the presence or

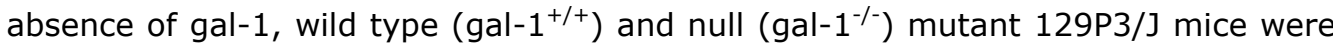
subcutaneously injected with syngeneic murine F9 teratocarcinoma cells. Three days after injection, a small palpable tumor developed in all mice, suggesting that tumor initiation and initial growth is not dependent on gal-1. However, subsequent tumor growth was significantly abrogated in the gal- $1^{-/-}$mice compared to the wildtype animals. Fifteen days after injection, the tumor volumes in the $\mathrm{gal}-1^{-/-}$mice were approximately 4 -fold smaller compared to those in the gal-1 ${ }^{+/+}$mice (Figure $4 \mathrm{~A}$ ). As expected, immunohistochemical analysis showed high expression of gal-1 in the EC of tumor vessels in the wild-type animals and no expression in the null mice (Figure 4B). Quantification of microvessel density revealed a significant lower amount of blood vessels in null mice compared to wild-type mice (Figure 4C). In addition, parameters of vessel architecture were decreased (Suppl. Table 2). Since gal-1 has been shown to mediate apoptosis in activated $T$ cells, which could contribute positively to tumor growth ${ }^{27}$, we also quantified the amount of peripheral blood leukocytes, and the presence of $\mathrm{CD}_{4} 5^{+}$and $\mathrm{CD}^{+}$cells in the tumors. There was no significant difference in these parameters between $\mathrm{gal}-1^{+/+}$ and $\mathrm{gal}-1^{-/-}$animals (Suppl. Fig. 3) which strongly suggests that, in this particular model, impaired tumor progression in gal-1 null mice largely results from decreased angiogenesis.

\section{Galectin-1 is a target protein for angiostatic therapy}

Because gal-1 was initially identified as a receptor for the angiostatic peptide anginex, we also analyzed the effect of anginex treatment in wild type and gal-1 null mice. In wild-type animals, anginex significantly inhibited tumor growth by approximately $70 \%$ (Figure 4D) and vessel density by approximately 55\% (Figure $4 \mathrm{E})$, which is comparable with previous observations for anginex in other tumor 


\section{Figure 3 - Loss of zebrafish galectin- 1 L2 and L3 results in hemorrhages in the} brain and defective vessel formation
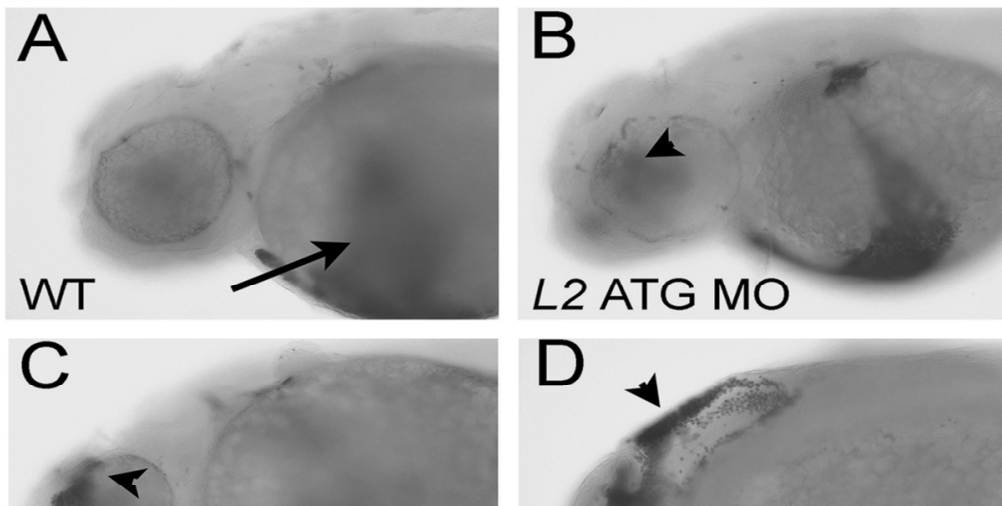

L3 ATG MO
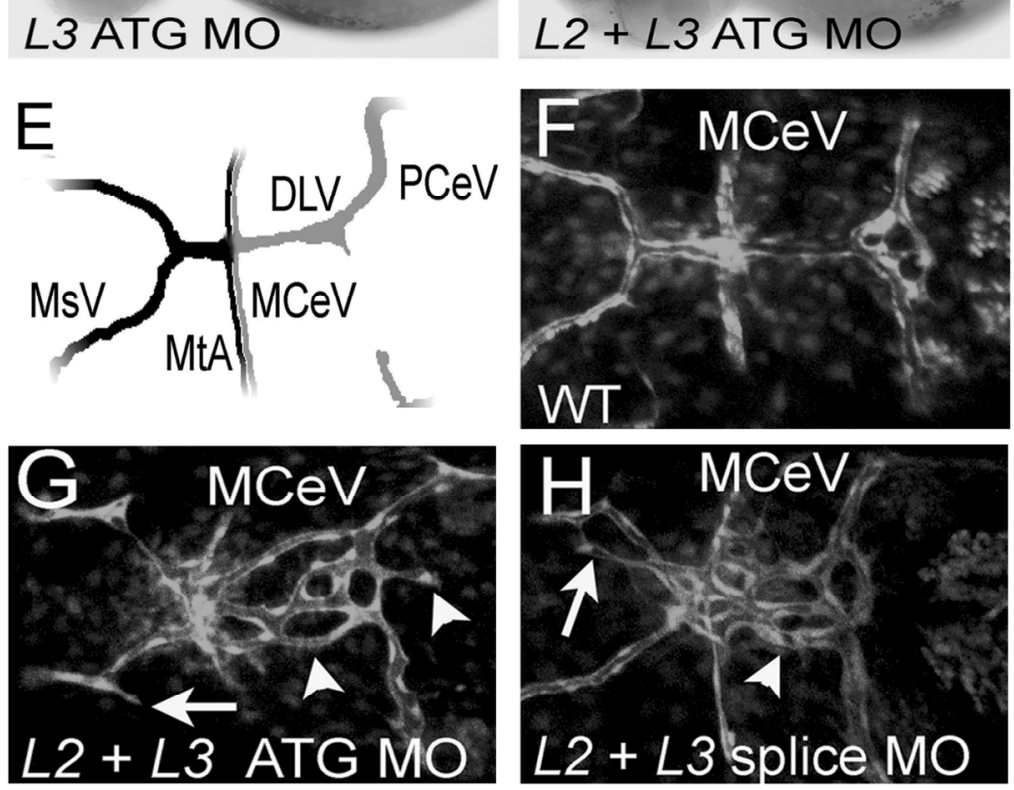

models ${ }^{5,28}$. In gal-1/- mice, treatment with anginex had no effect on tumor growth (Figure 4F). In addition, anginex treatment did not significantly affect the number of infiltrating $\mathrm{CD}_{4} 5^{+}$or $\mathrm{CD}^{+}$cells in the tumors of both the wild type and null mice (Suppl. Fig. 4). These data demonstrate that gal-1 mediates the angiostatic activity of anginex and that gal-1 can serve as a target for angiostatic therapy. 
Figure 3 - Loss of zebrafish galectin-1 L2 and L3 results in hemorrhages in the brain and defective vessel formation

(A-D) o-Dianisidine staining for hemoglobin on $2.5 \mathrm{dpf}$ embryos. (A) wild type control or injected with (B) Lgals 1 L2 AT-MO, (C) Lgals-1 L3 ATG-MO, (D) both Lgals-1 L2 and L3 ATG-MOs. Co-injection of $L 2$ and $L 3$ ATG-MO results in severe hemorrhaging in the brain region (arrowheads). Arrow in (A) shows blood accumulating on the yolk and in the heart of a control embryo. (E) Schematic drawing of blood vessels in the dorsal brain at $2.5 \mathrm{dpf}$ (modified from ${ }^{46}$ ). (F-H) Projection of Z-stacks made by confocal microscopy from $\mathrm{Tg}$ (fli : :egfp)yl transgenic embryos at the level of the dorsal brain vessels at 2.5 dpf. (F) wild type control embryo. (G) Embryos co-injected with Lgals-1 L2 and L3 ATG-MO display aberrant sprouting and misguidance of the middle cerebral vein (MCeV) into the dorsal longitudinal vein (DLV) (arrowheads). Defective angiogenic sprouting is also observed in the mesencephalic vein (arrow). (H) Co-injection of the Lgals- 1 L2 and L3 splice-MO shows similar defects in angiogenic sprouting of the brain vessels. DLV, dorsal longitudinal vein; MCeV, middle cerebral vein; MsV mesencephalic vein; MtA, metencephalic artery; PCeV, posterior cerebral vein.

\section{Discussion}

The current study is the first to demonstrate that gal- 1 is important in tumor angiogenesis and that targeting of gal-1 can be an efficient angiostatic therapeutic strategy. Previous studies have shown that gal-1 is key in two mainstays of cancer. Firstly, gal-1 supports metastasis formation, because it facilitates interactions between tumor cells and endothelial cells (EC) ${ }^{29,}{ }^{30}$. Secondly, it protects the tumor against immunity since it can induce apoptosis in tumor infiltrating cytotoxic leukocytes ${ }^{14,27}$. This study now reports a critical role in angiogenesis, a third important pillar in tumor growth. Our results reveal a direct role of gal-1 in EC biology. We found a direct involvement of gal-1 in EC proliferation and migration in vitro and in tumor angiogenesis in vivo. While the angiogenesis-independent onset of F9 tumor growth was similar in gal-1 null and wild type mice, the angiogenesis dependent outgrowth of tumors was severely hampered in the null mice. The low microvessel density in the null mice led us to conclude that the abrogated tumor growth is caused by inefficient angiogenesis. It has been shown that gal-1 null mice have subtle neuronal abnormalities that become apparant upon challenge ${ }^{31,32}$. In line with this, the effect on angiogenesis also becomes apparent by challenging the mice with a growing tumor. This corroborates with our observations in the CAM and the zebrafish, in which acute interference with gal-1 function also results in aberrant angiogenesis. Obviously, the presence of gal-1 is required for a proper response to an acute stress or pressure on EC biology and angiogenesis. It remains to be investigated whether vascular development in the null mice is indeed normal, or that subtle vascular defects do exist.

We also observed that intervening with gal-1 function results in irregular patterning of the vasculature. The abnormal vessel architecture in the CAM, the 


\section{Figure 4 - Hampered tumor growth and lack of responsiveness to anginex in} galectin-1 deficient mice

A

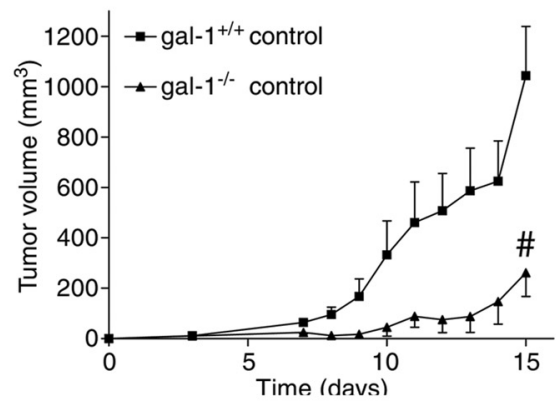

C

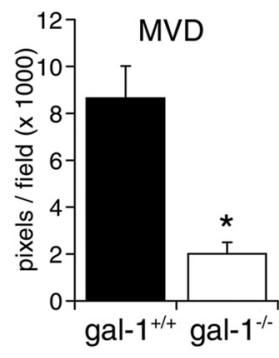

$E$

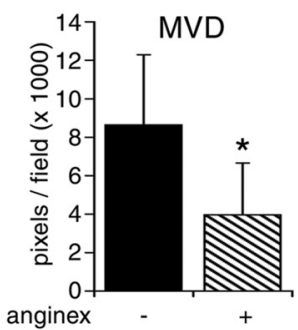

B

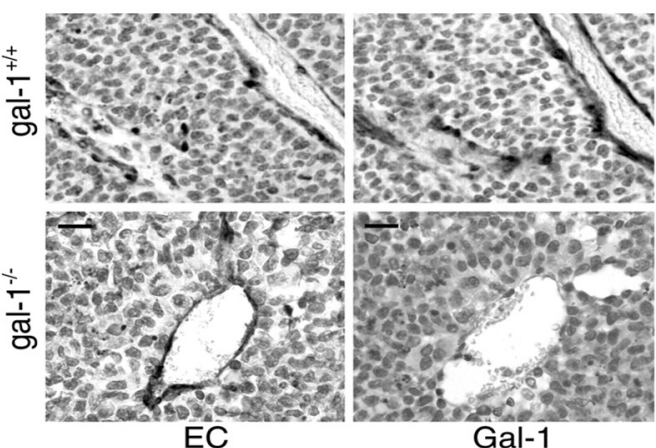

$\mathrm{D}$

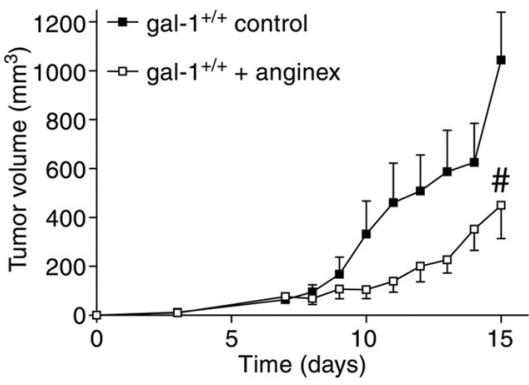

$\mathrm{F}$

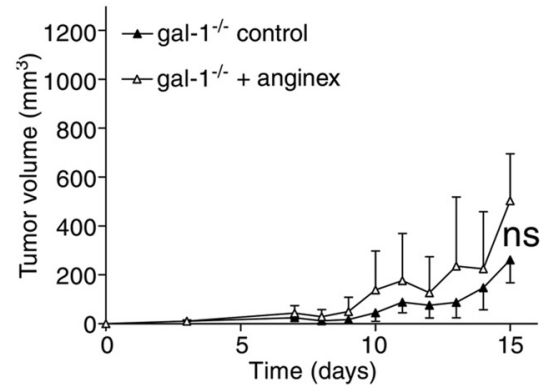

zebrafish model, and in knockout mice tumors, suggest that gal-1 is involved in vascular network formation. Recent studies have shown that the development of both vascular and neuronal networks is regulated by the same receptor/ligand pairs, i.e. Robos/Slits, Ephrins/Eph receptors, Neuropilins/Semaphorins, and Netrins/Unc5B 33, 34. Interestingly, for gal-1 a role in neuronal pathfinding has already been identified 35 . Furthermore, gal-1 null mice show neuronal abnormalities in adulthood ${ }^{32}$. Together with the role of gal-1 in angiogenesis described here, these data strongly suggest that gal-1, as well as other members of 
Figure 4 - Hampered tumor growth and lack of responsiveness to anginex in galectin- 1 deficient mice

(A) F9 teratocarcinoma tumor growth in gal-1+/+ (solid squares) and gal-1\% (solid triangles) mice. $\# p<0.001$. (B) Immunohistochemical evaluation of vasculature and gal-1 expression in tumors from gal- $1^{+/+}$(upper panels) and gal-1\% (lower panels) mice. The left panels show vessel staining with EC marker 9Fl (brown). In the right panel, gal-1 staining (brown) is shown in consecutive sections. Bars represents $20 \mu \mathrm{m}$. (C) Quantification of microvessel density (MVD) in tumors from gal-1+/+ (black bars) and gal-1\% (white bars) mice. ${ }^{*} p<0.001$ vs. wild type mice. (D) F9 teratocarcinoma tumor growth in gal-1+1+ mice during treatment with PBS (solid squares) or anginex (open squares). $\# p<0.001$ vs. control. (E) Quantification of microvessel density (MVD) in gal-1 $1^{+/+}$mice after treatment with PBS or anginex. ${ }^{*} \mathrm{p}<0.05$ vs. untreated. (F) F9 teratocarcinoma tumor growth in gal-1 1- during treatment with PBS (filled triangles) or anginex (open triangles). ns=non significant.

the galectin family (galectin- ${ }^{36,37}$ ) are also involved in both neuronal and vascular development.

It has been proposed that galectins can serve as molecular targets for cancer therapy $27,38-40$. Interestingly, we identified gal-1 as a receptor for the angiostatic peptide anginex. Anginex has been shown to inhibit tumor growth by inhibition of tumor angiogenesis ${ }^{4-6}$. A previous study reported that transport to the tumor vasculature is facilitated by fibronectin ${ }^{41}$. Our results now show that for the angiostatic activity on EC, galectin-1 is required. Anginex treatment in gal-1 null mice did not result in further inhibition of the already hampered tumor growth, while wild type mice responded as reported previously ${ }^{5,6}$. This indicates that gal-1 is essential for the activity of anginex and that gal-1 can indeed serve as a target for angiostatic cancer therapy. We also observed high expression of gal-1 in EC in mouse tumors as well as in human colon and breast carcinomas. There are other reports on the expression of gal-1 in tumor stroma, mainly in studies comparing the expression between normal and cancerous tissues (reviewed by ${ }^{40}$ ). Elevated stromal expression of gal-1 has been reported in several cancers including cancer of the ovaries ${ }^{42}$, breast ${ }^{43}$, prostate ${ }^{44}$, and colon ${ }^{45}$. These results suggest that the increased expression in tumors makes the protein an excellent target for diagnostic or therapeutic purposes.

It is attractive to speculate that, since gal-1 is crucial in several prerequisites for unlimited tumor growth, gal-1 targeting compounds may have multimodal activities. Interfering with gal-1 function could (i) prevent metastasis formation through inhibition of gal-1 facilitated tumor cell-EC interactions ${ }^{29,30}$, (ii) abrogate tumor escape from immunity through blockade of gal-1 induced apoptosis in activated T lymphocytes ${ }^{14,27}$, and (iii) prevent the execution of tumor angiogenesis (this study). This makes gal-1 an excellent target for cancer therapy. 


\section{References}

1. Folkman, J. (1972) Anti-angiogenesis: new concept for therapy of solid tumors. Ann Surg 175, 409-416

2. Griffioen, A.W., and Molema, G. (2000) Angiogenesis: potentials for pharmacologic intervention in the treatment of cancer, cardiovascular diseases, and chronic inflammation. Pharmacol Rev 52, 237-268

3. van Beijnum, J.R., and Griffioen, A.W. (2005) In silico analysis of angiogenesis associated gene expression identifies angiogenic stage related profiles. Biochim Biophys Acta 1755, 121-134

4. Griffioen, A.W., van der Schaft, D.W., Barendsz-Janson, A.F., Cox, A., Struijker Boudier, H.A., Hillen, H.F., and Mayo, K.H. (2001) Anginex, a designed peptide that inhibits angiogenesis. Biochem J 354, 233242

5. van der Schaft, D.W., Dings, R.P., de Lussanet, Q.G., van Eijk, L.I., Nap, A.W., Beets-Tan, R.G., Bouma-Ter Steege, J.C., Wagstaff, J., Mayo, K.H., and Griffioen, A.W. (2002) The designer anti-angiogenic peptide anginex targets tumor endothelial cells and inhibits tumor growth in animal models. Faseb J 16, 1991-1993

6. Dings, R.P., van der Schaft, D.W., Hargittai, B., Haseman, J., Griffioen, A.W., and Mayo, K.H. (2003) Anti-tumor activity of the novel angiogenesis inhibitor anginex. Cancer Lett $194,55-66$

7. Drickamer, K. (1988) Two distinct classes of carbohydrate-recognition domains in animal lectins. J Biol Chem 263, 9557-9560

8. Hirabayashi, J., and Kasai, K. (1993) The family of metazoan metal-independent betagalactoside-binding lectins: structure, function and molecular evolution. Glycobiology 3, 297-304

9. Barondes, S.H., Castronovo, V., Cooper, D.N., Cummings, R.D., Drickamer, K., Feizi, T., Gitt, M.A., Hirabayashi, J., Hughes, C., Kasai, K., and et al. (1994) Galectins: a family of animal beta-galactoside-binding lectins. Cell 76, 597-598

10. Cooper, D.N. (2002) Galectinomics: finding themes in complexity. Biochim Biophys Acta 1572, 209-231

11. Houzelstein, D., Goncalves, I.R., Fadden, A.J., Sidhu, S.S., Cooper, D.N., Drickamer, K., Leffler, H., and Poirier, F. (2004) Phylogenetic analysis of the vertebrate galectin family. Mol Biol Evol 21, 1177-1187
12. Hughes, R.C. (2001) Galectins as modulators of cell adhesion. Biochimie 83, 667-676

13. Scott, K., and Weinberg, C. (2004) Galectin1: a bifunctional regulator of cellular proliferation. Glycoconj J 19, 467-477

14. Perillo, N.L., Pace, K.E., Seilhamer, J.J., and Baum, L.G. (1995) Apoptosis of T cells mediated by galectin-1. Nature 378, 736739

15. Park, J.W., Voss, P.G., Grabski, S., Wang, J.L., and Patterson, R.J. (2001) Association of galectin-1 and galectin-3 with Gemin4 in complexes containing the SMN protein. Nucleic Acids Res 29, 3595-3602

16. Poirier, F., and Robertson, E.J. (1993) Normal development of mice carrying a null mutation in the gene encoding the L14 Stype lectin. Development 119, 1229-1236

17. Pace, K.E., Hahn, H.P., and Baum, L.G. (2003) Preparation of recombinant human galectin-1 and use in T-cell death assays. Methods Enzymol 363, 499-518

18. Brandwijk, R.J., Nesmelova, I., Dings, R.P., Mayo, K.H., Thijssen, V.L., and Griffioen, A.W. (2005) Cloning an artificial gene encoding angiostatic anginex: From designed peptide to functional recombinant protein. Biochem Biophys Res Commun 333, 1261-1268

19. Thijssen, V.L., Brandwijk, R.J., Dings, R.P., and Griffioen, A.W. (2004) Angiogenesis gene expression profiling in xenograft models to study cellular interactions. Exp Cell Res 299, 286-293

20. Lussanet, Q.G., Backes, W.H., Griffioen, A.W., Padhani, A.R., Baeten, C.I., van Baardwijk, A., Lambin, P., Beets, G.L., van Engelshoven, J.M., and Beets-Tan, R.G. (2005) Dynamic contrast-enhanced magnetic resonance imaging of radiation therapy induced microcirculation changes in rectal cancer. Int J Radiat Oncol Biol Phys

21. Harder, R., Uhlig, H., Kashan, A., Schutt, B., Duijvestijn, A., Butcher, E.C., Thiele, H.G., and Hamann, A. (1991) Dissection of murine lymphocyte-endothelial cell interaction mechanisms by SV-40-transformed mouse endothelial cell lines: novel mechanisms mediating basal binding, and alpha 4integrin-dependent cytokine-induced adhesion. Exp Cell Res 197, 259-267

22. Lawson, N.D., and Weinstein, B.M. (2002) In vivo imaging of embryonic vascular development using transgenic zebrafish. Dev Biol 248, 307-318 
23. Nasevicius, A., Larson, J., and Ekker, S.C. (2000) Distinct requirements for zebrafish angiogenesis revealed by a VEGF-A morphant. Yeast 17, 294-301

24. Hammerschmidt, M., Pelegri, F., Mullins, M.C., Kane, D.A., Brand, M., van Eeden, F.J., Furutani-Seiki, M., Granato, M., Haffter, P., Heisenberg, C.P., Jiang, Y.J., Kelsh, R.N., Odenthal, J., Warga, R.M., and NussleinVolhard, C. (1996) Mutations affecting morphogenesis during gastrulation and tail formation in the zebrafish, Danio rerio. Development 123, 143-151

25. Larson, J.D., Wadman, S.A., Chen, E., Kerley, L., Clark, K.J., Eide, M., Lippert, S., Nasevicius, A., Ekker, S.C., Hackett, P.B., and Essner, J.J. (2004) Expression of VEcadherin in zebrafish embryos: a new tool to evaluate vascular development. Dev Dyn 231, 204-213

26. Ahmed, H., Du, S.J., O'Leary, N., and Vasta, G.R. (2004) Biochemical and molecular characterization of galectins from zebrafish (Danio rerio): notochord-specific expression of a prototype galectin during early embryogenesis. Glycobiology 14, 219-232

27. Rubinstein, N., Alvarez, M., Zwirner, N.W., Toscano, M.A., Ilarregui, J.M., Bravo, A., Mordoh, J., Fainboim, L., Podhajcer, O.L., and Rabinovich, G.A. (2004) Targeted inhibition of galectin-1 gene expression in tumor cells results in heightened $T$ cellmediated rejection; A potential mechanism of tumor-immune privilege. Cancer Cell 5, 241-251

28. Dings, R.P., Yokoyama, Y., Ramakrishnan, S., Griffioen, A.W., and Mayo, K.H. (2003) The designed angiostatic peptide anginex synergistically improves chemotherapy and antiangiogenesis therapy with angiostatin. Cancer Res 63, 382-385

29. Lotan, R., Belloni, P.N., Tressler, R.J., Lotan, D., Xu, X.C., and Nicolson, G.L. (1994) Expression of galectins on microvessel endothelial cells and their involvement in tumour cell adhesion. Glycoconj J 11, 462468

30. Clausse, N., van den Brule, F., Waltregny, D., Garnier, F., and Castronovo, V. (1999) Galectin-1 expression in prostate tumorassociated capillary endothelial cells is increased by prostate carcinoma cells and modulates heterotypic cell-cell adhesion. Angiogenesis 3, 317-325

31. McGraw, J., McPhail, L.T., Oschipok, L.W., Horie, H., Poirier, F., Steeves, J.D., Ramer, M.S., and Tetzlaff, W. (2004) Galectin-1 in regenerating motoneurons. Eur $J$ Neurosci $20,2872-2880$
32. McGraw, J., Gaudet, A.D., Oschipok, L.W., Steeves, J.D., Poirier, F., Tetzlaff, W., and Ramer, M.S. (2005) Altered primary afferent anatomy and reduced thermal sensitivity in mice lacking galectin-1. Pain 114, 7-18

33. Klagsbrun, M., and Eichmann, A. (2005) A role for axon guidance receptors and ligands in blood vessel development and tumor angiogenesis. Cytokine Growth Factor Rev $16,535-548$

34. Weinstein, B.M. (2005) Vessels and nerves: marching to the same tune. Cell 120, 299302

35. Puche, A.C., Poirier, F., Hair, M., Bartlett, P.F., and Key, B. (1996) Role of galectin-1 in the developing mouse olfactory system. Dev Biol 179, 274-287

36. Nangia-Makker, P., Honjo, Y., Sarvis, R., Akahani, S., Hogan, V., Pienta, K.J., and Raz, A. (2000) Galectin-3 Induces Endothelial Cell Morphogenesis and Angiogenesis. Am J Pathol 156, 899-909

37. Kuklinski, S., Vladimirova, V., Waha, A., Kamata, H., Pesheva, P., and Probstmeier, R. (2003) Expression of galectin-3 in neuronally differentiating PC12 cells is regulated both via Ras/MAPK-dependent and -independent signalling pathways. J Neurochem 87, 1112-1124

38. Zou, J., Glinsky, V.V., Landon, L.A., Matthews, L., and Deutscher, S.L. (2005) Peptides specific to the galectin-3 carbohydrate recognition domain inhibit metastasis-associated cancer cell adhesion. Carcinogenesis 26, 309-318

39. Liu, F.T., and Rabinovich, G.A. (2005) Galectins as modulators of tumour progression. Nat Rev Cancer 5, 29-41

40. van den Brule, F., Califice, S., and Castronovo, V. (2004) Expression of galectins in cancer: a critical review. Glycoconj J 19, 537-542

41. Akerman, M.E., Pilch, J., Peters, D., and Ruoslahti, E. (2005) Angiostatic peptides use plasma fibronectin to home to angiogenic vasculature. Proc Natl Acad Sci U S A 102, 2040-2045

42. Allen, H.J., Sucato, D., Woynarowska, B., Gottstine, S., Sharma, A., and Bernacki, R.J. (1990) Role of galaptin in ovarian carcinoma adhesion to extracellular matrix in vitro. J Cell Biochem 43, 43-57

43. Gabius, H.J., Brehler, R., Schauer, A., and Cramer, F. (1986) Localization of endogenous lectins in normal human breast, benign breast lesions and mammary carcinomas. Virchows Arch B Cell Pathol Incl Mol Pathol 52, 107-115 
44. van den Brule, F.A., Waltregny, D., and Castronovo, V. (2001) Increased expression of galectin-1 in carcinoma-associated stroma predicts poor outcome in prostate carcinoma patients. J Pathol 193, 80-87

45. Lotan, R., Matsushita, Y., Ohannesian, D., Carralero, D., Ota, D.M., Cleary, K.R., Nicolson, G.L., and Irimura, T. (1991)
Lactose-binding lectin expression in human colorectal carcinomas. Relation to tumor progression. Carbohydr Res 213, 47-57

46. Isogai, S., Horiguchi, M., and Weinstein, B.M. (2001) The vascular anatomy of the developing zebrafish: an atlas of embryonic and early larval development. Dev Biol 230, 278-301 


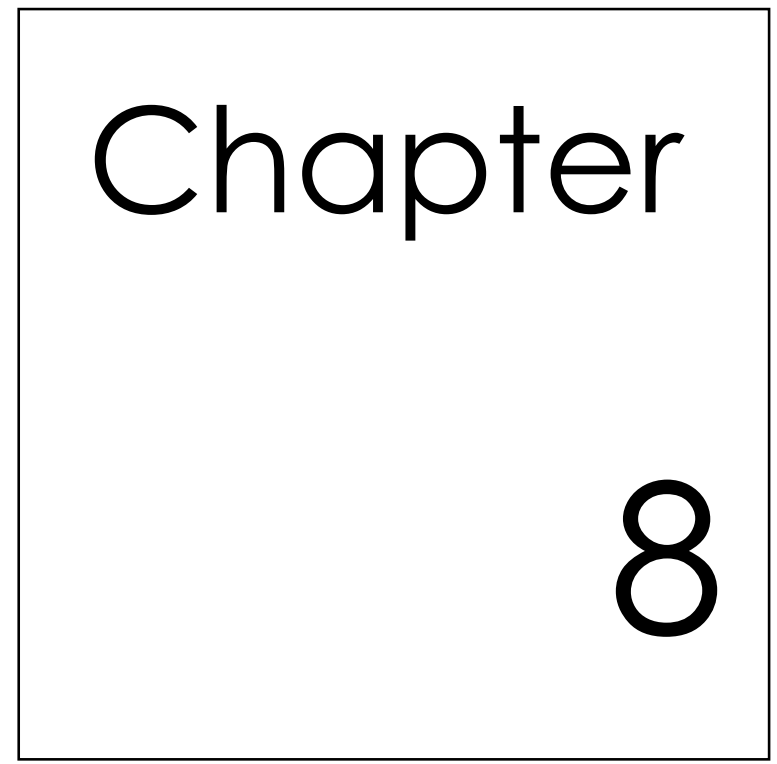

General discussion 
In this thesis, we have studied whether anginex, besides its application as synthetic angiostatic peptide, could be utilized in different ways to set up new anti-cancer strategies. We hypothesized that an artificial anginex gene would provide a functional recombinant protein and could be used as a molecular tool for angiostatic gene therapy, receptor identification, and tumor vasculature targeting. From the experimental studies can be concluded that a functional artificial gene has been designed which validates the use of the gene in molecular biology based strategies. A rationale for the use of the gene in gene therapy applications was provided by showing an inhibitory effect on tumor growth after integrating the anginex gene into the genome of a tumor cell line. Furthermore, the anginex gene has lead to the identification of galectin-1 as the main EC receptor for anginex. Additionally, we have provided evidence that anginex can be used as targeting moiety to activated EC for liposomal vehicles. 


\section{Validation of the anginex gene and recombinant protein}

The possibility to block tumor neovascularization represents a fascinating approach for the treatment of cancer. Even though every cancer type is a unique disease, the tumor endothelium is present in most tumors with unique but also similar characteristics. Therefore, EC represent a preferential target for angiostatic cancer therapy. As described in chapter 1, many extracellular, cell surface, and intracellular molecules involved in angiogenesis have been identified over the last decades. Understanding the molecular activity of these molecules and unraveling the pathways regulating and mediating neovascularization in tumors has created the possibility to selectively interfere with tumor angiogenesis. Nowadays, many endogenous and exogenous angiogenesis inhibitors have been identified. The potent inhibitor anginex was designed as a stable water soluble synthetic peptide with angiostatic capacity. To fully exploit the potential of the peptide, a gene encoding anginex was designed. This gene would enable the use of anginex as a molecular biological tool. Obviously, the recombinant protein encoded by the anginex gene had to be validated. Therefore, we chose to produce recombinant anginex in the yeast Pichia pastoris, which has proven to be suitable for the production of high levels of functionally active angiogenesis inhibitors like endostatin, angiostatin and tumstatin ${ }^{1-3}$. Recombinant endostatin isolated from yeast entered already clinical testing and was found to be safe and well tolerated ${ }^{4}$. We have demonstrated that recombinant anginex has comparable angiostatic properties as the synthetic peptide both in vitro and in vivo. The small differences between synthetic and recombinant anginex in some assays can have a number of causes. First, although not demonstrable, the relatively simple and batch wise isolation method might have introduced small impurities. Fermentation technology in combination with a standardized and automated isolation will stabilize the purity and quality of the batches. As a result, the small differences in activity will probably become smaller. Second, it might be argued that the addition of the C-terminal Cmyc and His-tag as well as the three to seven extra amino acids at the $\mathrm{N}$-terminal side might interfere with the function of anginex. Possibly, these extra amino acids or increased size of the protein interfere with the interaction with the biological receptors of anginex. However, from previous studies it is known that besides the $\beta$-sheet structure, the key amino acids for function are situated inside the first two chains of the $\beta$-sheet. Furthermore, the $C$-terminal side of the third chain can actually be removed without losing activity ${ }^{5}$. Because the C-terminus is apparently not relevant for activity, we chose for a system that makes use of C-terminal tags which can be used for isolation and detection purposes. Moreover, also at the $\mathrm{N}$ terminal side several amino acids can be removed without affecting its angiostatic activity ${ }^{6}$. These amino acids are not needed to form the $\beta$-sheet and they form a flexible end of the protein. Therefore, it is unlikely that the addition of extra amino 
acids at the $\mathrm{N}$-terminal side would have a disadvantageous effect. Indeed, conjugation of anginex to human serum albumin did not inhibit the activity ${ }^{7}$. In both in vivo models used for validation of recombinant anginex, the recombinant protein, although not significant, seems to have a stronger inhibitory effect than the synthetic peptide based on vessel morphology and tumor size. Unexpectedly, this can not be related to the microvessel density. Possibly, there are some differences in pharmacokinetics as a result of the size of the recombinant protein or the interaction with its receptor is changed due to the additional amino acids. Also the decreased tendency of recombinant anginex to form dimers might contribute to the difference of the in vivo activity and receptor binding capacity. To get more insight in the angiostatic capacity and the influence of the additional amino acids of the recombinant protein in future experiments, a peptide could be synthesized with exactly the same composition.

Based on the obtained results, we are confident that the anginex gene encodes for a fully functional recombinant protein and can be used as a molecular biological tool. Furthermore, the applied strategy allows for the functional design of specific synthetic antagonists in order to block or stimulate cellular pathways and to translate these molecules into biologically active genes.

\section{Gene therapy using the anginex gene}

Gene therapy can be an attractive approach for anti-angiogenic therapy. Preclinical studies have clearly indicated that most inhibitors (e.g. avastin) exert cytostatic rather than cytotoxic effects ${ }^{8}$, implying the need for long-term administration in order to obtain a prolonged therapeutic effect. This feature of angiostatic therapy and the difficulty in synthesizing large amounts of functional recombinant proteins have prompted several studies, which have investigated the delivery of angiostatic proteins by a gene therapy approach ${ }^{9}$. The possibility of angiostatic gene therapy has been demonstrated by studies using endostatin ${ }^{10}$. Endostatin gene therapy using the full-length protein significantly inhibited growth of primary tumors and their metastasis. In animal studies, inhibition was seen in the majority of the studies. A benefit of angiostatic gene therapy is that delivery of the gene into a subset of tumor cells may already be sufficient to prevent progression of micro-metastases into macroscopic disease ${ }^{11}$. We hypothesized that the anginex gene could be used for angiostatic gene therapy. Anginex could be especially suitable since it is only affecting the process of angiogenesis and overcoming EC anergy in tumors ${ }^{12}$. Additionally, because of its small size in comparison to the majority of inhibitors, and given the obtained results with recombinant anginex, it was expected that in vivo production would be easy. In contradiction to the bi-phasic antiangiogenic effect of endostatin ${ }^{13}$, extra systemic addition of anginex does not lead to less antitumor effect. Therefore, we expect 
anginex to be a more effective inhibitor after in vivo gene delivery. To provide a rational for the use of anginex in gene therapy, we made a stable transfectant of a B16F10 mouse melanoma cell line. Although no secretion signal was included, the supernatant of the transfected cell line was already capable of inhibiting EC proliferation. After injection of these cells in $\mathrm{C} 57 \mathrm{Bl} / 6$ mice, tumor growth was effectively inhibited from the onset, most likely due to the local production of recombinant anginex. Because the anginex produced by the stable transfected cell line was not labeled with tags and the available antibody 2D10 against synthetic anginex is not able to recognize recombinant anginex, analysis on the protein level was not possible. Probably, the 2D10 antibody is not able to recognize recombinant anginex because the protein has always a $\mathrm{N}$-terminal methionine, whereas the antibody has the free $\mathrm{N}$-terminal alanine of the synthetic peptide as its key recognition site. Instead, the expression of anginex was confirmed by measuring the mRNA expression levels. A possible explanation for the impressive tumor growth delay after injection in mice might be the elevated levels of anginex inside the tumor as a result of the local production in comparison to systemic delivery. Now, anginex is produced at sites where almost no circulation is present; which is the site where angiogenesis is initiated. Furthermore, the continuous production of the protein by transfected cells prevents a fast clearing inside the tumor in comparison to systemic treatment with anginex. It remains to be investigated if the incorporation into the genome does not affect the in vivo tumor take. However, since growth speed and morphology of transfected cells are not affected, this is not likely. This was supported by earlier studies with angiostatin and endostatin using the same vector system ${ }^{14}, 15$. The obtained results with the transfected cell line suggest that the anginex gene might be used for gene therapy-based angiostatic cancer therapy.

Although some studies show an anti tumor response after restoration of a defective gene in established tumors (e.g. p53 in lymphoma and sarcoma ${ }^{16,17}$ ), the obtained data confirm that antiangiogenic treatment will be most successful when applied immediately after the start of tumor angiogenesis. This appears logical since initiation of angiogenesis is known to be an early event in cancer progression 18. This is an aspect that should be considered when a clinical trial for an angiogenesis inhibitor is designed. New anticancer drugs are traditionally administered to patients with advanced cancers in which previous therapies have failed. Therefore, these patients have large tumors which are poorly vascularized, oxygen independent, have more maturated tumor vessels and are thus less dependent on angiogenesis than early stage tumors. Consequently, novel angiostatic agents should be tested at the start of the disease rather than on advanced tumors. The sooner angiostatic (gene) therapy is started the more effective it will be. Therefore, the development of better imaging methods and diagnostic molecular tests is required. Identification of early angiogenesis markers 
which can be detected in serum or used for imaging are needed. Given the strong anti-tumor response in the stable transfected tumor cells, the anginex receptor might be suitable for this purpose. Besides application as combination therapy to the primary tumor, perhaps angiostatic gene therapy is at present most suited for the treatment of small (future) metastases in the clinic, since angiogenesis is still highly stimulated at these sites. This treatment will be most effective when especially specific tumor angiogenesis targeted or inducible systems are applied. In the future, (angiostatic) gene therapy might also be used for vaccination purposes. Like classical vaccination, an immune response is elicited after (temporarily) expression of a protein after applying gene therapy. The most easy and safe way to do this is using naked DNA.

\section{Anginex mediated targeting of tumor angiogenesis}

Vascular targeting aims at marking the tumor vasculature for imaging purposes or to guide therapeutic molecules in order to shutdown or damage established tumor vasculature. The advantage of the latter is that by applying specific local treatment, less therapeutic agent is needed and possible negative side effects will be constrained. To employ targeting, specific markers are needed to discriminate between the target cell and other cells inside the body. The existence of tumor vasculature markers can be predicted because the vasculature in tumors is disorganized which results in irregular blood flow through the tumor capillaries. This leads to an environment which is nutrient starved and under oxidative stress. The continuously activated EC in tumor vessels respond to those stimuli by inducing a differential expression pattern, resulting in an increase in the level of specific tumor markers of angiogenesis ${ }^{19}$. These differences and the advances in molecular biology have allowed the development of agents capable of selectively targeting tumor endothelial cells. Unfortunately, till now only a few marker/targeting ligands pairs are suitable to use in specific therapies. The reason for this is that in most studies cultured primary cells or immortalized cell lines are used. As explained above, EC expression profiles are determined by the microenvironment, which is difficult to imitate in vitro. Furthermore, immortalized cells have usually lost some of the characteristics of the original cells, which can change function and expression of cell surface antigens. Regarding the limitations of EC culture, it is probably better to test the expression of specific markers and the use of targeting ligands on EC from different origins. In most studies, mouse in vivo models are used for the initial testing tumor vascular targeting strategies. However, they may not be totally predictive of the outcome in trials in human subjects. One of the reasons for this is the difference in regulation between species. This is most likely also the cause why many angiogenesis inhibitors fail in the clinic. Furthermore, it is probably important 
to choose a marker/ targeting ligand pair which is specific for the stage of the disease.

As described in chapter 5, a broad spectrum of viral and non-viral targeting devices (also called vectors) can be used for targeting studies. However, a problem in the field of tumor vascular targeting with vectors is the need to demonstrate that a candidate marker of tumor vascular EC is truly specific for the tumor vascular EC and that the vector is capable to specifically recognize and interact with this marker. Based on previous studies in which targeting of fluorescently labeled anginex to tumor EC was shown 20, 21, we hypothesized that both synthetic and recombinant anginex can be used for tumor vascular targeting of viral and non-viral vectors. This is supported by the fact that anginex is i) non-immunogenic, since it is hard to raise antibodies against the peptide, ii) anginex is small which prevents large changes to the structures of the vectors, iii) the protein can be formed recombinantly or simply conjugated as a synthetic peptide, and iv) anginex is affecting angiogenesis. To investigate the targeting ability of anginex, we conjugated anginex to fluorescent and paramagnetic liposomes. We demonstrated by MR imaging and phase contrast microscopy that these particles were able to bind to HUVEC and to the immortalized endothelial cell line EVL-C2, this in contrast to unconjugated liposomes. By performing competition experiments with unconjugated anginex, we proved that binding of the anginex targeted liposomes was dependent on the presence of the ligand conjugated to the liposomes. Fluorescent microscopy revealed that a substantial part of the anginex-liposomes, like RGD-liposomes, was internalized in vesicles. This observation suggests receptor mediated uptake. The applicability of the anginex targeted paramagnetic liposomes as a contrast agent for MR imaging was confirmed. Whether anginex targeting agents are suitable for treatment and imaging at the same time remains to be investigated. Considering the results obtained with the competition experiments it is expected that the angiostatic treatment will not be effected when a combination of contrast agent and unconjugated anginex is used simultaneously. On the other hand, when a combination is used the MRI signal will be diminished which might be a problem given the current sensitivity of imaging techniques. If anginex will be used for both angiostatic treatment and targeting ligand for contrast agents it is probably better to use the targeted contrast agent to monitor the effect of treatment with the unconjugated protein after a certain time interval. In our study, we compared anginex-liposomes with liposomes using the well known targeting ligand cyclic arginine-glycin-aspartic (RGD) peptide. Nowadays, RGD peptides are a popular tool for the targeting of drugs and imaging agents to av $\beta 3$-integrin 22-25. The expression of av $\beta 3$-integrin is upregulated in newly formed blood vessels in response to a variety of angiogenic factors. Studies show that av $\beta 3$ integrin is a critical target downstream of perhaps all angiogenic factors ${ }^{26}$. The RGD-peptide has successfully been used for tumor vascular targeting of viral or non-viral vectors 
27 , and thus serves as a good control to explore the targeting abilities of anginex. Although the RGD-peptide is a promising targeting ligand it is not specific for (tumor) angiogenesis, since the av $\beta 3$-integrin is also expressed on e.g. vascular smooth muscle cells, platelets and T-lymphocytes ${ }^{28}$. Therefore, some side effects can be expected.

The differential expression profile of EC is dependent of the angiogenic factors in its microenvironment ${ }^{29}$ and therefore it is possible that not every angiogenesis marker can be used in every tumor type. Another important reason for searching new targeting ligands is sensitivity. By using a targeting ligand with a higher affinity, less drug or contrast agent is needed and simultaneously, a more effective treatment or earlier diagnosis is possible. Additionally, by applying different targeting ligands it might be possible to obtain more information about the stage of the tumor. Apart from affinity, the specificity of the target and targeting ligand is also important ${ }^{30}$. A low affinity might be overcome by the design of multivalent targeting devices. Considering the $T 1$ values obtained with MRI, anginex can probably be used as a targeting ligand with at least equal abilities as the established targeting RGD-peptide for EC targeting.

The targeting ability of anginex should be further verified. Although, previous studies did not indicate that anginex affects other cell types besides EC, this can not be completely excluded since the receptor for anginex (galectin-1) is not only expressed on (tumor) EC (see below). However, given the location of EC, systemically administered anginex targeted vehicles are likely to mainly target tumor vasculature. This issue could be addressed by applying the anginex targeted liposomes in vivo in future research. Apart from cell-type specificity, it is also possible that a given targeting ligand is not suitable for every vector or tumor type. For example, the expression of a targeting ligand can have an affect on the structure of viral proteins, thereby modifying functioning of wild-type proteins ${ }^{31}$. The fact that anginex is small and can be modified by removing the non-essential $\mathrm{C}$ - and N-terminal amino acids without affecting activity is an advantage for these applications.

\section{Identification of the angiostatic mechanism of anginex}

To design new effective and selective anti-angiogenesis inhibitors, it is essential to understand the mechanisms and pathways underlying tumor angiogenesis. Thus, to directly improve anginex or to find new ways to attain its angiostatic effect, the mechanism behind should be unraveled. The identification of the receptor makes it possible to design peptides with a better interaction capability. Furthermore, strategies can be set up to enhance the inhibition of the downstream pathways or to apply a specific combination therapy, thereby influencing other pathways involved in angiogenesis. 
The existence of an anginex receptor was expected because the protein was detected at the membrane of intracellular vesicles by immuno-electron microscopy. Furthermore, receptor mediated uptake was also suggested considering the results obtained with the anginex-liposomes. To identify binding partners for anginex, yeast two-hybrid $(\mathrm{Y} 2 \mathrm{H})$ analysis, a well-known method to identify protein-protein interactions, was applied. Clones encoding (part of) galectin-1 (gal-1) turned out to be dominant in the identified ligands. Galectins are a family of animal lectins with diverse biological activities, which can function both intracellularly and extracellularly ${ }^{32,33}$. In cancer they contribute to neoplastic transformation, tumor cell immune escape through induction of apoptosis in cytotoxic leukocytes and tumor cell metastasis ${ }^{34,35}$. Galectins are defined by their ability to bind $\beta$-galactose and by their consensus amino-acid sequences ${ }^{36}$. All galectins contain conserved carbohydrate-recognition domains (CRDs), and these are responsible for carbohydrate binding. Since anginex originally is a synthetic peptide it is not glycosylated. Therefore, it is not expected that anginex will bind in the CRD. Previously, it has already been shown that gal-1 is capable of carbohydrate independent protein-protein interactions (e.g. with RAS) ${ }^{37}$ and indeed preliminary data using NMR suggest a different binding site for anginex. Identification of the exact interaction site of anginex on gal-1 might provide information to further improve the structure of anginex or to design new inhibitors.

The fact that approximately $66 \%$ of the obtained gal-1 clones from the $\mathrm{Y} 2 \mathrm{H}$ screening have an N-terminal deletion, which seems to have a higher affinity for anginex based on interaction studies in yeast, suggests that there might be a specific gal-1 isoform present inside the (tumor) vasculature. The existing of an isoform of gal- 1 with an $\mathrm{N}$-terminal deletion has already been described by Miura et al $^{38}$. It is possible that recombinant anginex compared to synthetic anginex has a slightly altered affinity for the possible existing isoform.

One of the other identified ligands was fibronectin, of which recently is described that it facilitates the transport of anginex to the tumor vasculature ${ }^{20}$. The binding of gal-1 to fibronectin has already been described in several studies as summarized by Camby et.al. ${ }^{39}$. This indicates that a reliable $\mathrm{Y} 2 \mathrm{H}$-screening was performed. The receptors for BPI and PF4 (resp. lipidA/heparin and CXCR3b ${ }^{40,41}$ ), the angiostatic molecules of which the structure of anginex is based on, were not identified. This can be explained because part of the amino acid sequence in the $\beta$-sheet domain of BPI which is present in anginex is inactive as an anti-angiogenic agent when made synthetically ${ }^{42}$. Additionally, PF4 acts cytostatically whereas anginex acts cytotoxic, indicating different functioning on the molecular level 42, 43. Probably, the novel combination of amino acids within the $\beta$-sheet structure of anginex is responsible for its angiostatic activity.

Because we identified gal-1 as the main receptor for anginex we evaluated the unknown role of gal-1 in tumor angiogenesis. In correspondence with other studies 
34, 44, we observed overexpression of gal-1 in endothelial cells of different human tumors. We tested whether interference with protein function had impact on EC function in vitro as well as in vivo. Expression knockdown in cultured EC inhibited proliferation and migration, whereas knockdown in zebrafish resulted in impaired vascular guidance and growth of dysfunctional vessels. Furthermore, in gal-1-null mice tumor growth was significantly inhibited and additional treatment with anginex did not result in further inhibition. The obtained results imply a prominent role of gal-1 in tumor angiogenesis.

Based on the results in zebrafish, a model of developmental angiogenesis, it might be expected that absence of gal-1 results in severe vascular defects or even lethality. However, the null mice are viable and have no obvious phenotype ${ }^{45}$. Apparently, during normal physiological development there exist compensatory mechanisms. However, it remains to be investigated whether vascular development in the knock-out mice is really normal and if such mechanisms also exist in tumors.

The interaction between anginex and gal-1 together with the observed upregulated expression on activated EC and the essential role of gal-1 for functioning of anginex, makes the anginex/gal-1 interaction an excellent pair for tumor vessels targeting purposes. The mechanism and pathways downstream of gal-1 after binding of anginex are not yet understood. Binding of anginex might interfere with the dimerization of gal-1. Moreover, as mentioned above gal-1 can interact with Ras, and more specifically, gal-1 is required for H-ras membrane anchorage ${ }^{37}$. Furthermore, gal-1 expression results in the sustained activation of Raf1 and ERK ${ }^{46}$. This pathway is common in angiogenesis ${ }^{47-52}$. By elucidating the anginex/gal-1 pathways new strategies can be developed, like specific down regulation of involved factors using SiRNA and miRNA approaches.

\section{Concluding remarks}

In agreement with our expectations, we were successful in designing an artificial anginex gene encoding for a fully functional recombinant protein with comparable properties as the original synthetic peptide. Therefore, we were able to use the gene as a molecular tool and demonstrated its use for gene therapy and receptor identification. Additionally, we confirmed the use of anginex as a targeting ligand.

Although all the promising results, the success of anginex in the clinic is hard to predict. The protein has many beneficial properties like 1) a good penetration capacity, 2) good angiostatic activity, 3) virtually no impact on physiological angiogenesis, 4) low immunogenicity, 5) potential for gene therapy, 6) targeting abilities, and 7) EC selectively via a receptor. However, to reach optimal efficacy in the clinic, it is most likely that multiple angiostatic agents should be applied. Each step of the angiogenic cascade represents a target for antiangiogenic therapy and blocking all involved pathways might thus act synergistically. Preclinical evidence 
indicates that combining anginex or other angiostatic agents with conventional cytotoxic agents or radiation therapy results in additive or synergistic anti-tumor effects ${ }^{53-55}$. Most of the available angiostatic proteins and peptides have been developed and used for experimental purposes and although the majority is not applicable in the clinic, they have contributed to the understanding and the modulation of the mechanisms underlying tumor angiogenesis. The development of anginex has at least contributed to the perspective of functional design and added a new function to gal-1 in tumor angiogenesis.

Further understanding of the mechanism of action of anginex and other stimulatory and inhibitory angiogenic factors and their mutual interactions will, probably in combination with other types of anti cancer agents, lead to a new generation of cancer treatments in the future. Much more research will be needed to answer the question whether targeting and the next generation of gene therapy vehicles make anti cancer strategies more effective, safer, and with less impact on the patient. Hopefully, improved in vitro and in vivo assays along with improved clinical trial design will provide a better and faster prediction whether new angiostatic strategies will succeed in the clinic. The apparent successful transformation of anginex into a mimetic ${ }^{56}$, which eventually might lead to an angiostatic pill, may be the first step towards the next generation of cancer treatments without a raise of the existing health care budget. 


\section{References}

1. Dhanabal, M., Volk, R., Ramchandran, R., Simons, M., and Sukhatme, V.P. (1999) Cloning, expression, and in vitro activity of human endostatin. Biochem Biophys Res Commun 258, 345-352

2. Maeshima, Y., Manfredi, M., Reimer, C., Holthaus, K.A., Hopfer, H., Chandamuri, B.R., Kharbanda, S., and Kalluri, R. (2001) Identification of the anti-angiogenic site within vascular basement membranederived tumstatin. J Biol Chem 276, 1524015248

3. Sim, B.K., O'Reilly, M.S., Liang, H., Fortier, A.H., He, W., Madsen, J.W., Lapcevich, R., and Nacy, C.A. (1997) A recombinant human angiostatin protein inhibits experimental primary and metastatic cancer. Cancer Res 57, 1329-1334

4. Kulke, M.H., Bergsland, E.K., Ryan, D.P., Enzinger, P.C., Lynch, T.J., Zhu, A.X., Meyerhardt, J.A., Heymach, J.V., Fogler, W.E., Sidor, C., Michelini, A., Kinsella, K., Venook, A.P., and Fuchs, C.S. (2006) Phase II study of recombinant human endostatin in patients with advanced neuroendocrine tumors. J Clin Oncol 24, 3555-3561

5. Dings, R.P., Arroyo, M.M., Lockwood, N.A., van Eijk, L.I., Haseman, J.R., Griffioen, A.W., and Mayo, K.H. (2003) Beta-sheet is the bioactive conformation of the antiangiogenic anginex peptide. Biochem J 373, 281-288

6. Mayo, K.H., Dings, R.P., Flader, C., Nesmelova, I., Hargittai, B., van der Schaft, D.W., van Eijk, L.I., Walek, D., Haseman, J., Hoye, T.R., and Griffioen, A.W. (2003) Design of a partial peptide mimetic of anginex with antiangiogenic and anticancer activity. J Biol Chem 278, 45746-45752

7. Dings, R.P., van der Schaft, D.W., Hargittai, B., Haseman, J., Griffioen, A.W., and Mayo, K.H. (2003) Anti-tumor activity of the novel angiogenesis inhibitor anginex. Cancer Lett 194, 55-66

8. Van De Wiele, C., Oltenfreiter, R., De Winter, O., Signore, A., Slegers, G., and Dierckx, R.A. (2002) Tumour angiogenesis pathways: related clinical issues and implications for nuclear medicine imaging. Eur J Nucl Med Mol Imaging 29, 699-709

9. Indraccolo, S. (2004) Undermining tumor angiogenesis by gene therapy: an emerging field. Curr Gene Ther 4, 297-308

10. Folkman, J. (2006) Antiangiogenesis in cancer therapy--endostatin and its mechanisms of action. Exp Cell Res 312 594-607

11. Yoon, S.S., Eto, H., Lin, C.M., Nakamura, H., Pawlik, T.M., Song, S.U., and Tanabe, K.K. (1999) Mouse endostatin inhibits the formation of lung and liver metastases. Cancer Res 59, 6251-6256

12. Dirkx, A.E., oude Egbrink, M.G., Castermans, K., van der Schaft, D.W., Thijssen, V.L., Dings, R.P., Kwee, L., Mayo, K.H., Wagstaff, J., Bouma-ter Steege, J.C., and Griffioen, A.W. (2006) Antiangiogenesis therapy can overcome endothelial cell anergy and promote leukocyte-endothelium interactions and infiltration in tumors. Faseb J 20, 621-630

13. Celik, I., Surucu, O., Dietz, C., Heymach, J.V., Force, J., Hoschele, I., Becker, C.M. Folkman, J., and Kisker, O. (2005) Therapeutic efficacy of endostatin exhibits a biphasic dose-response curve. Cancer Res 65, 11044-11050

14. Cui, R., Takahashi, K., Takahashi, F. Tanabe, K.K., and Fukuchi, Y. (2006) Endostatin gene transfer in murine lung carcinoma cells induces vascular endothelial growth factor secretion resulting in upregulation of in vivo tumorigenecity. Cancer Lett 232, 262-271

15. Yang, D.Z., He, J., Zhang, J.C., and Wang, Z.R. (2006) Expression of angiostatin cDNA in human gallbladder carcinoma cell line GBC-SD and its effect on endothelial proliferation and growth. World J Gastroenterol 12, 2762-2766

16. Martins, C.P., Brown-Swigart, L., and Evan, G.I. (2006) Modeling the therapeutic efficacy of p53 restoration in tumors. Cell $127,1323-1334$

17. Ventura, A., Kirsch, D.G., McLaughlin, M.E., Tuveson, D.A., Grimm, J., Lintault, L., Newman, J., Reczek, E.E., Weissleder, R., and Jacks, T. (2007) Restoration of p53 function leads to tumour regression in vivo. Nature 445, 661-665

18. Hanahan, D., and Folkman, J. (1996) Patterns and emerging mechanisms of the angiogenic switch during tumorigenesis. Cell 86, 353-364

19. St Croix, B., Rago, C., Velculescu, V., Traverso, G., Romans, K.E., Montgomery, E., Lal, A., Riggins, G.J., Lengauer, C., Vogelstein, B., and Kinzler, K.W. (2000) Genes expressed in human tumor endothelium. Science 289, 1197-1202 
20. Akerman, M.E., Pilch, J., Peters, D., and Ruoslahti, E. (2005) Angiostatic peptides use plasma fibronectin to home to angiogenic vasculature. Proc Natl Acad Sci U $S$ A 102, 2040-2045

21. van der Schaft, D.W., Dings, R.P., de Lussanet, Q.G., van Eijk, L.I., Nap, A.W., Beets-Tan, R.G., Bouma-Ter Steege, J.C., Wagstaff, J., Mayo, K.H., and Griffioen, A.W. (2002) The designer anti-angiogenic peptide anginex targets tumor endothelial cells and inhibits tumor growth in animal models. Faseb J 16, 1991-1993

22. Alghisi, G.C., and Ruegg, C. (2006) Vascular integrins in tumor angiogenesis: mediators and therapeutic targets. Endothelium 13, 113-135

23. Cai, W., and Chen, X. (2006) Antiangiogenic cancer therapy based on integrin alphavbeta3 antagonism. Anticancer Agents Med Chem 6, 407-428

24. Chen, X. (2006) Multimodality imaging of tumor integrin alphavbeta3 expression. Mini Rev Med Chem 6, 227-234

25. Liu, S. (2006) Radiolabeled multimeric cyclic RGD peptides as integrin alphavbeta3 targeted radiotracers for tumor imaging. $\mathrm{Mol}$ Pharm 3, 472-487

26. Kumar, C.C. (2003) Integrin alpha v beta 3 as a therapeutic target for blocking tumorinduced angiogenesis. Curr Drug Targets 4, 123-131

27. Temming, K., Schiffelers, R.M., Molema, G., and Kok, R.J. (2005) RGD-based strategies for selective delivery of therapeutics and imaging agents to the tumour vasculature. Drug Resist Updat 8, 381-402

28. Shattil, S.J. (1995) Function and regulation of the beta 3 integrins in hemostasis and vascular biology. Thromb Haemost 74, 149155

29. van Beijnum, J.R., and Griffioen, A.W. (2005) In silico analysis of angiogenesis associated gene expression identifies angiogenic stage related profiles. Biochim Biophys Acta 1755, 121-134

30. Zhong, H., and Bowen, J.P. (2006) Antiangiogenesis drug design: multiple pathways targeting tumor vasculature. Curr Med Chem 13, 849-862

31. Henning, P., Lundgren, E., Carlsson, M., Frykholm, K., Johannisson, J., Magnusson, M.K., Tang, E., Franqueville, L., Hong, S.S., Lindholm, L., and Boulanger, P. (2006) Adenovirus type 5 fiber knob domain has a critical role in fiber protein synthesis and encapsidation. J Gen Virol 87, 3151-3160

32. Hughes, R.C. (1999) Secretion of the galectin family of mammalian carbohydrate- binding proteins. Biochim Biophys Acta 1473, 172-185

33. Liu, F.T., Patterson, R.J., and Wang, J.L. (2002) Intracellular functions of galectins. Biochim Biophys Acta 1572, 263-273

34. Clausse, N., van den Brule, F., Waltregny, D., Garnier, F., and Castronovo, V. (1999) Galectin-1 expression in prostate tumorassociated capillary endothelial cells is increased by prostate carcinoma cells and modulates heterotypic cell-cell adhesion. Angiogenesis 3, 317-325

35. Liu, F.T., and Rabinovich, G.A. (2005) Galectins as modulators of tumour progression. Nat Rev Cancer 5, 29-41

36. Barondes, S.H., Castronovo, V., Cooper, D.N., Cummings, R.D., Drickamer, K., Feizi, T., Gitt, M.A., Hirabayashi, J., Hughes, C., Kasai, K., and et al. (1994) Galectins: a family of animal beta-galactoside-binding lectins. Cell 76, 597-598

37. Paz, A., Haklai, R., Elad-Sfadia, G., Ballan, E., and Kloog, Y. (2001) Galectin-1 binds oncogenic $\mathrm{H}$-Ras to mediate Ras membrane anchorage and cell transformation. Oncogene 20, 7486-7493

38. Miura, T., Takahashi, M., Horie, H., Kurushima, H., Tsuchimoto, D., Sakumi, K. and Nakabeppu, Y. (2004) Galectin-1beta, a natural monomeric form of galectin-1 lacking its six amino-terminal residues promotes axonal regeneration but not cell death. Cell Death Differ 11, 1076-1083

39. Camby, I., Le Mercier, M., Lefranc, F., and Kiss, R. (2006) Galectin-1: a small protein with major functions. Glycobiology 16, 137R-157R

40. Bikfalvi, A. (2004) Platelet factor 4: an inhibitor of angiogenesis. Semin Thromb Hemost 30, 379-385

41. van der Schaft, D.W., Wagstaff, J., Mayo, K.H., and Griffioen, A.W. (2002) The antiangiogenic properties of bactericidal/permeability-increasing protein (BPI). Ann Med 34, 19-27

42. Griffioen, A.W., van der Schaft, D.W., Barendsz-Janson, A.F., Cox, A., Struijker Boudier, H.A., Hillen, H.F., and Mayo, K.H. (2001) Anginex, a designed peptide that inhibits angiogenesis. Biochem J 354, 233242

43. Gupta, S.K., and Singh, J.P. (1994) Inhibition of endothelial cell proliferation by platelet factor-4 involves a unique action on S phase progression. J Cell Biol 127, 11211127

44. van den Brule, F., Califice, S., and Castronovo, V. (2004) Expression of 
galectins in cancer: a critical review. Glycoconj J 19, 537-542

45. Poirier, F., and Robertson, E.J. (1993) Normal development of mice carrying a null mutation in the gene encoding the L14 Stype lectin. Development 119, 1229-1236

46. Elad-Sfadia, G., Haklai, R., Ballan, E., Gabius, H.J., and Kloog, Y. (2002) Galectin1 augments Ras activation and diverts Ras signals to Raf- 1 at the expense of phosphoinositide 3-kinase. J Biol Chem 277, 37169-37175

47. Chavakis, E., and Dimmeler, S. (2002) Regulation of endothelial cell survival and apoptosis during angiogenesis. Arterioscler Thromb Vasc Biol 22, 887-893

48. Gerber, H.P., McMurtrey, A., Kowalski, J., Yan, M., Keyt, B.A., Dixit, V., and Ferrara, N. (1998) Vascular endothelial growth factor regulates endothelial cell survival through the phosphatidylinositol 3'-kinase/Akt signal transduction pathway. Requirement for Flk1/KDR activation. J Biol Chem 273, 3033630343

49. Gupta, K., Kshirsagar, S., Li, W., Gui, L., Ramakrishnan, S., Gupta, P., Law, P.Y., and Hebbel, R.P. (1999) VEGF prevents apoptosis of human microvascular endothelial cells via opposing effects on MAPK/ERK and SAPK/JNK signaling. Exp Cell Res 247, 495-504
50. Herbst, R.S. (2004) Review of epidermal growth factor receptor biology. Int $\mathrm{J}$ Radiat Oncol Biol Phys 59, 21-26

51. Papapetropoulos, A., Fulton, D., Mahboubi, K., Kalb, R.G., O'Connor, D.S., Li, F., Altieri, D.C., and Sessa, W.C. (2000) Angiopoietin-1 inhibits endothelial cell apoptosis via the Akt/survivin pathway. J Biol Chem 275, 9102-9105

52. Zachary, I. (2003) VEGF signalling: integration and multi-tasking in endothelial cell biology. Biochem Soc Trans 31, 11711177

53. Dings, R.P., Williams, B.W., Song, C.W., Griffioen, A.W., Mayo, K.H., and Griffin, R.J. (2005) Anginex synergizes with radiation therapy to inhibit tumor growth by radiosensitizing endothelial cells. Int $J$ Cancer 115, 312-319

54. Gasparini, G., Longo, R., Fanelli, M., and Teicher, B.A. (2005) Combination of antiangiogenic therapy with other anticancer therapies: results, challenges, and open questions. J Clin Oncol 23, 1295-1311

55. Jain, R.K. (2005) Normalization of tumor vasculature: an emerging concept in antiangiogenic therapy. Science 307, 58-62

56. Dings, R.P., Chen, X., Hellebrekers, D.M., van Eijk, L.I., Zhang, Y., Hoye, T.R., Griffioen, A.W., and Mayo, K.H. (2006) Design of nonpeptidic topomimetics of antiangiogenic proteins with antitumor activities. J Natl Cancer Inst 98, 932-936 


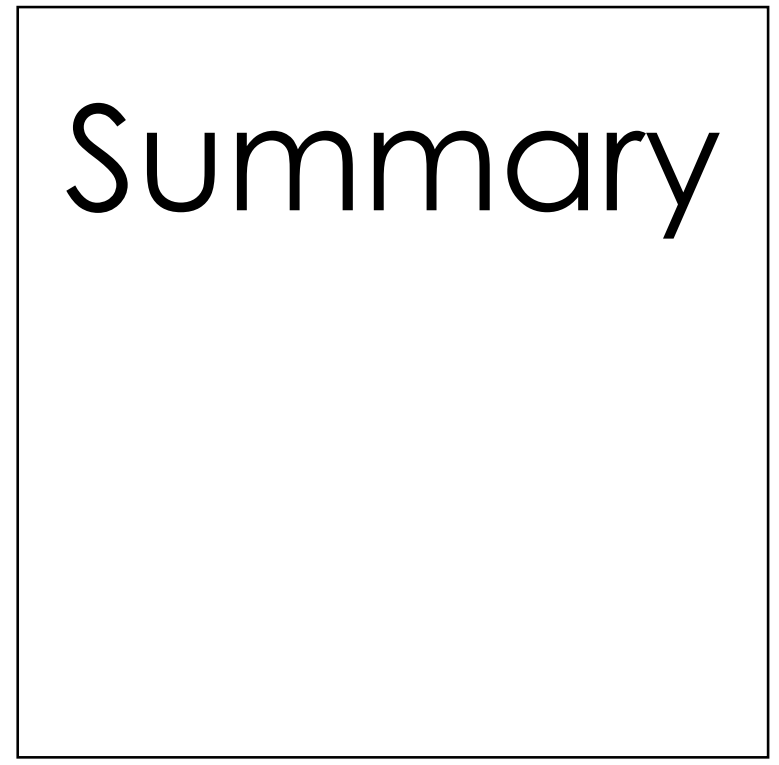


This thesis describes the development of the recombinant equivalent of the synthetic angiogenesis inhibitor anginex and the use of the anginex gene and recombinant protein in order to develop new angiostatic strategies for anticancer treatment. Angiogenesis, i.e. the formation of new blood vessels from pre-existing ones, is essential for tumor growth and the formation of metastasis. It is mainly initiated by a deficiency in oxygen and nutrients in the growing tumor, after which a cascade of events occur. Because of its key role in tumor progression, the abrogation of angiogenesis has been suggested as an anticancer therapy. Perhaps never before has any anticancer therapy generated such interest, skepticism and expectations as antiangiogenic therapy.

The concept of antiangiogenic therapy is simple and elegant: inhibit the growth of activated EC to starve the tumor to death with little acquired resistance and sideeffects. This inspired researchers to search for molecules capable of inhibiting tumor angiogenesis. Many angiogenesis inhibitors are derived from endogenous molecules, like e.g. endostatin from collagen XVIII. In our laboratory, anginex was developed as a synthetic angiostatic peptide. The sequence of the peptide was based on the structure of known endogenous inhibitors and basic folding principles in order to form a water soluble $\beta$-sheet forming peptide. Anginex is a potent angiogenesis inhibitor capable of inhibiting in vitro adhesion, migration and proliferation of activated EC and subsequent induction of apoptosis in these cells. In vivo, anginex is an effective anti-tumor agent.

We hypothesized that an artificial anginex gene encoding recombinant protein could be used as a molecular tool for receptor identification, angiostatic gene therapy and targeting. To be able to use anginex in such strategies, the anginex gene encoding for a functional recombinant protein with comparable characteristics had to be developed. In addition to traditional techniques to screen for angiostatic and biochemical properties, we first developed a new approach to simultaneously study the effects of an angiogenesis inhibitor on the in vivo angiogenic expression profile of several important angiogenic factors in tumor cells and vascular cells within a single tumor in a xenograft tumor model (Chapter 2). Therefore, humanand mouse-specific primers were designed for these factors and used in quantitative real-time RT-PCR to determine their expression levels. We observed that in response to angiostatic treatment, tumor cells significantly upregulate bFGF expression and downregulate VEGF receptor expression. This was accompanied by downregulation of VEGF-B and -D, and upregulation of angiopoietin-3 as well as angiopoietin receptors in non-tumor cells. Subsequently, we constructed the artificial gene encoding the biologically peptide and produced the recombinant protein in Pichia Pastoris (Chapter 3). Analysis on the structural level revealed that recombinant anginex, like the synthetic peptide, has a $\beta$-sheet structure and the preference for forming a dimer. Analysis on the functional level in vitro showed that the recombinant protein is active at inhibiting EC growth and migration. The in vivo 
angiostatic capacity of the recombinant protein was determined in a model of developmental angiogenesis (chicken chorioallantoic membrane assay) and in a xenograft mouse tumor model (human MA148 ovarian carcinoma in athymic mice) (Chapter 3 and 4). In both models, recombinant anginex showed comparable angiogenesis inhibiting properties as its synthetic equivalent. These studies demonstrated that it is possible to produce a functionally active protein version of a rationally designed peptide, using an artificial gene and the recombinant protein approach.

To explore the therapeutic applicability of the anginex gene, stable transfectants of murine B16F10 melanoma cells expressing recombinant anginex were made (Chapter 4). Culture supernatants of these cells inhibited endothelial cell proliferation, in contradiction to supernatants of the wild type cell line. In addition, subcutaneous injection of these stable transfected cells in C57BL/ 6 mice revealed an extensive additional delay in tumor growth in comparison to systemic treatment with synthetic anginex. These data suggest that the anginex gene can be applied in gene therapy approaches and that angiostatic therapy is most effective when applied at the start of the angiogenic process.

Gene therapy has been a promise for cancer treatment for years. To fulfil its expectations, the delivery systems have to be optimized and specific targets must be identified to allow specific cancer treatment. Targeting tumor vessels is especially interesting since the vasculature is easily accessible, less prone to mutations and treating the vasculature gives probably rise to fewer side effects. In Chapter 5, we review the use of targeted gene delivery for angiostatic cancer treatment, with a focus on the most commonly and frequently used gene transfer vehicles and targeting strategies for viral as well non-viral delivery systems.

From previous studies it was known that anginex homes to the angiogenic vasculature inside tumors. Therefore, we hypothesized that anginex could be used as targeting ligand. To investigate this application, we conjugated anginex to fluorescently labeled paramagnetic liposomes (Chapter 6). Using phase contrast and fluorescence microscopy, we demonstrated that conjugated liposomes bind to endothelial cells. By performing competition experiments with unconjugated synthetic anginex, we demonstrated that this binding was anginex dependent. Using magnetic resonance imaging (MRI), we showed that anginex is at least as suitable for targeting MRI contrast agents as the well known cyclic RGD-peptide. This study suggests the applicability of anginex as an angiogenesis targeting ligand.

To get more insight in the mechanism of the angiostatic capacity of anginex and to be able to improve the interaction with its receptor, a receptor-finding study using yeast two-hybrid screening was applied, thereby identifying galectin-1 (gal-1) as its main target protein (Chapter 7). Galectin-1 was found to be overexpressed in endothelial cells of human tumors. Expression knockdown in vitro and in vivo lead to respectively inhibition of EC proliferation and migration, and disturbed and 
defective vessel formation. The role of gal-1 in tumor angiogenesis was demonstrated in gal-1-null mice. In these mice, tumor growth was hampered and they did not respond to additional anginex treatment. The data imply that gal- 1 is an important regulator of tumor angiogenesis and could be a potential target/marker for angiostatic cancer therapy.

From this thesis can be concluded that synthetic anginex as well as its recombinant equivalent are potent angiostatic proteins and that their use is not limited to the applicability as systemic inhibitors of angiogenesis. The encoding gene and protein have the potential to be a valuable tool in gene therapy and anticancer targeting strategies. The identification of the anginex receptor will possibly lead to the development of new inhibitors or to new intervention possibilities for tumor angiogenesis. 
Samenvatting 
Dit proefschrift beschrijft de ontwikkeling en het gebruik van de recombinante equivalent van de synthetische angiogenese remmer anginex met als doelstelling het ontwikkelen van nieuwe anti-angiogenese strategieën als behandeling gericht tegen kanker. Angiogenese is gedefiniëerd als de vorming van nieuwe bloedvaten vanuit bestaande vaten. Angiogenese is noodzakelijk voor tumorgroei en de vorming van metastasen en het wordt voornamelijk geïnitieerd door een tekort aan zuurstof en voedingsstoffen in de groeiende tumor. Hierdoor wordt een verscheidenheid aan elkaar gerelateerde processen in gang gezet. Gezien de sleutelrol tijdens de tumorontwikkeling is het stopzetten van het angiogene proces gesuggereerd als potentiële anti-kanker therapie. Dit heeft geleid tot een enorme interesse, verwachtingen en skeptisisme ten opzichte van anti-angiogene therapie.

Het principe van anti-angiogenese therapie is elegant en eenvoudig: door de groei van geactiveerde endotheel cellen te voorkomen zal een tumor een hongerdood sterven zonder ernstige bijwerkingen en het ontwikkelen van resistentie gericht tegen de therapie. Dit concept heeft vele onderzoekers geïnspireerd te zoeken naar middelen die tumor angiogenese kunnen remmen. Veel angiogenese remmers zijn afgeleid van endogene moleculen, zoals bijvoorbeeld endostatine van collageen XVIII. In ons laboratorium hebben we de synthetische angiogenese remmer anginex ontwikkelt. De samenstelling van dit peptide is gebaseerd op de structuur van bekende angiogenese remmers en eiwitvouwing principes, zodat een wateroplosbaar $\beta$-sheet vormend peptide ontstaat. Het is gebleken dat anginex een krachtige angiogenese remmer is. Het is in staat om in vitro de adhesie, migratie en proliferatie van geactiveerde endotheel cellen te remmen en vervolgens in deze cellen apoptose te induceren. In vivo is anginex een effectief anti-tumor middel.

Wij stelden de hypothese dat een kunstmatig anginex gen coderend voor anginex gebruikt zou kunnen worden als moleculair hulpmiddel voor receptor identificatie, anti-angiogene gen therapie en targeting doeleinden. Om anginex voor deze strategieën te kunnen gebruiken diende eerst het anginex gen ontwikkeld te worden dat codeerd voor een recombinant eiwit met vergelijkbare eigenschappen. Als aanvulling op bestaande technieken om angiogenese remming en biochemische eigenschappen te bepalen, hebben wij eerst een methode ontwikkelt die op hetzelfde moment de invloed van een angiogenese remmer bepaalt op het expressie niveau van verschillende belangrijke angiogene factoren in de tumor- en vasculaire cellen binnen dezelfde tumor (Hoofdstuk 2). Daartoe zijn primers ontwikkelt die specifiek zijn voor de humane of muis angiogene factoren en gebruikt kunnen worden om het expressieniveau te bepalen met behulp van een quantitatieve "real-time"-PCR. Het is gebleken dat tumoren als reactie op angiogenese remming, de expressie van bFGF verhogen en de expressie van VEGFreceptoren verlagen. Op hetzelfde moment was in de niet tumorcellen de expressie van VEGF-B en $D$ verminderd en zowel de expressie van angiopoietine-3 en de 
angiopoietine receptoren verhoogd. Vervolgens hebben wij het kunstmatige anginex gen gevormd dat codeerd voor de biologisch variant van de peptide en deze geproduceerd in de gist Pichia Pastoris (Hoofdstuk 3). Wij hebben aangetoond dat recombinant anginex op structureel niveau, net zoals het synthetisch peptide, een $\beta$-sheet structuur heeft en bij voorkeur een dimeer vormt. Analyse op functioneel niveau in vitro liet zien dat het recombinante eiwit in staat is om EC proliferatie en migratie te remmen. De in vivo angiostatische activiteit van het recombinante eiwit werd bepaald in een model van ontwikkelings angiogenese (chorionmembraan van het kippenei) en in een tumor model (humane MA148 ovarium carcinoma in naakte muizen) (Hoofdstuk 3 en 4). In beide modellen is aangetoond dat recombinant anginex een vergelijkbare werking heeft als zijn synthetische equivalent. Deze studies hebben aangetoond dat het mogelijk is om van een rationeel ontworpen peptide een functioneel biologische variant te maken door middel van de ontwikkeling van een kunstmatig gen en recombinante productie.

Om de mogelijk therapeutische toepasbaarheid van het anginex gen te onderzoeken is een stabiele transfectant van de muizen B16F10 melanoma cellijn gemaakt die in staat is om anginex tot expressie te brengen. (Hoofdstuk 4). In tegenstelling tot kweek supernatanten van de wild-type cellen, zijn de supernatanten van de getransfecteerde cellen al in staat om proliferatie van endotheel cellen te remmen. Het injecteren van de getransfecteerde cellen in C57/BL6 muizen leidde tot een extra vertraging van de tumor groei in vergelijking tot systemische behandeling van wild-type tumoren met synthetisch anginex. De verkregen resultaten suggereren dat het anginex gen kan worden toegepast voor gen therapie en dat een anti-angiogene behandeling het meest effectief is indien deze wordt toegepast wanneer een tumor initiëel begint te groeien.

Gen therapie is al vele jaren een veel belovende kanker therapie. Om deze verwachtingen waar te maken moeten de systemen die het gen naar de plaats van interesse brengen geoptimaliseerd worden en specifieke moleculen dienen geïdentificeerd te worden die het mogelijk maken alleen tumoren te behandelen. Het specifiek behandelen van tumor bloedvaten is met name interessant omdat deze goed toegankelijk zijn, minder gevoelig zijn voor het ontwikkelen van resistentie tegen de medicatie en waarschijnlijk niet al te veel bijwerkingen geven. In Hoofdstuk 5 beschrijven wij het gebruik van al bekende hulpmiddelen voor gen overdracht ten behoeve van een anti-angiogene behandeling. Hierbij hebben wij ons geconcentreerd op de meest voorkomende virale en niet virale gen overdracht methoden en hoe deze specifiek te maken zijn voor angiogenese.

Uit eerdere studies was bekend dat anginex zich specifiek verzameld in bloedvaten van tumoren. Dit leidde tot de hypothese dat anginex gebruikt kan worden als targeting ligand. Om deze toepassing te onderzoeken werd anginex geconjugeerd aan fluorescent gelabelde paramagnetische liposomen (Hoofdstuk 6). 
Met behulp van fase contrast en fluorescentie microscopie hebben wij aangetoond dat deze geconjugeerde liposomen in staat waren te binden aan endotheel cellen. Wij hebben aangetoond dat deze binding het gevolg is van de aanwezigheid van anginex door het uitvoeren van competitie experimenten met niet geconjugeerd synthetisch anginex. Door het gebruik van een MRI-scanner (Magnetic Resonance Imaging) hebben we laten zien dat anginex minstens even goed werkt als targeting ligand als de al bekende en veel gebruikte cyclische RGD-peptiden. Deze studie suggereert het gebruik van anginex als ligand voor angiogenese targeting.

Om meer inzicht te krijgen in het mechanisme ten grondslag aan de antiangiogene eigenschappen van anginex en om het molecuul verder te kunnen verbeteren, werd een studie gestart om de biologisch receptor van anginex te vinden door het gebruik van de gist 2-hybride techniek toe te passen. Hiermee werd galectine-1 (gal-1) geïdentificeerd als de voornaamste receptor (Hoofdstuk 7). Het blijkt dat gal-1 een hoger expressie niveau heeft in endotheel cellen van humane tumoren. Remming van gal-1 expressie in vitro en in vivo leidt respectievelijk tot remming van proliferatie en migratie van endotheel cellen en tot verstoorde en niet functionele bloedvat vorming. De functie van gal-1 in tumor angiogenese werd aangetoond in muizen zonder gal-1 expressie. In deze muizen was geen normale tumor groei ontwikkeling en tevens reageerden zij niet op additieve behandeling met anginex. Deze bevindingen veronderstellen dat gal-1 een belangrijke regulator is van tumor angiogenese en eventueel gebruikt kan worden als target/marker voor het toepassen van anti-angiogene kanker behandeling.

Uit de resultaten beschreven in dit proefschrift kan geconcludeerd worden dat zowel synthetisch als recombinant anginex potente angiostatische eiwitten zijn en dat het gebruik ervan niet gelimiteerd is tot het gebruik als angiogenese remmer na systemische toepassing. Het gen en daaruit voortkomende eiwit hebben de potentie om een waardevol hulpmiddel te zijn ten behoeve van gen therapie en een gerichte behandeling van kanker. De identificatie van de gal-1 als anginex receptor leidt mogelijk tot de ontwikkeling van nieuwe inhibitoren of interventie mogelijkheden voor tumor angiogenese. 
- 172 - 
Abbreviations 
$-174-$ 


\begin{tabular}{|c|c|c|c|}
\hline AAV & adeno associated virus & MRI & magnetic resonance imaging \\
\hline Ad & adenovirus & MS & mass spectrometry \\
\hline Ang & angiopoietin & MVD & microvessel density \\
\hline $\mathrm{ax}$ & anginex & NRP & neuropilin \\
\hline r-anginex & recombinant anginex & PBS & phosphate buffered saline \\
\hline bFGF & basic fibroblast growth factor & PCR & polymerase chain reaction \\
\hline BPI & $\begin{array}{l}\text { bactericidal/permeability- } \\
\text { increasing protein }\end{array}$ & PDGF & placenta derived growth factor \\
\hline CAM & $\begin{array}{l}\text { Chicken chorioallantoic } \\
\text { membrane }\end{array}$ & PEG & polyethylene glycol \\
\hline CAR & $\begin{array}{l}\text { Coxsackie adenovirus } \\
\text { receptor }\end{array}$ & PEI & polyethylenimine \\
\hline $\mathrm{CCL}$ & coated cationic liposome & PET & positron emission tomography \\
\hline$C D$ & circular dichroism & PF4 & platelet factor 4 \\
\hline CT & computed tomography & PPE & preproendothelin \\
\hline cDNA & Complementary DNA & QRT-PCR & quantitative real time PCR \\
\hline EC & Endothelial cell & RGD & arginine-glycine-aspartic acid \\
\hline ECM & extracellular matrix & $\mathrm{ROBO}-4$ & roundabout 4 \\
\hline EDB & extra-domain B & SAGE & $\begin{array}{l}\text { serial analysis of gene } \\
\text { expression }\end{array}$ \\
\hline EndoPDI & $\begin{array}{l}\text { endothelial protein-disulfide } \\
\text { isomerase }\end{array}$ & scFv & single chain variable fragment \\
\hline EPC & endothelial precursor cell & SPECT & $\begin{array}{l}\text { single photon emission } \\
\text { tomography }\end{array}$ \\
\hline Erk & $\begin{array}{l}\text { extracellular signal regulated } \\
\text { kinase }\end{array}$ & $\mathrm{SSH}$ & $\begin{array}{l}\text { suppressive subtractive } \\
\text { hybridisation }\end{array}$ \\
\hline FLT-1 & fms-like tyrosine kinase-1 & TEM & tumor endothelial marker \\
\hline HSPG & $\begin{array}{l}\text { heparan sulphate } \\
\text { proteoglycan }\end{array}$ & Timp & $\begin{array}{l}\text { tissue inhibitor if } \\
\text { metalloproteinases }\end{array}$ \\
\hline HSV & herpes simplex virus & TGF & transforming growth factor \\
\hline HUVEC & $\begin{array}{l}\text { human umbilical vein } \\
\text { endothelial cell }\end{array}$ & TK & tyrosine kinase \\
\hline ICAM & $\begin{array}{l}\text { intracellular adhesion } \\
\text { molecule }\end{array}$ & TNF & tumor necrosis factor \\
\hline IL & interleukin & TSP & thrombospondin \\
\hline LTR & long terminal repeat & VEGF & $\begin{array}{l}\text { vascular endothelial growth } \\
\text { factor }\end{array}$ \\
\hline MMP & matrix metalloproteinase & VEGFR & $\begin{array}{l}\text { vascular endothelial growth } \\
\text { factor receptor }\end{array}$ \\
\hline MPS & $\begin{array}{l}\text { mononuclear phagocyte } \\
\text { system }\end{array}$ & $\mathrm{vm}$ & vascular mimicry \\
\hline
\end{tabular}




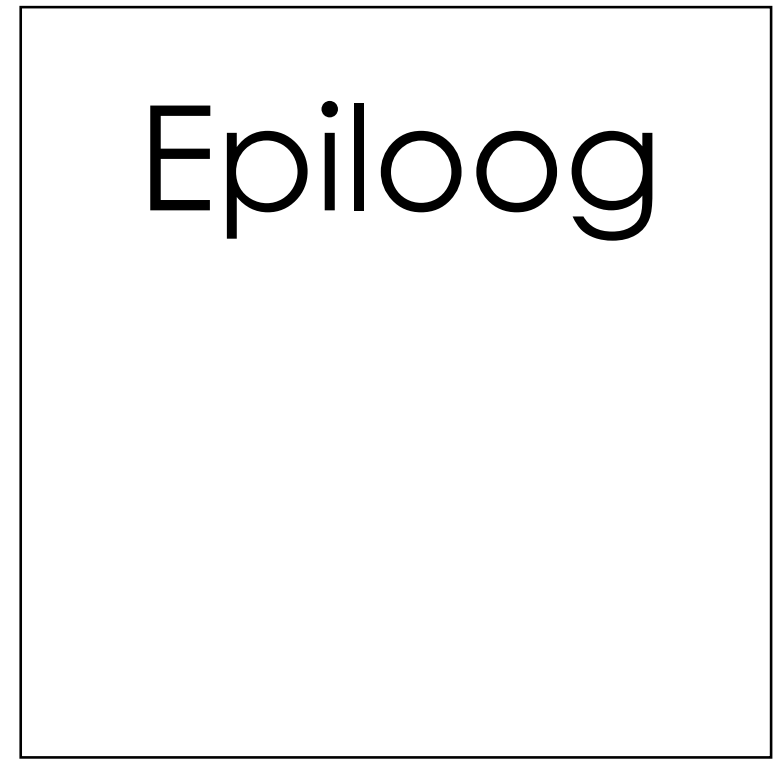


Volgens sommigen het makkelijkste en voor anderen het moeilijkste gedeelte van 'het boekje'. Ik ben ook toegekomen aan het persoonlijke en tevens meest gelezen hoofdstuk. Wat dat betreft zou het dan ook een plaats vooraan moeten krijgen. Wat dit hoofstuk wat gemakkelijker maakt is dat het niet nagekeken hoeft te worden. Niet dat de heren dit niet goed deden, maar het is toch ook fijn een keer volledig je eigen woorden en zienswijze te gebruiken zonder dat je bijvoorbeeld iets moet veranderen in eigenlijk hetzelfde maar dan met andere volgorde of woorden (Had ik bij het vak Nederlands vroeger toch maar wat beter mijn best gedaan cq opgelet. Aan de andere kant kun je zeggen: je bent een beta of je bent het niet). En ook al is het nu taaltechnisch wellicht niet volledig in orde. Het is wel mijn manier en ik weet wat ik ermee wil zeggen en dat is nu het belangrijkste.

$\mathrm{Na}$ een uiterst leuke en leerzame stage, begon mijn Maastrichts avontuur alweer meer dan negen jaar geleden. Geheel onverwachts kreeg ik de aanbieding om bij de groep van Hennie Hoogenboom te gaan beginnen. Daar dit een logisch vervolg op mijn stage was besloot ik mijn spullen te pakken en vanuit de zware rivierklei de hoge gronden van het zuiden te gaan opzoeken. Na wat omzwervingen en een nogal natte periode, kwam ik dan uiteindelijk op mijn eerste stekkie in de Bredestraat terecht. Komende van het platteland kwam ik er achter dat wonen in hartje centrum toch ook zijn voordelen heeft, zeker als groen, historie, voorzieningen en horeca op wandel dan wel kruipafstand liggen. Na drie leuke en leerzame jaren, waarin de basis werd gelegd voor goede vriendschappen en de start van mijn wetenschappelijke loopbaan, kwam de volgende stap in mijn Mestreechse bestaan (hoezo ingeburgerd). Een andere baan en kennismaking met de romantiek (zover dat mogelijk is bij mij dan). Weer een jaartje later werd het schijnbaar tijd om de eerste wilde haren te verliezen. Inmiddels weet ik dat je er grijze voor terug krijgt. Huisje, tuintje en niet veel later Floris was een feit. Dit was voldoende om weer een stukje verder te gaan. Inmiddels was het analisten bestaan een beetje aan het kriebelen. De beperkte perspectieven en de drang naar meer na de eerste resultaten als gevolg van noeste zelfstandige arbeid, brachten mij ertoe de stoute schoenen aan te trekken. In een goed gesprek met Arjan, waarvan hij van te voren dacht dat ik mijn vertrek ging aankondigen, heb ik vervolgens mijn toekomstvisie kenbaar gemaakt. Gelukkig deelde hij mijn mening en werd besloten langzaamaan een traject uit te zetten voor een promotie (bij deze nog bedankt voor dit vertrouwen). Vervolgens zijn verscheidende onderzoeksprojecten opgezet al dan niet in samenwerking met anderen en met meer of minder succes. Het was leuk, leerzaam en soms frusterend om nieuwe wegen te bewandelen. Gelukkig hebben een deel ervan toch de eindstreep gehaald ook al was het initiëel anders bedoeld. We hebben het onszelf wellicht ook te moeilijk gemaakt door welliswaar zeer interessante maar ook complexe en lastige onderwerpen te nemen waarmee we bovendien ook nog geen ervaring hadden en deze ook niet naast de deur voor 
handen was. Als je dan langzaam in een promotie traject rolt, waardoor je toch een soort einddatum krijgt, dan moet je wel wat beginnersgeluk hebben en adequaat beslissingen nemen om het op tijd af te krijgen. Laat dit een les zijn voor de toekomst. Helaas was het geluk, op het werk tenminste, niet altijd m'n partner in het onderzoek. En zoals iedere promovendus heb ook ik weleens eraan getwijfeld om door te gaan. Maar van die beslissing kun je alleen spijt krijgen. Je kunt achteraf wel een stapje terug doen, maar in de toekomst kijken hoe het geweest zou kunnen zijn als je het afgemaakt zou hebben blijft altijd gissen. Caroline mede door jouw steun en het vertrouwen van Arjan op een goed einde hebben er voor gezorgd dat het tot een goed einde is gekomen. Ik weet nu dan ook dat het de juiste beslissing is geweest om door te gaan.

Het is onmogelijk om stil te staan bij alle mensen die hebben bijgedragen aan mijn loopbaan tot nu toe (sorry hiervoor, maar toch bedankt). Toch verdienen een aantal mensen wat extra aandacht zonder anderen te kort te doen. Naar mijn mening een van de belangrijkste voorwaarden voor succes is een prettige werkomgeving. Met name mijn collega's van het angiogenese lab, VMT en werkkamer hebben hier een belangrijk aandeel in. Al was het soms toch wel fijn dat ik me terug kon trekken uit het 'voornamelijk jong en vrouwelijk kippenhok' op mijn eigen rustige stekkie. Mijn befaamde luchtjes hebben er wellicht voor gezorgd dat het daar ook relatief rustig bleef. Ook de verschillende studenten die meegelopen hebben in onze groep dragen bij aan de ontspannen sfeer door altijd voldoende stof te geven voor een levendige discussie tijdens werk of lunch. Natuurlijk wens ik mijn collega promovendi veel succes met de laatste loodjes en focus je daarbij op wat je uiteindelijk wilt bereiken.

Uiteraard is een begeleidingsteam belangrijk voor een promovendus. Arjan, gelukkig heb je het aangedurft om met een analist een promotietraject in te gaan en nieuwe wegen te bewandelen en ziehier het is dan ook gelukt. Je positieve instelling ten aanzien van resultaten heeft deze nuchtere kip vaak de moed gegeven weer iets nieuws te proberen. Victor, ik ben blij dat je bij onze groep kwam. Eindelijk een extra moleculair bioloog. Iemand die begreep, waar de celbiologen het vaak zo moeilijk mee hebben, dat de eenvoudige schema's waarmee je de moleculaire biologie in kunt weergeven in de praktijk toch wel een stuk lastiger zijn. En als het dan niet lukt, er Fingerspitze gefühl en ervaring bij komt kijken om het dan toch te doen slagen. Wat dat betreft lijkt mij de coupelogie altijd makkelijker. Er kleurt namelijk altijd wel iets en dat valt te tellen. Op bepaalde punten van mijn onderzoek heb je redelijk wat invloed gehad. Ik ben ook blij dat ik twee van je artikelen kan en mag gebruiken voor mijn boekje. Keep your feet to the ground but don't forget to walk en dan komt het met je onderzoek wel goed. 
Het is altijd goed om iemand in je werkomgeving te hebben op wie je kunt terugvallen in geval van frustraties, luisterend oor, advies of kleine klusjes bij afwezigheid. In mijn geval was dat Edith. Al vele jaren collega's en met name in de vroege uurtjes is er al veel besproken, dit zal ik wel gaan missen. Zeker op het eind was je een trouwe bondgenoot toen je direct op mijn onderzoek bent gaan meewerken. Barry, als gelijkgestemde en voormalig partner in crime bij pathologie, vind ik het fijn dat jij de rol van paranimf op je neemt.

Verschillende projecten zouden niet mogelijk zijn geweest zonder de hulp van andere universiteiten. Willem, ondanks dat ik weleens het gevoel had dat we langs elkaar aan het praten waren hebben we beide kunnen profiteren van onze samenwerking. Ik hoop dat jij je enthousiasme voor het onderzoek nog aan velen kunt overdragen. Erik, helaas is het niet meer tot een hoofdstuk gekomen. Desondanks ben ik je erkentelijk voor de vele uren werk die er in zijn gaan zitten en ik ben er nog steeds van overtuigd dat het mogelijk moet zijn. Zoals je hebt kunnen zien had het project een logisch gevolg dienen te worden op hoofdstuk 5. Ruud and Kevin, your experiments and thoughtful discussions improved several chapters.

Om op je werk het beste uit jezelf te halen is het ook belangrijk om daarbuiten goed in je vel te zitten. Met andere woorden zonder ontspanning geen inspanning. Een aantal zaken zijn gelukkig gedurende de jaren niet veranderd en dat zijn onder andere de culinaire en culturele woesdagavonden. Al duren ze niet zo lang meer als vroeger en zijn de onderwerpen wat veranderd, ik heb ze toch altijd bijzonder gewaardeerd en zal ze in de toekomst zeker gaan missen. Gelukkig is er vanuit deze avonden en niet te vergeten de weekendjes, met hier en daar een aanvulling, een leuke groep ontstaan waarmee hopelijk nog vele feestjes, culinaire diners, uitjes en weekendjes gevuld en gevierd gaan worden.

Een van de belangrijkste steunpilaren zijn misschien nog wel de familieleden, Arjen, Aad, Greet, Stijn, Nienke, Jeroen, Sabine en uiteraard pap en mam. Wetende dat jullie er altijd zijn en achter mij/ons zullen staan no matter what, is een fijne gedachte en verder hoef ik het denk ik niet uit te leggen.

Jannik, gelukkig heb je het me niet te lastig gemaakt tijdens de laatste loodjes. Je onvoorwaardelijke glimlach laat alle ongemakken smelten als sneeuw voor de zon. Ik verheug me er nu al op dat we samen buiten kunnen ravotten.

Lieve Caroline, wat je voor me betekent is niet te beschrijven en dat zal ik dan ook niet proberen. Ik ga niet zeggen dat we, nu het achter de rug is, meer tijd voor onszelf overhouden. Dit is al vele malen tevergeefs door anderen gezegd, maar je weet dat als je meer tijd nodig hebt dat je dat gewoon moet zeggen en wie ben ik 
dan om dat te kunnen weigeren. Pop, als geen ander herken je mijn twistpunten en ben je bereid mij hierin onvoorwaardelijk te steunen en te volgen ondanks dat dit soms veel van je vraagt. Daarvoor heel veel dank - en voor ál het andere!

Ricardo 


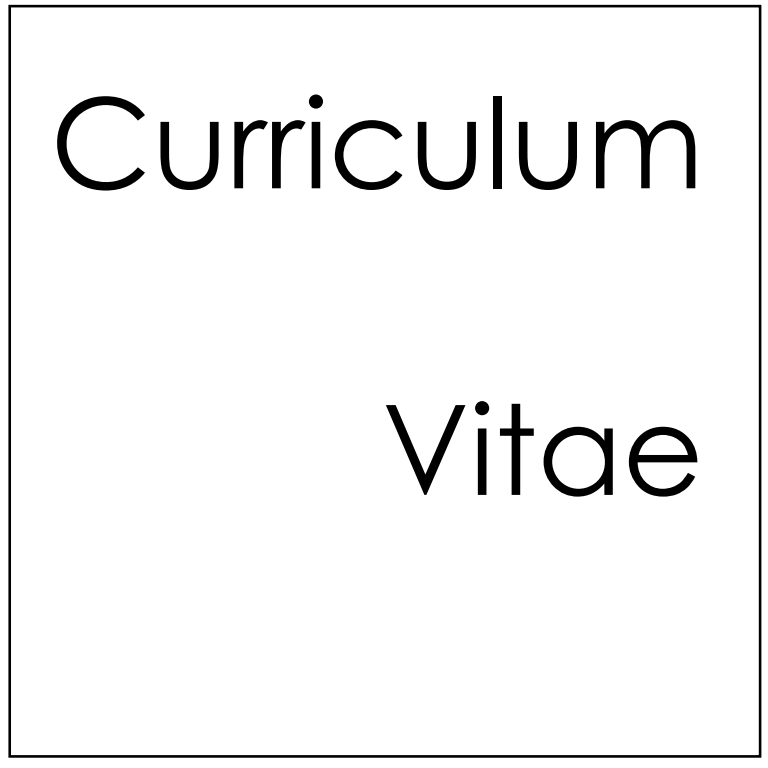


Jan-Marinus Gerardus Everadus (Ricardo) Brandwijk

The author of this thesis was born on October $25^{\text {th }} 1976$ in Leuth. He graduated from the Canisius College Mater Dei in Nijmegen (HAVO) in 1994. After that, he started at the Hogeschool van Arnhem en Nijmegen his study biochemistry/biotechnology. He obtained his bachelor degree in 1998. His first steps in the world of research were during his traineeship at the department of Biochemistry of the Catholic University of Nijmegen under supervision of Dr. Guido Jenniskens and Dr. Toine van Kuppevelt. He started his career as a research technician in the research group CESAME under supervision of Dr. Hennie Hoogenboom at the department of pathology at the Maastricht University in 1998. In 2001 he switched to the Angiogenesis Laboratory at Maastricht University under supervision of prof. Dr. Arjan Griffioen. Initial he started as a research technician, but along the years he became a PhD-student within this research group and his goal was the developing of alternative strategies to use the angiogenesis inhibitor anginex for anticancer therapy. In 2007, he started as a post-doc at the Research Laboratory for Pediatric Oncology at the UMC St. Radboud in Nijmegen.

\section{Publications}

1. Brandwijk RJMGE, Mulder WJ, Thijssen VLJL, Griffioen AW. Anginex as targeting ligand for targeted delivery of diagnostic or therapeutic liposomes to activated endothelial cells. Bioconjugate Chemistry 2007; 13(5): 200209

2. Brandwijk RJMGE, Thijssen VLJL, Griffioen AW. Targeted gene delivery strategies for angiostatic cancer treatment. Trends in Molecular Medicine 2007; 18(3): 785-790

3. Thijssen VLJL, Bakker J, Brandwijk RJMGE, Satijn S, Poirrier, BaumL, Griffioen AW, Galectin-1 is a key mediator of the early on-set of angiogenesis.. Proc Natl Acad Sci U S A. 2006 Oct 24;103(43):15975-80 
4. Brandwijk RJMGE, Van der Linden E, Dings RPM, Thijssen VLJL, Mayo K,Griffioen AW. Anti-angiogenesis and anti-tumor activity of recombinant anginex. Biochem Biophys Res Commun. 2006 Oct 27;349(3):1073-8

5. Mulder W.J., Koole R, Brandwijk R.J., Storm G., Chin P.T., Strijkers G.J., deMello Donega C., Nicolay K., Griffioen A.W. Quantum dots with a paramagnetic coating as a bimodal molecular imaging probe. Nano Lett. 2006 Jan;6(1):1-6.

6. Brandwijk RJMGE, Nesmelova I, Dings RPM, Mayo KH, Thijssen VLJL, Griffioen AW. Cloning an artificial gene encoding angiostatic anginex: from designed peptide to functional recombinant protein. Biochem Biophys Res Commun. 2005 Aug 12;333(4):1261-8

7. Thijssen VL, Brandwijk RJ, Dings RP, Griffioen AW.Angiogenesis gene expression profiling in xenograft models to study cellular interactions. Exp Cell Res. 2004 Oct $1 ; 299(2): 286-93$

8. Somers VA, Brandwijk RJ, Joosten B, Moerkerk PT, Arends JW, Menheere P, Pieterse WO, Claessen A, Scheper RJ, Hoogenboom HR, Hufton SE. A panel of candidate tumor antigens in colorectal cancer revealed by the serological selection of a phage displayed cDNA expression library. J Immunol. 2002 Sep $1 ; 169(5): 2772-80$.

9. Jenniskens GJ, Oosterhof A, Brandwijk R, Veerkamp JH, van Kuppevelt TH. Heparan sulfate heterogeneity in skeletal muscle basal lamina: demonstration by phage display-derived antibodies. J Neurosci. 2000 Jun $1 ; 20(11): 4099-111$

10. Hufton SE, Moerkerk PT, Brandwijk R, de Bruine AP, Arends JW, Hoogenboom HR. A profile of differentially expressed genes in primary colorectal cancer using suppression subtractive hybridization. FEBS Lett. 1999 Dec 10;463(1-2):77-82 
